\title{
Über den Verschluß der fötalen Augenbecherspalte, die Entwicklung der Sehnerveninsertion und die Anlage des Pecten bei Vögeln.
}

\author{
Fon \\ ¿. Lindahl und A. Jokl. \\ (Aus dem Anatomischen Institute der Lniversitit Tpsala. [Vorstand: Prof. J. A. Ha m mar].) \\ Wit 69 Textabbillungen. \\ (Eingegangen am 19. Juli 1921.)
}

Einleitung (S. 227).

Frühere Untersuchungen (S. 228).

Eigene Untersuchungen:

Allgemeines (S. 23t).

Podiceps crist.:

Stadienbeschreibung (S. 236 ).

Zusammenfassung (S. 251).

Anas dom.:

Stadienbeschreibung (S. 260).

Zusammenfassung (S. 277).
Inhalt.

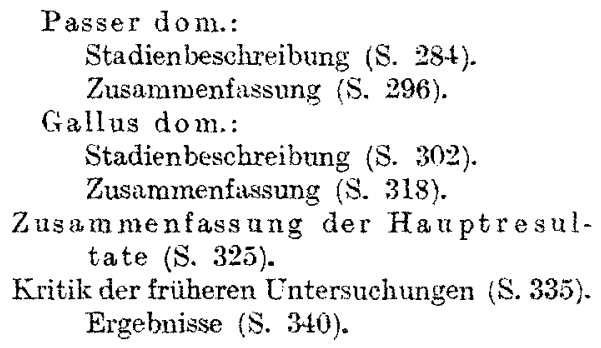

\section{Einleitung.}

Die vorliegende Arbeit ist gedacht als der erste Teil einer die verschiedenen Wirbeltierklassen umfassenden Darstellung über den Verschluß der fötalen Augenspalte und die Entwicklung der mit dieser in Zusammenhang stehenden Bildungen (Pecten, Campanula usw.) und der Sehnerveninsertion, Aus diesem Grunde gehen wir hier sowohl bei Anführung der Literatur als auch bei der Darstellung der eigenen Untersuchungsresultate ausschlieflich auf die Vögel ein und lassen vergleichend anatomische Betrachtungen der Verhältnisse hier mit denen anderer Wirbeltiere vorläufig beiseite.

Zunächst einige Worte über das Pecten des erwachsenen Vogelauges: Es ist bekannt, daß am Auge des erwachsenen Vogels der Sehnerv nicht mit kreisförmiger Fläehe am Bulbus inseriert, sondern da $B$ die an der ventralen Bulbuswand gelegene Ansatzfläche ein langgestrecktes, mit ihrer Längsachse meridional gestelltes Oral bildet. Entsprechend dieser Ansatzfläche erscheint der Sehnerv in seinem distalsten Anteile plattenförmig verbreitert. Natürlich hat. auch der Sehnerveneintritt oder die Papilla nervi optici eine langgestreckte Form. $\mathrm{Zu}$ dieser ziehen die Nervenfasern aus der Retina bündelweise von beiden Seiten her und lassen an ihrer Vereinigungsstelle eine langgestreckte Einsenkung zwischen sich frei, die der Excavatio physiologica papillae n. opt. bei Sâugetieren entspricht. Aus dieser Einsenkung erhebt sich ein plattenförmiges, vielfach ge- 
faltetes, bei verschiedenen Arten verschieden weit frei in den Glaskörperraum hineinragendes Organ: das Pecten. Es besteht aus zahlreichen, stark pigmentierten Zellen, die nenerdings (Bloch man $n$ und $v$. Husen 1911, v. Husen 1913) als Gliazellen identifiziert wurden und aus zahlreichen GefäBen, welche alle aus dem „Basalgefä $B^{\prime:}$ des Pecten stammen, das an der Pectenbasis in der Mulde zwischen den Sehnervenfasern gelegen ist.

Sehnerveninsertion und Pecten nehmen, wie ebenfalls bekannt ist, einen Teil des Gebietes ein, in welchem sich in früheren Entwicklungsstadien die fötale Augenbecherspalte befand. Was die Sehnerveninsertion betrifft, so hat dieses Verhalten nach Froriep (1906) seinen Grund darin, daß die Becherspalte überhaupt zu dem Zwecke entsteht, um als Bahn für die Sehnervenfasern bei ihrem Wege rom Auge zum Gehirn zu dienen (,der Lichtrezeptionsapparat hält sich den kürzesten Weg zum Zentralorgan offen:" [S. 231]).

\section{Frühere Untersuchungen über den Verschluß der Augenbecherspalte und die Bildung des Pecten.}

Nahezu alle Untersucher brachten die Pectenbildung mit der Becherspalte in Zusammenhang. Die erreichten Resultate lassen sich in zwei Gruppen einteilen; die älteren Untersucher faßten das Pecten als ein Produlat des Mesoderms auf ${ }^{\mathbf{x}}$, während $\mathrm{es}$ sich nach den neueren Untersuchungen aus dem Augenbecher entwickeln sollte, also ektodermaler Natur sei.

Die Befunde der alteren Autoren (Huschke 1827, Re mak 1851, Lieberkühn 1872, Mihalkowics 1873, Beauregard 1876, Kessler 1877) lassen sich kurz folgendermaßen zusammenfassen. Die Augenbecherspalte schließt sich zuerst längs eines kleinen, distalen Abschnittes und bleibt in ihren größeren, proximalen Teile offen. In diesen schiebt sich Hesoderm ein und dieses Mesoderm ist die Grundlage für das Pecten. Utber den VerschluB der Becherspalte in diesem Gebiete gehen die Angaben auseinander. Nach den einen Autoren wird die mesodermale Pectenanlage durch in den offenen Spaltenteil einwachsende Nervenfasern allmählich von dem Mesoderm ventral vom Augenbecher getrennt und die Spalte so rerschlossen (Mihalkowics), während nach Kessler sich die Becherspalte überhaupt nicht schlieBt, sondern zeitlebens durch das Pecten offen gehalten wird.

Da diese älteren Arbeiten von den neueren Untersuchern (Bernd 1905, ₹. Husen 1913) mehrfach kritisiert wurden und ihre Unrichtigkeit erwiesen wurde, glauben wir hier nicht näher auf dieselben eingehen zu müssen und verweisen diesbezüglich auf die Arbeiten dieser Autoren.

$\mathrm{Zn}$ der alteren Gruppe müssen wir auch die Darstellung der Pectenentwicklung durch F rorie p (1906) in Hertwigs Handbuch der Entwicklangsgeschichte (2. Bd., 2. Teil) rechnen. In offenbarer Unkenntnis der Arbeiten Parreidts (1901) und Bernds (1905) leitet auch er noch wie die älteren Autoren das Pecten vom Mesoderm ab. Da v. Husen (1913) Frorieps Darstellung unberücksichtigt gelassen hat, so soll hier ihr Tnhalt kurz angegeben werden:

1) Eine Ausnahme bildet die Arbeit Denissenkos (1881), welcher auf Grund seines Studiums der GefäBverhältnisse bei dem erwachsenen Organ einen Zusammenhang des Pecten mit der Chorioidea ablehnt und dieses der Retina zurechnet. 
Nach Froriep finden wir (S. 251) das Augenbechergefäß bei Hühnerembryonen des 5. Tages noch unterhalb der Höhe, in der die Spaltenlippen aneinandertreten. Von der Mitte oder dem Ende des 5. Tages ab findet man es oberhalb dieser Linie: es ist jetzt, umgeben von Mittelblattgewebe, ins Innere des Bechers aufgenommen und stellt hier in der Furche, welche die Spaltenlippen

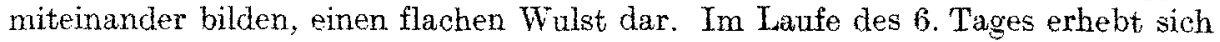
dieser Wulst und wird zu einer plamparallelen Platte, die an ihrer Basis durch die Becherspalte mit dem umgebenden Bindegewebe zusammenhängt. Das Angenbechergefäß erhält sich an der Basis der Platte. Es verläßt den Augenbecher am Rande der Pars ciliaris.

Vom 7 . Bebrütungstage an kommt es zu einer enormen Zunahme der Nerrenfasern, welche die Fächeranlage von den Spalträndern abdrängen und so teilweise in die Fächerbasis zu liegen kommen. ,So kommt alinählich das eigentümliche Verhalten zustande, daß der Fächer aus dew Sehnerven herrorgewachsen scheint, während in Wirklichkeit der Sehnerv durch sein excessives Dickenwachstum den ganzen vom Fächer offen gehaltenen Abschnitt der Becherspalte mit in Beschlag genommen hat. Das Augenbechergefä $B$ bewahrt seine Lage in der Basis des Fächers und ruht hier nun in der Rinne zwischen den Opticus. fasen. Uber der Arterie erhebt sich die Platte des Fächers. Diese wird in geringer Höhe plötzlich dünner: auf einem dickeren Sockel erhebt sich dann der Hauptteil als gleichmäBig dïnne Wand ${ }^{x:}$ (S. 251/52).

In einer kürzlich erschienenen Arbeit über die Entwicklung des Auges und seiner Anhangsgebilde bei Passer domesticus von J.R. Slonaker (1921) widmet der Verf, auch der Entwicllung des Peeten ein kurzes Kapitel. Das Referat. hierüber sei hier eingereiht, da Slonaker im Ansehluß an ältere tutoren, vor allem an Frorieps Darstellung, das Pecten als ein mesodermales Gebilde auffaßt.

Nach Slonaker erscheint das Pecten bei 7 Tage alten Sperlingsembryonen zuerst in Form einer kleinen Zellmasse, die von einem Blutgefä $B$ begleitet ist. Die Zellen sind undifferenziert und ähneln stark den Mesodermzellen, welche das Auge umgeben. "In other words, the cells of the mesoderm seem to be flowing into the eye-chamber, apparently through the chorioid fissure. Some of the indifferentiated chorioid cells may be included in this migration, but there is no evidence in the sections at hand of any of the retinal cells taking any part in the formation of the pecten. The ungrating cells and the retinal cells are quite different in appearance and in their ability to take the stain. In my opinion, the pecten is formed by the mesoderm.

Die neueren Autoren, auf deren Cntersuchungen sich unsere heutige Kenntnis von der Entwicklung des Pecten gründet, leiten dieses, wie schon erwähnt wurde, vom Augenbecher ab. Der erste, der dieser Auffassung deutlichen Ausdruck gibt, ist $\mathrm{NuBbaum}$ (1899 [nicht, wie $\nabla . \mathrm{Husen}$ erklärt, Parreidt]).

$\mathrm{Nu} \mathrm{Bbaum}$ sagt (S. 11) ,Bei ... Vögehn richten sich die vorher klaffenden. Ränder des Augenspaltes auf und wachsen gegen das Augeninnere vor, um , . das Pecten zu erzengen".

$\mathrm{NuBbaum}$ hat diese seine Entdeckung selbst nicht weiter verfolgt, sondem das Thema seinem Schüler Bernd überlassen, wie dieser einleitend angibt (s. u.). 
230 C. Lindahl und A. Jokl: Thber den Terschuß der fötalen Angenbecherspalte,

Offenbar ohne Kenntnis der Angabe $\mathrm{NuBbaums}$ gelangte Parreidt (1901) ebenfalls zur Auffassung einer ectodermalen Entstehung des Pecten, die jedoch von der Vorstellung, die Nußbaum über die Pectenbildung hat, wesentlich verschieden ist. Parreidt untersuchte das Auge von Eudyptes chrysocome. Beim Studium von Embryonen dieser Tierart fiel ihm auf (S. 23), daB die Bilder, die er hier fand, mit den bisher über die Entwicklung des Pecten veröffentlichten nicht übereinstimmten. Um $z u$ entscheiden, $o b$ es sich nicht um den Pinguinen eigentümliche Verhältnisse handelt, untersuchte Parreidt daraufhin die Entwicklung des Pecten bei Hühnerembryonen. Er erhielt hier die gleichen Befunde wie bei Eudyptes. Am 4. Bebrütungstage erhebt sich bei Hühnerembryonen uber dem schon deutlich erkennbaren Opticus eine kleine Leiste, die sich auf Querschnitten als kleines Dreieck darstellt, dessen Zellen denen der Retia gleichen. Am 5. Tage bildet das Pecten einen kleinen Zapfen. Vom 6. Tage an beginnt das Pecten schneller zu wachsen usw.

Auf Grund dieser Befunde glaubt Parreidt schließen zu dürfen, daß der Kamm weder ein Teil, noch ein Anhangsgebilde der Chorioidea ist, sondern seinem Ursprung nach der Retina zugerechnet werden muB. In seiner Zusammenfassung (S. 25) erklärt er: ,Der Pecten entsteht nicht als Teil oder Anhang der Chorioidea, sondern aus Zellen, die denen der Retina völlig gleichen".

Die Arbeit Parreidts hat in der Literatur wenig Beachtung gefunden. Bernd (1905) kennt sie überhaupt nicht. v. Husen (1913) nimmt bei ihren Untersuchungen keine Rücksicht auf dieselbe und,Franz (1913) fertigt sie nur mit ein paar Worten ab. Als die wichtigsten Arbeiten über die Entwicklung des Pecten gelten die Bernds (1905) und v. Husens (1913).

Bernd hat, wie schon erwähnt, von seinem Lehrer $\mathrm{NuBbaum}$ die Aufgabe bekommen, die von letzterem gemachte Entdeckung, daß das Pecten aus den Rändern der Augenbecherspalte entstehe, näher zu verfolgen. Als Material verwendete Bernd Hühnerembryonen (12 Schnittserien im Alter von $4^{\mathrm{d}} 6^{\mathrm{h}}$ bis

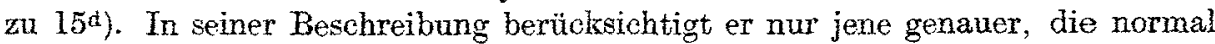
auf die Längsrichtung der Becherspalte, bzw. des Pecten geschnitten waren.

Nach Bernd steht die Augenbecherspalte in jüngeren Stadien $\left(4^{d} 6^{\mathrm{h}}\right.$, $\left.4^{d} 13^{1} / 2^{h}, 4^{d} 22^{h}\right)$ zum größten Teile offen und ist nur auf einer kurzen Strecke distal geschlossen. Ein Mesodermkeil schiebt sich zu dieser Zeit in den offenen Teil der Spalte ein. In einem späteren Stadium $\left(5^{d} 6^{\text {h}}\right)$ findet er, daß die Ränder der Augenbecherspalte sich zu beiden Seiten dieses Mesodermkeiles hinaufgeschoben haben und am weitesten proximal über den freien Rand derselben miteinander verwachsen sind. Dadurch ist proximal ein Tunnel von Ektoderm über dem Mesodermkeil entstanden, der aus den Rändern der Augenbecherspalte gebildet wird. Dieser Tunnel ragt in Form einer Leiste in die Augenbecherhöhle binein und stellt die erste Anlage des Pecten dar. Die Tunnelbildung schreitet sodann distalwärts fort; dabei verschwindet das Mesoderm gleichzeitig aus der Tunnelhöhle, um hier einer mit dem äußeren Augenbecherblatt zusammentängenden Zellgruppe Platz zu lassen, die der Anlage des Becherstiels entspricht. Bei einem Stadium von $6^{d} 10^{1} / 2^{\mathrm{h}}$ ist die Tunnelbildung über eine Strecke fortgeschritten, die der proximalen Hälfte des Mesodermkeiles entspricht, wobei der letztere hier fast vollständig verschwunden ist, so daß die Pectenanlage 


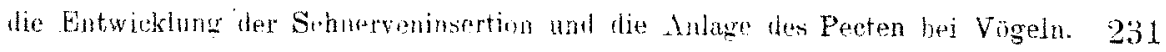

hier nahezu ausschließlich ektodermal ist. An der Stelle des verschwundenen Mesodermkeils ist hier wieder der früher erwähnte Wulst des Opticusstiels vorhanden. Für dieses Stadinm macht Bernd auch einige Angaben über den histologischen Bau der Pectenanlage. Fr findet, daß die Pigmentierung in den Zellen des Pigmentblattes dort, wo die Augenspaltränder sich aufzurichten beginnen, verschwunden ist, während die Zellen der ektodermalen Deckhülle (der Pectenanlage) viel weniger intensiv gefärbt erscheinen, was nach Bernd darauf beruht, "daß die Zellen der Retina weit dichter stehen, die Kerne näher aneinander liegen wie im Pecten, wo die reihenweise Anorrnung der Zellagen, wie man sie beim innern Blatt der Augenblase um diese Zeit beobachtet, einem regellosen Durcheinander Platz gemacht hat" (S. 32). Dis Sehnervenfasern treten in diesem Stadium nicht, wie Kessler u. a. meinten, durch die Angenspalte zur Retina, sondern laufen vom Opticusstiel aus in den Augenblasenblättern parallel mit der Spalte linsenwärts, dann und wann Bündel aus diesen heranssendend, wodurch die Trennung des Pecten von dem Retinalteil der Augenblasenblätter vorbereitet wird.

Bei einem $7^{\text {d }}$ alten Stadium ist die Tunnelbildung in distaler Richtung über den ganzen Mesodermkeil fortgeschritten, so daß dieser vollständig vom Ektoderm überwachsen ist. Das Pecten selbst ist höher und breiter geworden, die Differenzierung zwischen den Pectenzellen und den Retinazellen ist schärfer und die Pectenanlage ist durch die vermehrten Nervenfasern deutlich von der Retina abgegrenzt. Das Mesoderm im Tunnel nimmt proximalwärts gegen den Opticus hin an Breite und auch an Höhe ab und ist ungefähr von der Mitte des Pecten an zu einer schmalen Zunge reduziert.

Bei einem Stadium von $7^{d} 16^{\mathrm{b}}$ bildet das Pecten im Querschnitt einen sehr dünnen Zapfen und Mesoderm und ektodermale Deckschicht gehen unregelmäßig ineinander über und sind nicht mehr so deutlich getrennt wie in jüngeren Stadien. Am Rande des Zapfens (Pecten) stehen die Kerne dichter als in seiner Mitte, namentlich an der Basis, wo viel Vesoderm liegt.

v. Husen (1913) untersuchte 34 in Serie geschnittene Hühnerembryonen in einem Alter von $48^{\mathrm{h}}-19^{4} 1^{\mathrm{h}}$.

In jungen Stadien $\left(58^{\mathrm{h}}, 61^{\mathrm{h}}, 3^{\mathrm{d}} 22^{\mathrm{h}}\right)$ findet $\mathrm{v}$. Husen (S. 237) Mesoderm in die Angenbecherspalte eindringen, welches almählich durch Zellproliferation an Menge zunimmt und zu dem von Bernd beschriebenen Mesodermkeil wird, der sich über das ganze Gebiet der Becherspalte erstreckt. Spater wird dieser Mesodermkeil in proximodistaler Richtung von den Rändern der Augenblasen. spalte überwachsen, welche über demselben verschmelzen. Diese Überwachsung beginnt unmittelbar hinter dem Ùbergang des Augenblasenstiels in die sekundäre Augenblase. Da hier das Mesoderm nicht in die Augenbecherhöhle hineinragt, so ist der Ektodermtunnel nur niedrig. In den folgenden Stadien streckt er sich hier stark in die Höhe, während er distalwärts weiter vorwächst. Bei einem Stadium von $5^{\text {d }}$ sind die Ränder der offenen Spalte etwas , aufgebäumt" (diesen Ausdruck hat $v$. H use $n$ von Bernd entlehnt; gemeint ist damit, daß die Becherspaltränder gegen das Becherinnere zu eingebogen sind). Diese Einbiegung ist am rostralen (nasalen) Rande stärker ausgesprochen als caudal (temporal). Außerdem ist dieser Rand gegen die Spalte zu mächtiger als sonst. In seinem 
292 C.Lindahl mul A. Jokl: Uher den FersehluB der fötalen Angenbecherspalte,

proximalen Teile wird er von Nervenfasern durchzogen, welche von der Ruetina kommen und zu dem noch weiter proximal gelegenen Augenblasenstiel ziehen.

Die Verschiedenheit in der Mächtigkeit der beiden Spaltränder wird in späteren Stadien noch mehr ausgesprochen. Bei einem Stadium von $7^{\mathrm{a}} \mathbf{1}^{\mathrm{h}}$ findet v. Husen die stärkere, ,lappenartige" Verdickung des rostralen Spaltrandes dem caudalen gegenüber scharf hervortretend. (Offenbar befindet sich hier auch im Bereiche des caudalen Randes ein solcher Lappen, der jedoch schwächer ist als der rostrale.) Durch diese beiden Lappen nehmen die Nervenfasern aras der Retina ihren Verlauf zum Becherstiel. Weiter distal sind die Ektodermlappen an beiden Seiten gleich mächtig; die Nervenfaserbildung ist so weit noch nicht vorgedrungen. y. Husen faßt diese beiden Lappen als Bahn für den vorwachsenden Opticus auf. Demnach wäre also die Opticusanlage distal zweigeteilt und zerfiele in eine mächtigere rostrale and eine schwächere caudale Portion. zwischen die sich der Mesodermkeil einschiebt. Diese Zweiteiligkeit verschwindet ganz allmählich im Laufe der Entwicklung von proximal nach distal, Hand in Hand mit dem Verschwinden des Mesodermkeiles. Es geht also nach v. Husen ,der Sehnerv im Vogelauge nicht nur aus dem Augenblasenstiel hervor, sondern sein distaler, unterhalb des Pecten verlaufender Abschnitt entwickelt sich in dem beim Verschmelzen der Augenblasenblätter gebildeten Gewebe" (S. 241). Frorieps Auffassung, dal3 der Sehnerv bei Vögeln ,einen mehr oder weniger ausgedehnten Abschnitt der Augenbecherspalte in Anspruch nimmt und diesen dadurch dauerad offen erhält", wäre nach $v$. H usen dahin zu berichtigen, ,daß gerade der Sehnerv den Verschluß der Spalte bildet, da er hier innerhalb der geschlossenen Spaltränder entsteht" (S. 241).

Die so viel stärkere Entwicklung des Ektodermlappens am rostralen Spaltenrande erklärt es nach v. Husen zugleich, warum der Opticus die Bulbuswand schräg durchsetzt.

Mit einigen Worten geht $\vee . \mathrm{H}$ usen sodann auf den Verschluß der Augenbecherspalte ein. $\nabla$. Husen unterscheidet zwei Verschlußgebiete: ein proximales, wo der Verschluß der Spalte in der von Bernd beschriebenen Weise durch die über dem Mesodermkeil verschmelzenden Spaltenränder, in proximo. distaler Richtung fortschreitend, vor sich geht. Dieser Verschluß beginnt also gleichzeitig mit der Pectenbildung nach v. Husen bei einem $4^{\mathrm{d}} \mathbf{1}^{\mathrm{h}}$ alten Embryo. Das zweite Verschlußgebiet nennt $v$. Husen das distale und bezeichnet damit die Strecke zwischen dem Pecten und dem nach $\mathrm{NuBba}$ u bei manchen Arten (Huhn, Fasan) offen bleibenden Ciliarteil der Spalte. Hier verschmelzen die Spaltränder ohne Vorwölbung und Leistenbildung miteinander. Das auch hier durch die Spalte in die Augenhöhle hindurchtretende Mesoderm, welches in seinem unteren Teile schon vorher Rückbildung zeigt, wird dabei von seinem Mutterboden abgeschnürt. Der Verschluß vollzieht sich hier am 6.-7. Bebrütungstage, also bevor im ersten VerschluBgebiet, d. h. im Pecten, die Verschmelzung der aufgewölbten Ränder sich völlig vollzogen hat. Von diesen zwei getrennten Verschlußgebieten ist auch das Verhalten des in der ganzen Ausclehnung der Spalte angelegten Mesodermkeiles abhängig. Der proximale Teil desselben wird mit seinen Gefäßen in die Pectenanlage aufgenommen und durch die verschmolzenen Spaltenränder vom Glaskörperraum abgetrennt. Der distale Teil 
im zweiten VerschluRgebiet vexbleibt, von seinem Mutterboden getrennt, inner. halb des Glaskörpers und wirl mit den reichlich in ihm entwickelten Hyaloid. gefäßen allmählich rückgebildet.

Am 6.-8. Bebrütungstage nimmt die Pectenanlage an Ausdehnung und an Höhe zu. Thr Gewebe ist von der Retina verschieden, es ist lockerer und die Kerne sind regellos angeordnet. Der eingeschlossene Mesodermkeil ist im proximalen Teile nur noch undeutlich zu unterscheiden. - Die Nervenfaserbildung schreitet distalwärts fort, so daß hier schon ein größerer Abschnitt des Peeten der Mulde aufsitzt, welche die beiderseits von der Retina kommenden Nervenfasern unter ihm bilden.

Bei einem Embryo von $7^{\text {i }} 11^{\text {h }}$ ist der proximale Teil des Mesolermteils berits in seiner ganzen Ausdehnung vom Ektoderm überdeckt. Bei einem 8d $2^{1}:$ h alten Embryo ist die Bildung von Nervenfasern in Retina und Opticus bis ans distale Ende des Pecten vorgedrungen und die beiden aus der Verschmelzung der Spaltenränder hervorgegangenen Organe, Pecten und Opticus, sind dadurch histologisch von einander unterschieden.

Uber das Schicksal des ins Pecten eingeschlossenen Mesoderms iubert sich v. Fusen nicht mit Bestimmtheit, nimmt jedoch an, daß dasselbe mit Ausnahme der zur Gefäbildung verwendeten Anteils resorbiert wird.

Der im Anfang, wie erwihnt, distal zweigeteilte Optieus wird nach und nach mit dem Verschwinden des Mesoderms einheitlich.

In cinem kürzlich erschienen Aufsatze behandelt Man n (1921) den VerschluB der Becherspalte und die Entwicklung der Sehnerveninsertion und des Pecten beim Huhn. Mann findet, dal die Becherspalte bei jungen Hühnerembryonen ganz kurz und vertikal nach abwärts gerichtet ist. Während die Spalte sich mit zunehmenlem Wachstum verlangert, schließt sie sich erst in ihrem mittleren Teile. Proximal bleibt sie zuniichst offen, um gefäßführendes Mesoderm eintreten zn lassen. welohes nach seinem Eintritt die Becherhöhle passiert und dieselbe durch den distalen, ebenfalls noch offenstehenden Teil der Spalte wieder verläßt.

Nach Mann geht das Wachstum der unteren (ventralen) Retinalwand in den Rändern der Becherspalte und ihrer nächsten Umgebung vor sich. Diese bilden zwei Fortsätze (,Cornua“), von denen der malare (temporale) rascher wächst als der vordere (nawale). Die Folge davon ist, daB die anfangs, wie erwähnt, vertikal gestelte spalte allmählich eine mit fortschreitender Entwicklung immer mehr ausgesprochene schiefe Richtung bekommt.

Im Bereiche der Spalte ist nach Man n das innere Retinalblatt ektropioniert, so daß es sich zu beiden Seiten derselben ein Stück weit über die Außenseite des Augenbechers erstreckt. Bei dem in proximodistaler Richtung fortschreitenden Verschlusse des proximalen, noch offenen spaltanteils kommen diese ektropionierten Partien des inneren Retinalblatts zur Aneinanderlagerung. Dabei entstehen zwei Wülste, einer an der Anßen- und einer an der Innenseite der Augenbecherwand. Der äuBere dient zur Aufnahme der von der Retina zur Sehnerveninsertion ziehenden Nervenfasern und entspricht der Cauda nervi optici des erwachsenen Vogelauges; der innere Wulst wird zum Pecten. Da die Ektropionierung des inneren Blattes distal weniger stark ausgesprochen ist, Lann es daselbst nur zur Bildung des inneren, nicht aber zur Entstehung des änReren Wulstes kommen. Durch die beiderseits aus der Retina zum äuBeren 
234 C. Lindah I und A. Jok 1: Öher ten TerschluB der fötalen Augenbecherspalte,

Wulst wachsenden Nervenfasern wird der innere gleichsam abgeschnitten und die Pectenanlage kommt darlurch in die Einsenkung wischen den von beiden Seiten her kommenden Nervenfasern zu liegen.

Die Zellen der Pectenanlage gleichen zu Beginn Spongioblasten, nach Abschneidung der Anlage nehmen sie ein mehr retikuläres Aussehen an. Das ganze erscheint wie ein loses Maschenwerk von Zellen und Fasern, welches an der freien, gegen den Glaskörper zu gewendeten Fläche von der Membr. lim. int. begrenzt wird. Mit fortschreitendem Wachstun wird das Pecten zu einem in den Glas. körper hineinragenden Septum ${ }^{1}$ ).

Einen ziemlich breiten Raum nimmt in den meisten Arbeiten über die Pectenentwicklung die Beschreibung der GefäBverhältnisse des embryonalen Pecten ein. Da wir bei unserer Untersuchung auf die Pectengefäße nicht näher eingegangen sind, sondern diesbezügliche Befunde nur nebenbei erwähnt haben, so glauben wir von einem Referieren der recht verschiedenen Auffassungen über die Pectengefäße absehen zu können und verweisen diesbezüglich auf die Darstellung v. H u sens. Hier sei nur soviel bemerkt, daß nach Kessler die Arteria basalis pect. wahrscheinlich ein rückläufiger Ast der Augenbecherarterie (unseres Glaskörpergefäßes) sein dürfte, Ma $n n$ gibt derselben Auffassung mit Bestimm theit Ausdruck, während nach $\vee$. H u se n die Art. bas. pect. (Arterie I v. H usen) ein selbständiges, aus dem Mesoderm stammendes GefäB ist, welches aber mit der Augenbecherarterie (unserem Glaskörpergefäß) in Verbindung tritt. Diese letztere wird nach $v$. H usen ins Pecten aufgenommen und zur Arterie II des bleibenden Organs.

Von Bedeutung für unsere Untersuchung sind noch einige Angaben über das Offenbleiben der Augenbecherspalte an einer Stelle im Ciliarteil des Auges. Lieberkühn (1879) beschrieb diese Spalte zuerst (beim Huhn), faBte sie aber als eine bedentungslose MiBbildung (Ciliarkörpercolobom) auf. $\mathrm{Nu}$ uba u m (1901) verfolgte ihre Bildungsweise, deutete sie richtig als Rest der Augenspalte und gibt ein Bild von einem 13 Tage alten Hühnerembryo. Sie soll seinen Angaben nach auch beim erwachsenen Huhn und beim erwachsenen Fasan vorhanden sein. Nach Hess (1912) hat diese Öfnung eine funktionelle Bedeutung als Kommunikationsweg zwischen dem vorderen und dem hinteren Augenabschnitte. Bei Nachtvögeln (Käuzchen, Ohrcule) suchte er vergebens nach derselben.

\section{Eigene Lintersuchungen.}

In der folgenden Tabelle ist das Material für unsere Untersuchung (sämtlich aus den Sammlungen des Anatomischen Institutes in Upsala) zusammengestellt.

Wie aus dieser Tabelle hervorgeht, wurde nicht nur das Studium der histologischen Schnitte, sondern auch die Rekonstruktionsmethode ( $n$. Born) in ausgedehnter.Weise bei der Bearbeitung des Materials herangezogen. Dabei wurde immer auf einen Vergleich des Schnittbildes mit dem Rekonstruktionsmodell besonderes Gewicht gelegt, da es sich bald herausstellte, daß die hier in Frage kommenden, komplizierten Verhältnisse sich bei der Anwendung bloß einer dieser Methoden nicht lösen ließen. Außerdem erwies es sich bald als sehr wertvoll, die Verhält-

1) A. v. Szily hat beim internat. OphthalmologenkongreB in Wien am 6. Aug. 1921 über neue, von ihm angestellte Untersuchungen, die Augenbecherspalte und die Pectenentwicklung bei Vögein betreffend, gesprochen. Ein näheres Eingehen auf dieselben behalten wir uns nach Ersebeinen seiner: ansführlichen Publikation vor. 


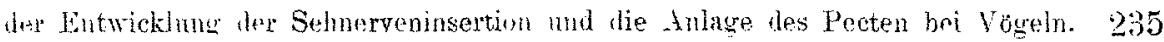

nisse bei ungefähr gleich entwickelten Embryonalstadien der versehiedenen von uns untersuchten Spezies miteinander zu vergleichen, da gewisse Entwicklungsverhältnisse bei den verschiedenen Arten verschieden deutlich hervortraten. Es wurde daher ein solcher Vergleich. wo immer angängig, durchgeführt.

Tabelle über das Material unserer Untersuchung.

\begin{tabular}{|c|c|c|c|c|c|c|c|c|}
\hline \multicolumn{2}{|c|}{ Podiceps cristatus } & \multicolumn{3}{|c|}{ Anas domesticus } & \multicolumn{2}{|c|}{ Passer domesticus } & \multicolumn{2}{|c|}{ Galns domesticus } \\
\hline $\begin{array}{c}\text { Länge } \\
\text { in } \\
\mathrm{mm}\end{array}$ & Rekonstrulition & Alter & $\begin{array}{l}\text { Länge } \\
\text { in } \\
\text { min }\end{array}$ & Rekonstruktion & $\begin{array}{l}\text { Lange } \\
\text { in } \\
\mathrm{mm}\end{array}$ & & Alter & $\begin{array}{l}\text { Rekon: } \\
\text { struktion }\end{array}$ \\
\hline \begin{tabular}{r|}
7,8 \\
7,9 \\
8,0 \\
8,1 \\
8,2 \\
8,5 \\
9,0 \\
9,7 \\
10,0 \\
10,1 \\
11,0 \\
12,1 \\
12,2 \\
12,6 \\
12,8 \\
14,0 \\
14,8 \\
15,0 \\
17,0 \\
18,4 \\
20,0 \\
23,0 \\
23,9 \\
28,5 \\
29,5 \\
32,5
\end{tabular} & $\begin{array}{l}125 \times \\
85 x\end{array}$ & $\begin{array}{c}102^{\mathrm{h}} \\
114^{\mathrm{h}} \\
120^{\mathrm{h}} \\
126^{\mathrm{h}} \\
132^{\mathrm{h}} \\
137^{\mathrm{h}} \\
5^{1} / 2^{\mathrm{d}} \\
149^{\mathrm{h}} \\
150^{\mathrm{h}} \\
149^{\mathrm{h}} \\
161^{\mathrm{h}} \\
161^{\mathrm{h}} \\
173^{\mathrm{h}} \\
6^{1} / 2^{\mathrm{d}} \\
7 \mathrm{~d}^{\mathrm{d}} \\
135^{\mathrm{h}} \\
197^{\mathrm{h}} \\
7{ }^{\mathrm{y}} / 2^{\mathrm{d}} \\
209^{\mathrm{h}} \\
7^{\mathrm{l}} / 2^{\mathrm{d}} \\
8{ }^{1} / 2^{\mathrm{d}} \\
9^{\mathrm{d}}\end{array}$ & $\begin{array}{r}7,7 \\
7,5 \\
6,5 \\
7,5 \\
8,9 \\
8,5 \\
8,3 \\
9,5 \\
9,7 \\
10,0 \\
9,8 \\
10,2 \\
11,0 \\
12,2 \\
12,5 \\
13,0 \\
13,0 \\
16,4 \\
16,5 \\
17,0 \\
20,0 \\
22,8 \\
23,2 \\
30,4\end{array}$ & $\begin{array}{c}125 \times \\
125 \times 4,40 \times \\
125 \because \\
125 \times, 40 \\
40 \times \\
125 \\
40 \times \\
40 \times \\
40 \times\end{array}$ & $\begin{array}{r}3,3 \\
4,0 \\
4,1 \\
4,9 \\
3,0 \\
5,1 \\
5,6 \\
5,5 \\
6,0 \\
6,1 \\
6,3 \\
6,5 \\
7,0 \\
7,4 \\
7,5 \\
7,6 \\
7,7 \\
8,0 \\
8,2 \\
8,5 \\
8,7 \\
10,0 \\
10,2 \\
10,5 \\
11,0 \\
11,5 \\
12,0 \\
13,0 \\
13,5 \\
14,0 \\
17,0 \\
22,5\end{array}$ & $\begin{array}{l}40 \times \\
125 \times \\
125 \times\end{array}$ & 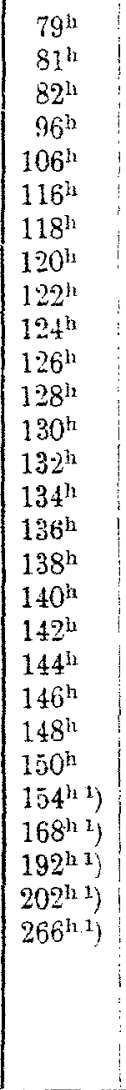 & $\begin{array}{l}125 \% \\
125 \% \\
125 \% \\
125 \%\end{array}$ \\
\hline $\begin{array}{l}\text { Suame } \\
\text { der } \\
\text { Stadien } \\
=26\end{array}$ & $\begin{array}{l}\text { Samme der Pekon- } \\
\text { struitionen }=10\end{array}$ & $\begin{array}{r}\text { Summe } \\
\text { die }\end{array}$ & $\begin{array}{l}\text { der Sta-1 } \\
=33\end{array}$ & $\begin{array}{l}\text { Summe der Re- } \\
\text { konstruktionen } \\
=17\end{array}$ & $\left\{\begin{array}{c}\text { Sumne } \\
\text { der } \\
\text { Stadien } \\
=33^{2}\end{array}\right.$ & $\begin{array}{l}\text { Summe der } \\
\text { Rekonstruk- } \\
\text { tionen }=11\end{array}$ & $\begin{array}{c}\text { Summe d. } \\
\text { Starlien } \\
=28\end{array}$ & $\begin{array}{l}\text { Summe der } \\
\text { Rekonstruk- } \\
\text { tionenil }=10\end{array}$ \\
\hline
\end{tabular}

Alle Stadien sind in kontinuierliche Schnittserien von 12 k Dicke zerlegt, mit Aus. nahme der mit $\left.{ }^{1}\right)$ bezeichneten, wo die Sehnittdicke $18 /$ beträgt, und mit HämatoxylinEosin gefärbt. Rekonstruktion nach der Bornschen Plattenmodelliermethode.

Da die Länge an den gekrümmten Embryonen gemessen wurde und diese Krümmung gegebenenfalls, wie bekannt, verschieden stark sein kann, so ergeben die angeführten Zahlen kein unbedingt vergleichbares MaB für den Entwicklungsqustand der betr. Stadien. 
Die im allgemeinen verwendete Schnittrichtung unserer Embryonen (quer auf die Längsrichtung der Körperachse) brachte es mit sich, daß die Schnitte furch die Augenanlage bei den jüngeren Stadien mehr oder weniger parallel zu der Längsrichtung der Augenbecherspalte verliefen, während sie bei älteren immer mehr normal auf sie (bzw. auf ihre Derivate) gerichtet waren. Die genaue Schnittrichtung in bezug auf clie Längsrichtung der Becherspalte ließ sich immer an den Rekonstrulstionsmodellen ablesen.

Wir beschreiben für jede Art erst eine Anzahl ausgewählter Stadien, die wir unserer Darstellung zugrunde legen und schildern dann den Entwicklungsgang zusammentassend.

\section{Podiceps cristatus.}

Stadium 1. $7,8 \mathrm{~mm}$ long.

Augenbecher ausgebildet mit ganz kmzem, hohlem sticle. Ein spaltförmiger Pest des Sehrentrilsels trennt noch wößtenteils seine beiden Blätter, fon denen das innere wesent-

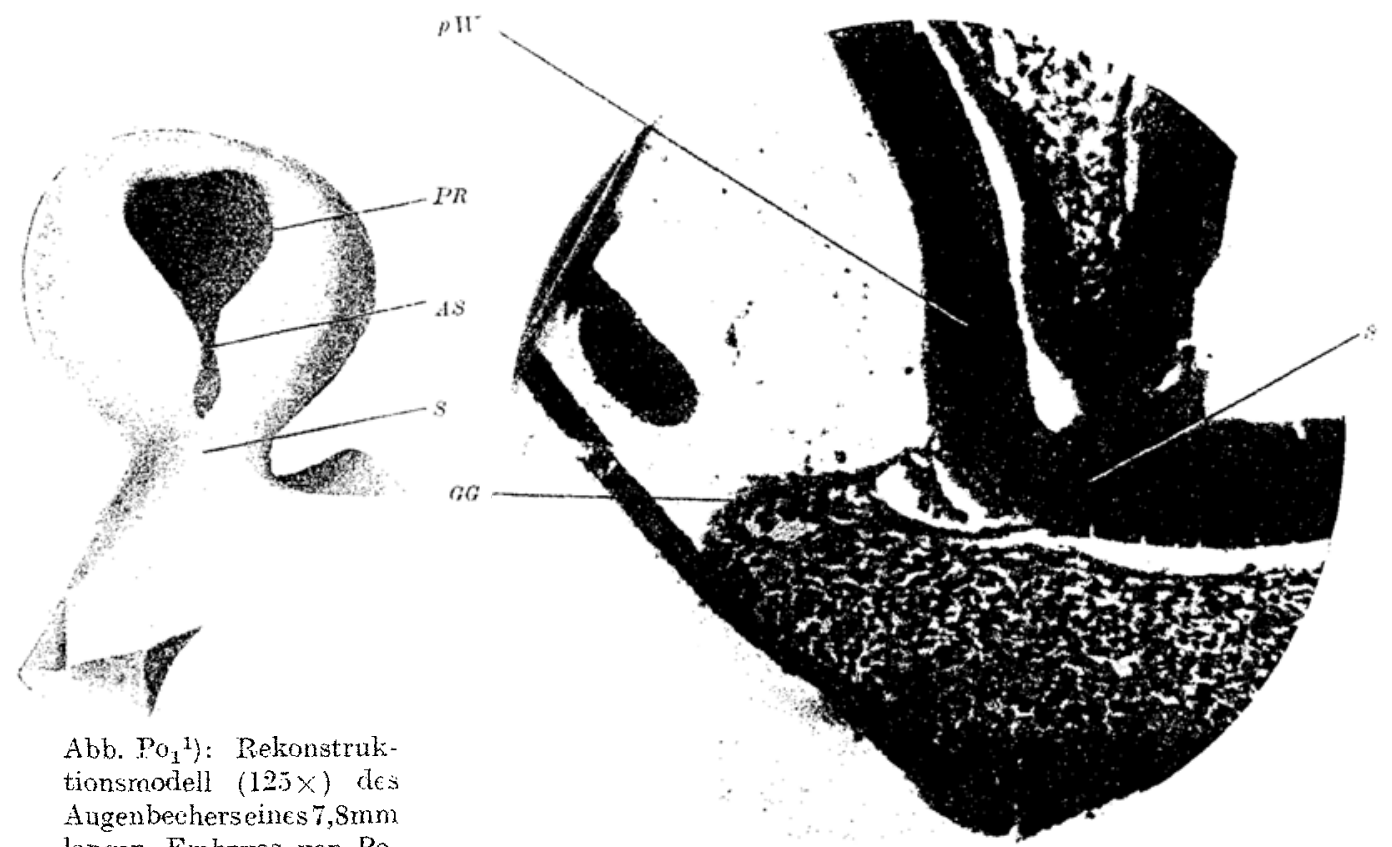
langen Embryos von Podiceps er., schief von unter und aufen her:geselaen. 8. d. nat. 'G?

Abb. $\mathrm{Po}_{2}{ }^{1}$ ): Photographie eincs Lüngsschnits durch clie offene fötale Augenspalte eines $7,8 \mathrm{~mm}$ langen Embryos ron Podiceps er. Vergr. 168:1.

lich dieker ist als das äußere ( $v g l . ~ A b b . ~ P O_{2}$ ). Außeres Blatt mit hochzylindrischen Zellen. noch kein Pigment enthaltend. Inneres Blatt nit schmalem Randschleier im ventralen Teile der proximalen Becherwand. Linse: Die Linsenfasern sind bis zum vorderen Linsenepithel vorgewachsen; ein Rest des Linsenlumens ist noch in Form eines schmalen Spalts vorhanden.

Abb. $\mathrm{Po}_{1}$ zeigt ein Rekonstruktions modell (Vergr. 125) des Angenbechers sehief von lateral und rentral her gesehen. Die Augenbecherspalte (AS) is $t$ ihrer

1) Erklärung der Abkürzungen am Schluse der Arbeit (S. 342). 
die Entwiclung der Sohnerreninsertion und die Alage des Pecten hei Fogeln. 237

ganzen Länge nach bis zur Insertionsstelle des Becherstieles offen. Sie ist in ihrem mittleren Teile relativ eng und verbreitert sich von hier aus sowohl proximalwie distahwärts. Distal gehen ihre Pänder, allmählich divergierend, ohne scharfe Grenze in den Pupillarrand des Augenbechers itber. Die beiden Ränder der Spalte stehen nicht völlig symmetrisch. Es ist vielmehr der nasale Rand (in der thb. rechts) stärker gegen das Becherinnere zu eingebogen als der temporale. Infolgedessen bekommt die Spalte eine sehräge Pichtung und durchsetzt die Becherwand von nasal außen nach temporal innen. In der Augenbecherspalte liegt ein dünnwandiges $\left(\mathrm{Gefä} B^{1}\right.$ ) mit weitem Lumen ( $A b b, \mathrm{Po}_{2}, \mathrm{GG}$ ), welches sich bei diesen Objekte nicht weiter proximalwärts verfolgen läßt, aber, wie ein Vergleich mit anderen Präparaten zeigt, wahrscheinlich von einem Gefäßplexus herstammt, der sich an der ventralen Seite des Augenbecherstiels und des Diencephalon ausbreitet.

Stadium $: .10,1 \mathrm{~mm}$ lang.

Pigmentblatt enthält Pigment, jedoch nur in seinem distalen und seinem dorsalen Abschnitte. Sein ventraler Teil, namentlich die Gegend der früheren fötalen Augeabecher.

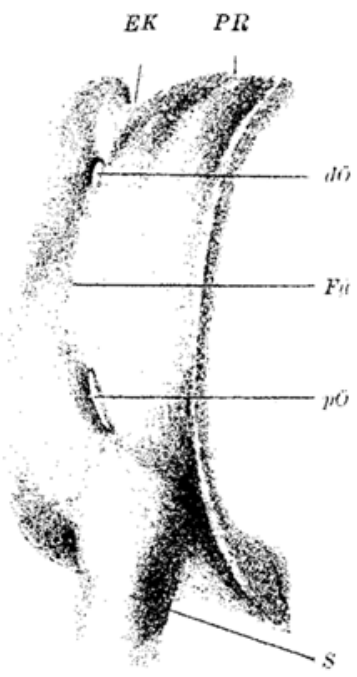

Abb. $\left.\mathrm{Po}_{3}{ }^{2}\right)$ : Rekonstruktionsmodell (125x) eines Teiles der ventralen Wand des Augenbechers fon Podiceps mit der Sehnerveninsertionsanlage und den Resten der teilweise verschlossenen Becherspalte, von außen gesehen. Länge des Embryos $10,1 \mathrm{~mm}$. ${ }^{s_{15}}$ d. nat. Gr.

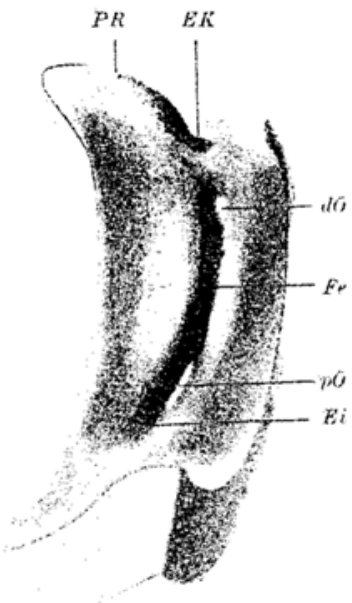

Ahb. $\left.\mathrm{PO}_{4}{ }^{3}\right)$ : Das gleiche Rekonstruktionsmodefl von innen her gesehen. $8 / 1$ d. nat. Gris

spalte, ist frei von Pigment. Das retinale Blatt ist vom Pigmentblatt gröBtenteils durch einen Spaltraum getrennt. Die Differenzierung des retinalen Blattes betrifft nur die nächste Umgebung der Insertionsstelle des Becherstiels und die angrenzenden Teile der proximalen Retinalwand. Hier befindet sich an der der Becherhöhle zugewendeten Seite eine schmale kernfreie Zone von fibrillärer Struktur, welche gegen den Becherstiel hin an Breite zunimmt und in die rentrale Wand desselben übergeht. Diese Schicht stellt die erste Anlage der Opticusfaserschicht der Retina dar und führt die Nervenfasern aus den sich differenzierenden Teilen der Retina der ventralen Wand des Becherstiels zu.

Augenbecherstiel noch durchgehends mit offenem Lumen. Linse: Vordere Wand stärker gewölbt als die hintere. Die Linsenfasern sind fast allenthalben bis ans Linsenepithel vorgewachsen, so daß rom Linsenlumen nur stellenweise ein schmaler. Spałt zurückgeblieben ist.

1) In die Rekonstruktion nicht mitaufgenommen.

2) Erklarung der Abkürzungen am Schlusse der Arbeit ( $S .342$ ). 
Ein Rekonstruktions modell dieses Stadiams ${ }^{1}$ ) (125 , Abb. $\mathrm{Po}_{3}$ and $\mathrm{Po}_{4}, \mathrm{~S} .235$ ) zeigt folgende Verhältnisse:

Die Augenbecherspalte ist in ihrem mittleren und eine Strecke weit in ibrem distalen Abschnitte geschlossen. Zwei Öfnungen sind in der Wand des Augenbechers als Reste von ihr zurückgeblieben: eine proximale von der Form einer kurzen Spalte ( $p \ddot{O})$ und eine distale von der Form eines ovalen Loches $(\mathrm{d} \ddot{\mathrm{O}})$. An der Außenseite des Augenbechers $\left(\mathrm{Abb} . \mathrm{Po}_{3}\right.$ ) werden diese beiden Öffnungen durch eine flache Furche miteinander verbunden (Fa), welkhe der Versehlubstelle der fötalen Becherspalte entspricht. Außer dengenannten Öffnungen findet sich ein Rest des am meisten distal gelegenen Teiles der Becherspalte in Form

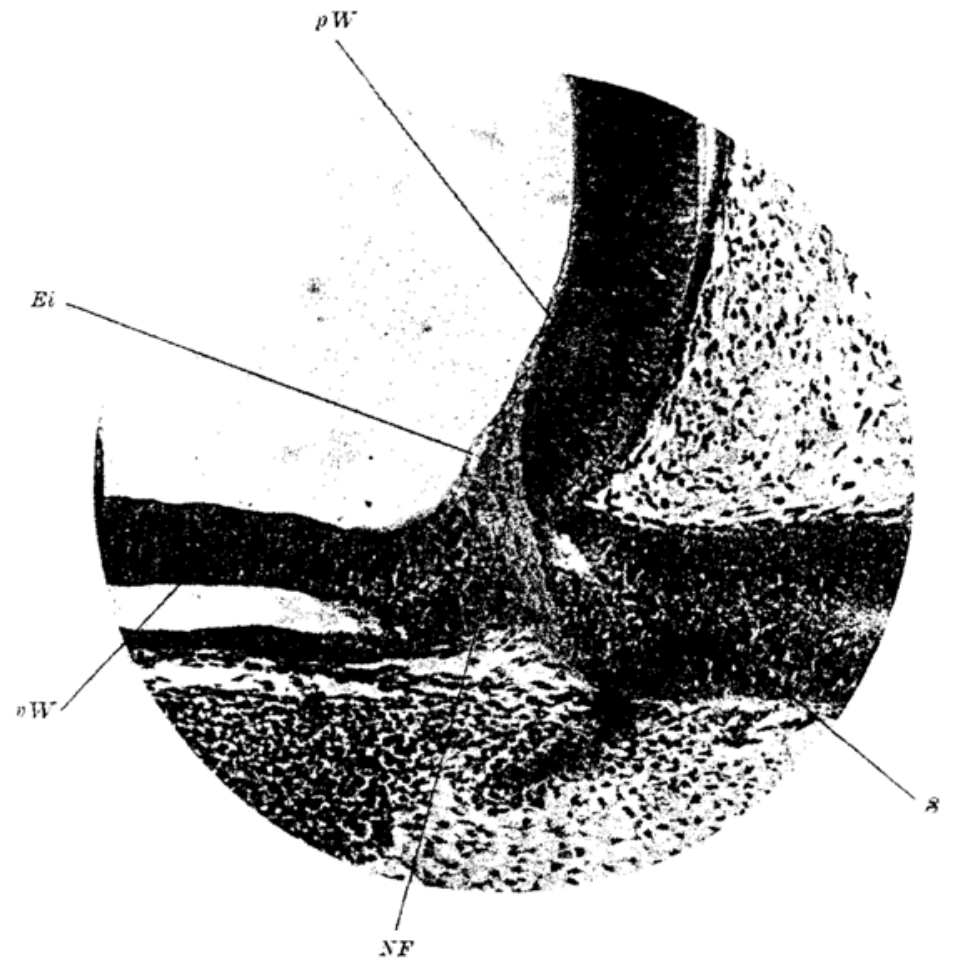

Abb. $\mathrm{Po}_{5}{ }^{2}$ ): Photographie eines parallel zur Becherspalte geführten Sehnittes durch den ventralen Teil des hinteren Augenabschnittes eines $7,3 \mathrm{~mm}$ langen Embryos von Podiceps er. Vergr. $178 ;]$.

einer spitzwinkligen Einkerbung des Papillarrandes vor (EK). Die proximale, schlitzförmige Öffnung reicht mit ihrem proximalen Ende bis an die Ansatzstelle des Becherstiels (S) heran (vgl. Abb. Po $\mathrm{O}_{3}$ ). Dieser letztere ist schief in die Wand des Augenbechers eingepflanzt, indem seine ventrale Wand ohne scharfe Grenze in die ventrale Wand des Augenbechers übergeht, während zwisehen seiner dorsalen Wand und der angrenzenden proximalen Wand des Augenbechers ein spitzer Winkel entsteht. Seine Ansatzfläche am Augenbecher hat die Form eines Dreiecks mit abgerundeten Ecken.

1) Hier und bei den folgenden Rekonstruktionen ist nicht melor der ganze Augenbecher, sondern nur die Gegend der fötalen Augenbecherspalte. der Becherstiel resp. die Sehnerveninsertion mit dem Endstück des Opticus und die nächste Umgebung dieser Gebilde in die Rekonstruktion mitaufgenommen worden.

$\Rightarrow$ E) Erklärung der tbkürzungen am Schlusse de: Arbeit (S. 342). 
Betrachtet man das Rekonstruktionsmodell von der Innenseite (Abb. $\mathrm{Po}_{4}[\mathrm{~S} .237]$ ), so erkennt man folgende Details: Es sind die beiden Öffnungen hier durch eine tiefe Furche (Fi) mitcinander verbunden, welche seitlich durch zwei Wülste begrenzt wird. Die Furche ent. spricht offenbar der Versehlußstelle des mittleren Teiles der Spalte, während die beiden Wülste den gegen die Augenbecherhöhle hin eingebogenen, mit ihren Seitenflächen aneinander gelagerten frïheren Begrenzungsrändem der Becherspalte entsprechen. Der nasale Wulst (in $\mathrm{Abb} . \mathrm{PO}_{4}$ rechts von $\mathrm{Fi}$ ) ist deutlich höher als der temporale, was offenbar den Verhält. nissen im Stadium 1 entspricht, daß der nasale Rand der offenen fötalen Spalte stärker gegen das Angenbecherinnere zu eingebogen ist als der temporale.

In der proximalen Fortsetzung der proximalen Offnung, genau der Insertion des Becher . stiels an der Außenseite entsprechend, befindet sich an der Innenseite des Augenbechers, an der Grenze zwischen proximaler und ventraler Wand, eine seichte Grabe ( $\mathrm{Ei}$ in $\mathrm{Abb} . \mathrm{Po}_{4}$ und $\mathrm{Po}_{6}$ ). Sie entspricht jenem Gebiet, in welchem die, wie erwähnt, hauptsiichlich von der proximalen Wand des Augenbechers stammenden Nervenfasern sich sammeln, um zur ventralen $W$ and des Becherstiels zu ziehen $\left(\mathrm{Abb} . \mathrm{PO}_{5}\right.$. NF). Im Bereiche desselben verlaufen sie, zu einem Bündel vereinigt, an der ventralen Seite der ventralen Wand. Diese ist dadurch verdickt und das Iumen des Becherstiels etwas dorsalwärts versehoben.

Stadium 3. $8,1 \mathrm{~mm}$ lang.

Dieses Stadium steht dem früberen ziemlich nahe, ist jedoch etwas weiter entwickelt, wie aus dem Rekonstruktions modell $(125 \times)$ ), welches einen Teil der ventralen Wand des Augenbechers dieses Stadiums wiedergibt, hervorgeht. $\mathrm{Abb} . \mathrm{Po}_{6}$ zeigt dieses Modell von innen her gesehen. Die in früheren Stadium spitzwinkelige Einkerbung des Augenbecherrandes (EK in $\mathrm{Abb} . \mathrm{Po}_{3}$ und $\mathrm{Po}_{4}$ ), ist hier mehr abgerundet und stampfwinkelig ( $\mathrm{EK}$ in $\mathrm{Abb}$. $\mathrm{Po}_{\mathrm{b}}$ ). Ferner ist hier die Ansatzstelle des Becherstiels schärfer als vorher von der ventralen $W$ and abgesetzt and ihre distale Spitze weiter distalwärts verlängert. Wie in vorigen Stadium endigt dieselbe unmittelbar proximal fon der proximalen öffnung.

Die beiden Öfnungen in der Augenbecherwand und die sie verbindende Furche an der Innenseite des Augenbechers dienen einem Gefä zum Durchtritt, resp. zur Einlagerung, welches auch bei dem früheren Stadium vor. handen war, aber dort in die Rekonstruktion nicht mit aufgenommen wurde. Hier ist dieses GefäB mitrekonstruiert worden. $\mathrm{Abb} . \mathrm{Po}_{\mathrm{B}}$ zeigt den die Augenbecherböhle passierenden Teil des GefäBes (GG). Es verläuft zunächst an der Außenseite des Angenbechers in einer seichten Furche entlang dem temporalen Insertionsrande des Becherstiels bis zur proximalen Öffnung, durch welche es die Becherhöhle betritt. Dann lagert es sich der oben beschriebenen Furche an der Innenseite des Augenbechers ein (vgl. $\mathrm{Abb} . \mathrm{Po}_{6}$ ) und verläBt die Becherhöhle durch die distale öffnung. Dieses Gefäß entspricht offenbar jenem, welches wir bei Stadium $l$ in der dort noch vollkommen offenen Augenbecherspalte gefunden haben; bei dem Verschlus der Spalte wurde dieses Gefiab teilweise in den Augenbecher aufgenommen, so daß es den beschriebenen Verlauf bekommt.

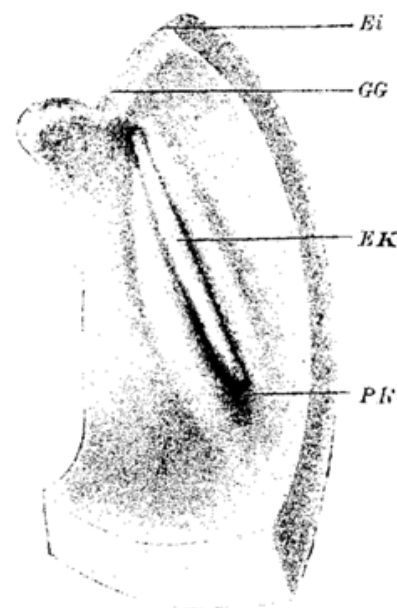

Abb. $\mathrm{Po}_{8}{ }^{2}$ ): Rekonstruktionsmodell $(125 x)$ eines Teiles der ventralen Wand des Augenbechers eines $8,1 \mathrm{~mm}$ langen Embryos von Podiceps cr. mit dem GlaskörpergefäB, von innen her gesehen. ${ }^{8} ;$ d. nat. Gr.

Stadium 4. $12,2 \mathrm{~mm}$ lang.

Pigmentblatt enthalt im allgemeinen (s. u.) reichliches Pigment, Sehventrikel noch zum großen Teile vorhanden; besonders weit ist er in der Tmgebung des Becherstieleintritts. Retinales Blatt in seiner proximalen Wand am dicksten. Hier ist in der Umgebung der Beeherstielinsertion eine Nerrenfaserschicht ansgebildet, welche gegen den Stiel hin an

1) Erklärung der Ablk̈̈rungen am Schlusse der Arbeit (S. 342). 


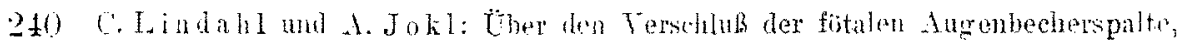

Breite zunimmt. Innerhalb der übrigen, noch undifferenzierten Ratina stehen die größtenteils ovalen Kerne mit ihrer Längsachse radiar (anders im Gobiet der proximalen Spalte, s. später). Der Becherstiel zeigt einen etwa S-förmigen Verlauf. In seinem distalea Teile ist er zu einem soliden Strang umge wandelt, indem seine ventrale Wand sich durch die Menge der eingewachsenen Nervenfasern bedeutend verdickt hat und das Lumen gleichzeitig varschwunden ist. Im proximalen Drittel tindet sich noch ein enges Lumen vor. Ebenso ist ein kleiner Rest des Lumens im distalsten Teile des Becherstiels, bei seinem Übergange in den Augen becher vorhanden. Wir finden hier, daß sich das Pigmentblatt desselben in die dorsale Wand des Becherstiels umschlägt und daß sich der hier noch offene Sehventrikel eine kurze Strecke weit in den Becherstiel hinein fortsetzt. Es kommt so im distalen Teile der Optiousanlage zur Ausbildung giner kleinen, taschenartigen Ansstülpung des Sehventrikel. restes in den Becherstiel hinein.

Linse: Hintere Wand flach, vordere stärker gewölbt. Die Linsenfasern bilden eine hügelförmige Vorwölbung gegen das Linsenepithel zu. Die zentralsten der Linsenfasern liegen dem Epithel am nächsten, ohne jedoch in direkter Berührung mit demselben zu stehen, wihhend in den peripheren Partien der Abstand zwischen Epithel und Fasern größer ist.

Rekonstruktionsmodell $(25 \times)$.

A uBenseite (Abb. $\mathrm{Po}_{7}[\mathrm{~S}, 241]$ ). Die Optieusanlage (S) lommt von der nasalen Seite her an den Augenbecher heran und erreicht denselben mit einer scharfen Biegung. Es erscheint daher bei diesem und bei den folgenden Modellen das distalste Stiiok der Opticusanlage, welches in die Rekonstruktion mitaufgenommen wurde, äberall mehr oder weniger scharf nach der nasalen Seite hin umgebogen.

Die Insertionsfläche der Opticusanlage hat die Gestalt eines langgestreckten Ovals, welehes sich distalwärts immer mehr versehmälert und schließlich mit einer Spitze unmittelbar proximal von der proximalen üfnnng ( $p \ddot{0})$ endigt. An dieser Insertionsfläche setzt sich der Opticus in Form eines Wulstes an, welcher proximal am höchsten ist und distalwärts bis an sein zugespitztes Ende gleichmäßig und allmählich an Höhe abnimmt. Durch zwei seitliche Furchen läbt sich die Opticusinsertion deutlich ron der Becherwand abgrenzen. Von dieser ist die temporale schärfer markiert und setzt sich direkt gegen die proximale Offnung $(\mathrm{p} \ddot{0})$ hin fort. Sehnerveninsertion und proximale Offnung liegen nicht genau in derselben Linie. Denkt man sich eine durch die proximale Öfnung gelegte Ebene proximalwärts verlängert, so liegt eine größere Hälfe der Opticusingertion nasal von dieser Ebene als temporal.

Die proximale Offnung ist bedeutend länger als im Stadium vorher und von spalt. fürniger Gestalt. Sie soll daher in folgenden als "proximale Spalte" bezeichnet werden. Thr nasaler Rand (in Abb. $\mathrm{Po}_{7}$ links) ist stärker gegen das Becherinnere zu eingebogen als der temporale (vgl. Abb. $\mathrm{Po}_{1 l}$, S. 243). Es bekommt dadurch die Spalte eine schiefe Richtung: sie durchsetzt die ventrale sugenbecherwand von nasal wußen nach temporal innen. ( $\mathrm{Vgl}$. Abb. $\mathrm{Po}_{10}$; näheres über den histologisehen Bau der Spaltränder s. später).

Innenseite des Modells (Abb. $\left.\mathrm{Po}_{3}[S .241]\right)$ :

Der verlängerten Sehnerveninsertion an der Außenseite entspricht an der Innenseite des Augenbechers eine verlängerte Einsenkung. Aus dieser Einsenkung erhebt sich ein flacher Wulst ( $\mathrm{Pe}$ ), welcher, in proximo-distaler Richtung ein wenig an Höhe und an Breite zunehmend, bis zur proximalen Spalte reicht. Da dieser Wulst die Einsenkung fast völlig ausfullt - ihr Rest bildet nur eine schmale Furche un den Wulst herum, die ihn von der um gebenden Becherwand trennt -, so stimmt auch ex seiner Lage, Form und Pichtung nach mit der Sehnerveninsertionsfläche an der Außenseite des Augenbeehers überein. Diese w ulst för mige Vorwölbung stellt die ers te Anlage des Pect en dar (über den histologischen Bau desselben s. später).

Entsprechend seiner stärkeren Einbiegung (vg1. Abb. $\mathrm{P}_{0_{10}}$, S. 243) tritt der nasale Rand der proximalen Spalte (in $\mathrm{Ab}$. Pos links) stärker gegen die Becherhöble zu vor und bildet einen die proximale Spalte nasalwärts begrenzenden flachen Wulst ( $\mathrm{nW}$ ). Der temporale Rand der proximalen Spalte ist flach (vgl. Abb. Po $\mathrm{x}_{0}$ ). Zwischen proximaler und distaler Öffnung auch hier an der Innenseite eine seichte Furche, welche nasalwärts von einem Wulst begrenzt wird, der die Fortsetzung des die proximale Spalte nasalwärts begrenzenden vorgewölbten Randes bildet. 
Die histologischen Details der Pectenregion stellen sich folgendermaßen dar: Ein Sichnitt unmittelhar proximal von der Pectenanlage zeigt uns die bei der Beschreibung des Hodells erwähnte. Finsenkung. Sie wird durch die Yervenfasern gebildet, welche ans der wich differenzierenden Retina zum Opticus ziehen. Diese sammeln sich nämlich hauptsächlich in zwei Portionen, einer nasalen und einer temporalen, welche die Nervenfasern aus den resp. Hälfen der Retina entbalten. Inden diese beiden Tervenfaserportionen von nasal

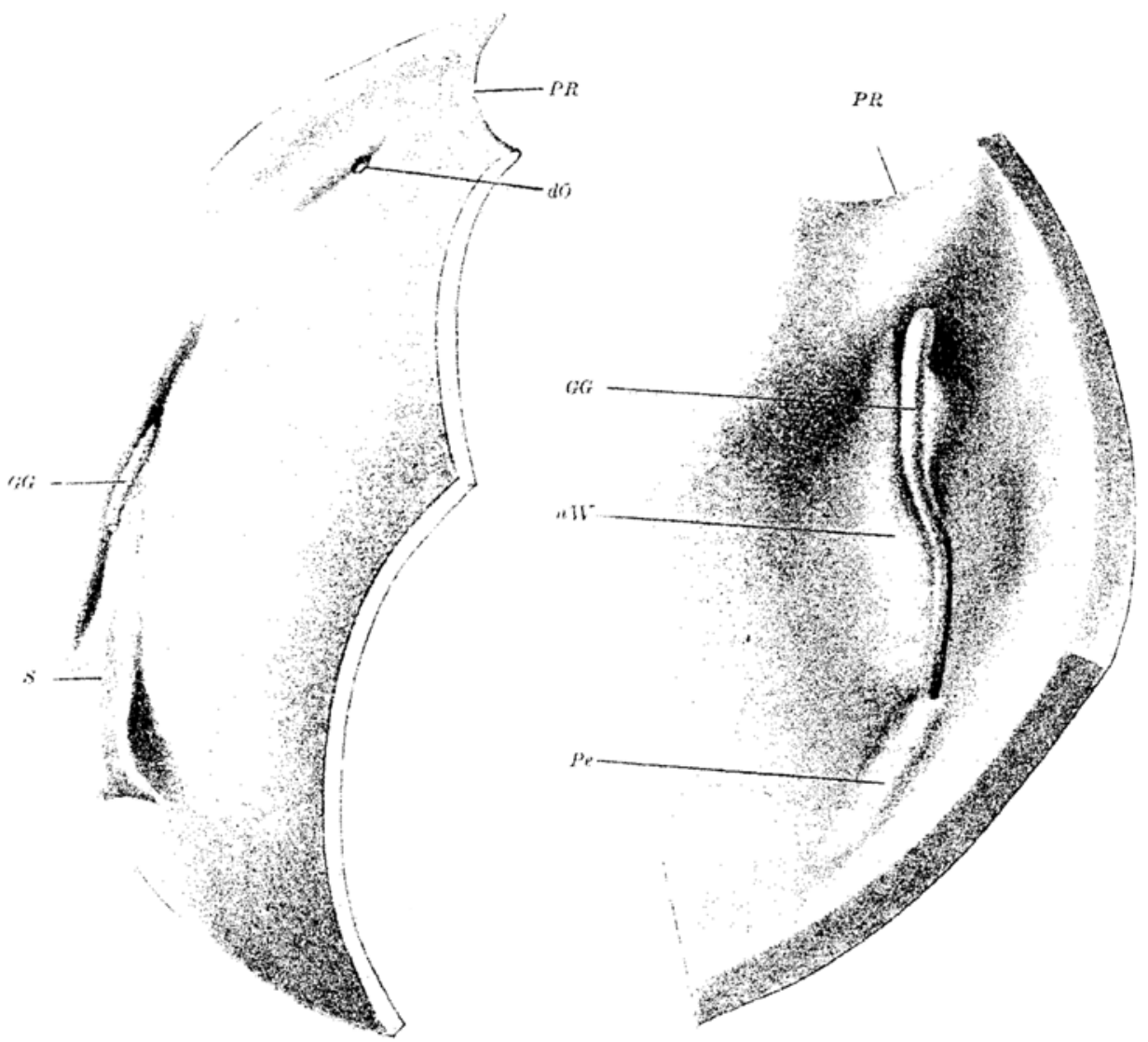

Abb. $\left.\mathrm{PO}_{7}{ }^{1}\right)$ : Rekonstruktionsmodell ( $125 \times$ ) eines Teiles der ventralen Wand des Angenbechers eines $12,2 \mathrm{~mm}$ langen Enbryos von Podiceps"cr, von auben her gesehen.

Abb. Bog $_{9}{ }^{1}$ ): Das gleiche Rekonstruktions. modell (Podiceps cr., $12.2 \mathrm{~mm}$ lang) von der Innenseite her, ${ }^{3}$ d. nat. Gr.

und von temporal her in den Sehnervon hineinziehen, lassen sie die besagte Einsenkung zwischen sich frei. Ebenso wie innerhalb der Retina sind diese Nervenfasern bis zu ihrer Vereinigung im Opticus vollkommen kernfrei. Erst inaerhalb der Opticusanlage treten zwischen ihnen Kerne azat, die offenbar Gliazellen angebören. Das Gewebe, welches die Wände und den Grund der besagten Einsenkung bildet, besteht hier also asschliebhich aus diesen kernlosen Aeryenfasern.

Betrachtet man Sohnitte etwas weiter distal, so fiadet man, daß das am trüheren Schnitte kernfreie Gewebe am Boden der betr. Einsenkung nunmehr eine Anzahl Kerne enthält. Diese Kerne stimmen ihrem Aussehen nach vollkommen mit den Gliazellkernen der

1) Erklarung der Akkirzungen am Schlusse der Arbeit (S. 342). 
Opticusanlage überein und unterscheiden sich deutlich von den Kernen der benachbarten Retina. Sie sind wesentlich heller als die meisten won ihnen, gröbtenteils von ovaler Form und stehen radial, mit ihrer Längsachse in der Richtung des Sehnerven. Es kann nach dem Ausseben dieser Zellen kein $Z$ weifel darüber berrschen, daB es sich hier um Gliazellen bandelt, welche sich von der Opticusanlage aus in die Nerven. faserschicht der Retina hinein vorgesohobe $n$ haben. Je weiter man die Schnittserie distalwärts verfolgt, desto zahlreicher werden diese Zellen, ihre Einwachsungszone in die Nervenfaserschicht der Retina verbreitert sich, sie schieben sich in die besagte Einsenkung hinein vor, füllen dieselbe aus und bilden eine leichte, gegen das Becherinnere zu vorragende Vorwölbung ( $\mathrm{Ab}$ b. $\mathrm{Po}_{9}, \mathrm{Pe}$ ), welche dem am Rekonstrulitionsmodell früher beschriebenen, in der besayten Einsenkung gelegenen Wuste entspricht. Fine Betrachtung der Ablildung $\left(\mathrm{Po}_{9}\right)$ läBt deutlich erkennen, daß diese Zellanbäufung eine unmittelbare Fortsetzung des

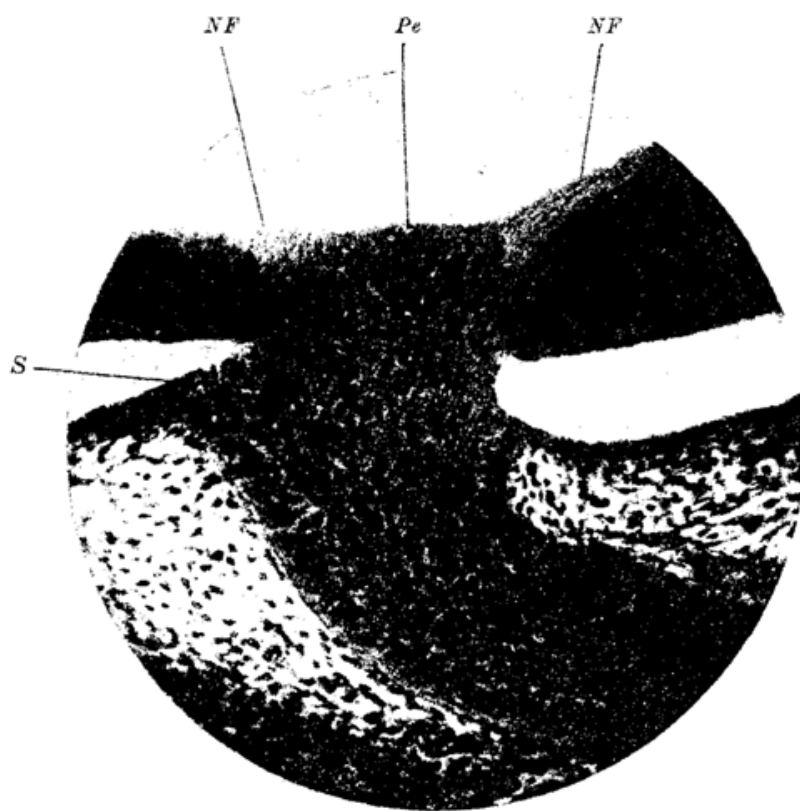

Abb. $\left.\mathrm{Po}_{\mathbf{9}}{ }^{1}\right)$ : Photographie eines Sehnittes duruh die Anlage der Sehnerveninsertion und des Pecten eines 12,2 mm langen Embryos von Podiceps cr. Vergr. 168/1. Optiens in die Nervenfaserschicht der Iaetina ( NF) hinein darstellt. Es wird diese durch den Pecten. wulst in zwei Portionen, eine nasale und eine temporale geteilt, von denen die nasale (in der Abb. rechts) etwas mächtiger ist als die temporale.

Die Vorwölbung des Pecten zeigt ihrer ganzen Länge nach den gleichen histologischen Clarakter. Distalwärts erstreckt sie sich, wie wir bereits bei der Betrachtung des Rekonstruktionsmodells konstatieren konnten, ebenso weit wie die Sehnerveninsertion an der Außenseite. Es ergibt also das Studium der histologischen Schnitte, daB dis Pecten ein Differenzierungsprodukt der Seh. nerveninsertion ist und lägs ihrer ganzen $\pm n s a t z$. fläche zur Entwicklung lionmt.

Die Anlage des Pecten an der Innenseite und die Anlage der Sehnerveninser. tion an der AuBenseite des Augenbechers gehen distal ohne scharfe Grenze in eine besonders charakterisierte Zone der Pünder der proximalen Spalte ä ber. Betrachtet man einen Schnitt durch die spaltgegend (Abb. Pon $)$, so findet man, daß die der Spalte zunächst gelegenen Zonen ihrer Rander einen besonderen Bau aufweisen und sich histologisch von der übrigen Petina unterscheiden. Es endigt der Sehventrikel jederseits eine Strecke weit rom Spaltrande entfernt, und Pigmentblatt an der Außen-, retinales Blatt an der Innenseite des Augenbechers verändern gegen die Spaite zu ihren Charakter: die Zellen des Pigmentblattes, welohe innerhalb der übrigen Retina flach und pigmenthaltig sind, werden gegen die Spalte zu immer hïher und frei von Pigment; die Zellen des Retinablattes, welche sonst in radiären Reihen angeordnet sind, zeigen hier eine unregelmäBige Anordnung und stehen dichter als innerhalb der übrigen Retina. Die histologisch derart charakterisierte Zone betrifft am nasalen Rande (in Abb. Po links) ein gröBeres Gebiet als am temporalen. Der Charakter, den die Zellen hier zeigen, stimmt mit jenem überein, den in jüngeren Stadien alle Zellen des Pigment- und des retinalen Blattes aufweisen. Es hat also die beschriebene Randzone offenbar den DifferenzierungsprozeB der

1) Erklärung der Abkïrzungen am Schlusse der Arbeit ( 8.342 ). 
übrigen Petina nicht mitgemaeht, sontem die Zellen hier sind auf einem frühen Entwieklungsstadium stehen geblieben. Es ist diese undifferenzierte Randzone, in welehe Sehnerveninsertion und Pectenanlage distalwärts übergehen and in denen das dis tale Vorwaehsen dieser Gebilde erfolgt. Die Crsache, warum die Zellen innerhalb dieser Zone den DifferenzierungsprozeB der übrigen Retina nicht mitmachen, ist offenbar die, daß diese Zone nicht für die gleichen Funktionen wie die übrige Retina bestimmt ist, sondern als Bahn für das distalwärts vorwachsende Neuropecten dienen soll.

Das bei der Beschreibung des früheren Stadiums erwähnte Gefäb $\left\{G G\right.$ in $A b b$. Po $_{z}$ und $\mathrm{Po}_{\mathrm{s}}$ ) verlänft auch hier zunächst in der erwähnten Furche an der Temporalseite der Sehnerveninsertion bis zur proximalen Spalte, durchsetzt diese in schräger Richtung ibrer ganzen Länge nach, lagert sich daun eine kurze Strecke weit dem proximalsten Teile der Furche zwischen proximaler und distaler Offnung an der Innenseite des Angenbechers ein, erhebt sich sodann über dieselbe und zieht in einem flachen Bogen frei durch die Becherhöhle zur distalen Offnung, durch welche es austritt. Auf seinem ganzen Verlaufe ist das Gefäß von relativ spärlichen Mesodermzellen begleitet.

Fassen wir die wichtigsten Befunde dieses Stadiums zusammen, soergibt sich folgendes:

1. Hit den an Menge ständig zunehmenden Opticusfasern, die a as der Retina zur ventralen Wand des Becherstiels ziehen, wird diese immer mehr.

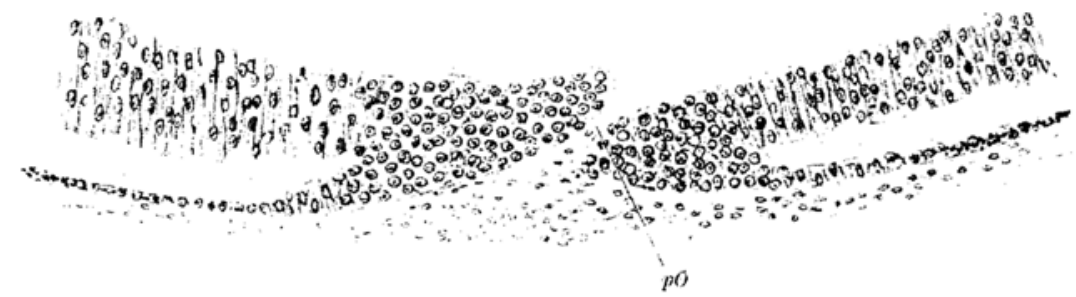

Abb. $\left.P_{\left(0_{10}\right.}{ }^{1}\right)$ : Zeichnung eines Schnittes durch das Gebiet der proximalen Spalte mit ihren undifferenzierten Randteilen von einem 12,2 mm langen Eubryo von Podiceps cr. Vergr. $195 / 1$; auf ${ }^{9 / 10}$ verkleinert.

verdickt und legt sich an die dorsale $W$ and an, wobeidas Lumen des Becherstiels fast vollständig verschwindet. Es wird damit der früher von der Stiel. insertion eingenommene Raum allmählich von Nervenfasern ausgefält.

2. Aus der früher beschriebenen, der Schnerveninsertion an der $A u B e n$. seite entsprechenden Einsenkung an der Innenseite des Augenbechers erhebtsich eine flache Vorwölbung (Pe in Abb. $\mathrm{Po}_{3}, \mathrm{~S} .241$ ), welche a us mit den Gliaztlen der Sehnervenanlage vollkommen übereinstimmenden Zellen besteht ( $P e$ in $A b b . P_{9}, S .24$ ) and in Form, Lage und Richtung mit der Sehnerveninsertionsitelle an der A uBenseite des Augenbechers übereinstimmt. Diese Vorwölbung stellt die erste Anlage des Pecten dar.

3. Die proximale spalte ist sekundär bedentend länger geworden. Thr nasaler Rand ist stärker gegen das Becherinnere zu eingebogen als der tem. porale (vgl. Abb. Pons), wodurch sie eine schiefe Richtang bekommt und die Becherwand ron nasal a uen naeb temporal innen durehsetzt. Thre Rinder zeigen ein von der ubrigen Retina abweichendes Ferhalten, indem hier die Zellen sowohl des Pigment. wie des retinalen Blattes den weriger. differenzierten Charakter jüngerer Stadien beibehalten haben. Diese Struk. tureigentiamlichkeit erstreokt sich im Bereiche des nasalen Randes a uf ein gröBeres Gebiet als im Bereiche des temporalen (vgl. Abb. Po $0_{10}$. Pecten an der Innenseite und Sehnerveninsertion an dex AuBenseite des Augenbechers verlieren peripherwïrts allmählich ihren früher beschriebenen Charakter und gohen in diese undifferenzierten Randteile äber.

1) Erklärung der Abkürzungen am Sehusse der Arbeit (S. 342). 
244 C. Lindahl unl t. Jukl: Cher deu Verschlub der fötalen Augenbeherspalte.

Stadium 5. $14 \mathrm{~mm}$ lang.

Der Differenzierungszustand der Retina ist derselbe wie früher, nur ist clie Nervonfaser. schicht über ein größeres Gebiet ausgebreitet. Sie ist an der nasalen Seite der Retina wesentlich dicker und unfaßt dort ein gröberes Gebiet als an der temporalcn.

Rekonstruktionsmodell (125 K).

Außenseite: Distales Stück des Sehnerven kräftig entwickelt, mit einer längsovalen, ziemlich breiten. distalwärts spitz zulaufenden Ansatzfläche am Augenbecher inserierend. Der größere Teil der Insertionsfläche liegt auch hier wieder an der Nasalseite einer Verlaingerungslinie der proxima len Spalte proximalwärts. Letztere ist noch länger als im Stadium

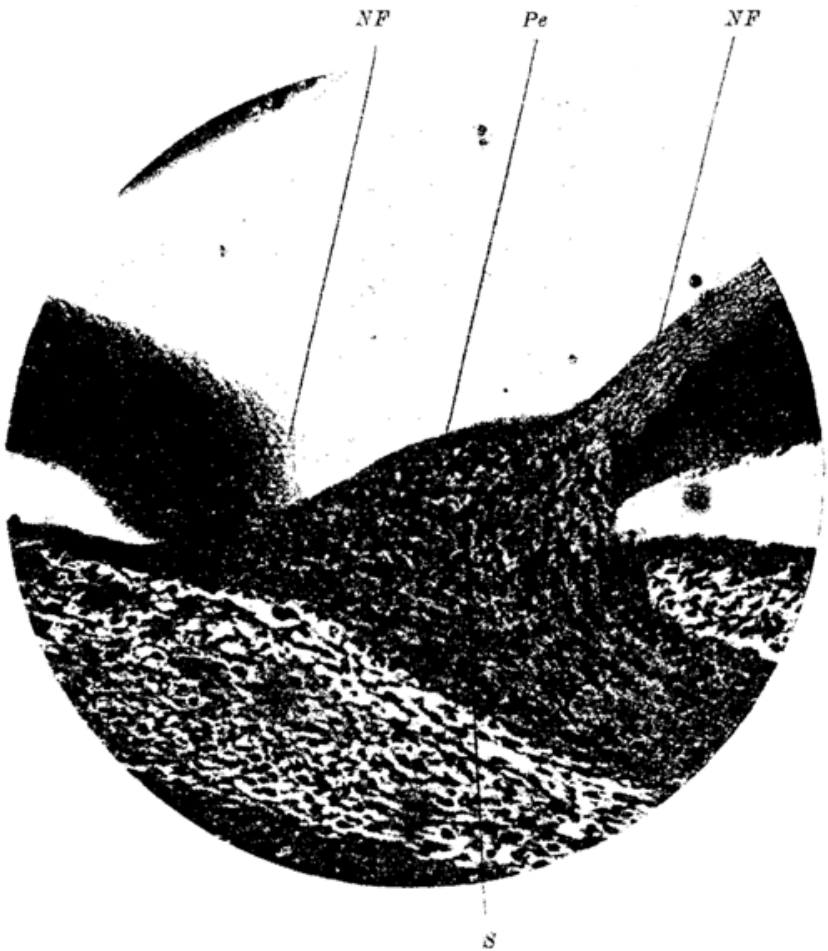

Abh. $\left.\mathrm{Po}_{11}{ }^{1}\right)$ : Photographie eines Schnittes durch die Anlage von Sehnerveninsertion and Pecten eines $14 \mathrm{~mm}$ langen Embryos von Podiceps or. Vergr. 168:1. vorher; ihr nasaler Rand tritt etwas stärker hervor als der temporale. Zwischen proximalex spalte und distaler Offnung eine clistalwärts immer seichter werdende Furche. Distale Oflnung ein ganz kleines i undes Loch.

Innenseite: Langgestreckte, leicht vorgewolbte Pectenlage, die sich hier aus einer relativ ticfen Einsenkung erhebt. sie füllt die Einsenkung nahezu vollständig aus; ein Rest derselben umgibt die Pectenanlage in Form eines deutlich ausgesprochenen Grabens und gremat sie dadurch ron der übrigen Becherwand ab. Die Pectenanlage reicht distal bis zur proximalen Spalte und entspricht auch bei diesen Präparat in Lage. Form und Ausdehnung der Opticusinsertion ancler tußenseite. Proximale Spaite mit etwas stäker eingebogenem nasalen Rande. Die Furche zwischen proximaler spalte und distaler Öffnung nur schwach angedentet. An ihrer nasalen Seite befindet sich ein Wulst. der eine direhte Fortsetzung des nasalen, stärker eingebogenen Randes der proximalen Spalte darstellt.

Bezüglich der histologischen Details der Pectenregion dieses Stadiums (Abb. $P o_{11}$ ) sei nochmals auf den Unterschied in der Dicke der Xervenfaserschicht (NF) an der nasalen (in der Abbildung rechts) und an der temporalen Seite der Retina hingewiesen. Was die Pectenanlage $(\mathrm{Pe})$ anbelangt, so macht sich im Bereiche derselben eine gewisse Differenzierung insofern geltend, als an der der Becherhöhle zugewendeten Fläche der Anlage die Zellen besonders dicht gelagert sind und etwas dunkler tingierte Kerne besitzen als die Ghazellen des Opticus. Eine schärfere Abgrenzung der Pectenanlage gegen die Behnerveninsertion ist noch nicht möglich.

2) Erklärung der Abkürzungen am Schluss der Arbeit (S. 342). 
Im Bereiche der Spaltrinder fillt auch hier der gleiche Nangel einer Differenzierung auf wie in Stadium vorher, und Pectenanlage an der Innenseite und Sehnerveninsertion an der AuBenseite des Augenbechers setzen sich distalwärts unmittelbax in die undifferenzierten Randteile der proximalen Špalte fort, von denen der nasale auch hier wieder mächtiger entwickelt ist als der temporale.

Stadium 6. $15 \mathrm{nim}$ lang.

Die Retina läßt im Bereiche der proximalen Augenbelherwand folgende Differenzierungszonen erkennen: an die Yervenfasershicht, welche hier ein riel weiteres Gebiet unfaßt als un früheren Falle und sich wuch anf dic äbrigen Winde des Augenbechers ziemlich weit ausgebreitet hat, schließt sich eine deutlich ausgebildete Ganglienzellschicht. Dieser folgt nach außen zu eine schmale, kernlose Zone, dic erste Anlage der innelen retikulären Sohicht. Diese tremt die Ganglienzellenschicht von dem noch undifferenzierten, weiter auben gelegenen Bezirke der Retina. - Anlage der Ciliarfortsaitze deutlich entwickelt. Bindegewebiger Teil dey Irisanlage bis aum Pupillarrand roichend.

Rekonstruktionsmodell (85 $\because$ ) ( $\mathrm{Abb}, \mathrm{Po}_{12}$ ) AuBenseite: Der distalste Teil der Bebnervenanlage (S), soweit er in das Rekonstruktionsmodell wit aufgenommen ist, stark nasalwärts ungcbogen. Die Insertion des Sehnerven biluet an der Anbenseite des dugenbechers einen Wulst. der proxinul am hochsten ist und distalwärts immer niedriger wird. Die Insertionsfläche bildet ein langes, schmales, distalwäts in eine Spitze auslaufendes Oval. Der gröBere distale Tell der Sehnerveninsertion liegt in einer Furche. die sich clistalwärts über das Gebiet der proximalen Spalte himaus fortsetzt, wolurch diese in die Tiefe der Furche an liegen konmt. Die Sehnerveninsertion reicht mit ihrer spitze nicht bis an die proximale Spalte heran. Die erwïhnte Furche ist offenbar durch die starke Einbiegung der Rander der proximalen Spalte entstanden und die distale Spitze der Sehnerveninsertion hat sich so präsentieren sich die Verhälnisse weuigstens am Rekonstruktionsmodell … ron proximal her in die proximale spalte hinein vorgeschoben. (Wie sich dieses scheinbare Einwachsen histologisch erklärt, soll später auseinandergesetzt werden.) Bei diesem Einwachsen hat die Sehnerveninsertion eimen Teil der proximalen

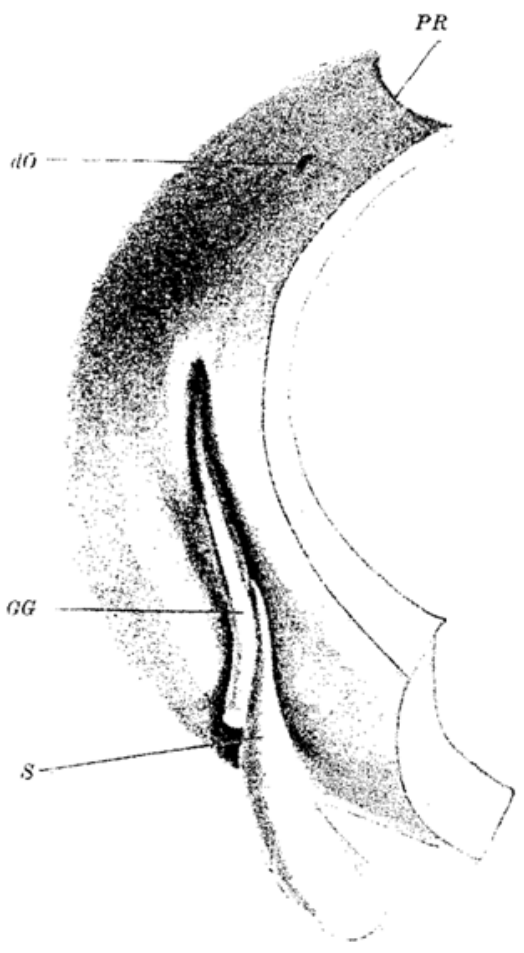

Abb. $\left.\mathrm{P}_{12}{ }^{1}\right)$ : Rekonstruktionsmodell $(85 \times)$ eines Teiles der ventralen Wand des Augenbechers eines 15 mm langen Embryos von Podiceps er, von anßen her gesehen. ${ }_{i a}$ d. nat. Gr. Spalte zum Verschluß gebracht. Infolgedessen ist die proximale spalte hier dem früheren Stadium gegenïber bedentend verkinzt. Thre Ränder sind, wie oben erwähnt, so stark gegen das Becherinnere za eingebogen, daß sie eine Furche $z$ wischen sich bilden, in deren Tiefe die Spalte an liegen kommt. Diese Einbiegung ist im Bereiche des nasalen Randes stärker ausgesprochen als im Bereiche des temporalen, weshalb dieser letztere auch stärker nach auBen vorspringt.

Die Furche zwischen proximalex Spalte und histaler Offnung fast vullig verstrichen. Distale Offnung (dO) ganz klein geworden.

An seiner I n ne nseite zeigt das Rekonstruktionsmodell folgende Verhältnisse (Abb. $\mathrm{Po}_{13}$ ).

Die Pectenanlage (Pe) ist $\mathrm{zu}$ einem relativ mächtigen Gebilde angewachsen. Ihre

1) Erktärung der Abkürzungen an Schlusse der Arbeit (S. 342). 
breitesta und höchste Stelle liegt ungefähr an der Grenze zwischen proximalem and mittlerem Drittel. Fon hier aus nimmt sie nach beiden Richtungen hin an Höhe und auch an Breite ab. Besonders distalwärts rerschmälert sich die Pectenanlage bedeutend und endigt diatal unit einer lang ausgezogenen Spitze in glaicher Weise wie die Sehnerveninsertion an der Aubenseite (Vgl. Abb. Po $_{12}$, S). Die ganze Pectenanlage ist ein wenig temporalwärts (in der Abb. rechts) geneigt und stimmt in ihrer Länge, Form und Richtung auch hier wieder

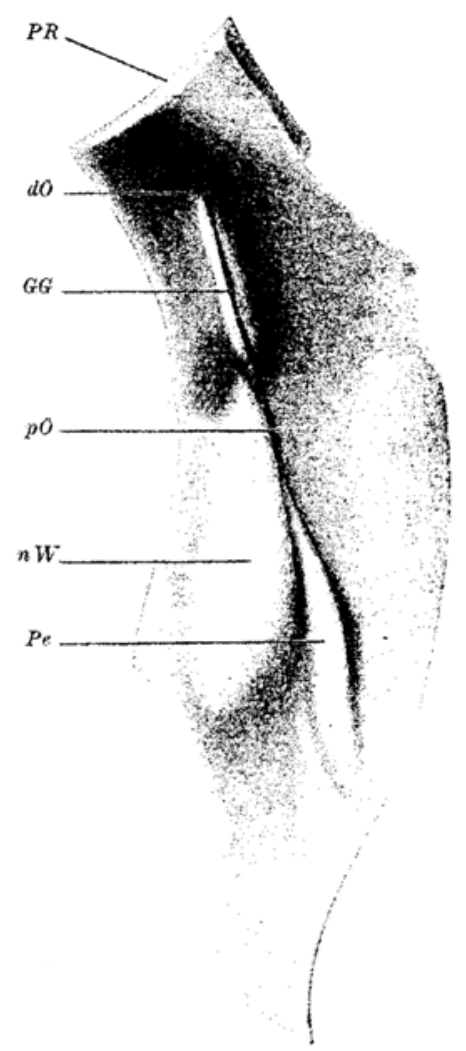

Abb. $\left.\mathrm{Po}_{13}{ }^{1}\right)$ : Dasselbe Rekon* struktionsmodell (Podiceps cr., $15 \mathrm{~mm}$ lang) von cler Innenseite her. $1: 9$ d. nat. Gr. vollkommen mit der Sehnerveninsertion an der Außenseite des Augenbechers überein. Ihr proximaler Teil erheht sich wie früher aus der beschriebenen Einsenkung. Weiter distal aber befindet sich an der nasalen seite der Pectenanlige ein breiter, hoher Wulst $(\mathrm{nW})$, welcher, distalwärts an Höhe und Breite abnelimend, bis ans distale Ende der proximalen Spalte reicht. Dieser Wulst entspricht offenbar dem aufgeworfenen nasalen Begren zungsrande der proximalen Spalte im früheren Stadium, der hier noch stärker gegen das Becherinnere zu eingebogen ist als dort. - Die Tatsache, $\operatorname{da} B$ die Pectenanlage hier mit ihrem distalen Teile neben diesen Wulst zu liegen $\mathrm{kam}$, weist darauf hin, daß die Pectenanlage hier. - in Übereinstimmung mit der Sehnerveninsertion distalwärts in das Gebiet der proximalen Spalte vorgewachsen ist und die letztere dabei verschlossen hat. Hierfür spricht anch der C'mstand, daß die proximale Spalte $(p 0)$ hier relativ ganz bedeutend kürzer ist als im Falle vorher.

Auf Grand der Tatsache, dab einander Sehnerveninsertion a der A uBen-und Pectenanlage an der Innenseite des Augenbechersin allen Entwicklungsstadien, was ihre Lage, Form und Richtung anbelangt, vollkommen entsprechen und ihr Vorwachsen distalwarts vollkommen gleichsinnig erfolgt, halten wir uns für berechtigt, Pecten und Sehnerven. insertion $z u$ einem einheitlichen morpholo. gischen. Gebilde zusammenzufassen, welches wir "Neuropecten" nennen wollen. Dieses Neuropecten erscheint an unseren Modellen als ein Keil, der sich von proximal her in die proximale Spalte hinein rorschiebt, wobei dieselbe zum Verschlub kommt. Entsprechend dem Umstande, daß die proximale Spalte eine schiefe Richtung hat und die Becherwand von nasal außen nach temporal innen durohsetzt, ist auch der in den Spaltbereich vorgewachsene Nouropectenkeil in der gleichen Richtung schief gestellt: die Sehnerveninsertion (Abb. $P_{12}$ S, S, 245) liegt hauptsächlich der nasalen Wand der durch die eingebogenen Spaltränder gebildeten Furche an, in der sie liegt, während die Pectenanlage ein wenig temporalwärts geneigt ist.

Das früher beschriebene Gefüß (Abb. $P_{0_{12}}, G G, S .245$ ) lagert sich der Furche, welche die Sehnerveninsertion temporalwärts begrenzt, ein und zieht in derselben zur proximalen Spalte, durchsetzt dieselbe, wie in den früheren Stadien, in schiefer Richtung, hebt sich nach Betreten der Becherhöhle $\left(\mathrm{Abb}\right.$. $\left.\mathrm{Po}_{13}, G \mathrm{G}\right)$ fast unmittelbar von der ventralen Wand $a b$ und zieht in einem steileren Bogen als bei dem früher beschriebenen Stadium, sonst aber in gleicher Weise wie dort frei durch den Glaskörperraum zur distalen öffnung. Diese letztere liegt, wie die Schnittbilder zeigen, distal von der Ora serrata zwischen den Anlagen $z$ weier Ciliarfortsätze.

1) Erklärung der Abkürzungen am Schlusse der Arbeit (S. 342). 
Im mikroskopisehen Bilde (Abb. Po Po $_{13}$ weist die Pectenanlage dem früheren Stadium gegenüber wesentliche Verschiedenheiten auf. Während die Zellen an der der Becherhöhle zugewendeten Oberfläche der Pectenanlage (Pe) relativ dicht stehen, zeigen sie innerhalb derselben auffallend weite Zwischenrüume und Lücken. Daduroh bekommt die Gewebsstruktar der Pectenanlage einen porösen, schwammigen Charakter. Die Zellen besitzen Fortsätze nach allen Richtungen, welche miteinander anastomosieren. In diesem Stadium läßt sich die Pectenanlage auch schärfer von der Sehnerveninsertion (S) abgrenzen, indem die nun in größerer Zahl von nasal und von temporal her aus der Retina kommenden, fast völlig kernfreien, zum Sehnerven ziehenden Nervenfasern unter der Pectenanlage hinwegziehen und sie derart vom ubrigen Sehnerven abgrenzen. Von den beiden aus

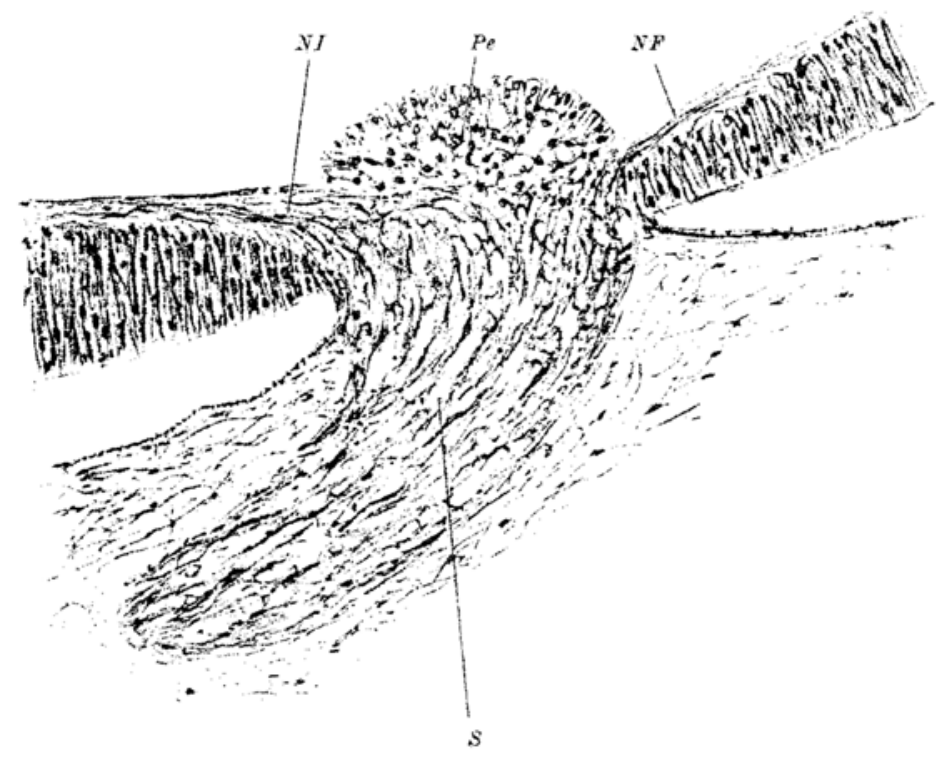

Abb. $\left.\mathrm{Po}_{14}{ }^{1}\right)$ : Schnitt durch den distalen Teil der Anlage von Sehnerveninsertion und Pecten bei einem $15 \mathrm{~mm}$ langen Embryo von Podiceps cr. Vergr. 195/1; auf $\$ / 10$ verkleinert.

der Retina zum Sehnerven ziehenden Vervenfaserportionen ist die nasale (in der Abb. links) wesentlich kräftiger entwickelt als die temporale, entsprechend der Tatsache, dab auch die Nervenfaserschicht der Retina nasal dicker ist als temporal.

Weiter distal wird das Gewebe der Pectenanlage kompakter, und an ihrer nasalen Seite finden wir den schon bei der Modellbeschreibung erwähnten Wulst. Derselbe wird von dem differenzierten Teile des nasalen Spaltrandes gebildet; eine undifferenzierte Randzone findet sich in der Nachbarschaft des Neuropecten nicht ror. Sie erscheint erst wieder im Gebiete der offenen Spalte und zeigt hier den gleichen Bau wie im Stadium vorher: innerhalb einer der Spalte zunächst gelegenen Zone ihrer Pünder bohe, pigmentfreie Zellen des Pigmentblattes, unregelmälfig angeordnete Zellen im Bereiche des retinalen Blattes; die undifierenzierte Zone am nasalen Rande kräftiger als am tenporalen.

In diese undifferenzierte Randzone der offenen Spalte setzt sich das Neuropecten distalwärts ohne scharfe Grenze fort. Da eine solche Randzone im Bereiche des Neuropecten nicht vorhanden ist, sondern das Neuropecten überall an die differenzierte Retina grenzt, so müssen wir annehmen, daß diese Zone bei dem Vorwachsen des Neuropecten distalwärts in dieses aufgenommen wurde.

1) Erklärung der Abkürzungen am Schlusse der Arbeit (S. 342). 
248 C. Lindahl und A. Jokl: Cher den Vershlub der tötalen Anumberherspalts.

Wir haben bisher immer von einem "Torwachsen" des Neuropecten in proximo-distaler Richtung gesprochen, weil sich die beschriebenen Entwicklungsvorgänge an unseren Modellen so präsentieren und so am klarsten beschreiben lassen. Histologisch erklärt sich das beschriebene Vorwachsen des Neuropecten distalwärts in der Weise, daB mit fortschreitender Differenzierung der Retina Nervenfasern a us immer weite? distal gelegenen Teilen derselben der Sehnerveninsertion zustreben und sich dabei distal a uf die schon a usgebildeten Fasern a uflagern, wodurch die sehnerveninsertion sich distalwäts verlängert. Bei diesem Verlaufe a as der Retina zum Sehnerven benutzen die Nervenfasern die undiferenzierten Randteile dex proximalen spalte als Bahn. Gleichzeitig gelangen dieselben, offenbar infolge derdurch die A ufnahmeder Nerrenfasern bedingten Dickenzunahme - zur Aneinanderlagerung, wodurch die proximale Spalte sich in diesem Gebiete schließt. Es bleiben also die besehriebenen Randteile offenbar ans dem Grunde undifferenziert, weil sie nicht für dieselben Funktionen wie die äbrige Retina bestimmt sind, sondern als Durchtrittshahn für die ans der Retina zum Opticus ziehenden Nervenfasern dienen. Das Pecten aber ist ein Produkt der Sehnerveninsertion und kommt in ihrem ganzen Bereiche zur Entwicklung. Mit der Verlängerung der Sehnerveninsertion distalwärts wächst auch die Pectenanlage in gleicher Richtung und reicht distal ebenso weit wie diese. Nicht also die offene proximale Spalte ist es, in die das Neuropecten von proximal her einwächst - wie es an den Modellen den Ansehein hat - sondern ihre undifferenzierten Randteile sind $e s$, in denen das Vorwachsen des Neuropecten ertolgt. Dabei gelangen die Spaltränder selbst zur Aneinanderlagerung und die Spaite schlielit sich.

Stadium $7.20 \mathrm{~mm}$ lang.

Die Differenzierung der Petina ungefähr ebenso weit wie bei dem früheren Stadium, doch sind die einzelnen Schichten noch deutlicher voneinander abgegrenzt. Es fällt auf. daß die Nervenfaserschicht nasal bedentend dicker ist als temporal und sich weiter distalwairts erstreckt.

Rekonstruktionsmodell ( $85 \times$ ).

Aulsenseite: Distalster Teil des Sehnerven wie früher nasalwärts umgebogen. Insertionsfläche noch weiter als beim Stadium vorher distalwärts ausgedehnt und lang zugespitzt endigend. Sie liegt wie früher in einer Einsenkung, stärker an die nasale Wand clerselben angelehnt. Sie reicht hier nicht rollkommen bis zur proximalen Spalte. Die Einsenkung, in der sie liegt, erstreekt sich über ibr distales Ende hinaus distalwärts bis über das Gebiet der proximalen Spalte. Die letztere hat hier dem früheren Stadium gegenüber abermals bedeutend an Länge abgenommen und ist $z \mathfrak{u}$ einem kleinen Loche geworden. Das früher erwähnte Gefäß verläuft in der Furche an der temporalen Seite der Sehnerveninsertion distalwärts und dann in der Furche zwisehen dieser und dex proximalen Spalte bis zu letzterer und betritt durch dieselbe die Becherhöhle.

Innenseite: (Abb. $\mathrm{Po}_{15}$ ) Die Anlage des Pecten (Pe) ist in die Länge und auch bedeutend in die Höhe gewachsen und besitzt nun die Form eines langen, schmalen, in nasotemporaler Richtung abgeplatteten Grates, der seine größte Höhe etwa an der Grenze zwischen proximalem and mittlerem Drittel hat und von bier aus nach beiden Seiten hin allmählich verflacht. Dieser Grat steht nicht genau vertikal, sondern ist im ganzen ein wenig temporalwärts geneigt. Der proximale Teil der Pectenanlage erhebt sich wie fruiher aus der mehrfach erwähnten Einsenkung; ihr distaler Teil hat an seiner nasalen Seite wieder wie bei dem zuletzt beschriebenen Stadium jenen Wulst ( $\mathrm{nW}$ ), der dem aufgeworfenen (differenzierten) Eande der früheren proximalen Spalte entspricht. Das distale, spitz zulaufende Ende der Pectenanlage reicht distal bis zur proximalen Spalte ( $p O ̈)$. Diese ist hier nicht melrr langgestreckt wie im früheren Stadium, sondern stellt ein kleines, rundes Loch dar, gerade groß genug, um dem GefaßBe (GG) den Durchtritt zu gestatten, welches von hier in einem weit in die Augenbecherhöhle vorspringenden, noch steileren Bogen als vorher zur distalen Öffnung (dÖ) zieht. Diese letztere liegt wie früher distal von der Ora serrata im Gebiet des Ciliarkörpers.

Es seheint bei diesem Stadiun am Modell die Pectenanlage an der Innenseite des Augenbechers bis zur proximalen Spaltöfnung zu reichen, die Sehnerveninsertion aber ein Stück weit 
proximal ron ihr zu endigen. Das mikroskopische Bild gibt die Erklikrung für dieses Verhalteu. Im mikroskopischen Bilde hat die Pectenanlage proximal ungefähr denselben $\mathrm{Bau}$ wie in dem zuletzt beschriebenen Falle (vgl. Abb. $\mathrm{Po}_{14}$. S. 247). Man erkennt die aus einer Einsenkung zwischen den von nasal und ron temporal her zum Sehnerven verlaufenden Nervenfisern sich erhebende Vor. wölbung der Pectenanlage, die sich recht scharf von dem Gewebe der Sehnerveninsertion ventral von ihr abgrenzen läbt. Auch hier liegen die Zellen in der Peripherie relativ dicht, withrend sie im Inneren der Anlage weite Liicken zwischen sich freilassen. Geht man in der Serie weiter distalwärts, so gelangt man zn jenem Teile der Pectenanlage, der als ein schmaler und relativ hoher Grat von cler Sehnerveninsertion atus frei in die Becherhöhle hin. einragt und sich an Querschnitt $\left(\mathrm{Ab} b . \mathrm{Po}_{2 \mathrm{~B}} \mathrm{Pe}\right)$ als zapfenförmige Vorwölbung prïsentiert. Dieser Teil der Pectenanlage zeigt eine leichte Neigung nach der temporalen Seite. Die Lïk. ken. wele he die Zellen im Imeren des Pecten

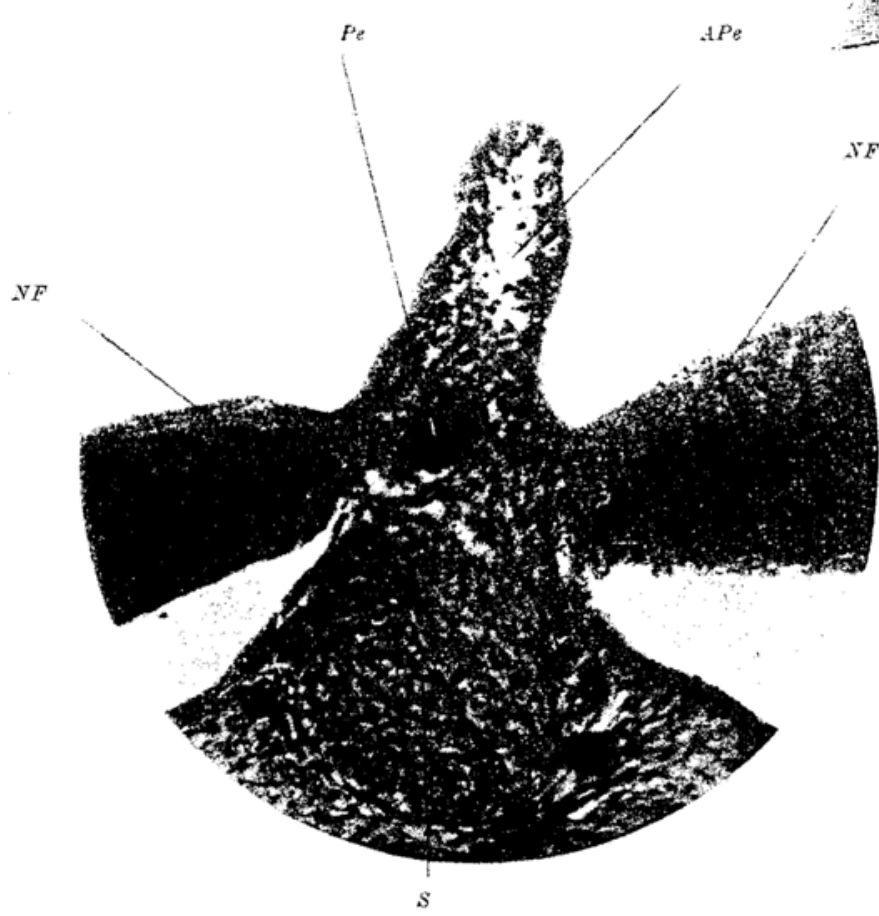

Abb. $P_{o_{16}}$ : Photographie eines Sehnittes durch die Anlage der Sehnerveninsertion und des Pecten eines $20 \mathrm{~mm}$ largen Finbryos von Podiceps cr., Vergr. 168/1.

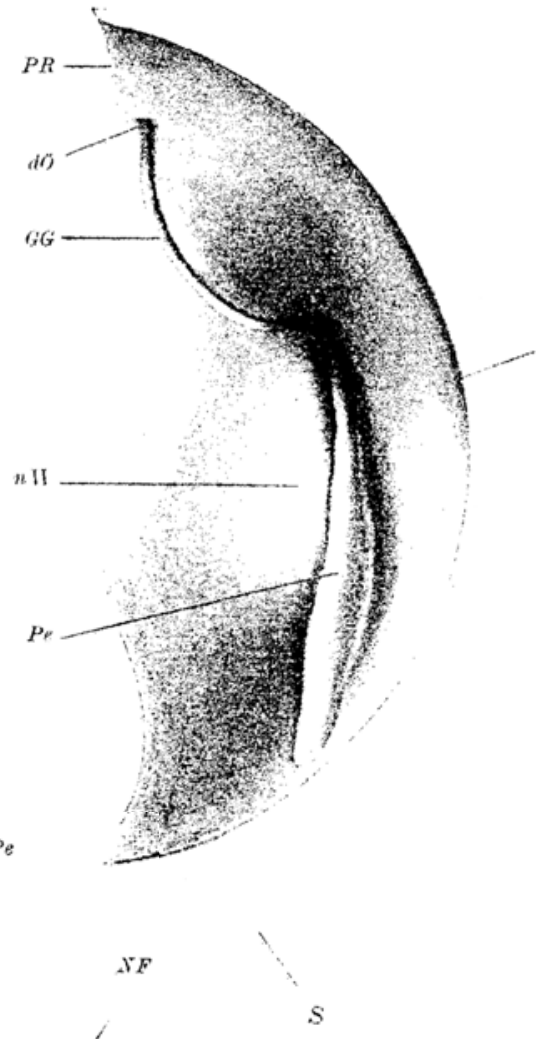

Abb. Po $\left._{10}{ }^{2}\right)$ : Rekonstruktions. modell $(85 x)$ eines Teiles der rentralen Wand eines $20 \mathrm{~mm}$ langen Embryos, von Podiceps cr., von innen her geseheu. $1 / 3$ d. nat. Gr.

beim früheren Stadium zwischen sich freiließen, sind hier zu einem Hohlraum konfluiert, an dessen Peripherie and auch teilweise in dessen Innern die gleichen, locker gelagerten, mit zablreichen anastomosierenden Fort. sätzen versehenen Zellen liegen wie früher.

Dieses ist im Laufe der Entwicklung des pecten das erste Stadium, welches ein Pectengefä $B$ enthält. Wie die Abbildung zeigt, liegt dieses (Abb. $\mathrm{Po}_{16}, \mathrm{APe}$ ) an der Basis der Pectentanlage, eingebettet

i) Erklärung der Abkürzungen am Schlusse der Arbeit (S. 342). 
in die Furche, welche hier von den nasal- and temporalwärts divergierenden Opticusfasern gebildet wird. Dieses Gefäß, welches antangs sehr dünnwandig und nur bei entsprechender Blutfüllnng deutlich sichtbar ist, läßt sich nur mit Schwierigkeit bis an seinen Ursprung verfolgen. Wahrscheinlich stammt es von einem der zahlreichen Gefäße, welche im Mesoderm ventral von der Sehnervenanlage verlaufen, dieser dicht angelagert sind und stellenweise in dieselbe eindringen. Die Art, wie dieses GefäB wahrseheinlich an den ihm zukonmenden Platz gelangt, soll spïter auf Grund der Abb. Po ${ }_{1 z}$ (S. 251) kurz besprochen werden. Trotz sorgfialtigen Suchens gelang es nicht, eine Verbindung dieses GefäBes, welches die exste Anlage der Art. basalis pectinis darstellt, mit dem mehrfach erwähnten, die Becherhöhle passierenden Gefäße aufzufinden.

Fin Verfolgen der histologischen Sehnittbilder zeigt uns, das auch in diesem Stadium nicht nur die Pectenanlage, sondern wuch die Sehnerveninsertion distalwärts bis zur proximalen Spalte reicht und nicht, wie es am Modell den Anschein hat, ein Stück weit proximal von ihr endigt. Die Sehnerveninsertion liegt hier nämlich so tief zwischen die stark eingebogenen (differenzierten) Teile der Ründer der proximalen Spalte eingeschoben, daß sie an der Außenseite mieht als Wulst hervortritt. Sie läßt sich aber, wenn auch verschmälert, bis an die proximale Spalte verfolgen.

Im Bereiche des Gefabdurchtritts ist noch ein Rest der undifferenzierten Ründer der öffnung erkennbar.

Stadium $8.23 \mathrm{~mm}$ lang.

Innere retikulïre Sehicht bedeutend breiter als vorher. In dem sonst noch undifferenzierten äußeren Teile der Retina erscheint peripher eine schmale, helle Zone, die erste Anlage der äußeren retikulären Schicht.

Die Schichten der Retina breiten sich nasalwärts weiter aus als tempornlwärts. Aveh sind die differenzierten Schichten an der Nasalseite dicker.

Rekonstruktionsmodell $(40 \times)$.

Außenseite: Sehnerveninsertion von der gleichen, distalwärts zugespitzten Gestalt wie früher. Die Einsenkung, in der sie liegt, setzt sich in Form einer Furche über ihr distales Ende hinaus noch eine Strecke weit distalwärts fort. Proximale Spalte und distale Öffnung sind völlig versehwunden.

Innenseite: Die Pectenanlage stellt in diesem Stadium einen der basalen Wand des Augenbechers aufsitzenden, temporalwärts geneigten Grat dar, welcher, in seinem proximalen Absehnitte breit und niedrig, distalwärts schmäler und höher wird, um seine höchste Höhe ungefähr in der Mitte der Anlage zu erreichen und von hier aus peripherwärts wieder zu verflachen. Auch an der Innenseite ist weder von der proximalen Spalte, noch von der distalen Öffnung ein Rest $z$ u sehen, doch ist das frühere distale Ende der proximalen Spalte durch einen atrophischen GefäBrest markiert, welcher sich hier aus der distalen Spitze der Pectenanlage zu erheben scheint. Dieser Gefäßrest läßt sich nicht weiter in die Becherhöhle hinein verfolgen und von einer distalen öffnung lassen a uch die histologischen Schnittbilder jede $\mathrm{S}$ pur vermissen.

Es ist also in diesem Stadium das Neuropecten bis an das distale Ende der proximalen Spalte yorgewachsen und hat diese dabei zum Verschlasse gebracht.

Vergleicht man bei diesem Objekta die Pectenanlage mit der Ansatzstelle des Sehnerven, so läßt sich auch hier wieder am Modell eine gewisse Inkongruenz zwischen diesen beiden Gebilden insofern konstatieren, als die spitz zulaufende Sehnerveninsertion an der Außenseite des Augenbechers weniger weit distalwärts reicht als die Anlage des Pecten an der Innenseite. Die Ursache dieser Inkongruenz ist, wie das histologische Schnittbild zeigt, die gleiche wie früher: die Sehnerveninsertion liegt mit ihrem distalen Anteile so tief zwisohen den differenzierten Teilen der stark eingebogenen Ränder der früheren proximalen Spalte eingebettet, so daB sie gleichsam Bestandteil der Becherwand geworden ist und an der Außenseite nicht als Wulst hervortritt. Vorhanden ist sie aber längs der ganzen Pectenanlage, und selbst ihrer distalsten Spitze entsprechend läbt sich an der Ventralseite Sehnervengewebe nachweisen.

Wie erwähnt, erhebt sich die Sehnerveninsertion mit ihrem proximalen Teile aus jener Einsenkung, welche durch die eingebogenen Ründer der früheren proximalen Spalte gebildet 
wird. Dabei liegt sie auch hier größtenteils der nasalen Wand dieser Einsenkung an. Im distalsten Teile ist die temporale Wand beinahe gar nicht mehr engagiert und die Sebnerveninsertion, welche hier an Umfang bereits stark abgenommen hat, liegt ausschließlich der nasalen Wand der besagten Einsenkung an.

Die histologische Differenzierung der Pectenanlage ist nicht wesentlich weiter fortgeschritten als beim Falle vorher, nur liegen die Zellen im Innern der Anlage dichter und der zentrale Hohlraum ist größtenteils ausgefüllt.

Abb. $P_{O_{17}}$ zeigt einen Querschnitt durch den mittleren Teil der Anlage von Pecten und Sehnerveninsertion von einem $23,9 \mathrm{~mm}$ langen Ernbryo. Die Pectenanlage ist bedeutend in die Höbe gewachsen und dabei relativ schmal. An ihrer Obertläche beginnen sich die Zellen epithelial anzuordnen. Im Innern der Anlage kein Hohlraum mehr, die Zellen liegen auch hier relativ dicht. Die Abgrenzung der Pectenanlage gegen die Sehnerveninsertion zu ist scharf. An der Basis der Pectenanlage, zwischen dieser und den zum Opticus ziehenden Nervenfasern, liegt wieder das schon erwähnte PectengefüB ( $\mathrm{APe}=$ Art. bas. pect.). Dieses ver. läuft hier am dorsalen Rande einer schmalen Vesoclemlamelle (Me), welche sich von ventral her quer durch die ganze Sehnerveninsertion bis zur Pectenbasis erstreckt. Durch diese Lamelle wird die Sehnerveninsertion in ihrer ganzen dista. len Hälfte in zwei Teile geteilt, von denen der nasale (in der Abb. rechts) wesentlich mächtiger ist als der temporale. Es ist möglich, dab die Art. bas. pect. immer mit einer solchen Lamelle an die Pectenbasis gelangt, daß aber die Lamelle bald versehwindet und nur das Gefä $B$ zurückbleibt.

Bei einem Stadi um von $28,5 \mathrm{~mm}$ Länge ist die Differenzierung der Pectenanlage in folgender Weise weiter fortgeschritten: Im proximalen Teile der Anlage finden wir noch dasselbe Bild wie friher: Eine über die Nervenfasern des Opticus sich erhebende, in Querschnitt hügelförmige Vor. wolbung mit epithelartig angeordneten Zellen an ihrer Oberfläche, einem großen Hohlrium in Innern und polymorphen Zellen mit zahlreichen Fortsätzen in seiner Ungebung und z. T. auch im Tnnern clesselben.

In ihrem mittleren Teile hat die Pecten. anlage folgendes tussehen: Man kann hier an

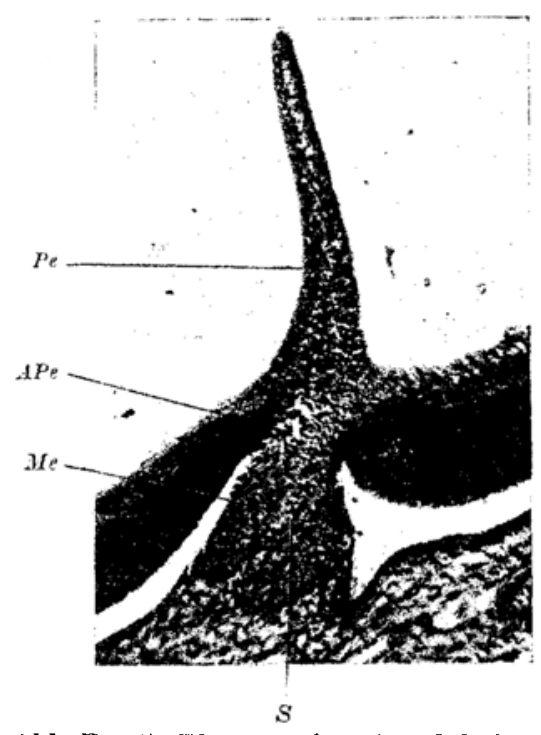

Abb. $\mathrm{Po}_{13}{ }^{1}$ ): Photographie eines Schnittes durch die Anlage der Sehnerveninsertion und des Pecten eines $23,9 \mathrm{~mm}$ langen Embrycs von Podiceps cr. Vergr. 82/1. ihr 2 Anteile unterscheiden: einen basalen, im Quersehnitt dreieckig geformten Anteil, in dem die Zellen ziemlich dicht liegen, und einen schmalen, in den Glaskörperraum bineinragenden plattenförmigen Anteil. Dieser letztere ist gefäßrei und besteht im wesentlichen aus den epithelialen Wandzellen.

Zwei etwas ältere Stadien (29,5 und $32,5 \mathrm{~mm}$ lang) ergaben weder hinsichtlich der morphologischen Verhältnisse von Sehnerveninsertion und Pectenanlage noch bezüglich der histologischen Strukturdetails des letzteren wesentlich neve Verhültuisse, mit dem zuletzt beschriebenen Stadium verglichen,

\section{Zusammenfassung.}

Die fötale Augenspalte (AS) ist bei dem jüngsten untersuchten Stadium ( $\vec{\tau}-\$ \mathrm{~mm}$ lang; $\left.\mathrm{Abb} . \mathrm{Po}_{1}, \mathrm{~S} .236\right)$ ihrer ganzen Länge nach offen. Sie ist in ihrem proximalen Anteile relativ weit, weiter distal nähern sich ihre

1) Erklärung der Abkürzungen am Sehlussa der Arbeit. (S. 342). 
Pänder, un dann, allmählich divergierend, ohne scharfe Grenze in den Pupillarrand überzugehen. Ihr nasaler Rand ist gegen das Becherinnere zu stärker eingebogen als der temporale, wodurch die Spalte eine schiefe, von nasal außen nach temporal innen gerichtete Stellung bekommt. Die Spalte wird ihrer ganzen Länge nach von einem Gefäß durchzogen ( $\mathrm{Abh}$. $\mathrm{Po}_{2}, \mathrm{GG} ; \mathrm{S} .236$ ), welches von einem an der Basis von Diencephalon und Becherstiel sich ausbreitenden Gefäßplexus stammt.

Die Spalte schliebt sich, wie das nächste Stadium (10,1 mm lang, Abb. $\mathrm{Po}_{3}$ and $\mathrm{Po}_{4}, \mathrm{~S} .237$ ) zeigt, in ihrem mittleren Abschnitte und in einem Teile ihres distalen Abschnittes. Als ihre Reste erscheinen zwei Offnungen in der Becherwand: eine etwas langgestreckte proximale ( $p \ddot{O})$ und eine ovale distale (dÖ) sowie eine spitzwinkelige Einkerbung des Pupillarrandes (EK). Die beiden Wandöfnungen stehen an der Außen- und an der Innenseite des Augenbechers durch Furchen ( $\mathrm{Fa}$ $\left[\mathrm{Abb}, \mathrm{PO}_{3}\right]$ und $\mathrm{Fi}\left[\mathrm{Abb} . \mathrm{Po}_{4}\right]$ ) miteinander in Verbindung, welche durch Aneinanderlagerung der Augenspaltenränder aneinander entstanden sind. Die Furche an der Innenseite ( $\left.\mathrm{Abb} . \mathrm{Po}_{4}, \mathrm{Fi}\right)$ wird durch zwei Wülste begrenzt, welche offenbar durch Einbiegung des innersten Teiles der Spaltränder gegen das Augen. becherinnere zu entstanden sind. Entsprechend der Tatsache, daß diese Einbiegung der Spaltenränder sich nasal stärker geltend machte als temporal. ist auch der nasale Wulst ( $\mathrm{nW}$ ) mächtiger entwickelt als der temporale.

Bei dem Verschluß der Augenbecherspalte wird das erwähnte Gefäß zum Teil in die Augenbecherhöhle aufgenommen ( $\mathrm{Abb} . \mathrm{Po}_{3}, \mathrm{GG}, \mathrm{S} .239$ ), so daB es dieselbe nunmehr durch die proximale Öffnung betritt, sich der erwähnten Furche zwischen den beiden $W$ ülsten an der Innenseite einlagert und durch die distale Offnung wieder austritt.

Während die dem distalsten Teile der Becherspalte entsprechende Einlierbung des Augenbecherrandes (EK), die anfangs spitzwinkelig war ( $\mathrm{Abb} . \mathrm{Po}_{3}$ und $\mathrm{Po}_{4}$, \$. 237) allmählich stumptwinkelig wird $\left(\mathrm{Abb} . \mathrm{Po}_{6}, \mathrm{~S} .239\right)$, und sehließlich ganz verschwindet (Abb. $\mathrm{Po}_{7}$ und $\mathrm{Po}_{\S}$ S. 2tl), wächst die proximale Öffnung in distaler Richtung bedeutend in die Länge. Sie nimmt dabei die Form einer langgestreckten Spalte an und soll daher von nun an ,proximale Spalte" genannt werden. Diese proximale Spalte zeigt, sobald sie eine gewisse Länge erreicht hat, wiederum die von der Augenspalte übernommene, schief von nasal außen nach temporal innen geneigte Richtung. Von ihren Begrenzungsrändern ist wiederum der nasale stärker gegen das Becherinnere zu eingebogen und bildet so einen an der Innenseite der Spalte hervortretenden Wulst ( $\mathrm{nW}$ in $\mathrm{Abb} . \mathrm{Po}_{\mathrm{s}}$, S. 241, $\mathrm{Po}_{13}$, S. 246, $\mathrm{Po}_{15}$, S. 249).

Das erwähnte Gefäß durchzieht die derart in die Länge gewachsene proximale Öffnung in schräger Richtung ihrer ganzen Länge nach (GG in $\mathrm{Abb}$. $\mathrm{Po}_{7}$, $\left.\mathrm{Po}_{8}, \mathrm{Po}_{12}, \mathrm{Po}_{13}\right)$. Nach dem Betreten der Becherhöhle hebt es sich aber im Laufe der Entwicklung allmählich von der ventralen Wand ab (Abb. Po, S. 241) und zieht in einem mit zunehmender Entwicklung immer steiler werdenden Bogen (Abb. $\mathrm{P}_{13}, \mathrm{~S} .246$ und $\mathrm{Po}_{15}, \mathrm{~S} .249$ ) zur distalen Offnung. Entsprechend dieser Abhebung verstreicht auch die Furche (Fi in Abb. $\mathrm{Po}_{4}[\mathrm{~S} .237]$ ) zwischen proximaler und distaler Öffnung, in welcher das Gefäß früher eingebettet lag, und es bleibt nur 
noch eine Zeitlang ihr nasaler, stärker vorspringender Begrenzungsrand zurück, der sich als direkte Fortsetzung des die proximale spalte begrenzenden nasalen Wulstes präsentiert (vgl. Abb. $\mathrm{Po}_{13}, \mathrm{Po}_{15}$ ).

Da der nun zu beschreibende Verschluß der proximalen Spalte mit dem Wachstum der Sehnerveninsertionsanlage und mit der Entwicklung des Pecten in innigem Zusammenhang steht, so soll erst auf diese Verhältnisse eingegangen werden.

Der Becherstiel (S) tritt in dem jüngsten unserer Stadien (in $4 b b . \mathrm{Po}_{1}, \mathrm{~S} .236$ ) an der Grenze zwischen ventraler und proximaler Wand an den Augenbecher heran. Die Insertionsflache, hier von etwa elliptischer Form, erhält im nächsten Stadium (Abb, $\mathrm{PO}_{3}, \mathrm{~S} .237$ ) das Aussehen eines Drejeckes mit etwas abgerundeten Ecken und Seiten, das mit einer Spitze proximal von der proximalen Öffnung endigt. Im Laufe der weiteren Entwicklung nimmt der am Augenbecher inserierende Teil des Becherstiels die Form eines Wulstes an (S in Abb. Po, S. 241 and $\mathrm{Po}_{12} \mathrm{~S} .245$ ), welcher proximal am höchsten und breitesten ist, sich distalwîrts immer mehr verschmälert und abflacht und unmittelbar proximal von der proximalen Spalte endigt. Dieser Wulst der Sehnerveninsertion wächst mit zunehmendem Alter distalwärts immer mehr in die Länge (vgl. Abb. $\mathrm{Po}_{7}$ und $\mathrm{Po}_{12}$ ) und grenzt sich dabei durch zwei seitliche Furchen immer schärfer von der Augenbecherwand ab. Die Insertionsfläche wird dabei zu einem langgestreckten Oval, welches eine langausgezogene Spitze gegen die proximale Spalte hin richtet.

An der Innenseite des Augenbechers befindet sich in den jüngeren Stadien der Entwicklung, der Ansatzstelle des Stiels außen entsprechend eine flache Einsenkung. Aus dieser erhebt sich - zum ersten Nale sichtbar bei einem Stadium von $12.2 \mathrm{~mm}$ Länge - ein breiter, flacher Wulst, die erste Anlage des Pecten (Pe in Abb. $\mathrm{Po}_{\S}$, S. 24l). Das Pecten, welches, wie die histologische Untersuchung ergibt, ein Produkt des Sehnerveneintritts darstellt (s. später), entspricht seiner Lage und der Form seiner Ansatzfläche nach an der Innenseite des Augenbechers vollkommen der Sehnerveninsertion an der AuBenseite und kann daher mit dieser als eine morphologische Einheit zusammengefabt werden und wir nennen beide Gebilde mit einem gemeinsamen Namen Neuropecten.

Beim Vergleich der Rekonstruktionsmodelle verschieden alter Stadien bekommt man den Eindruck, daß sich das Neuropecten mit fortschreitender Entwieklung wie ein Keil in proximale Spalte hineinschiebt und diese dabei zum Verschluß bringt (vgl. Pe in Abb. $\mathrm{Po}_{8}$; $\mathrm{Po}_{13}$ und $\mathrm{Po}_{15}$ and $\mathrm{S}$ in $\mathrm{Abb} . \mathrm{Po}_{7}$ und $\left.\mathrm{Po}_{19}\right)$. Sein innerer Teil, die Pectenanlage, wird dabei immer höher und wandelt sich zu einem schmalen, plattenförmigen Gebilde mit etwas verbreiterter Basis um, welches in seinem mittleren Teile am höchsten ist und von hier aus distal- und proximalwärts kontinuierlich an Höhe abnimmt.

Beim Vorwachsen distalwärts gelangt das Pecten mit seinem distalen Teile in die Nachbarschaft des mehrfach erwähnten, die proximale Spalte nasalwärts begrenzenden Wulstes ( $\mathrm{nW}$; vgl. $\mathrm{Abb} . \mathrm{Po}_{8}, \mathrm{Po}_{13}$ und $\mathrm{Po}_{15}$, während die Sehnerveninsertion distal in die Einsenkung zwischen den eingebogenen Augenspalträndern zu liegen kommt. 
254 C. Lindahl and A. Jokl: C̈ber den Vexschlub rer fütalen Angenbecherspalte,

Entsprechend der schiefen Richtung von nasal außen nach temporal innen, in welcher die proximale Spalte die Wand des Augenbechers durchsetzt, bekommt auch das einwachsende Neuropecten eine schiefe Stellung: die Pectenanlage an der Innenseite neigt sich temporalwärts und die Sehnerveninsertion außen kommt hauptsächlich an die nasale Wand der erwähnten Einsenkung zu liegen.

In dieser Weise scheint also - so präsentiert sich dieser Vorgang wenigstens auf unseren Modellen - das Neuropecten die proximale Spalte ihrer ganzen Länge nach in proximodistaler Richtung zu durch. wachsen. Das erwähnte Gefäß wird dabei immer mehr gegen das distale Spaltende hin verschoben (vgl. GG in $\mathrm{Abb} . \mathrm{Po}_{8}, \mathrm{Po}_{13}$ und $\mathrm{Po}_{15}$ ). Mit dem vollständigen Verschluß der Spalte kommt dieses GefäB zur Obliteration und verschwindet. Darauf schlieBt sich auch seine Austrittsstelle, die distale Öffnung. Sie verschwindet vollkommen und in den späteren Stadien ist ein Rest von ihr nicht nachweisbar.

Die Einbiegung der Ränder der proximalen Spalte ist, wie erwähnt wurde, distal stärker ausgesprochen als proximal. Infolgedessen kommt die Sehnerveninsertion in älteren Entwicklungsstadien mit ilbrem distalen Teile so tief zwischen die früheren Spaltränder zu liegen, daß sie gleichsam in die ventrale Wand des Augenbechers aufgenommen erscheint und an der Außenseite nicht mehr als Wulst hervortritt. Es scheinen einander daher in späteren Entwicklungsstadien am Rekonstruktionsmodell Pectenanlage an der Innen- und Sehnerveninsertion an der Außenseite des Augenbechers nicht mehr vollkommen zu entsprechen: die Pectenanlage scheint weiter distalwärts zu reichen als die Sehnerveninsertion. Die Schnittbilder zeigen jedoch, daß sich die letztere in Wirklichkeit auch dem distalen Teile der Pectenanlage entsprechend in die Tiefe der Einsenkung zwischen den Spaltenrändern eingelagert vorfindet und sich bis an das distale Ende der Pectenanlage verfolgen läßt.

Es bildet also, nach den Rekonstruktionsmodellen zu urteilen, die proximale Spalte die Bahn, in welcher das Neuropecten vorwächst und das distale Ende der proximalen Spalte bezeichnet a uch die Grenze für sein Wachstum. In dem Endstadium, bis zu welchem wir die Entwicklung verfolgt haben, erscheint also die proximale Spalte durch das Neuropecten vollkommen ausgefült. Dieses letztere steht etwas schief, die Pectenanlage ist temporalwärts, der Wulst der Sehnerveninsertion nasalwärts gewendet, entsprechend der schiefen Pichtung der prox. Spalte, in welcher das Neuropecten vorgewachsen ist. Das die Becherhöhle durchsetzende Gefä $B$ ist ebenso wie seine distale Austrittsöffnung restlos verschwunden.

Es soll nunmehr das Wichtigste aus der Histogenese des Pecten zusammengefaßt werden.

An den jungen Stadien bildet die gestreckt zur Pupillaröffnung verlaufende ventrale Wand mit der in ihrem ventralen Teile ebenfalls geradlinig sich erhebenden proximalen Wand einen deutlich markierten Flächenwinkel. Entsprechend der Becherspalte hat die ventrale Wand einen Defekt. Dieser Flächenwinkel wird allmählich abgemundet mit Ausnahme der unmittelbaren Nacbbarschaft des proximalen Spaltendes bzw. des prox. Endes der prox. Offnung (die Spalte 
ist zu diesem Zeitabschnitt bereits teilweise geschlossen). Es entsteht dadurch unmittelbar proximal von der proximalen Spalte eine Einsenkung, die sich direkt in die proximale Spalte fortsetzt ( $\mathrm{Ei}$ in $\mathrm{Abb}$. $\mathrm{Po}_{4}, \mathrm{~S} .237$ und $\mathrm{Po}_{6}, \mathrm{~S} .239$ ). Durch die Wände dieser Einsenkung ziehen die ersten Nervenfasern, die im Bereiche der proximalen Retinalwand ausgebildet werden, zur ventralen Wand des Becherstiels ( $\mathrm{NF}$ in $\mathrm{Abb}, \mathrm{PO}_{5}, \mathrm{~S} .238$ ). Mit dem Fortschreiten der Differenzierung in der proximalen Retinalwand nehmen naturgemäß die Nervenfasern an Zahl zu und ziehen in zwei Portionen, einer größeren nasalen und einer kleineren temporalen zum Becherstiel. Indem diese beiden Portionen bei ihrem Eintritt in die Sehnerveninsertion sich nicht sogleich vereinigen, sondern eine Rinne zwischen sich freilassen, wächst die früher erwähnte Einsenkung kontinuierlich distalwärts in die Länge.

I m Bereiche derOpticusanlage treten $z$ wischen den Nervenfasern alsbald Gliazellen a uf und wir können bei aufeinander folgenden Stadien verfolgen, wie sich eine Anzahl dieser Zellen zwischen den Nervenfasern gegen die besagte Einsenkung hin vorschiebt. Sie erreichen den Grund derselben, schieben sich weiter gegen die Becherhöhle zu vor und bilden alsbald eine am Querschnitt flach hügelförmige Vorwölbung, die sich aus der besagten Einsenkung erhebt (Pe in Abb. Po, S. 242, und $\mathrm{Po}_{11}$, S. 244). Diese Vorwölbung ist die erste Anlage des Pecten. Die hier befindlichen Zellen stimmen in jungen Stadien in allen ihren Qualitäten mit den Gliazellen der Opticusanlage ỉberein. Es handelt sich um Zellen mit großen, hellen Kernen, die sich von den meist dunkler pigmentierten Kernen der benachbarten Retina deutlich unterscheiden. An der Membr. lim. int. endigen sie stellenweise mit Radiärfaserkegeln. Eine Abgrenzung dieses Zellkomplexes gegen die Sehnerveninsertion zu ist in diesem Stadium nicht möglich. Das Pecten stellt also in seiner ersten Anlage ein Differenzierungsprodukt der Sehnerveninsertion dar.

Indem immer mehr Fasern aus der sich differenzierenden Retina der Sehnerveninsertionsanlage zuwachsen, wächst diese, wie wir gesehen haben, in proximo-distaler Richtung kontinuierlich in die Länge. Diesem Längenwachstum der Sehnerveninsertion folgt auch die Pectenanlage. Längs der ganzen gliazellenhaltigen Sehnerveninsertion schieben sich Gliazellen zwischen den ihr zuwachsenden kernlosen Nervenfasern gegen die besagte Einsenkung hin vor, füllen sie aus und bilden eine in die Becherhöhle hineinragende Vorwölbung.

Die Zellen der Sehnervenanlage gleichen nur in den frühesten Stadien denen der Sehnerveninsertion vollkommen. Bald kommt es innerhalb der Pectenanlage zu Differenzieruagsvorgängen, die den Zellen hier ein eigenes Gepräge geben und diese Bildung als etwas der Sehnerveninsertion gegenüber Selbständiges hervortreten lassen.

Während die Zellen anfangs in der ganzen Anlage ungefähr gleich dicht liegen, verdichten sie sich alsbald an der inneren, der Becherhöhle zugewendeten Seite der Pectenanlage zu einer dichteren Lage (vgl. Abb. Po $\mathrm{O}_{n 1}$, S. 244). Sie scheinen hier auch etwas dunkler fürbbare Kerne zu bekommen als die übrigen Pectenzellen. Gleichzeitig mit dieser Zellverdichtung an der Oberfläche kommt 
es zu einer Auflockerung der Zellen im Innern der Anlage. Dann wird die Vorwölbung der Pectenanlage stärker (Abb. $\mathrm{Po}_{14}$, S. 247), seine Abgrenzung gegen die Sehnerveninsertion wird durch das Einwachsen zahlreicherer kern. loser Nervenfasern schärfer; die dichter liegenden Zellen an der Oberfläche ordnen sich epithelartig an, während die Auflockerung der Zellen im Innern der Anlage immer stärker wird (vgl. Abb. $\mathrm{Po}_{14}$ ). Es entstehen hier größere und kleinere Zwischenräume zwischen diesen Zellen, welch letztere eine unregelmäßige Form haben und durch zahlreiche Protoplasmafortsätze miteinander in Ferbindung stehen.

Während dieser Differenzierungsvorgänge wächst die Pectenanlage in allen Dimensionen, am wenigsten in die Breite, am meisten in die Länge und bekommt. so die Gestalt eines langgestreckten, schmalen Grates, sowie sie uns auf unseren Wodellen von älteren Stadien entgegentritt.

Die oben erwähnte Auflockerung der Pectenzellen im Innern der Anlage scheint in gewissen Stadien so weit zu gehen, daß es hier zur Ausbildung eines Hohlraumes im Innern der Anlage kommt (vgl. Abb. Po ${ }_{16}, \mathrm{~S} .249$ ), in dessen Umgebung und auch teilweise in dessen Innern die gleichen, unregelmäßig gestalteten Zellen liegen, die früher die ganze Anlage erfüllten ${ }^{1}$ ). Später verschwindet dieser Hohlraum wieder (vgl. Abb. Po ${ }_{17}$ [S. 25l]).

An unseren ältesten Stadien stellt die Pectenanlage größtenteils eine schmale Platte dar, die sich frei in die Becherhöhle erhebt. Diese Platte besteht ausschlieBlich oder nahezu ausschlieBlich aus den epithelialen Wandzellen, welche einen schmalen Hohlraum zwischen sich freilassen, in welchem mitunter hier und da spärliche, unregelmäßig gestaltete Zellen liegen. Diese Platte setzt sich basalwärts in einen wesentlich kleineren, im Querschnitt etwa dreieckigen Pectenteil fort, der mit seiner Basis den von nasal und von temporal her kommenden Sehnervenfaserportionen aufsitzt. Er trägt an seiner Oberfläche die gleichen epithelialen Zellen wie der plattenförmige Anteil, in seinem Innern aber Zellen von mehr unregelmäBiger Form, die hier wieder relativ dicht liegen und keine Lücken zwischen sich aufweisen.

Relativ s pät, erst bei unserem Stadium von 20 mm Länge, finde $n$ wir a $n$ der Basis der Pectenanlage ein Gefäß, die Arteria basalis pectinis (APe in Abb. Po $\mathrm{P}_{16}$, S. 249). Trotz genauen Suchens ließ sich weder bei diesem, noch bei den folgenden Stadien eine Verbindung dieses Gefäßes mit dem früher beschriebenen, die Becherhöhle durchziehenden Gefäße auffinden. $\mathrm{Abb} . \mathrm{Po}_{1 \bar{z}}$, S. 251 (von einem 23,9 mm langen Embryo) kann uns vielleicht einen Hinweis dafür geben, wie dieses Gefäß in die Pectenanlage gelangt. Wir sehen hier, daß sich eine Nesodermlamelle (Me) von außen her durch die ganze Opticusinsertion bis za dem an der Pectenbasis befindlichen GefäBe (APe) hin erstreckt. Es ist möglich, daß die Arteria basalis pectinis mit einer solchen Mesodermlamelle durch die Sehnerveninsertion hindurch bis zur Pectenbasis einwächst, daß aber die letztere sehr bald versehwindet, wobei das Gefäl zurückbleibt. In diesem Falle müßte es sich jedoch um ein sehr passageres Entwicklungsstadium handeln,

1) Es muß indessen dahin gestellt gelassen werden, inwieweit dieser Hohlraum nicht vielleicht ganz oder teilweise ein Kunstprodukt ist, obgleich er sich in einem gewissen Alter bei mehreren, sonst gut erhaltenen Objekten in typiseher Weise vorfand. 
denn wir konnten diese Mesodermlamelle nur in einem einzigen Stadium, dem eben erwähnten, konstatieren, hier jedoch mit voller sicherheit. Sie teilt hier die Opticusinsertion in zwei ungleich große Hältten, eine gröbere nasale und eine kleinere temporale. Wir haben es hier bei Podiceps also mit einer unvollständigen, nur die Sehnerveninsertion betreffenden Teilung des Neuropecten zu tun. Wie wir später hören werden, ist diese Teilung bei Anas vollkommen und auch bei den anderen Arten in verschiedener Weise angedeutet.

Eine besondere Beachtung verdienen die Ränder der proximalen Spalte. Während nämlich die Zellen innerhalb der übrigen Retina sich mit zunehmendem Alter immer weiter differenzieren, bleiben die Zellen in einer der Spaltöffnung zunächst gelegenen Partie auf einer relativ niedrigen Entwicklungsstufe stehen und nehmen an den Differenzierungsvorgängen innerhalb der übrigen Retina nicht teil (Abb. Po 10, S. 243). Die Zellen des Pigmentblattes bleiben hier in einer der Spalte zunächst gelegenen Zone pigmentfrei und behalten ihre hoch zylindrische Form bei. Im Bereiche des retinalen Blattes liegen die Zellen in dieser Randpartie nicht so regelmäßig in Reihen angeordnet wie im Bereiche der übrigen Retina, sondern mehr unregelmäßig. Der Sehventrikel endigt beiderseits in einiger Entfernung von der Spalte und es lassen sich dann retinales und Pigmentblatt nicht mehr voneinander unterscheiden. Stets erstreckt sich die so gebante Zone im Bereiche des nasalen Randes (Abb. Po, links) auf ein größeres Gebiet als im Bereiche des temporalen.

Was hat dieser eigentümliche Bau der Spaltränder, der sich bei allen untersuchten Arten mit großer Konstanz wiederfindct, für Bedeutung? Diese Erscheinung hängt mit dem mehrfach erwähnten Vorwachsen der Sehnerveninsertion und der Pectenanlage in der Spalte in proximolistaler Richtung zusammen und es soll jetzt besprochen werden, wie diese beiden Erscheinungen auf Grund des vergleichenden Studiums der Rekonstruktionsmodelle und der Schnittbilder erklärt werden können. Erinnern wir uns an unsere jüngsten Śtadien, so finden wir auch dort schon die proximale offnung mit ihrem proximalen Ende bis an den Becherstiel heranreichen (Fgl. $\mathrm{Abb} . \mathrm{Po}_{3}, \mathrm{~S} .237$ ). Die ersten Nervenfasern, die in der proximalen Retinalwand zur Ausbildung kommen, ziehen durch den proximalsten Winkel der proximalen offnung zum Becherstiel. Bei ihrer Passage benützen die Fasern hier das eigentümlich differenzierte Zellgebiet der erwähnten Einsenkung, welches hier also die funktionelle Bedeutung eines Randschleiers hat. Mit dem Fortschreiten der Differenzierung in der Retina kommen immer mehr Nervenfasern zur Ausbildung, welche alle die proximale Offnung als Durchgangspforte zum Opticus benützen. Gleichzeitig verlängert sich die proximale offnung distalwärts und wird zu einer lang ausgezogenen Spalte. Da die Differenzierung der Retina in proximodistaler Richtung fortschreitet, so kommen die Fasern aus inmer weiter distal gelegenen Abschnitten der Petina. Sie haben einen schiefen Verlauf und ziehen in der Hauptsache in zwei Partien, einer nasalen und einer temporalen gesammelt, in schiefer Richtung von distal-dorsal nach proximal-ventral konvergierend gegen den proximalsten Winkel der noch offenen proximalen Spalte. Bei ihrem Durchtritte durch die Spalte lagern sie sich den schon ausgebildeten Nervenfasern an. Auf diese Weise 
werden auch innerhalb der Sehnerveninsertion die neugebildeten Nervenfasern immer auf die schon vorhandenen aufgelagert, und erklärt sich das kontinuierlich distalwärts fortschreitende Wachstum der Sehnerveninsertion.

Die Nervenfaserbündel, welche sich von der nasalen und von der temporalen Seite der Retina sammeln, um dem Opticus zugeführt zu werden, sind von ver. schiedener Stärke. Es wurde erwähnt, daß die Nervenfaserschicht an der nasalen Seite der Retina wesentlich dicker ist als an der temporalen. Dem entsprechend bekommt der Opticus von nasal her weit nehr Nervenfasern als von temporal. Aus vergleichend embryologischen Grüden können wir annehmen, daß das Einwachsen der Mesodermlamelle Me (Abb. $\mathrm{P}_{17}$, S. 25I) zwischen die beiden Sehnervenfaserportionen des Opticus erfolgte, und wir erkennen hier, daß die nasale Portion (in der Abb. rechts von der Mesodernlamelle) wesentlich kräftiger entwickelt ist als die temporale.

Was die beschriebenen, der proximalen Spalte zunächst gelegenen Abschnitte ihrer Ränder anbelangt, welche in dem Zustande der Undifferenziertheit verbleiben, während die Differenzierung innerhalb der übrigen Retina längst weiter fortgeschritten ist, so steht diese Erscheinung in innigem Zusammenhang mit dem Einwachsen der Opticusfasern. Dieser Teil der Ränder ist offenbar nicht für dieselben Funktionen bestimmt wie die übrige Retina, er hat vielmehr die Aufgabe, den durchtretenden Nerventasern bei ihrem Verlaufe aus der Retina zum Opticusals Bahnzu dienen. Daßes sich wirklich so verhält, dafür sprechen mehrere Homente. Die undifferenzierten Randteile entsprechen ihrer Ausdehnung nach völlig dem später in ihr Gebiet einwachsenden Neuropecten. Am nasalen Rande umfaßt diese Zone, wie mehrfach hervorgehoben wurde, ein größeres Gebiet als am temporalen, entsprechend der Tatsache, daß anch die Sehnerveninsertion zum größeren Teile im Bereiche dieses Randes vorwächst. Auf diese Weise erklärt es sich auch ungezwungen, wieso das Neuropecten distal ohne scharfe Grenze in die Ränder der proximalen Spalte überzugehen scheint. Mit dem Einwachsen der Nerventasern werden diese Randteile offenbar so verdickt, daB sie zur Aneinanderlagerung und Verschmelzung kommen, womit die Spalte sich hier schließt. Deshalb finden wir überall im Bereiche der vorgewachsenen Sehnerveninsertion die proximale Spalte verschlossen. Die Zellen der Ränder werden offenbar zwischen die einwachsenden Sehnervenfasern aufgenommen und später wahrscheinlich in Gliazellen der Sehnerveninsertion umgewandelt. In dem Gebiete, wo das Neuropecten bereits vorgewachsen ist, existiert eine solche undifferenzierte Randzone nicht mehr, und das Neuropecten grenzt hier beiderseits an die differenzierte Retina. Es muB also die undifferenzierte Randzone im Neuropecten aufgegangen sein.

Wir müssen also unseren an den Modellen gewonnenen Eindruck, daß das Neuropecten in der proximalen Spalte vorwachse, a uf Grund des Schnittstudiums dahingehend modifizieren, daß nicht die proximale Spalte selbst, sondern ihre undifferenzierten Randpartien es sind, welche den einwachsenden Nervenfasern zum Durchtritt und damit der distalwäts vorwachsenden Seh. nerveninsertion als Leitbahn dienen. 
Noch eine mit der Entwicklung des N. opticus zusammenhängende Frage soll hier im Anschlusse diskutiert werden, nämlich das Verhältnis zwischen Becherstiel und Sehnerv. Der Becherstiel bildet bei den jüngsten untersuchten Stadien ein Rohr, dessen Wände aus einem mehrschichtigen Epithel bestehen. Die ersten ausdifferenzierten Nervenfasern wachsen, wie wir gehört haben, aus der proximalen Becherwand durch den proximalen Winkel der proximalen Spalte zur ventralen Wand des Becherstiels. Sie kommen hier in einen schmalen Randschleier zu liegen, den die Zellen der ventralen Wand an ihrer Außenseite ausgebildet haben. Mit zunehmender Wenge der Nervenfasern bilden diese ein immer breiter werdendes Lager an der Außenseite der ventralen Wand. Schließlich wird die ventrale Stielwand gegen die dorsale gedrückt, das Lumen des Becherstiels schließt sich und bald läBt sich der ursprüngliche, epitheliale Zellbestand nur längs einer schmalen Zone an der Dorsalseite der Opticusanlage in der nächsten Nähe des Augen bechers nachweisen, welche schließlich ebenfalls vollkommen verschwindet. In diesem Stadium wird die ganze Opticusanlage nur mehr von Nervenfasem und zwischen diesen liegenden Gliazellen gebildet.

Der Verschluß des Becherstiellumens erfolgt entsprechend dem Einwachsen der Nervenfasern in der Richtung von distal her proximalwärts. Indessen bleibt seiner Ansatzstelle am Augenbecher entsprechend an seiner Dorsalseite ein kleiner Rest seines Lumens zurück, der sich als unmittelbare Fortsetzung des in der Umgebung der Stielinsertion noch vorhandenen Sehventrikels eine Strecke weit taschenförmig dorsal in die Opticusanlage hinein erstreckt. Auch dieser Rest verschwindet im Laufe der Entwicklung schließlich völlig.

Wir können demgemäß an der Anlage des Sehnerven zwei Anteile unterscheiden, einen epithelialen und einen neurofibrillär. gliösen. Der epitheliale stellt die primäre Anlage dar und repräsentiert die Wand des arsprünglichen Verbindungsrohrs zwischen Augenbecher und Diencephalon. Zu dieser epithelialen Anlage kommt später ein zweiter, neurofibrillärer Anteil. Dieser ist anfangs a uf die AuBenseite der ventralen Wand beschränkt, nimmt dannmit fortschreitender Entwicklang a uf Kosten desepithelialen Anteils ständig an Umfang zu und substituiert so allmählich den letzteren. An der gleichen Stelle, wo bei jungen Stadien der Becherstiel am Augenbecher inserierte, finden wir bei älteren die Nervenfasern verlaufen. Der Vorgang ist dabei der, daß die zuerst gebildeten, ältesten Nervenfasern von den später einwachsenden jüngeren proximal- und dorsalwärts verschoben werden.

Betrachtet man, so wie wir es hier getan haben, die proximale Spalte mit ihren Rändern als die Durchgangsbahn für die Sehnervenfasern aus der Retina zum Opticus, so kann man den hier beschriebenen Vorgang der Substitution des Becherstiels durch die Sehnervenfasern auch in der Weise auffassen, daß sich die proximale Spalte auch proximalwärts über den Becherstiel hinaus erweitert hat, in diesem ihrem proximalsten Anteile jedoch sogleich durch einwachsende Nervenfasern verschlossen wurde. Damit verlaufen also sämtliche Nervenfazern aus der Retina durch die Randpartien der proximalen Spalte zum Sehnerven. 
260 C. Lindahl und A. Jokl: Cber den Verschluß der fötalen Augenbecherspalte,

Anas domesticus.

Stadium 1. $7,7 \mathrm{~mm}$ lang, $102^{\mathrm{h}}$.

Augenbecher ausgebildet. Retinales und Pigmentblatt liegen einauder gröbtenteils dicht an, so daß nur geringe Reste des Sehventrikels erkennbar sind. Pigmentblatt ein ein-

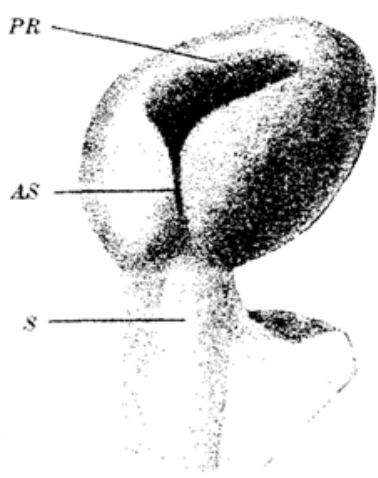

Abb. $A_{1}^{1}$ ): Rekonstruktionsmodell $(125 \times)$ des Augenbecherseines $7,7 \mathrm{~mm}$ langen Embryos von Anas dom., von ventral her gesehen. $8 / 15$ d. ant. Gr. reihiges Epithel, seine Zellen von kubischer bis zylinderischer Form, völlig frei von Pigment. Retina noch völlig undifferenziert bis auf eine leichte Aufhellung an der Innenseite in ventralen Teile der proximalen Wand (Vorbereitung der Randschleierbildnng). Linsenlumen bis auf einen schmalen Spalt zwischen Epithel und Fasern verschlosisen.

Rekonstruktionsmodell (125X) von ventral her gesehen (Abb. $A_{1}$ ): Die fötale A ugenbecherspalte (AS) vollständig offen. Sie wird ihrer ganzen Länge nach von einem von Mesontermzellen begleiteten Gefäß (in das Modell nicht mitgenommen) durchzogen, welches aus dem Mesenchym der ventralen Cmgebung des Augenbechers stammt. Der nasale Rand der Spalte (in Abb. links) scheint etwas stärker hervorzutreten als der temporale. Die Spalte ist in ihrem mittleren Anteile ein wenig verschmälert, nimmt ron hier aus nach beiden Richtungen hin an Breite zu, um distalwärts ohne scharfe Grenze in den Pupillarrand iuberzugehen.

Die ventrale Wand des Augenbechers relativ lium, verläuft geradlinig zur Papillaröffnung. Der dorsale Umschlagsrand und seine nächste Umgebung gegen die Papillaröfnung umgebogen, wodarch diese eine nach abwärts dezentrierte Lage erhält. Der Augenbecherstiel (s) kurz und plump, vollkommen hohl; er inseriert mit etwa querovaler Fläche am Übergang der ventralen und der proximalen Wand des Angenbechers.

Stadiun $2.6,5 \mathrm{~mm}$ lang, $120^{\mathrm{h}}$.

Pigment blatt mit noch verhältnismäßig hohen, völlig pigmentfreien Zellen. Retina noch undifferenziert bis auf einen schmalen Randschleier an der proximalen Wand nahe der In-

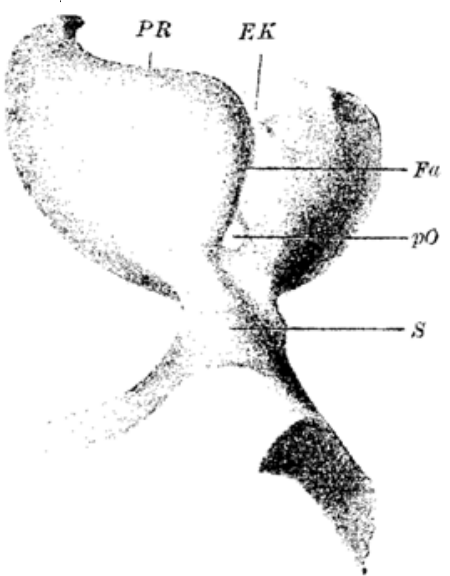

Abb. A, $\left.{ }^{1}\right)$ : Rekonstruktionsmodell $(125 x)$ des Augerbechers eines $6,5 \mathrm{~mm}$ langen Embryos von Anas dom., von ventral her geseben. ${ }^{s / 1 s}$ d. nat. Gr. sertionsstelle des Becherstiels. Linse mit schmalem, spaltförmigem Lumen $z$ wischen Fasem und vorderem Epithel. Rekonstruktionsmodell $(125 x)$ von ventral her' gesehen (Abb. $\mathbf{A}_{2}$ ).

Augenbecherstiel noch kurz und dick, mit breiter, asnähernd querovaler Fläche am ṫbergang der ventralen Augenbecherwand in die proximale inserierend. Die Becherspalte ist durch Aneinanderlagerung ihrer Ränder im mittleren Teile geschlossen. Ihr zurückgebliebener proximaler Teil bildet eine ovale. mit einer distalen Spitze gegen clen verschlossenen Teil der Becherspalte weisende Öfrnung (pö), ihr distaler Rest eine spitzwinkelige Einkerbung des Papillarrandes (EK), welche mit abgerundeten Ecken in denselben inbergeht. Die kurze, ziemlich gestreckt verlaufende ventrale Wanil des Augenbechers bildet in der Nachbuxschaft des Sehnerveneintrittes mit der hier in ihrem ventralen Teile ebenfalls geradlinig verlaufenden medialen Wand des Augenbechers einen spitzen Flächenwinkel, was an parallel mit der Becherspalte geführten Scbnitten deutlich erkennbar ist.

Das beim früheren Stadium die Becherspalte ihrer ganzen Länge nach durchziehende GefäB tritt nunmehr,

1) Erklărung der Abkürzungen am Schlusse der Arbeit (S. 342). 
wie fruiher von Wesenchymzellen begleitet, schräg durch die proximale Offnung in die Augenbecherhöhle ein und verläutt dicht an der ventralen Wand derselben zu der beschriebenen Einkerbung des Becherrandes. wo es dieselbe vieder verläßt.

\section{Stadium 3. $7,5 \mathrm{~mm}$ lang, $126^{4}$.}

Pigmentepitheizellen im äuBeren Blatte des Augenbechers abgeplattet, noch völing pigmentfrei. Tervenfaseruschicht nur in unmittelbarer Umgebung der Eintrittsstelle des Becherstiels ausgebildet. Sehventrikel zum groben Teile ver schwunden. Linse: Die Linsentasern reichen in der Witte bis zum Linsenepithel, whihrend seitlich noch ein schmaler Spaltraum zwischen Epithel und Linsenfasern zurückgeblieben ist.

Rekonstraktions modell (125\% Abb. $A_{3}$ ), ron ventral gesehen: Becherstiel (s) länger und dünner als bein vorhergehenden Stadium, noch vollkommen hohl. Seine In. sertionsstelle nicht scharf von der Becherwand abgrenzbar, von etwa hreisfömiger Gestalt. Die Becherspalte ist nun in ihrem mittleren Teile längs einer gröberen Strecke als

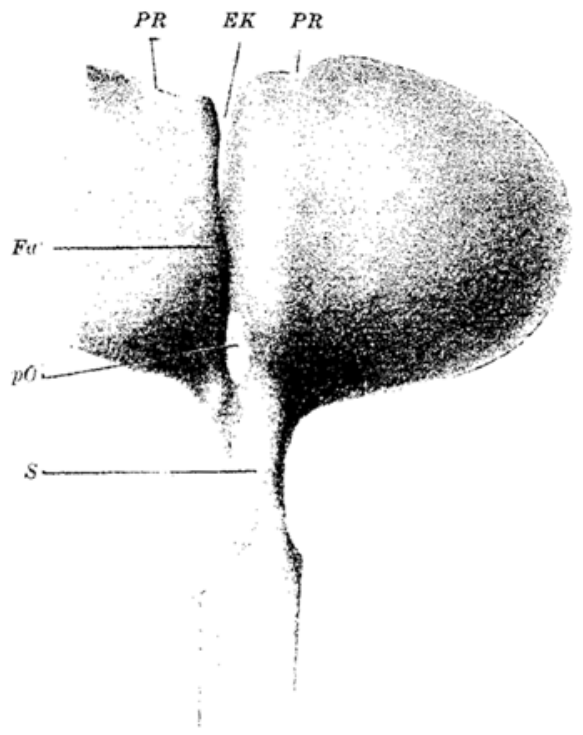

Abb. $\left.A_{3}^{1}\right)$ : Rekonstuktionsmodell (125x) der nasalen Hälte des Augenbechers eines $7,5 \mathrm{~mm}$ langen Embryos von Auas dom.. ron ventral her gesehen. 8: $d$, nat. Gr.

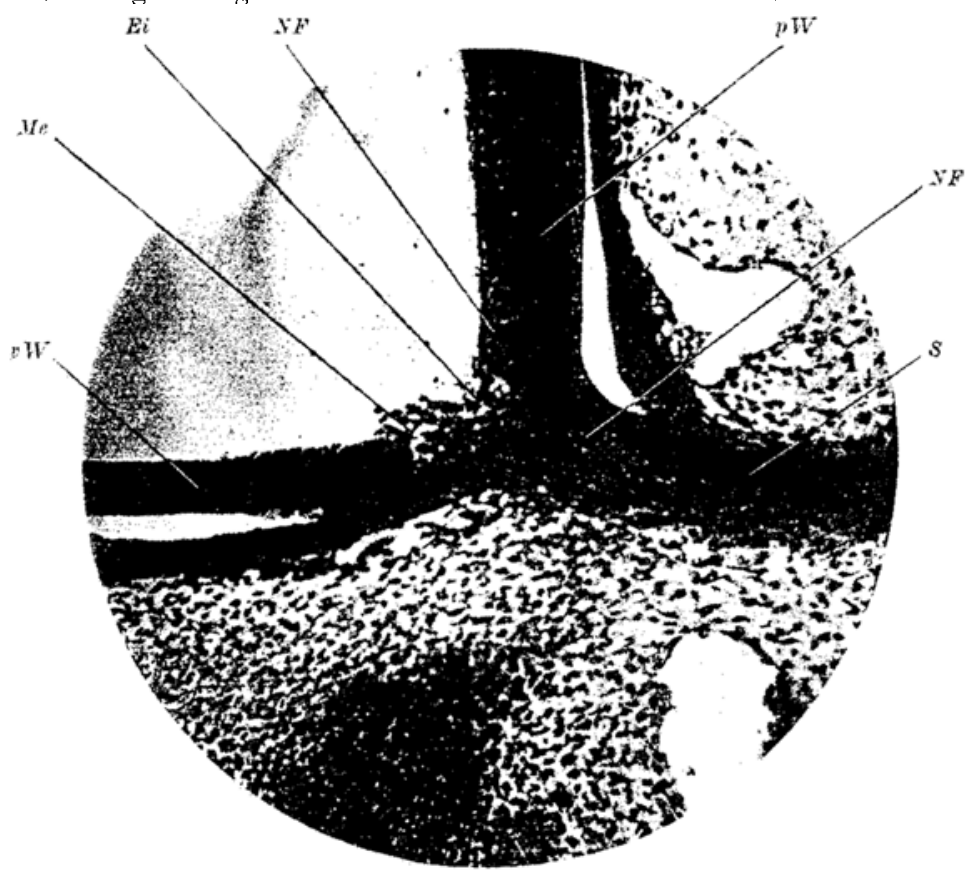

Abb. $\left.A_{4}{ }^{1}\right)$ : Photographie eines Sagittalschnittes durch den proximalen, ventralen Teil des Augenbechers eines $7,5 \mathrm{~mm}$ langen Embryos von Anas dom., unmittelbar neben der proximalen Offfnung. Vergr. 168/1.

1) El klärung der Abkiirzungen am Schhasse der Arboit (S. 342). 
262 C. Lindahl und A. Jokl: Lber den Yerschlub der fötalen Augenbecherspalte,

vorher geschlossen. Der Verschlußstelle entspricht an der Außenseite des Augenbechers eine Furche ( $\mathrm{Fa}$ ), deren nasaler Begrenzungsrand (in der $\mathrm{Abb}$. rechts) breiter ist und stärker hervortritt als der temporale. Das Oval der proximalen Öffnung (pö) ist schmäler geworden. Die beiden Ränder der dem distalen Ende der Becherspaite entsprechenden Einkerbung (EK) sind einander so weit genähert, daß der Winkel zwischen ihnen ganz spitz geworden ist.

Der Verlauf des Gefäßes, welches auch hier von relativ reichlichen Mesodermzellen begleitet ist, ist der gleiche wie im Falle vorher.

Pupillaröffnung wie früher ventralwärts dezentriert. Die ventrale Wand des Augenbechers nicht mehr gradlinig verlaufend, sondern leicht gekrümmt. Die übrigen Wände, besonders die dorsaje, stark gegen die Papillaroffnung umgebogen.

Der spitze Winkel, welcher in Stadium vorher die ventrale Wand des Augenbechers mit dera ventralen Teile der proximalen Wand an der Innenseite des Augenbechers in der Nähe des Becherstielseintritts bildete, ist nun zum großen Teile abgerundet und nur in un. mittelbarer Nachbarsehaft der proximalen Öfnung spitz geblieben. Es kommt dadurch an der Innenseite des Augenbechers eine der Insertion des Becherstiels an der Außenseite ent. sprechende Einsenkung zustande, welche proximal von der proximalen Öffnung gelegen ist und sich distalwärts in diese fortsetzt (Abb. $A_{4}$ Ei). Längs der Wand dieser Einsenkung nehmen nun die Nervenfasern aus dem differenzierten Teile der Retina ihren Weg, un zur ventralen Wand cles Stiels zu ziehen (NF). Es bildet also die beschriebene Einsenkung eine Art Trichter zwischen den von allen Seiten aus der sich differenzierenden Nervenfaserschicht kommenden, der ventralen Stielwand zustrebenden Nervenfasern.

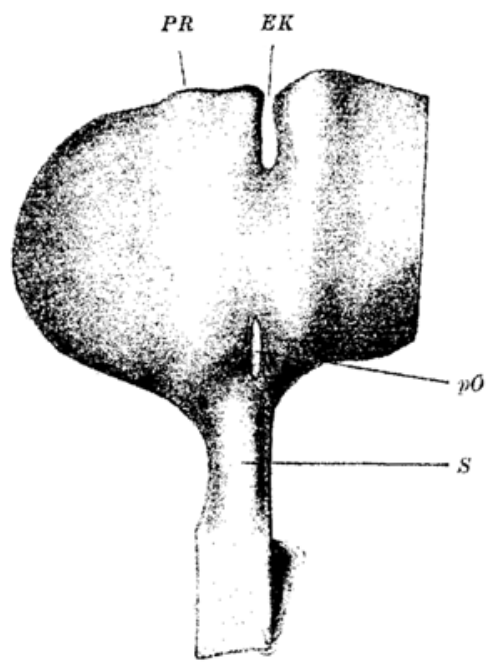

Abb. $\left.A_{5}{ }^{1}\right)$ : Rekonstruktionsmodell (125x) der nasalen Hälfte des Augenbechers eines $8,9 \mathrm{~mm}$ langen Embryos von Anas dom., von ventral her gesehen. ${ }^{8 / a}$ d. nat. Gr.

Stadium 4. $8,9 \mathrm{~mm}$ lang, $132^{\mathrm{h}}$.

Dieses Stadium ist in seiner Ausbildung von den vorigen nur wenig verschieden. Die Zellen des Pigmentblattes enthalten im Bereiche der proximalen Wand spärliches Pigment. Sehventrikel noch teilweise offen. Differenzierung der Retina nicht weiter fortgeschritten. Linsenlumen noch nicht ganz versch wunden. Hohler Becherstiel wie bei den früheren Stadien.

Rekonstruktions modell ( $125 \times$ ) von ventral her gesehen $\left(\mathrm{Abb}, A_{5}\right)$. Die Becherspalte ist längs einer noch etwas längeren Strecke als vorher geschlossen. Die proximale öffnung (pÖ) ist schmäler und deutlich spaltförmig geworden. Die Ränder der dem distalen $A b s c h n i t$ der Becherspalte entsprechenden Einkerbung(EK) d es Pu pil larrandes nähern sich in ihrem distalsten Abschnitte, auf diese Weise einen späteren Verschluß vorbereitend.

Das beschriebene Gefäß betritt, wie bei früheren Stadien von Mesodermzellen begleitet, den Augenbeeher dureh die proximale Öffnung, verläuft in der Augen becherhöhle der ventralen Wand derselben dicht angelagert distalwärts und verläBt die Becherhöhle durch den proximalen Teil der distalen Einkerbung. wo diese nooh relativ weit ist.

Stadium 5. 9,5 mm lang, $149^{\mathrm{h}}$.

Zellen des Pigmentblattes platt, nur im Bereiche der ventralen Wand und an dem dorsalen, umgebogenen Rande des Augenbechers böher. Sie enthalten uberall Pigment mit: Ausnahme der Umgebung der früheren Spalte. Differenzierung der Retina nicht weiter fortgeschritten als fruher. Sehventrikel im Bereiche der proximalen Wand spaltförmig, in der ventralen Wand and in dem dorsalen, ungebogenen Rande des Augenbechers breiter. Die

1) Erklärung der Abkürzungen am Schlusse der Arbeit (S. 342). 
aus der Retina sich sammelnden Nervenfasem ziehen zur ventralen Wand des Stiels, dessen Lumen noch seiner ganzen Länge nach offen ist. Linsenlumen nur als kleiner Rest in der Nähe des Äquators, an der Lmbiegungsstelle der Linsenfasern in das Linsenepithel vorhanden.

Rekonstruktionsmodell $\left.{ }^{1}\right)(125 \%)$.

$A$ a B ens eite $\left(\mathrm{Abb} . A_{6}\right)$ : Becherspalte wie bein vorigen Modell in der Mitte geschlossen, ihr früherer nasaler Rand (in der Abb. linkis) springt stärker vor als der temporale. Die proximale Offnung $(p \ddot{O})$ ein wenig verlängert, spaltförmig. A us der mehrfach erwähnten Einkerbung des Augenbecherrandes ist nun. mehr ebenfalls eine Öfnung (dö) geworden, indem die distalen Teile ihrer Ränder. deren Amnäherung wir in dem fruheren stadium konstatieren konnten (Abb. $A_{\tilde{y}}, \mathrm{EK}$ ), sich aneinander gelegt haben. Die auf diese Weise zustande gekommene distale Offnung ist hier wie die proximale schmal and spaltförmig und in diesem Stadium etwas länger als jene. Der Pupillarrand ist in cler Nachbarschaft der distalen Öffnung wulstig verdickt. Die Insertionsstelle des Becherstiels (S) ist in proximo-distaler Richtung etwas verlängert and wie früher von der Umgebung nicht scharf abgegrenzt. Ihr entspricht auch eine verlïngerte Einsenkung an der Innenseite.

Im histologischen Bilde (Abb. $A_{7}$ ) zeigt rlie Stelle dieser Einsenkung (Ei) folgendes Ver. halten: Zwischen den von der proximalen Wand der

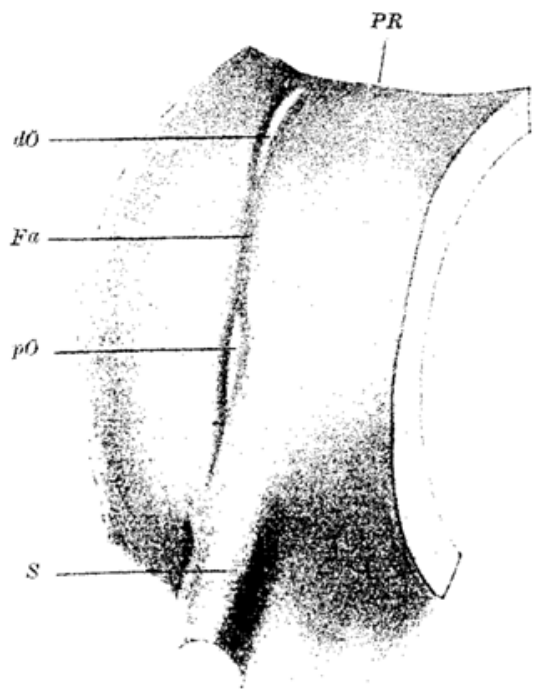

Abb. $\left.A_{S^{2}}{ }^{2}\right\}:$ Rekonstruktionsmodell (125 x) eines Teiles der ventralen Wand des Augenbechers eines $9,5 \mathrm{~mm}$ langen Embryos von Anas dom., von auken her gesehen. ${ }^{z_{i}}$ d d. nat. Gr.

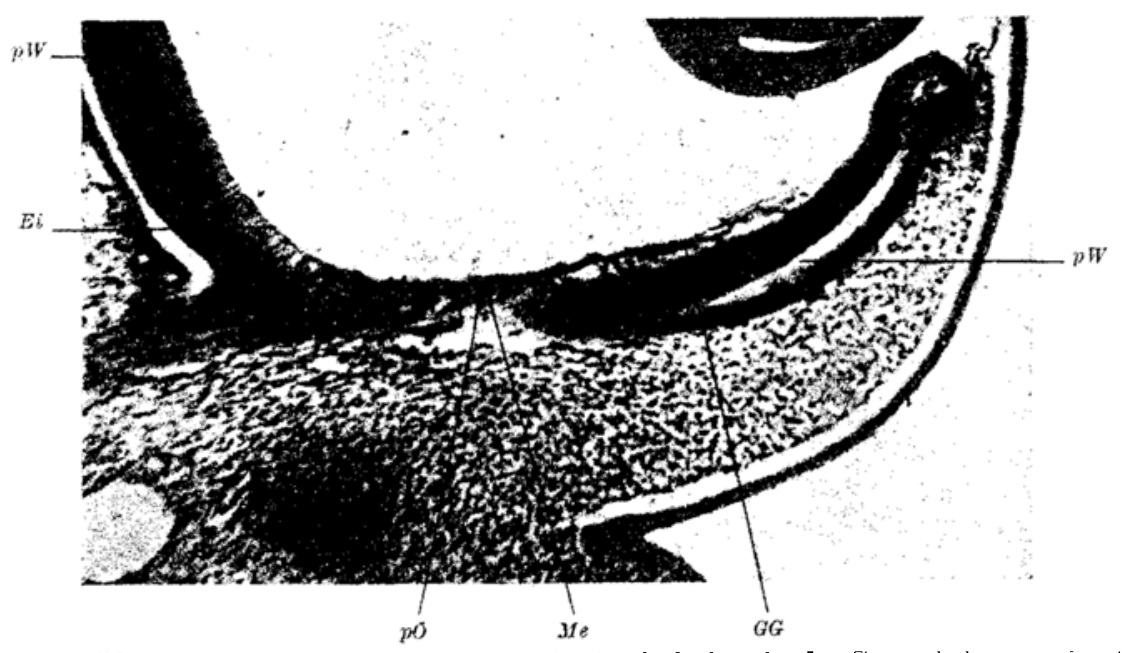

$\left.A_{b} b_{1} A_{7}^{2}\right)$ : Photographie eines etwas sehiefen sagittalsehnitts in der Gegend der proximalen Offnung durch das Ange eines $9,5 \mathrm{~mm}$ langen Embryos vou Anas dom. Vergr. 108:1; auf $3 / 4$ verkleinert.

$\left.{ }^{1}\right)$ Hier und bei den folgenden Modellen wurde nur ein Teil der proximalen und der ventralen Wand des Augenbechers bis zum Pupillarrand mit den distalsten Teile der Opticusanlage und der Becherspaltregion rekonstruiert.

) Erklärnng der Abkürzungen am Schlusse der Arbeit (S. 342). 


\section{$26 \pm$ C. Lindahl and A. Jukl: C̈her den Yerschluß der fötalen Augenbecherspalte,}

Retina kommenden und zur ventralen Wand der Opticusanlage ziehenden Nervenfasern und der ventralen Retinalwand erscheint das Gewebe hier eigentïmlich aufgelockert und zeigt unregelmäBige, größere und kleinere Lücken. Die relativ spärlichen Zellen in diesem Gebiete besitzen helle Kerne und späriches Protoplasma. An der Membr. lim. int. endigen sie mit deutlichen Radiärfaserkegeln. Es handelt sich offenbar um Zellen, welche den Viüllerschen Stützfazem der Retina entsprechen.

Das beschriebene Gefäß ( $A b b . A_{7}, G G$ ) hat denselben Verlauf wie friher und verläBt den Augenbecher durch die nun gebildete distale Öffnung. Wie bei den früheren Stadien ist es ron Mesodermzellen (Me) begleitet.

\section{Stadium 6. $102 \mathrm{~mm}$ lang, $161^{\mathrm{h}}$.}

Zellen des Pigmentblattes nun überall platt und reichliches Pigment enthaltend, mit Ausnahme der früheren Becherspaltränder (s. w.). Zellen des retinalen Blattes in radiären

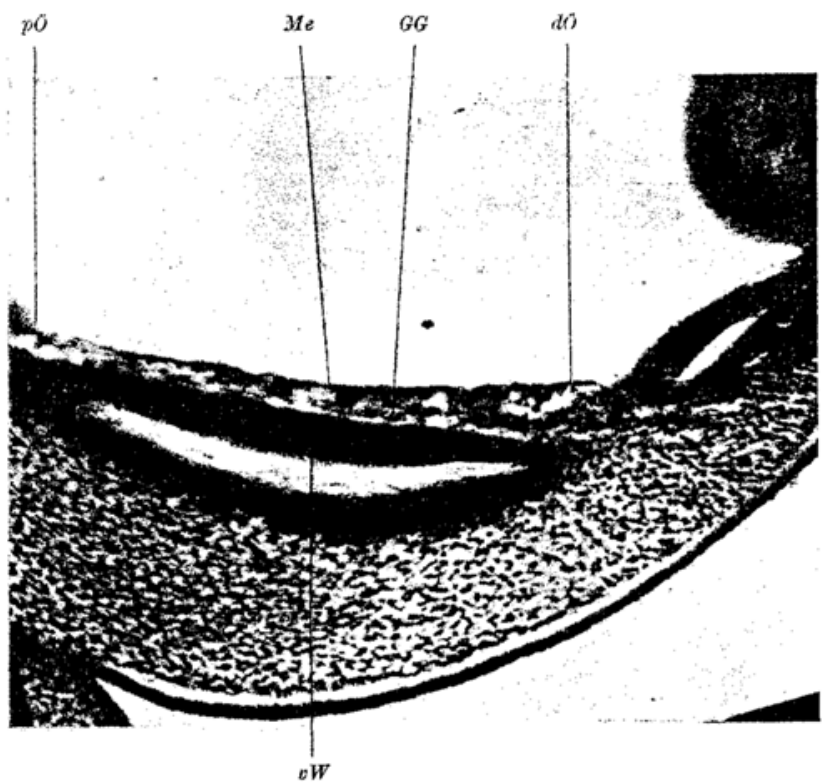

Abb. $\left.A_{8}{ }^{x}\right)$ : Photographie eines Sagittalsohnitts durch den ventralen Teil des Augenbechers eines 10,2 $\mathrm{mm}$ langen Embryos von Anas dom. mit dem durchtretenden Gefäße. Vergr. 106/1.
Reihen angeordnet, gleichfalls mit Ausnahme des Gebietes der früheren Spaltränder. Sehventrikel teilweise rerschwunden. Die Ausbildung der Opticusfaserschicht hat sich im Bereiche der proximalen Wand weiter ausgebreitet. Der Becherstiel noch vollkommen hohl, enthält die Nervenfasern, zu einem breiten Lager gesammelt, an seiner Ventralseite. Seine ventrale Wand ist dadurch, besonders im distalen Teil, wesentlich dicker geworden als die dorsale, wodureh das Lumen dorsalwärts verschoben und sebr schmal geworden ist. Linse mit spaltförmigem Lumen in der Aquator. gegend, entsprechend dem Ubergange der Linsenfasern in das Linsenepithel.

Das Rekonstruktions modell $(125 \times)$ zeigt an der A uBenseiteeine dem früheren Stadium gegenüber bedeutend verlängerte proximale öffnung, während die früher langgestreckte distale Offnung zu einem kleinen Loohe geworden ist. Die beiden Öffnungen stehen, wie früher an der Außenseite des Augenbechers durch eine Furche miteinander in Verbindung. Die Sehnerveninsertion gegenüber früher ein wenig verlängert und etwas sehärfer als früher von der Augenbecherwand abgegrenzt. Die Insertionsfläche hat etwa die Form eines Dreiecks, dessen distale Spitze der proximalen Öffnung zugewendet ist.

An der In ne nseite des Modells erkennen wir, daß die früher beschriebene, proximal von der proximalen öffnung gelegene Einsenkung nunmehr fast vollständig ausgeglichen ist. Das mikroskopische Bild zeigt, daß an dieser Stelle jedoch eine Einsenkung in der Nervenfaserschicht vorhanden ist, da $B$ diese aber von Gliazellen ausgefüllt ist. Die Ränder der proximalen Spalte (vgl, $\mathrm{Abb} . \mathrm{A}_{12}[\mathrm{~S} .268]$ ) zeigen ein eigentümliches, von dem Bave der übrigen Retina abweichendes Verhalten. In einem Gebiete unmittelbar an der Spalte, welches an der nasalen Seite gröBer ist als an der temporalen, finden wir, daB die Zellen des Pigmentblattes

1) Erklärung der Abkürzungen am Schlusse der Arbait (\$S. 342). 
đie Entwirklung dor Selnerveninsertion und die Anlage des Pecten bei Fögeh. 265

bedeutend höher sind als im Bereiche des übrigen Pigmentblattes, eine zylindrische Form haben und zum Cnterschied von diesen auch frei von Pigment sind ${ }^{1}$ ). Die Zellen des retinalen Blattes haben ebenfalls in diesem Gebiete den Charakter beibehalten, welcher dem ganzen Retinablatt in jüngeren Stadien zukommt. Während die Zellen des retinalen Blattes sonst radiür angeordnet stehen, zeigen sie nämlich in diesem Gebiet weiterhin ihre ursprünglich unregelmäBige Anordnung.

Das beschriebene GefäB tritt, von reichlichem Mesenchymgewebe begleitet, dureh die proximale Öfnung ein, verläuft entlang der ventralen Wand distalwärts und verläßt den Augenbecher durch die distale Öffnung ( $A b b . A_{3}, G G$ ).

Stadium $7.11 \mathrm{~mm}$ lang, $173^{\mathrm{h}}$

Pigmentepithel mit Ausnahme der Ränder der Becherspalte überall abgeplattet. Sehventrikel als schmaler Spalt vorhanden, stellenweise wahrscheinlich turch sekundäre Ab-

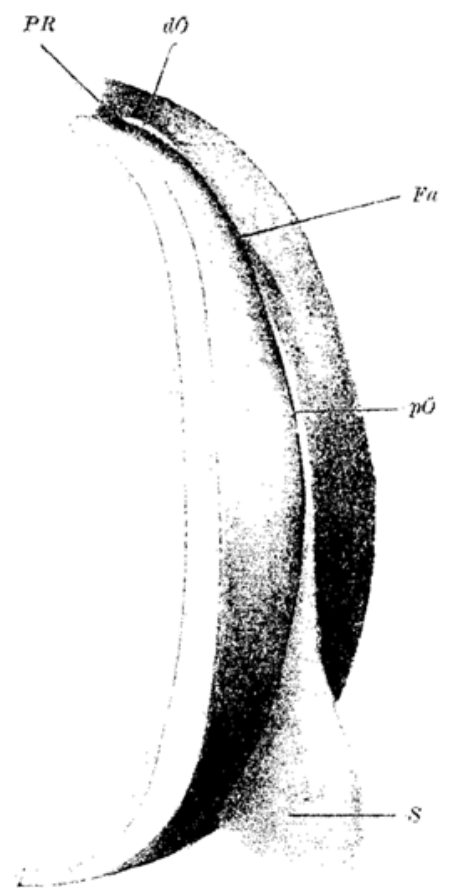

Abb. $\left.A_{y}{ }^{2}\right)$ : Rekonstruktionsmodell $(125 \times)$ eines Teiles der ventralen Wand des Augenbechers eines $11 \mathrm{~mm}$ langen Embryos von Anas dom., von außen her gesehen. nat. Gr.

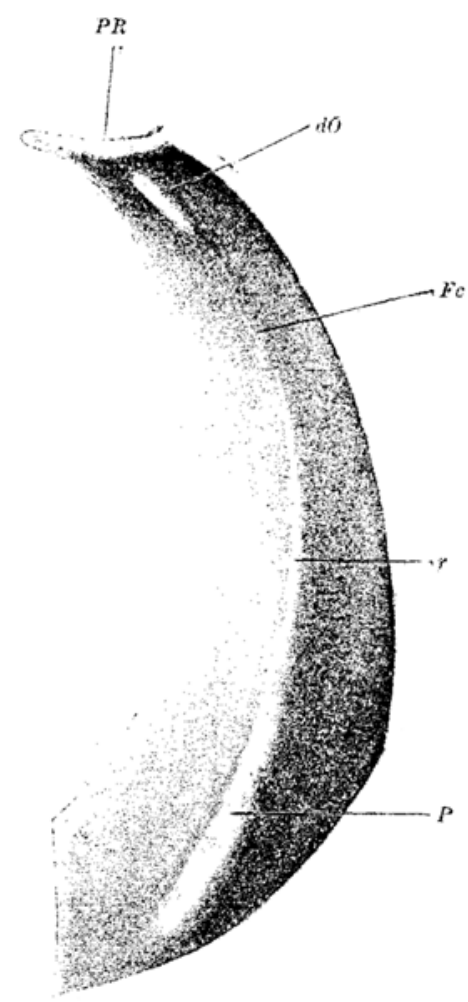

Abb. $\left.A_{10}{ }^{2}\right)$ : Das gleiche Pekonstruktions. modell (Anas dom., $11 \mathrm{~mm}$ lang), von der Innenseite her gesehen. $4 / 9 \mathrm{~d}$. nat. Gr.

hebung erweitert. Differenzierung der Retina nicht wesentlich weiter fortgeschritten, nur die Nervenfaserzone ist ausgedehnter. Opticusstiel mit engem Lumen an der Dorsalseite und breiter Nervenfaserzone in seiner ventralen Wand.

Das Rekonstruktions modell $(125 x)$ zeigt von der $A$ uBenseite $\left(A b b . A_{9}\right.$ ) her betrachtet eine dem früheren Stadium gegenüber jetzt sehr bedeutend verlängerte

1) Letzteres tritt auf der Photographie nicht deutlich hervor.

9) Erklärung der Abkürzungen am Schlusse der Arbeit (S. 342). 
Opticusinsertion (S). Sie läBt sich schärfer von der Wand des Augenbechers abgrenzen, und ihre Ansatzfläche am Augenbecher bildet ein schmales, sehr langgestrecktes Oval, welches sich distalwärts immer mehr verschmälert und mit einer lang ausgezogenen Spitze bis zur proximalen Öff $n$ ung (pö) reicht. Diese ist dem vorigen Stadium gegenüber ebenfalls bedeutend verlängert und zu einer langen Spalte geworden. Sie soll von nun an proximale Spalte genannt werden. Zwischen proximaler Spalte und distaler Öffnung (dÖ) an der Außenseite des Augenbechers eine Furche (Fa). Der hier befindliche geschlossene Teil der Augenbecherspalte ist relativ kurz. Die distale Offnung von ovaler Form, nahe dem Papillarrand gelegen.

An der Innenseite des Rekonstruktionsmodells ( $A b b . A_{10}$ ) erkennt man proximal von der proximalen Öffnung, in derselben Richtung wie diese verlaufend, eine lange, flache Vorwölbung $(\mathrm{Pe})$, welche sich aus einer sebr seichten Einsenkung erhebt. Diese Einsenkung, am Rekonstruktionsmodell nicht besonders stark hervortretend, am Schnitt jedoch bei stärkeren Vergrößerungen sehr deutlich erkennbar, entspricht in ihrer Lage und Ausdehnung vollkommen der Opticusinsertion an der AuBenseite, und die flache Vor. wölbung (Pe), die sich aus ihr erhebt, stellt die erste Anlage des Pecten dar. Die Pectenanlage durchsetzt die besagte Einsenkung ihrer ganzen Länge nach.

Die histologischen Schnittbilder durch die Pectenanlage zeigen folgendes:

Die Sehnervenfasern ziehen aus der sich differenzierenden Retina in zwei Por. tionen, einer etwas größeren nasalen und einer etwas kleineren temporalen, der langgestreck. ten Sehnerveninsertion zu. In der an der Vereinigungsstelle dieser beiden Portionen am Opticuseintritt gelegenen, langgestreckten Einsenkung sehen wir, daß die Gliazellen der Opticusanlage sich in diese Einsenkung eingeschoben haben, diese a usfüllen und eine über die Umgebung leicht erhabene Vorwolbung bilden. Die Zellen liegen hier relativ locker und lassen stellenweise kleine Lücken zwischen sich frek, welche durch Fortsätze, mittels welcher sie miteinander in Verbindung stehen, überbrückt sind. Auf diese Weise kommt die Vorwölbung der Pectenanlage zustande, die wir am Rekonstruktionsmodell gesehen haben (Abb. $A_{10}, \mathrm{Pe}$ ).

Das Pecten stellt also a uch hier bei Anas in seinerersten dnlage ein Differenzierungs prod ukt der Opticusinsertionsanlage dar und besteht in isohlie $B$. lich a us Gliazellen. Pectenanlage an der Innenseite und Sehnerveninsertionsanlage an der Außenseite des Augenbechers gehen distalwärts ohne scharfe Grenze in die Ründer der proximalen Spalte über. Diese zeigen in einer der Spalte zunächst gelegenen Partie der uibrigen Retina gegenüber den gleichen undifferenzierten Bau wie bei dem zuletzt beschriebenen Stadium. Diese Partie ist wie früher an der Nasalseite mächtiger als temporal und betrifft wie früher sowohl das Pigmentblatt wie das retinale Blatt. Im Bereiche des Pigmentblattes reicht diese undifferenzierte Partie zu beiclen Seiten der Spalte weiter peripherwärts als im Bereiche des retinalen Blattes.

Die proximale Öfnung wird ihrer ganzen Länge nach von einer Mesolermlamelle durchzogen, welshe nit dem Mesoderw an der Ventralseite des Augenbechers in Verbindung stelnt und sich frei in den Glaskörperraum erbebt. (In das Relonstruktionsmodell nicht mũ aurgenommen.) Das besprochene Gefaß betritt die proximale Öfnung erst in ihrem distalen Abschnitte. Es verläuft eine Strecke weit längs der ventralen Becherwand, hebt sich aber dann von derselben ab und erreicht in gestrecktem Verlnufe die distale offnung, durch welche es die Becherhöhle verläßt.

Stadium 8. $12,2 \mathrm{~mm} \mathrm{lang}, 6^{1 / 2} \mathrm{~d}$.

Pigmentblatt überall andifferenziert. Retinales Blatt von Pigmentblatt stellenweise ahgehoben. Differenzierung der Retina nicht weiter fortgeschritten als früher. Lumen des Becherstiels nun zu einer ganz schmalen, dorsal in der Opticusanlage liegenden Spalte reduziert. Linse: Zwischen Epithel und Fasern kein Spaltratum mehr.

Rekonstruktions modell (125x).

Außenseite: Die Sehnerveninsertion, hier noch wesentlich länger geworden als im Stadium vorher, scheint temporalwärts durch eine deutlich markierte, ziemlich tief einschneidende Furche abgegrenzt zu sein, während sie an ihrer nasalen Seite ohne scharie Grenze in die benachbarte Wand des Augenbeehers übergeht. Wie frïher reicht die Opticus- 
insertion distal mit ihrer lang ausgezogenen Spitze bis an die proximale Spalte heran und die erwähnte Furche setzt sich direkt in clieselbe fort.

An der Innenseite des Modells entspricht der verlängerten Sehnerveninsertion auch eine verlängerto Pectenanlage. Diese orhebt sich wie vorher aus der beschriebenen flachen Einsenkung und nimmt in proximo-distaler Richtung an Hobe zu. In ifrem distalen Teile hat die Pectenunlage hier die Gestalt eines niederen Grates, der sich aber die ventrale Wand des Augenbechers erhebt. An seiner nasalen Seite geht dieser Grat mit sanfter Neigung in die Becherwand uber, während er temporal steilwandig gegen dieselbe abfällt. Dadurch erhält die ganze Bildung eine leichte Neigung temporalwärts. Die proximale Spalte, welche nur unbedeutend länger ist als im Stadium vorher, zeigt eine deutliche Asymmetrie ihrer Ränder. Thr nasaler Rand, welcher, als eine direkte Fortsetzung des Pectenwulstes imponiert, springt an der Innenseite des Augenbechers deutlich stärker gegen das Augenbecherinnere vor als der temporale, welcher fast im gleichen Niveau wie die übrige Becherwand gelegen ist. An der Außenseite dagegen tritt der temporale Rand der Spalte stärker hervor. Infolge dieser Asymmetrie der Ränder durchsetzt auch die Spal te selbst die Becherwand in schiefer, von nasal außen nach tem. poral innen geneigter Richtung. Die Mesodermlamelle, welche auch hier die proximale Spalte durch-

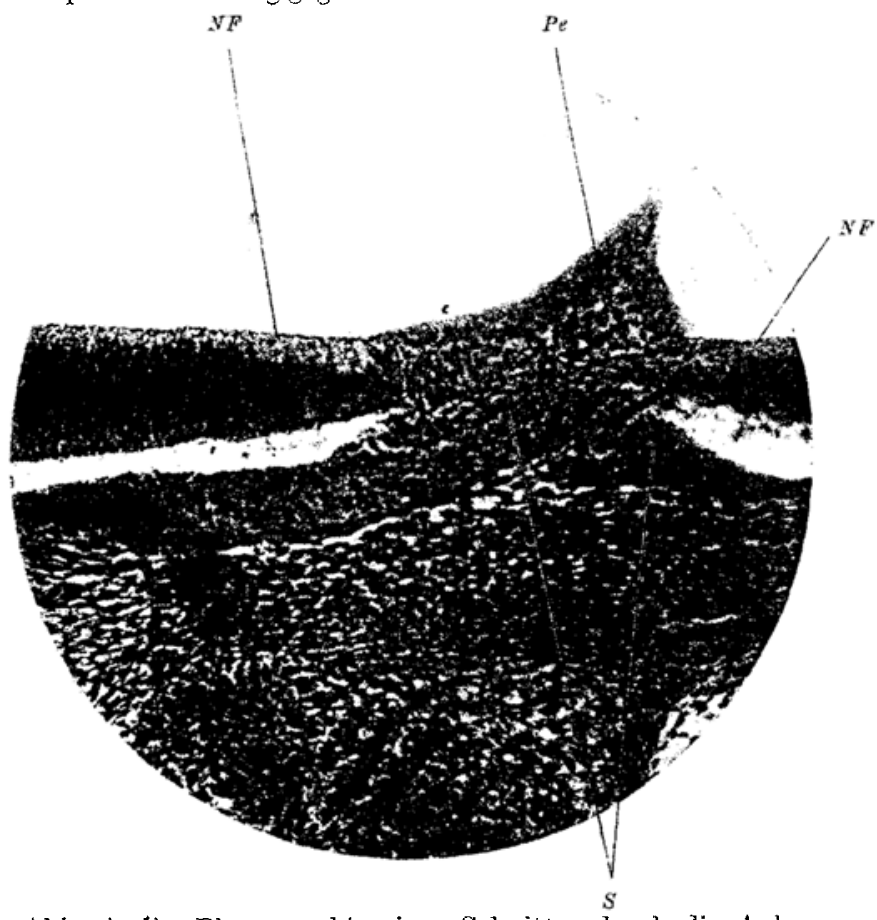

Abb. $A_{21}{ }^{1}$ ): Photographie eines Schnittes durch die Anlage von Sebnerveninsertion und Pecten eines $12,2 \mathrm{~mm}$ langen Embryos von Anas dom. Vergr. 168/1. zieht, wurde in der Rekonstruktion nicht mitgenommen, zeigt aber, wie das Sehnittbild erkennen läßt, eine der sehiefen Richtung der Spalte entsprecheude Schrïgstellung.

Das beschriebene GefäB, welches die proximale Spalte in ihrem distalen Ende betritt, heht sich nach dem Betreten der Becherhöhle sogleich von der Wand derselben ab und strebt im gestreekten Verlaufe der distalen Öffnung zu, durch welche es den Augenbecher wieder rerläBt. Es spannt sich wie eine Sehne ïber den gewölbten Teil der Becherwand zwischen proximaler Spalte und distaler Öffnung.

A $m$ his tologischen Sch nittbild zeigt das vorliegende Objekt folgende Verhältnisse: Im proximalen Teile der Pectenanlage zeigt diese ein ähnliches Bild wie vorher. Man erkennt eine aus Gliazellen bestehende Vorwölbung an der Innenseite des Augenbechers, welehe zwischen den von der temporalen und von der nasalen Seite her der Sehnervenanlage zustreben. den Nervenfasern eingebettet ist. Die Nervenfasern sind nasal in größerer Zahl vorhanden als temporal und bilden daher nasal ein mächtigeres und weiter peripherwärts reichendes Nervenfaserlager als temporal. Die Zellen im proximalen Teile der Pectenanlage liegen dichter als im vorigen Stadium, besonders an der Oberfläche des Organs, wo sie sich epithelartig anzuordnen beginnen. Weiter distalwärts geführte Schnitte zeigen ein eigentuimliches Bild (Abb. $A_{11}$ ).

1) Erklärung der Abkürzungen am Schlusse der Arbeit (S. 342).

Zeitschr. f. d. ges. Anat. I. Abt. Bd, 60. 
268 C. Lindahl and A. Jokl: Über den Verschluk der fütalen Augenberherspalte:

Die Sehnervenanlage (S) liegt flach ausgebreitet zum allergrößten Teile der ventralen Seite des nasalen Spaltrandes dicht an, füllt den Raum zwischen den beiden Rändern vollkommen aus und erstreckt sich nur eine ganz kurze Strecke weit über den temporalen Spaltrand. An der ventralen Seite der Sehnerveninsertionsanlage findet sich eine Furche, welche hier die Grenze zwischen den beiden Teilen der Anlage, dem größeren nasalen und dem kleineren temporalen, markiert. Es entspricht also die Furche, welche wir am Modell an der temporalen Seite der Opticusinsertion gefunden baben, in Wirklichkeit, wie das Sehnittbild zeigt, nicht ihrer temporalen Grenze. Sie erstreckt sich vielmehr mit einem schmalen Stücke über dieselbe hinaus auf den temporalen Rand, ist jedoch hier so schwach entwickelt, daß sie am Modell nicht als Wulst hervortritt. An ihrer Innenseite trägt die Sehnerveninsertion eine Pectenanlage ( $\mathrm{Pe}$ ), welche temporalwärts geneigt ist.

Es scheint also Sehnerveninsertion an der $A$ uBen- und Pectenanlage

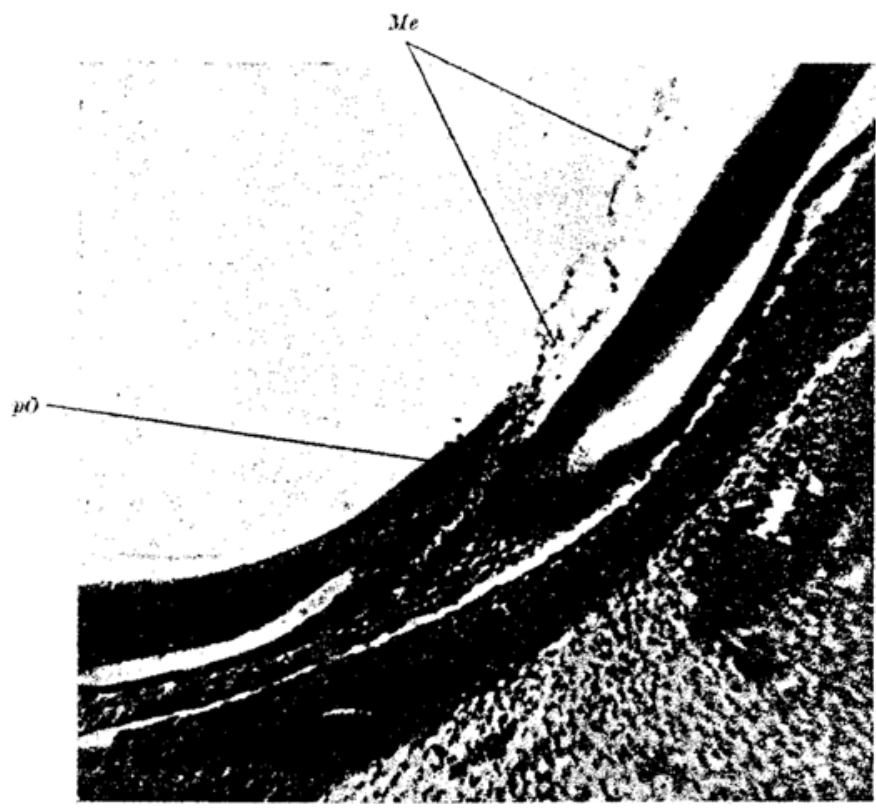

Abb. $\left.A_{1:}{ }^{1}\right)$ : Photographie eines Schnittes durch die proximale Spalte mit ibren undifferenzierten Randteilen von demselben Embryo (Anas dom., 12,2 mm). Vergr. 118/1. an der Innen seite des Augenbechers, welche beide Gebilde wir in Übereinstimmung mit dem Verhalten bei Podiceps (s. dort 8.246 ) a Is Neuro. pecten zusammenfas. sen, in proximo-dista. ler Richtung in das Gebiet der proximalen Spalte ein Stuck weit hineingewachsen zu sein. In Bereiche dieser Zone sehen wir nichts mehr von den undifferenzierten Randteilen, welshe früher durchwegs dieSpalte beiderseits begrenzten und von welchen der nasale mächtiger entwickelt war als der temporale, sondern es grenzt hier das Neuropecten direkt an die differenzierten Retinaränder (vgl. Abb. $A_{11}$ ). Es scheinen also diese undifferenzierten

Randteile als Bahn für die rorwachsende Opticusanlage zu dienen, wobei sich offenbardie

Spalte durch Aneinanderlagerung und Verschmelzung der Ránder ge. schlossen hat.

Weiter distal geht das Neuropecten ohne scharfe Grenze in die Ränder der offenstehenden Spalte über. Hier finden wir allmählich die gleichen Zellverhältnisse wie bei den früher beschriebenen Stadien im Bereiche der offenstehenden Spalte vor, nämlich eine undifferenzierte Beschaffenheit ihrer Ränder ( $\mathrm{Ab} b, \mathrm{~A}_{12}$ ). Auffallend ist die außerordentlich schiefe Richtung der proximalen Spalte durch die Becherwand, welche dadureh bedingt ist, daß der temporale Rand an der Außenseite ein gutes Stück über den eingebogenen nasalen Rand hinwegreicht.

Die Spalte läßt reichlich Mesodermzellen durchtreten, welche eine Lamelle bilden, die entsprechend der Richtung der Spalte sich schief in die Becherhöhle hineinschiebt (Me). Ent. sprechend dieser schiefen Richtung der Spalte hat auch das in derselben vorgewachsene Neuropecten eine schiefe Stellung erhalten.

1) Erklärung der Abkürungen am Schlusse der Arbeit (S. 342). 
Ein Stadium $\nabla$ on 12,5 mm $\mathrm{L}$ ange, welches ebenfalls rekonstruiert und in der Schnittserie untersucht wurde, ergab den zuletzt beschric benen gegenüber keine wesentlichen Ver. schiedenheiten, sondern bestitigte die dort erhobenen Befunde vollkommen.

Stadium 9. $13 \mathrm{~mm}$ lang, $197^{\mathrm{h}}$.

Die Ausbildung der Nervenfaserschicht hat sich nun über den größeren Teil der Retina ausgebreitet, sonst ist ihre Differenzierung aber nicht weiter fortgeschritten. Nervenfaserschicht nasalwärts von dem langgestreckten Sehnerveneintritt mächtiger entwickelt als temporal. Zwischen Pigmentblatt und Retinablatt ein offenbar sekundär entstandener Spaltranm. Stiellumen proximal noch offen, im distalen Teile gesohlossen, mit Ausnahme eines kleinen Restes am Utbergange des Stiels in den Augenbecher. Linse vollkommen ohne Lumen.

Rekonztruktionsmodell (125 X).

Außenseite: Sebnerveninsertion von im allgemeinen gleichem Aussehen wie bei dem unmittelbar vorhergehenden Stadium. Ihr d'stales Ende trägt jedoch hier an seiner Temporalkeits eine in der Längsrichtung der proximalen Spalte verlaufende und sich direkt in sie fortsetzende kurze Furche, welche den distalsten Teil der Opticusinsertion in zwei Teile teilt. Diesa beiden Teile, von denen der nasale mächtiger entwickelt ist als der temporale, gehen ohne scharfe Grenze in die Begrenzungsränder der proximalen Spalte uber. Diese ist dern früheren Stadium gegenüber noch mehr verlängert. Thre Ränder sind etwas nach in nen $z u$ eingebogen, wo durch dies palte selbst in die Tiefe einer Einsen. kung zu liegen kommt. Thr nasaler Begrenzungsrand ist breiter und tritt stärker hervor als der temporale. Die promixale Spalte setzt sich distalwärts in eine zur distalen öffnung ziehende Furche fort, deren nasaler Rand ebenfalls höher ist als der ternporale. Distale öffnung ein kleines, rundes Loch, unweit vom Papillarrande gelegen.

Ander Innenseite (Abb. $\mathrm{A}_{13}$ ) zeigt das Modell eine in Lage und Ausdehnung der Opticusinsertion auBen entsprechende Pectenanlage ( $\mathrm{Pe}$ ), welche sich aus einer hier dentlich markierten Einsenknng erhebt. Sie reicht distalwärts bis zur proximalen Spalte and setzt sich hier ohne scharfe Grenze in die bciden, zu niedrigen Wülsten erhobenen Ränder fort, welche die proximale Spalte an der Innenseite begrenzen. Dieselbe durchsetzt

1) Erklärung der Abkïrzungen am Schlusse der Arbeit (S. 342).

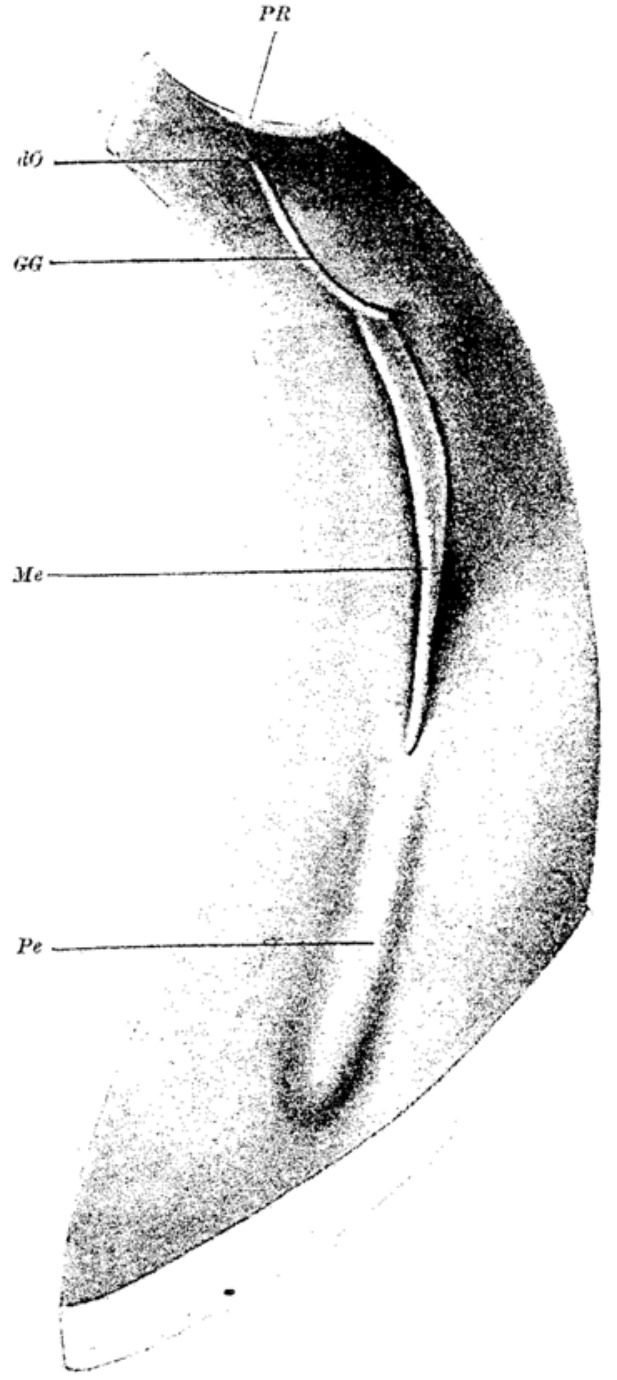

Abb. $\left.A_{13}{ }^{2}\right)$ : Pekonstruktionsmodell $(125 \times)$ eines Teiles der ventralen Wand des Augenbechers eines 13,5 mm langen Embryos ron Anas dom., von det Innenseite her gesehen. $1 / 3$ d. nat. Gr. 
auch hier we beim früheren Stadium in schräger Richtung von nasal außen nach temporal innen die Becherwand und dieser schiefen Richtung entspricht auch die Stcllung der Mesodermlamelle (Me), welche die Spalte ihrer ganzen Länge nach durchzieht und sich frei in den Glaskörperraum erhebt. Das Gefäß (GG) betritt die proximale öffnung an ihrem distalen Ende und zieht, von Mesodermzellen begleitet, zur distalen Öffnung, durch welehes es die Becherhöhle wieder verläßt.

Histologisch zeigt weder die Sehnerveninsertion noch die Pectenanlage dem zuletzt beschriebenen Stadium gegenüber wesentliche Verschiedeabeiten. Beide gehen wie früher ohne seharfe Grenze in die undifferenzierten Randteile der proximalen Spalte uber.

\section{Stadium 10. $16,5 \mathrm{~mm}$ lang, $209^{\mathrm{h}}$.}

Die Nervenfaserschicht der Retina hat an Breite zugenommen und sich über den größten Teil derselben ausgebreitet. Die innere reticuläre Schicht beginnt als schmaler, heller Streifen

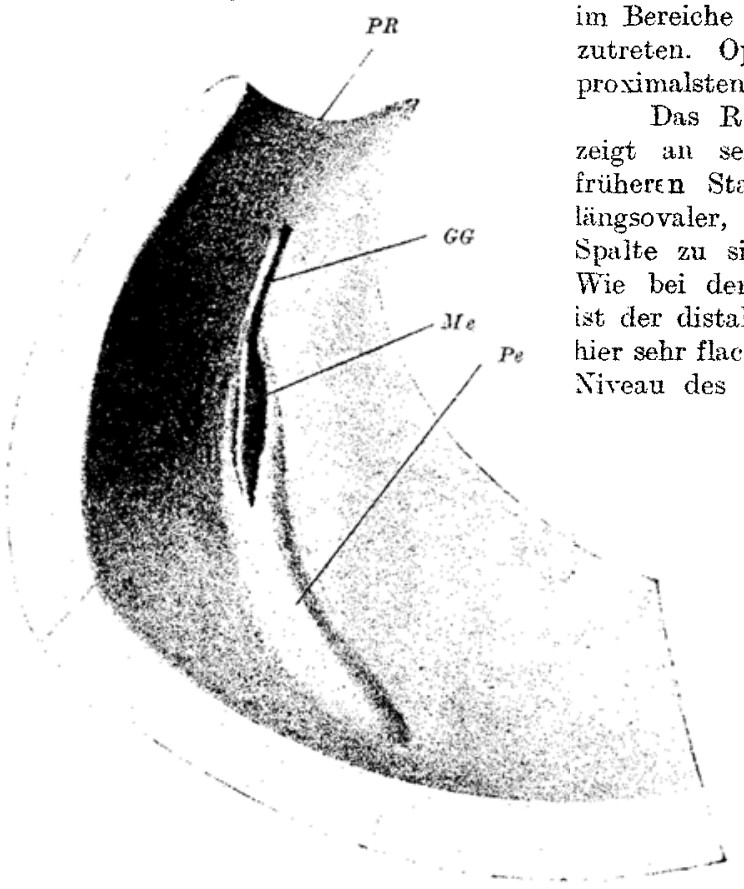

Abb. $\left.A_{11^{3}}\right)$ : Rekonstruktionsmodell $(65 x)$ eines Teíles der ventralen Wand des Augenbechers eines 16,5 mm langen Embryos von Anas dom., von der Innenseite her gesehen. $\$ / 9 \mathrm{~d}$. nat. Gr.

aus einer flachen Einsenkung die Anlage des Pecten (Pe). Diese nimmt in proximo-distaler Richtung an Höhe zu und erreicht ihren böehsten Punkt unmittelbar proximal von der proximalen Spalte. Hier geht sie, in zwei Teile geteilt, ohne scharfe Abgrenzung in die Seitenränder derselben über, welche, an Höhe allmählich abnehmend, im distalen Teil der Spalte fust vollkommen verflacht sind. Zwischen den Rändern der Öfnung erhebt sich auch hier die bereits mehrfach beschriebene Mesodermlamelle (Me), welehe eine leichte Neigung nach der temporalen Seite anfweist.

Schon die Betrachtung des Rekonstruktionsmodells labt vermuten, worum es sich hier handelt: Es scheint das Neuropecten in seinem distalen Teile in zwei Hälften geteilt zu sein,

3) Erklärung der Abkürzungen am Schlusse der Arbeit (S. 342). 
welche zu beiden Seiten der Mesodermlamelle den Ränclern der proximalen Spalte aufliegen. Der histologisehe Befund bestätigt diese Vermutung vollkommen.

E. zoll der Bau der Pectenregion in diesem Stadium an drei Schnittbildern klargelegt werden $\left(A b b . A_{15}, A_{16}, A_{17}\right.$ ). Im proximalen Teile der Pectenanlage, $A b b . A_{15}$, sehen wir dieselbe (Pe) zwischen den von nasal und temporal her dem Opticus zustrebenden Nervenfasem eingesenkt liegen. Sie besteht aus relativ locker liegenden Gliazellen von $\mathrm{d} \in \mathrm{m}$ früher beschriebenen Bau, welche an der Oberfläche relativ dicht stehen und epithelartig angeordnet sind. Weiter distalwïrts, Abb. $A_{16}$, ist das Neuropecten so tief zwischen die

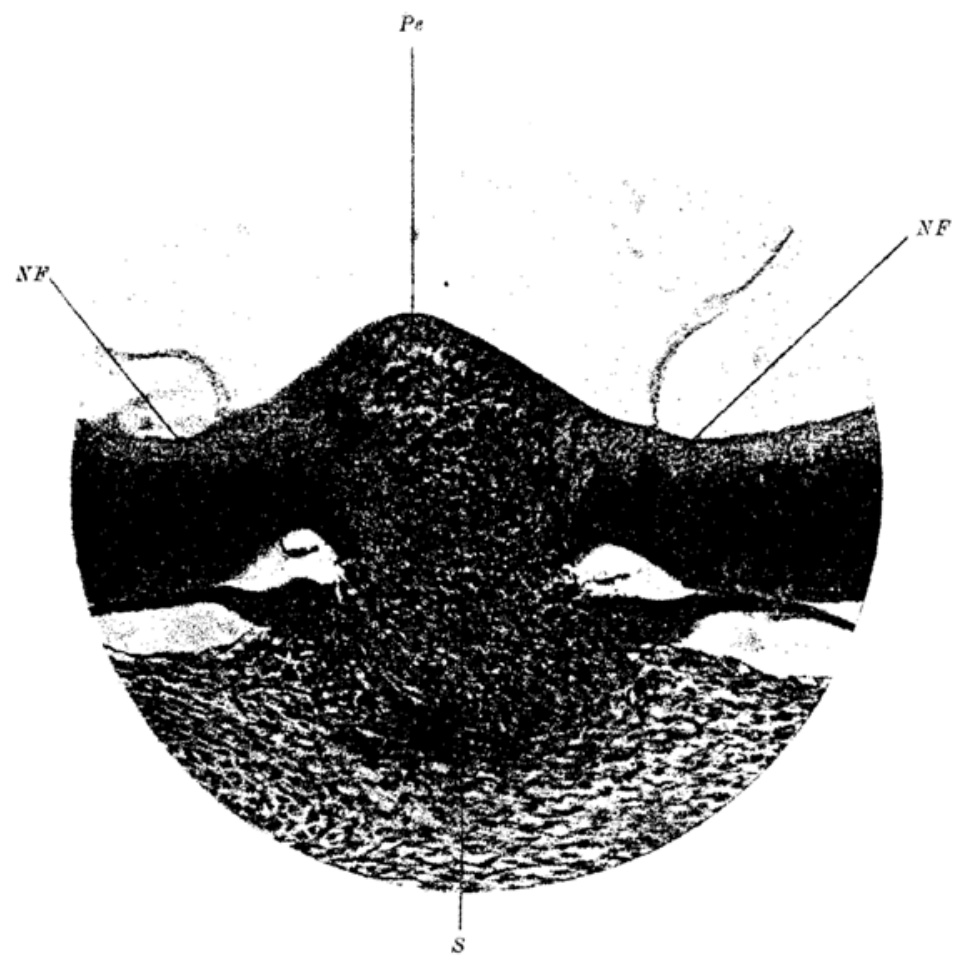

$\left.A b b . A_{15}^{1}\right)$ : Photographie eines Schnittes durch die Anlage von Pecten und Sehnerveninsertion in ihrem proximalen Teile von einen 16,5 mm langen Embryo von Anas dom. Vergr. 168/1.

Ränder der proximalen Öfnung verlagert, das die Sehnerveninsertion (S) an der Außenseite am Modell hier nur als ein sehr flacher Wulst hervortritt.

Wie die distalwärts folgenden Schnitte zeigen, entspricht jedoch das am Modell hervortretende scheinbare distale Ende der Opticusinsertionsfläche keineswegs dem wirklichen Ende der Sehnervenanlage. Diese setzt sich nämlich in der Tiefe zwischen den eingebogenen Rändern der proximalen Spalte distalwärts fort. Damit gelangen wir in den Bereich des ge. teil te $\mathrm{n}$ Ne uro pectens $\left(\mathrm{Abb} . A_{17}\right)$. Wir erkennen hier, daß die ganze Anlage so tief zwischen die Ründer der proximalen Spalte eingesehoben ist, daB die Sehnervenanlage (S) den Seiten dieser Ränder angelagert erseheint, während das Pecten (Pe) denselben innen gleichsam aufruht und sich etwas über dieselben ausgebreitet hat. Der Sehnerv trägt an seiner Außenseite eine tiefe Furche, welche von Mesodermzellen ausgefült ist. Diese setzen sich in Form einer Lamelle durch die ganze distale Anlage des Neuropecten bis in den Glaskörperraum hinein fort und teilen dadurch das Neuropecten in seinem distalen Teile in eine nasale und eine temporale Hälfte, welche den differenzierten Teilen der entsprechenden Spnltränder, diese teil-

1) Erklärung der Abkürzungen am Schlusse der Arbeit (S. 342). 
272 C. Lindahl und A. Jokl: Uber den Terschlub der futalen Augenhecherspalt"

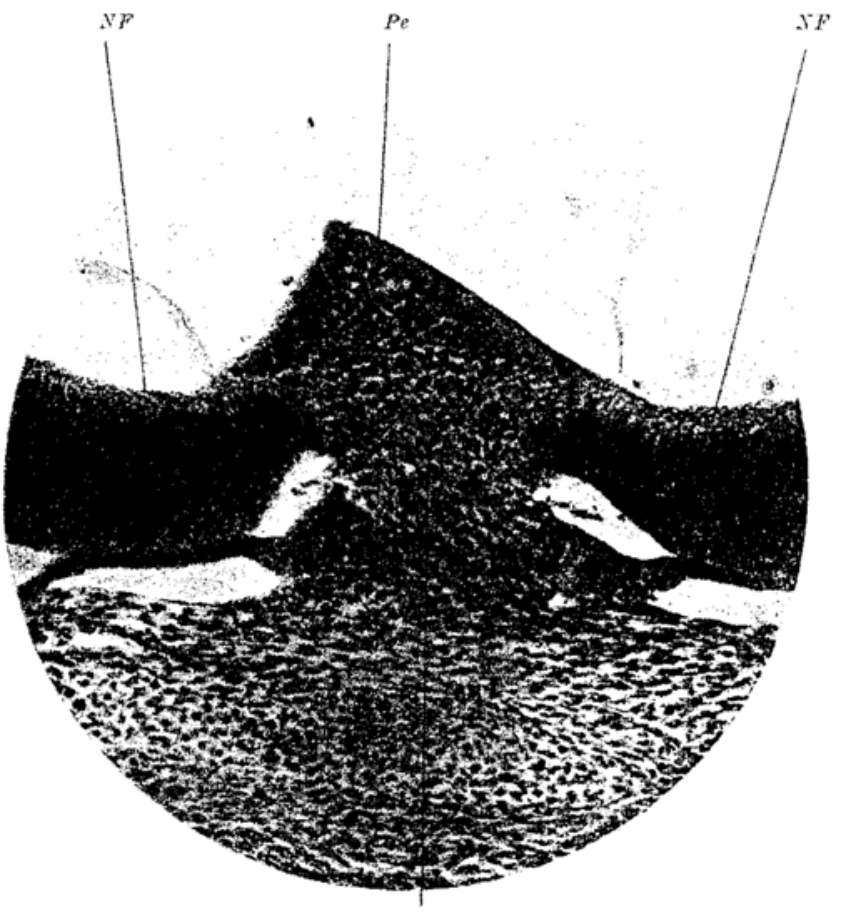

Abb. $\left.A_{16}{ }^{1}\right)$ : Photographie eines Schnittes durch die. selben Gebilde bei demselben Embryo (Anas dom., $16,5 \mathrm{~mm}$ lang) weiter distal. Vergr. $168: 1$.

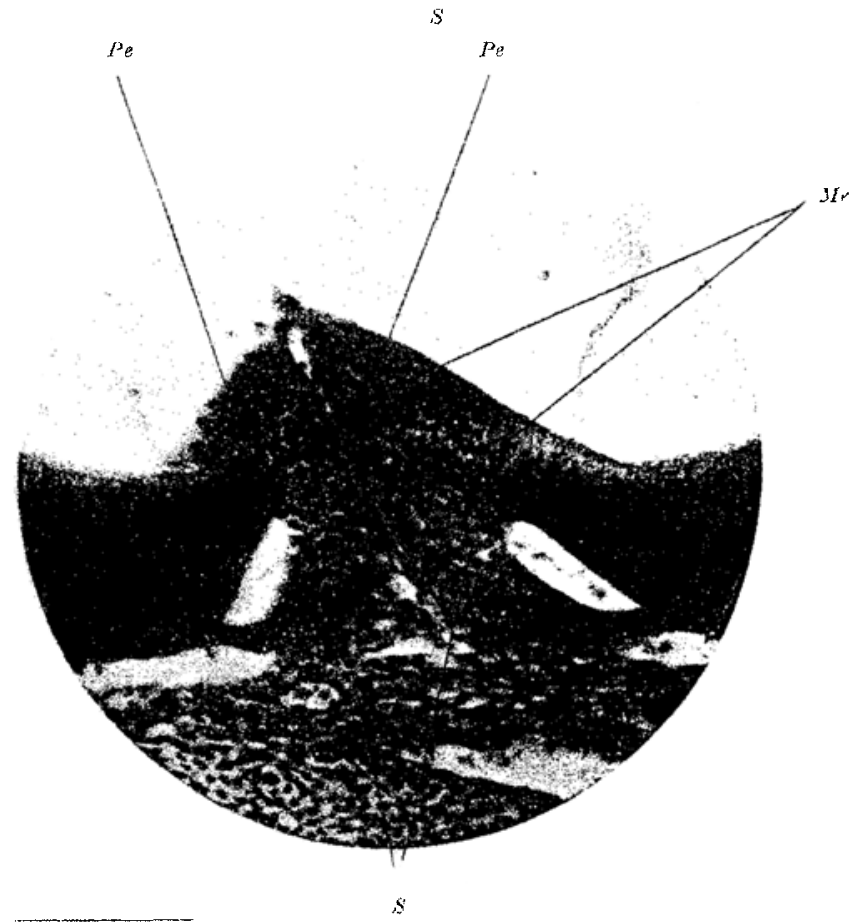

Abi). $\left.A_{17}{ }^{1}\right)$ : Photographie eines Schnittes durch die geteilte Sehnerveninsertionand Pectenanlage desselben Embryos, 10 Schnitte distal von $A_{18}$ (bei $12 \mu$ sehnitidicke). Vergr. $168 / 1$.

1) Erklärung der tbkürzungen am Schlusse der Arbeit (S. 342). 
weise umfassend, aufsitzen. Die beiden Hälften des distalen Neuropectens sind nicht gleich stark entwickelt, $€$ s ist vielmehr die dem nasalen Rande aufsitzende mächtiger als die temporale. Die nasale Portion des Neuropectens erstreckt sich auch weiter distalwärts als die temporale. Beide gehen distal ohne scharfe Grenze in die Randteile der proximalen Spalte über, welche hier wie früher in einer gewissen, der Spalte zunächst gelegenen Partie einen undifferenzierten Bau haben.

Die das Neuropecten durchziehende Mesodermlamelle enthält ein GefüB, welches, wie die Verfolgung cier Schnittserie zeigt, mit dem von uns mehrfach beschriebenen, das distale Ende der proximalen Spalte passierenden GefäBe (Abb. $A_{14}$, S. 270) nicht in Zusammenhang steht, sondern von einem der zahlreichen GefäBe stammt, die sich ventral von der Augenanlage ausbreiten. Dieses Gefäß wird spïter wahrseheinlich zur Arteria basalis pectinis und es zeigt uns daher dieses Stadium vielleicht auch, wie diese Arterie möghicherweise zum Pecten gelangt.

Vergleichen wir die hier erhobenen Befunde mit denen bei jüngeren Stadien von Anas und mit der Art des Yeuropectenwachstums bei Podiceps, so glauben wir dieselben in folgender Weise deuten zu düren: Das Neuropecten schiebt sich bei Anas zunächst in gleicher Weise wie bei Podiceps ungeteilt in den Rändern der proximalen Spaltedistalwarts vor. Dabei tößt es aber hier a d diedie proximalespalte durchziehende Mesodermlamelle, welche bei Podiceps fehlt, hier dagegen besonders kraftig entwickelt ist. Disse Lamelle bewirkt es nun, daß das weitere Vorwachsen des Neuropectens in den Rändern der proximalen Spalte nicht mehr ungeteilt, sondern in zwei Portionen, einer größeren nasalen und einer kleineren temporalen, geteilt erfolgt. Dabei ist das Neuropecten so tief zwiachen die eingebogenen Rander der proximalen $S$ palte eingesenkt, dab nicht nur die Sehnerveninsertion an der AuBenseite nicht als Wulst hervortritt, sondern daß hier das Neuropecten gleichsam a uf die Spaltränder hinaufgeschoben erscheint, wobei jede seiner beiden Portionen einen Spalt rand teilweise umgreift. Wir haben es also in diesem stadium mit einer in ihrem distalen Anteile geteilten Neuropectenanlage zu tun.

Stadium 1.1. 16, mm lang, $71 / 2^{\mathrm{a}}$.

Retinadifferenzierung nicht weiter fortgeschritten als in Fille vorher; innere retikuläre Schicht nur undeutlich zu erkennen. Bindegewebiger Teil der Irisanlage bis zum Papillarrand reichend. Opticusanlage enthält nur im proximalen Teile und distal an einer sehr kurzen, dem Augenbecher zunächst gelegenen Streeke an ihrer Dorsalseite ein Lumen.

Rekonstruktions modell $(40 x)$.

$A$ uBenseite $\left(A b b . A_{18}\right.$ ). Lange, durch seitliche Furchen von der Besherwand abgegrenzte Sehnerveninsertion (S), die peripherwärts allmählich schmäler und flacher wird. Sie scheint nicht bis an die proximale Spalte heranzureichen, sondern ein Stäck proximal von dieser za endigen. Ihr Endstück wird durch eine Furche in zwei Teile geteilt, welche wie bei den früheren Stadien, in die Seitenwände jener Finsenkung übergehen, die durch die eingebogenen Ründer der proximalen Spalte gebildet werden. Die Spalte ist im proximalen Teil dieser Einsenknng bereits geschlossen und öfnet sich erst weiter distal. Ihre Lünge ist demnach bedeutend geringer als vorher. Sie läßt Mesodermzellen und das erwähnte, in die Becherhöhle eintretende Gefäß passièren (im Rekonstruktionsmodell nicht mitgenommen).

An der Innenseite des Modells (Abb. $A_{19}$ ) erkennen wir, der verlängerten Sehnerveninsertion an der Außenseite entsprechend, ein sehr langes Pecten (Pe), welches sich aus einer, wem auch sehr seichten Einsenkung erhebt urd sich über einen großen Teil der ventralen Wand erstreckt. Es ist in seiner Mitte am böchsten und nimmt von hier aus nach beiden Richtungen hin an Höhe ab, wobei es proximalwärts an Breite etwas zunimmt. während sein distaler, proximal von der proximalen Spalte gelegener Teil durch eine, von dorsal her einschneidende Furche in zwei Teile unvollständig geteilt erscheint, von denen der nasale (in der Abb. links) höher und kräftiger entwickelt ist als der temporale. Die Furche setzt sich direkt in die proximale Spalte fort, während die durch diese Furohe getremnten Pectenteile ohme scharfe Grenze in die prulstigen Seitenrïnder der proximalen Sralte über- 
274 C. Lindahl und A. Jokl: Über den Verschluß der fotalen Augrubecherspalte

gehen. Die ganze Pectenanlage steht entsprechend der früher beschriebenen schiefen Richtung der proximalen Spalte, in deren Rändern sie vorgewachsen ist, ein wenig temporalwärts geneigt.

Die mikroskopische Untersuchung der Sehnittserie zeigt im proximalen Teile der Pectenanlage keine Veränderurgen dem früheren Stadium gegenüber. Weiter distalwärts haben sich die beiden früher getrennten Neuropectenportionen aneinander gelegt, während die zwischen ihnen gelegene Mesodermlamelle verschwunden ist. Zurückgeblieben ist von ihr nur ein Mesodermrest in der bei der Beschreibung des Modells erwähnten Furche im distalen Teile der Pectenanlage und die Arteria basalis pectinis, welche an der Grenze zwischen dem Pecten nnd den zur Opticusanlage ziehenden Nervenfasern gelegen ist. Das Studium der Schnittserie zeigt, da $B$ die Sehnerveninsertion nicht, wie aus dem Modell hervorzugehen seheint, proximal von der proximalen Spalte endigt, sondern dieselbe setzt sich an den Seitenwänden und am Grunde der am Modell beschriebenen, zur proximalen Spalte ziehenden Furche fort und geht allmählich ohne scharfe Grenze in die Ränder derselben ïber.

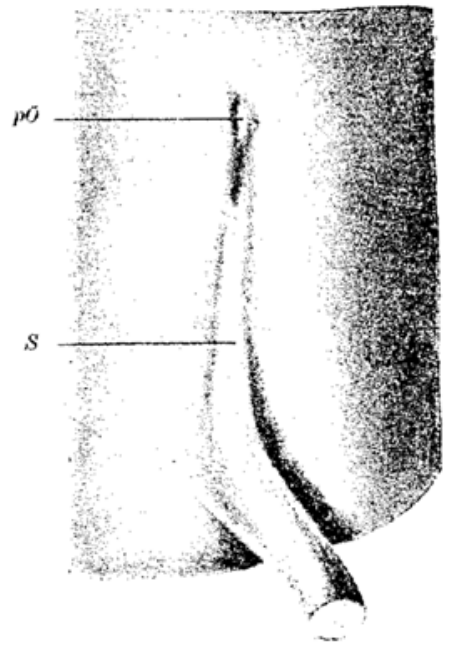

Abb. $\left.A_{13}{ }^{2}\right)$ : Rekonstrulationsmodell $(40 \times)$ eines Teiles der ventralen Wand des Augenbechers eines 16.4 mm langen Embryos von Anas dom. $8 / 15$ d. nat. Gr.

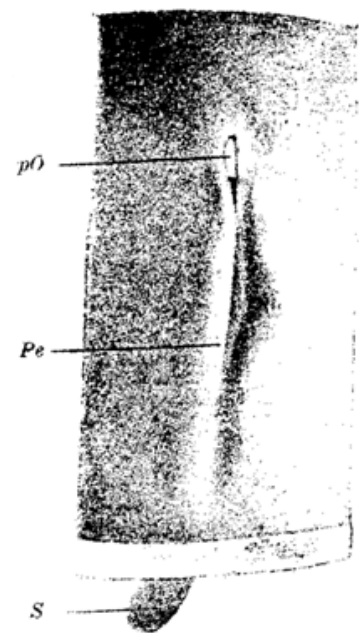

Abb. $\left.A_{19}{ }^{1}\right)$ : Dasselbe Rekonstruktionsmodell (Anas dom., 16. $1 \mathrm{~mm}$ lang), von der Innenseite her gesehen. ${ }^{*} / 15 \mathrm{~d}$, mat. Gr.

Das erwähnte, die Becherhöhle durchsetzende GefäB ist in seinem mittleren A bschnitt, welcher frei durch die Becherhöhle zog, a trophiert und größtenteils verschwunden. Zurückgeblieben ist nur sein Anfangsstück, welches clie frühere Eintrittsstelle in den Augenbecher am distalen Ende der proximalen Spalte maskiert und ein kurzes Stück vor ihrer Austrittsöffnung, welch letztere in Form eines kurzen Kinals retinales und Pigmentblatt durchsetzt.

$$
\text { Stadium 12. } 20 \mathrm{~mm} \text { lang. }
$$

Nervenfaserschicht der Retina breiter als vorher. Innere plexiforme Schicht, nun deutlich ausgebildet, trennt die Ganglienzellschicht von dem noeh undifferenzierten Teile der Retina. Opticusanlage ohne Lumen.

Rekonstruktionsmodell $(40 \times)$.

Außenseite: Sehnerveninsertion sehr langgestreckt, von der Augenbecherwand scharf abgegrenzt. Mit ihrem größeren distalen Anteil liegt sie wieder in der fruher besehriebenen Einsenkung, welche offenbar den eingebogenen Ründern der früheren proximalen Spalte entspricht. Die ganze Sehnerveninsertion erscheint nasalwärts gegen diesen

1) Erklärung der Abkürzungen am Schlusse der trbeit (S. 342). 
Rand geneigt. Eine Furche in ihrem distalen Teile ist angedeutet. Die proximale Spalte ist zu einem kleinen, ovalen Loche geworden.

An der Innenseite des Modells erkennt man auch hier, wie beim früheren Stadium, der langen Sehnerveninsertion entsprechend, ein langes, in seinem frei gegen die Becherhöhle zu vorragenden Teile plattenförmiges Pecten, welches ungefähr in seinem mittleren Teile am hüchsten ist und von hier aus nach beiden Seiten hin an Höhe abnimmt. Die Einsenkung, von deren Boden sich das Peeten bei den früheren Stadien erbob, ist hier nicht mehr vorhanden. Das ganze Pecten weist eine leichte Neigung nach der temporalen Seite hin auf. Der distalste Pectenanteil ist auch hier, wie die Schnitte noch deutlicher als das Modell erkennen lassen, durch eine von dorsal her einsebneidende Furche unvollständig in zwei Teile geteilt. Die

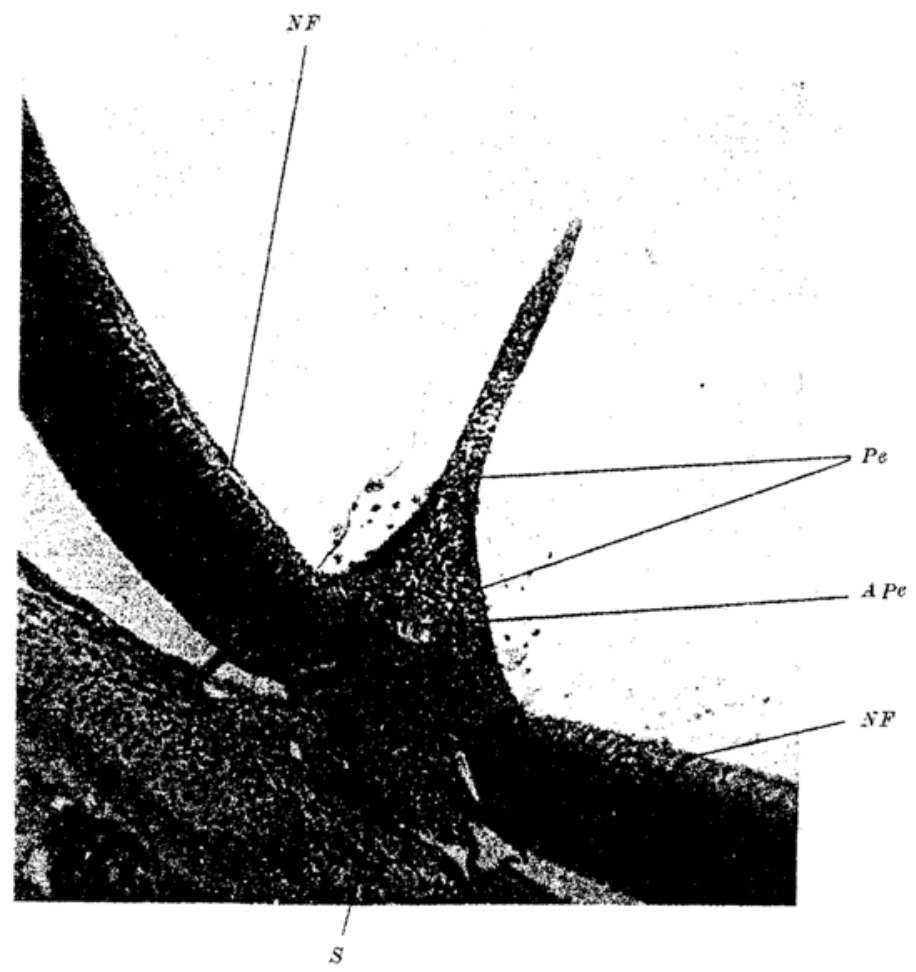

Abb. $A_{20}{ }^{2}$ ): Photographie eines Schnittes durch den mittleren Teil der Anlage von Sehnerveninsertion und Pecten eines $20 \mathrm{~mm}$ langen Embryos von Anas dom. Vergr. 106/1.

Furche liegt in der Pectenanlage ein wenig nach der temporalen Seite hin verschoben, entsprechend der früher beschriebenen stärkeren nasalen und der schwächeren temporalen Portion, welche hier miteinander verwachsen sind.

Die mikroskopische Durchsicht zeigt im proximalen Teile der Pectenanlage im wesentlichen ein ähnliches Bild wie früher. Das Pecten hat jedoch an Höhe zugenommen und besitzt nun am Querschnitte die Form eines spitzen Kegels, dessen temporale Wand steiler abfällt als die nasale, wodurch die ganze Bildung oine temporalwärts geneigte Lage erhält. Die Pecternanlage grenzt sich deutlich gegen den Sehnerven hin ab und besteht aus den beschriebenen, locker gefügten Gliazellen, welche an der Oberfläche dichter liegen und epithel. artig angeordnet sind. Die Sehnerveninsertion ist in Übereinstimmung mit den früher beschriebenen Stadien an die nasale Wand jener Einsenkung angelagert, welche durch die Einbiegung der Ränder der früheren Spalte entstanden ist. Weiter distalwärts nimmt

1) Erklärung der Abkürzungen am Schlusso der Arbeit (S. 342). 
276 C. Lindahl und A. Jokl: Über den Verschlub der fötalen dogenbecherspalte,

das Pecten an Höhe immer mehr zu und wird dabei in seinem frei in die Becherhöhle vorragenden Teile immer mehr abgeplattet. Hier (Abb. $\mathrm{A}_{\mathbf{2} 0}$ ) lassen sich an der Pectenanlage (Pe) schon in diesem Stadium zwei Abteilungen unterscheiden: eine der Opticusinsertion zunächst gelegene von im Querschnitte dreieckiger Gestalt, mit den locker gefügten Zcllen im Innern und epithelartig angeordneten Zellen an der Oberfläche. An diese ventrale Abteilung schließt sich eine schmale, abgeplattete dorsale Partie, welche ausschließhich aus diesen dichter liegenden Wandzellen besteht. Gehen wir noch weiter distal, so gelangen wir in eine Region, die eine vollständig geteilte Opticusinsertion aufweist. Der opticus trägt an seiner ventralen Seite eine Furche, die mit Mesoderm ausgefült ist, und aus dieser erhebt sich wie früher eine Mesodermlamelle, die jedoch nur bis an die Pectenbasis reicht. Es besteht also in diesem Teile des Neuropectens eine geteilte Opticusinsertion, aber ein einheitliches Peoten. Im Berciche desselben ist die früher dort vorhanden gewesene Mesodermlamelle hier offenbar schon spurlos verschwunden mit Hinterlassung der Art. basal. pect. an der Grenze zwischen Sehnerveninsertion und Pecten. Noch weiter distalwärts, nahe der proximalen Öffnung, ist wieder wie im früheren Stadium das ganze Neuropecten durch die Mesodermlamelle geteilt. Es zerfällt hier wieder in zwei asymmetrische Hälften, indem der nasale Teil mächtiger entwickelt und höher ist als der temporale. Am distalen Ende der proximalen Öffnung findet sich ein in die Bscherhöhle hineinragender, atrophischer GefäBrest. Die Stelle der distalen öffnung is tnoch deutlich erkennbar. Ein offener Kanal istzwarnicht mehr vorhanden, doch schlägt sich an der entsprechenden Stelle das retinale Blatt in das Pigmentblatt um und die Ränder des früheren Loches liegen $n$ un a neinander. (Vgl. Abb. A $A_{22}$, S. 277.)

Bei dem hier beschriebenen Stadium ist also das Neuropecten in proximo-distaler Richtung so weit distalwärts vorgewachsen, dab die proximale Spalte bis anf eine kleine, ovale Offnung verschlossen ist, welche ihrem früheren, distalsten Anteil entspricht. Das Vorwachsen erfolgtein zwei durch die Mesodermamellegetrennten etwas ungleich stark entwickelten Portionen. Als Bahn dienten dabei offenbar die undifferenzierten, der proximalen Spalte zunächst gelegenen Teile ihrer Ränder, denndie beiden Neuropecten portionengrenzen überall direktan diedifferenzierte Retina, dort, wo das innere Blatt sich in das düne, stark pigmentierte Pigmentblatt umsehlägt. Dabei versehwindet die Mesodermlamelle im proximalen Teile des Neuropectens, jedoch etwas früber im Pectenteile als im Opticus. Der Aneinanderlagerungsstelle entspricht im distalen Teile der Pectenanlage eine von dorsal her einschneidende Furche, welche entsprechend der ungleichen Mächtigkeit der zur Vereinigung gekommenen Teile ein wenig nach der temporalen Seite hin verschoben erseheint. Entsprechend der schiefen Richtung, in welcher die ursprüngliche proximale Spaltöffnung die Wand durchsetzt, hat auch das Neuropecten eine schiefe, von nasal auben nach temporal innen gerichtete Stellung.

Stadium 13. $30,4 \mathrm{~mm}$ lang.

Retina mit breiter äuferer retikulürer Schicht. Die innere retikuläre Schicht beginnt als schmale, helle Zone nicht weit von äuBerem Rande der Retina sichtbar zu werden. Die Oraserrota schruf markiert. Ciliarkörper angelegt.

Rekonstruktionsmodell $(40 \times)$.

A uBenseite: Lange, von der Becherwand scharf abgegrenzte Sebnerveninsertion. welche auch hier wiederum in einer offenbar durch die eingebogenen Ränder der früheren proximalen Spalte gebildete Einsenkung gelegen ist. Die ganze Sehnerveninsertion ist etwas gegen die nasale Wand dieser Einsenkung angelehnt, entsprechend der urspränglichen schiefen Richtung der Spalte. Die proximale Spaltöffroung ist nun völlig geschlossen.

An der Innenseite des Modells (Abb. $A_{21}$ ) erkennen wir ein langes Pecten (Pe), dessen Ansatzlläche, was Lage und Ausdehnung anbelangt, der Sehnerveninsertion röllig entspricht. Es stellt eine hohe, schmale Flatte dar, welche in distaler Richtung allmählich an Höhe zunimmt, um in ihrem distalsten Teile noch an Höhe abzunehmen. Die ganze Pectenanlage ist etwas temporalwärts geneigt. Wie die Schnitte erkennen lassen, ist ein deutlicher Rest der distalen öffnung im Ciliarkörpergebiet vorhanden. An dieser Stelle liegen die Ränder des früheren Loches einander an und sind gegen die Außenseite des Augenbechers zu umgebogen, so daß die Stelle im Schnitt sich als $z$ wei ei nander 
anliegende Lippen präsentiert, an deren nach auBengewendeten Ränderndas Pigmentblatt in das retinale Blatt übergeht ( $\mathrm{Abb} . \mathrm{A}_{\mathrm{g} 2}$ ).

Histolngisch bietct las beschriebene Stadinm sonst dem früheren beschriebenen

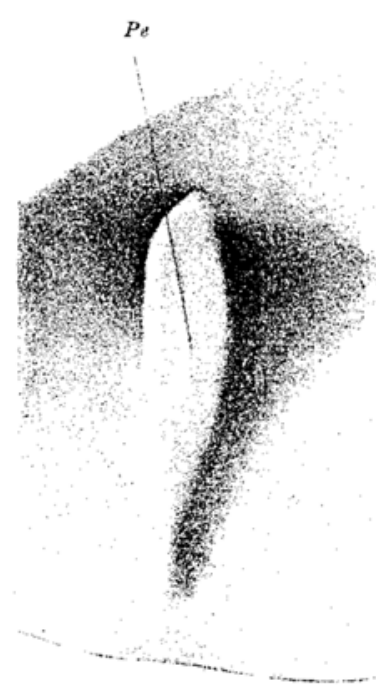

Abb. $\left.A_{* 1}^{1}\right)$ : Rekonstruktionsmodell ( $40 \times$ ) eines Teiles der ventralen Wand des Augenhechers eines $30,4 \mathrm{~mm}$ langen Fmbryos, yon inuen her sesehen. gegenüber keine Besonderheiten, abgesehen davon, dab der frei in den Glaskörperraum vorragende Teil der Pectenanlage wesentlich höher geworden ist. Die Mesoderm. lamelle, welche früher den distalen Teil des Neuropecten in zwei Halften teilte, ist mit Hinterlassung der Art. basal. pect. rollkommen verschwunden.

Wir kommen also auch hier zu einem Entwioklungsstadium, welches mit dem beschi iebenen altesten Stadium von Podiceps rollkommen übereinstimmt.

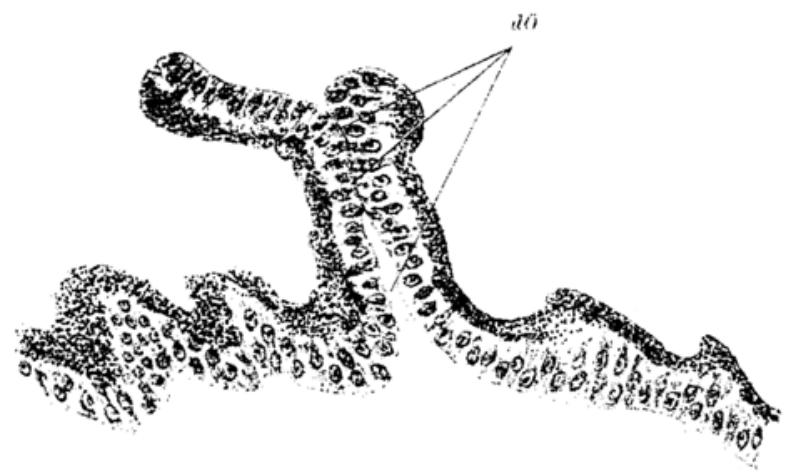

Abb. $\left.A_{2,2}{ }^{1}\right)$ : Zeichumg eines Sohnittes durch den Pest der distalen Offnung in Ciliarkörpergebiet ron einem $30,4 \mathrm{~mm}$ langen Embryo von Anas dom. Vergr. 268:1.

\section{Zusammentassung.}

Die besonders dichte Reihe von juagen Stadien, die uns bei Anas zur Verfügung stand, ermöglichte uns hier ein ganz genaues Verfolgen der Vorgänge beim Verschlusse der Augenbecherspalte. Wir sehen im jüng. sten Stadium (Abb. $A_{1}, S .260$ ), daB sie (AS) ihrer ganzen Länge nach offen ist; proximal reicht sie bis an die Insertion des Becherstiels (S), distal gehen ihre Ränder divergierend ohne scharfe Grenze in den Pupillarrand über. In ihren mittleren Partien nähern sich die Spaltränder etwas und verursachen dadurch eine leichte Verengerung der Spalte daselbst. Der nasale Rand der Spalte tritt etwas stärker hervor und ist etwas breiter als der temporale.

Wie die Schnittbilder zeigen, wird die Becherspalte ibrer ganzen Länge nach von einem GefäB durchzogen, welches aus der ventralen Umgebung des Augenbechers stammt und von Hesodermzellen begleitet ist.

Die Bechers palte schlie Bt sich, wie das nächste Stadium zeigt ( $\mathrm{Abb} . \mathrm{A}_{2}$, S. 260), zunächst in ihrem mittleren Teile durch Aneinanderlagerung ihrer Ränder. Als ihre Reste bleiben offen ihr proximaler Teil, der eine ovale, mit einer Spitze gegen die Verschlußstelle weisende Offnung darstellt (Abb. $\left.A_{2}, p O ̈\right)$ und ihr distalster Abschnitt, welcher

1) Erklärung der Abkürzungen an Schlusse der Arbeit (S. 3+2). 
278 (. Lindahl und A. Jokl: T̈ber den Ferschlub der fütalen Angenbohnerpalte,

eine spitzwinkelige Einkerbung (EK) des Pupillarrandes präsentiert, welche mit abgerundeten Ecken ohne scharfe Grenze in den Pupillarrand (PR) übergeht. Proximale Öffnung und distale Einkerbung stehen an der Außenseite des Augenbechers durch eine Furche ( $\mathrm{Fa}$ ) miteinander in Verbindung, welche der Aneinanderlagerungszone der etwas eingebogenen Spaltränder entspricht.

Das früher erwähnte Gefäß wird beim VerschluB der Spalte zusammen mit den Mesodermzellen, welche es begleiten, zum Teile in das Innere des Augenbechers aufgenommen, so daß es denselben nunmehr durch die proximale Öffnung betritt, im Innern desselben entsprechend der Verschlußstelle der Spaltränder die ventrale Wand entlang in gerader Richtung zur distalen Einkerbung verläuft und die Becherhöhle durch dieselbe wieder verläßt. Auf diesem ganzen Verlaufe ist es ron Mesodermzellen begleitet.

Die durch Aneinanderlagerung der Spaltränder zustande gekommene Verschlußstelle der Becherspalte in ihrem mittleren Teile nimmt in den nächstfolgenden Stadien (Abb. $A_{3}$, S. 261, $A_{5}$, S. 262) an Länge zu. Der proximale Rest der Spalte, die proximale Offnung, wird schmäler ( $\mathrm{p} O$ in $A b b . A_{3}$ und $A_{5}$ ) and schließlich spaltförmig (Abb. $\left.A_{b}, S .263, p O ̈\right)$. Gleichzeitig wird der Winkel, den die distale Einkerbung im Pupillarrand bildet, immer spitziger (EK in $A b b . A_{3}$, S. 261), seine Ränder nähern sich einander im distalsten Teile (Abb. $A_{5}$, EK) und legen sich schließlich aneinander, anf diese Weise die Einkerbung zu einem Loche abschließend (Abb. $A_{6}, S .263$, dÖ), durch welches nunmehr das erwähnte Gefäß die Becherhöhle verläßt.

Die proximale, spaltförmige Öffnung wächst nun bei den folgenden Stadien rasch und bedeutend in die Länge (pÖ in $A_{9}, S .265$, $A_{10}$, S. 265, $A_{13}$, S. 269). Thre Ränder sind nach innen zu etwas eingebogen, wodurch die Spalte an der AuBenseite des Augenbechers in eine Einsenkung zu liegen kommt, welche durch diese eingebogenen Pütnder gebildet wird ( $A b b . A_{9}$, S. $265, A_{12}, S .268$ ). Da der nasale Rand stärker eingebogen ist als der temporale und sich anßerdem über den nasalen etwas hinüberschiebt $\left(\mathrm{Abb}, \mathrm{A}_{12}\right.$ ), bekommt die Spalte eine schiefe Richtung: sie durchsetzt den Augenbecher von nasal außen nach temporal innen. Entsprechend der Verschiedenheit hinsichtlich der Einbiegung der Becherränder gegen die Augenbecherhöhle tritt an der Innenseite des Augenbechers der nasale Begrenzungsrand der Spalte als ein deutlicher Wulst hervor, während der temporale sich nicht über das Niveau der Augenbecherinnenfläche erhebt.

Die der proximalen Spalte zunächst gelegenen Abschnitte ihrer $P$ änder zeigen in ihrem histologisehen $B$ a u ein von der äbrigen Retina verschiedenes Verhalten, welches sowohl äuBeres wie inneres Retinalblatt betrifft ( $A b b . A_{12}$, S. 268). Wärend die Zellen des Pigmentblattes im Bereiche der übrigen Retina allmählich abgeplatte worden sind und sich reichliches Pigment in ihnen entwickelt hat, bleiben sie im Bereiche dieser Randteile hoch zylindrisch und frei von Pigment ${ }^{1}$ ), ein Verhalten, welches bei jungen Stadien die Zellen des ganzen Pigmentblattes betrifft. In gleicher Weise bleiben auch die Zellen des inneren Blattes innerhalb dieser Zone der beiden Ränder auf einer frühen Entwicklungsstufe stehen, indem sie hier ihre ursprüng-

$\left.{ }^{1}\right)$ Letzteres tritt auf der Photographie nicht dentlich hervor. 
liche unregelmäßige Anordnung beibehalten, während die Zellen des ganzen übrigen Retinalblattes eine deutliche radiäre Anordnung bekommen. Dieser undifferenzierte Bau beider Spaltränder betrifft den nasalen in einem viel gröBeren Gebiete als den temporalen ( $\mathrm{Abb}, \mathrm{A}_{12}$ ).

Die proximale Spalte wird ihrer ganzen Länge nach von einer Mesodermlamelle durchzogen (Me in Abb. $A_{12}, S .268 ; A_{13}, S .269$ und $A_{14}, S .270$ ), welche mit dem Mesoderm an der Ventralseite des Augenbechers zusammenhängt, die Spalte durchsetzt und sich frei in den Glaskörperraum erhebt. Entsprechend der schiefen Richtung der Spalte erhält auch die Mesodermlamelle eine schräge, von nasal außen nach temporal innen geneigte Lage. Das früher erwabnte GefäB betritt die Becherhöhle am distalen Ende der prox. Spalte und behält diese Durchtrittsistelle auch bei der Verlängerung der Spalte bei ( $G G$ in Abb. $A_{13}, S .269$, und $A_{11}$ : 5.270 ). Im Innerm des Augenbechers verlauft es anfangs entlang der ventralen Wand. In späteren Stadien hebt es sich nach dem Betreten der Becherhöhle alsbald von der ventralen Wand ab und zieht, die gewölbte Wandstelle zwischen proximaler Spalte und distaler Offnung wie eine Sehne überbrückend ( $A b b \cdot A_{13}, G G$ ), zur distalen Offnung, durch welche es die Becherhöhle verläßt.

Die weiteren Schicksale der proximalen Spalte hängen mit der Entwicklung von Sehnerv und Pecten ummittelbar zusammen und so soll daher zunächst anf die Anlage dieser Gebilde eingegangen werden.

Der kurze, hohle Augen becherstiel (S) setzt sich bei den jüngsten Stadien (Abb. $A_{1}$, S. $260, A_{2}$, S. 260) mit annähernd querovaler, später (Abb. $A_{3}, S .26 \mathrm{I}, A_{5}$, \$. 262) mit annätiernd kreisrunder Ansatzfläche am Augenbecher an. Der Ansatzstelle entspricht an der Innenseite des Augenbechers eine grubenförmige Einsenkung, welche dadurch zustande kommt, daß der spitze Winkel, den die in diesem Stadiuxa gradlinig verlaufende ventrale Wand (Abb. $A_{4}, S .261$, VW) mit dem ebenfalls geradlinig aufsteigenden ventralen Teile der proximalen $W$ and an der Innenseite des Augenbechers bildet, im Gebiet der Ansatzstelle des Becherstiels erhalten bleibt (Abb. $A_{4}$, Ei), während er seitlich davon abgerundet wird. Diese Einsenkung liegt unmittelbar proximal und dorsal von der proximalen Spaite (vgl. Abb. 7, S. 263, Ei) und setzt sich direkt in dieselbe fort. Längs der Wand dieser Einsenkang wachsen die ersten sich entwickelnden Nervenfasern (Abb. $A_{4}, S .261, N F$ ) aus der sich differenzierenden proximalen Wand des Augenbechers $\left(A b b . A_{4}, p W\right.$ ), in die ventrale Wand des Sehnerven hinein. Sie bilden hier an der Ventralseite der ventralen Wand des Stieles ein mit fortschreitender Entwicklung an Dicke immer mehr zunehmendes Lager von Nervenfasern. Bei dieser Dickenzunahme der ventralen Wand wird das Becherstiellumen dorsalwärts versehoben, immer mehr eingeengt und verschwindet schließlich völlig in distoproximaler Pichtung unter Zurücklassung eines kleinen, taschenförmigen Restes am Übergange der Becherwand in die dorsale Wand der Opticusanlage. Auf diese Weise wird das Gebiet des Becherstiels allmählich durch Opticusfasern substituiert und auch der genannte Rest des Lumens verschwindet schließlich vollständig.

Im weiteren Verlaufe der Entwicklung wächst die Opticasinsertion in die Lange und ihre Ansatzfläche bekommt die Form eines mit zunehmender Entwicklung immer länger werdenden 
Ovals, welches mit einer Spitze an der proximalen Offnung endigt. Entsprechend der Längenzunahme der Opticusinsertion an der Außenseite des Augenbechers nimmt auch die ihr entsprechende Einsenkung an der Innenseite desselben an Länge zu, wobei sie allmählich seichter wird. Bald erhebt sich aus dieser langgestreckten, seichten Einsenkung ein flacher Wulst (Abb. $A_{10}, S .265$, Pe), welcher hinsichtlich seiner Lage, Richtung und Längenausdehnung an der Innenseite des Augenbechers vollkommen der Sehnerveninsertion an der AuBenseite entspricht. Wie später genauer beschrieben werden wird, besteht diese Vorwölbung aus einer Anhäufung von Gliazellen und stellt die erste Anlage des Pecten dar. Wir haben demnach das Pecten als ein Differenzierungsprodukt der Opticusinsertion zu betrachten und fasse $n$ in Ubereinstimmung mit unserer Darstellung der Entwicklungsverhältnisse bei Podiceps Sehnerveninsertion und Pectenanlage als ,Neuropecten" zusammen.

Die Sehnerveninsertion und das Pecten wachsen nun in den früher beschriebenen undifferenzierten Randteilen (Abb. A $A_{12}$. S. 268) distalwärts vor. Man kann dies bei Verfolgung der Schnittserien daran erkennen, daß dort, wo das Neuropecten zwischen den Spalträndern vorgewachsen ist, eine undifferenzierte Randzone nicht länger vorhanden ist; hier grenzt vielmehr das Neuropecten direkt an die differenzierte Retina, dort, wo sich das Pigmentblatt in das retinale Blatt umschlägt (vgl. Abb. $A_{11}$, S. 267, $A_{15}$, S. 271, A $A_{16}$, S. 272, $A_{17}$, S. 272). Dabei kommt die Sehnerveninsertion in jene Einsenkung zu liegen, welche an der Außenseite des Augenbechers durch die eingebogenen Ränder der proximalen. Spalte gebildet wird, und zwar lagert sie sich hauptsächlich an die nasale Wand dieser Einsenkung an (Abb. $A_{11}$, S. 267 und $A_{16}$, S. 272), während die Pectenanlage hauptsächlich in den Bereich des temporalen Randes zu liegen kommt. Diese schiefe Stellung des Neuropectens ist eine Folge der schiefen Richtung der proximalen Spalte (Abb. $A_{12}$, S. 268), in deren undifferenzierten Randteilen das Neuropecten vorgewachsen ist.

In der beschriebenen Weise wächst also das Neuropecten durch den proximalen Teil der proximalen Öffnung vor, wobei diese im Bereiche des vorgewachsenen Neuropecten zum Verschluß kommt. Dem weiteren ungeteilten Vorwachsen des Neuropectens in distaler Richtung scheint jedoch die die proximale Spalte durchziehende Nesodermlamelle (Me in Abb. $A_{12}, S, 268, A_{13}: S .269$ und $A_{14}, S .270$ ) Widerstand entgegenzusetzen. Wir sehen nämlich, daß das weitere Vorwachsen des Neuropecten nicht mehr wie bisher ungeteilt, sondern in zwei Portionen zu beiden Seiten der Mesodermlamelle vor sich geht (Abb. $A_{17}$, S. 272). Dabei ist die ganze Anlage von außen her so tief in die Spalte hinein eingesenkt, daß die Sehnerveninsertion an der Außenseite der Modelle nicht mehr als Vorwölbung hervortritt, sondern der Innenseite der (differenzierten) Spaltränder anliegt, während die Pectenanlage jederseits der Sehnerveninsertion und den der Becherhöhle zugewendeten Kanten der Spaltränder aufruht. Ähnliche Lageverhältnisse zeigt das Neuropecten in diesem Stadium übrigens schon im distalen Teile der ungeteilten Anlage ( $\mathrm{Abb} . \mathrm{A}_{16}$, S: 272). Auch hier liegt die Sehnerveninsertion (S) tief zwischen den differenzierten Spalträndern eingebettet, so daß sie an der Außenseite kaum mehr als 
Wulst hervortritt, und die Pectenanlage (Pe) liegt der Sehnerveninsertion innen auf und breitet sich seitlich beiderseits ein Stück weit äber die differenzierten spaltränder aus.

Wir haben also in diese $\mathrm{m}$ Stadium (16.5 mm lang) ein Neuropecten vor uns, welches in seine $m$ proximalen Teile einheitlich, im distalen dagegen durch eine Mesodermlamelle geteilt ist.

Es mag vielleicht auffallend erscheinen, daß das Neuropecten bei seinem Vorwachsen distalwärts durch die im Verhälnis zu demselben relativ schwache Mesodermlamelle, geteilt" werclen kann. Zur Erklärung dieser Tatsache könnte man anführen, daß es sich in Wirklichkeit ja nicht um ein "Vorwachsen" des Neuropectens, sondern um ein appositionelles Wachstum der Opticusinsertion in proximodistaler Richtung handelt, welches durch ein Einwachsen von Opticusfasern aus immer weiter distalwärts gelegenen Retinaabschnitten in die undiffe. renzierten Ränder der proximalen Spalte bedingt ist. Diese in zwei Portionen von nasal und von temporal her dem Sehnerven zustrebenden Nervenfasern werden möglicherweise distal durch die Vesodermlamelle zunächst an ihrer Vereinigung gehindert, und auf diese Weise kommt vielleicht die Teilung des distalen Teiles der Opticusinsertion zustande. Und da wir andererseits das Pecten als ein Differentierungsprodukt der Optieuseintrittstelle erkannt haben, so ergibt sich daraus, daß mit einer Teilung dieser auch eine Teilung der Pectenanlage in ihrem distalen Anteile Hand in Hand geht.

Bei der Betrachtung eines Schnittes, der die Region des geteilten Neuropecten senkrecht auf die Richtung der proximalen Spalte durchsetzt (Abb. A, S. 272) das Rekonstruktionsmodell zeigt, daß die Schnitte tatsächlich so fallen - bemerkt man, daß die Neuropectenportion des nasalen Randes (in der Abb. rechts) mächtiger ausgebildet ist als die temporale. Diese Verschiedenheit erklärt sich in der Weise, daß von den von nasal und von temporal her aus der Retina in den Sehnerven einwachsenden Nervenfasern das nasale Bündel kräftiger entwickelt ist als das temporale. Vereinigen sich diese beiden Bündel in der Sehnerveninsertion nicht, sondern ist auch sie nock ein Stück weit geteilt, so muB natürlich ihr nasaler Teil kräftiger sein als der temporale. Andererseits differenziert sich natürlich aus einem größeren Teile der Sehnerveninsertion auch ein größeres Pecten, womit im gegebenen Falle der nasale Teil das geteilten Neuropecten kräftiger sein muß als der temporale.

Die Tatsache, daß der Sehnerveninsertion von nasal her mehr Nervenfasern zugeführt werden als von temporal, steht in Übereinstimmung damit, daß die undifferenzierte Partie des nasalen Spaltrandes, die eine gröbere Anzahl von Nervenfasern aufnehmen soll, ein größeres Gebiet umfaßt als die undifferenzierte Partie des temporalen Randes (vgl. Abb. A 1.2 S. 268), der nur von einer geringeren Anzahl Fasern durchsetzt wird.

Mit der distalwärts fortschreitenden Entwicklung des Neuropectens gelangt die Mesodermlamelle in proximodistaler Richtung zum Verschwinden. In älteren Stadien enthält sie neben dem mehrfach erwähnten, die proximale Spalte in ihrem distalsten Teile passierenden Gefäße noch ein zweites, mehr proximal gelegenes. Beide Gefäße stehen miteinander, soweit wir feststellen konnten, nicht in Zusammenhang. Wenn die Mesoderm- 
lamelle in der angedeuteten Weise in proximodistaler Richtung verschwindet, bleibt das proximale Gefäß zurück und wird zur Arteria basalis pectinis. Die Mesodermlamelle verschwindet nicht in der ganzen Anlage gleichzeitig, sondern zuerst im Pectenteile, später im Opticusteile derselben. In einer gewissen Periode der Entwicklung treffen wir dem entsprechend eine distal geteilte Opticusanlage, aber eine im entsprechenden Gebiete ungeteilte Pectenanlage. Bloß eine von dorsal her einschneidende, ein wenig temporalwärts verschobene Furche markiert nun die distal früher vorhanden gewesene Teilung der Pectenanlage. Noch später verschwindet auch im distalen Teile der Opticusinsertion die trennende Mesodermlamelle sowie die erwähnte Furche an der Dorsalseite der Pectenanlage, so da $B$ schließlich die ganze Neuropectenanlage durchwegs einheitlich geworden ist.

Mit dem Vorwachsen des Neuropecten bis zum distalen Ende der proximalen Spalte gelangt auch das hier eintretende Gefäß zur Atrophie. Ebenso versehwindet der frei durch den Glaskörperraum ziehende Teil des Gefäßes. Dagegen bleibt ein Rest der distalen ôfnung hier aufallend lange bestehen und ist auch an dem ältesten untersuchten Stadium deutlich markiert in Form $z$ weier aneinanderliegender, nach auswarts gewendeter Lippen, an deren Rändern das Pigmentblatt in das Retinablatt sich umschlägt (Abb. A $A_{22}$, S. 277).

Die histologische Differenzierung und die spätere Formentwicklung der Pectenanlage verläuft bei Anas in völlig gleicher Weise wie bei Podiceps und soll daher hier nur in ihren Hauptzügen geschildert werden; im übrigen sei auf die bei Podiceps gegebene Beschreibung verwiesen.

Wir haben im vorhergehenden mehrfach jene Einsenkung an der Innenseite des Augenbechers erwähnt, welche der Ansatzstelle des Becherstiels an der AuBenseite entspricht. ( $\mathrm{Ei}$ in Abb. $\mathrm{A}_{4}$, S. 261, $\mathrm{A}_{7}$, S. 263). Bei jenen Stadien, wo die ersten Nervenfasern sich in der proximalen Wand der Retina entwickeln, bekommen die Retinazellen in dem Bereiche dieser Einsenkung einen eigentümlichen Charakter (Abb. $A_{4}, S, 261$, Ei); das Gewebe erscheint aufgelockert, weist Lücken und Spalten zwischen den Zellen auf, die durch Zellfortsütze überbrückt sind. An der Membr. lim. int. endigen diese Zellen mit deutlichen Radiärfaserkegeln. Sie stimmen in allen ihren Charakteren mit den Müllerschen Stützzellen der Retina überein, und es scheinen nur solche innerhalb dieser Einsenkung vorzukommen. Diese Differenzierung der Retina dürfte den Zweck haben, für die später hier einwachsenden Nervenfasern den Boden zu bereiten, denn wir sehen, daß die ersten in der proximalen Wand der Retina zur Ausbildung kommenden Nervenfasern ihren Weg durch diese Einsen. kung zur ventralen Wand des Becherstiels nehmen. Wir können demnach die Gewebsdifferenzierung der Retina in dieser Einsenkung als ein funktionelles Homologon einer Randschleierbildung betrachten, wenn sie auch in ihrem histon logischen Bau von einer solchen abweicht.

Mit dem Vorwachsen der Opticusinsertionsanlage distalwärts verlängert sich auch, wie wir gesehen haben, die ihr entsprechende Einsenkung an der Innenseite, wobei mit der Vermehrung der einwachsenden Opticusfasern die eigentüm. liche Zellbeschaffenheit daselbst verschwindet. Die Sehnervenfasern werden, 
wie beschrieben, der langgestreckten Opticusinsertion in Form zweier Portionen zugeführt, von denen die gröBere von der Nasalseite. die kleinere von der Temporalseite herkommt. An ihrer Vereinigungsstelle befindet sich zwischen diesen beiden Portionen eine langgestreckte Einsenkung, welche nun der beschriebenen Einsenkung an der Innenseite des Augenbechers entspricht und sich direkt in die proximale Spalte fortsetzt. In diese Einsenkung schieben sich $n$ un a us der Opticusinsertion Gliazellen vor, füllen sie aus und bilden eine leichte Vorwölbung von langgestreckter Gestalt, die sich nun aus der besagten Einsenkung erhebt (Abb. $A_{10}$. $S$. 265). Die Zellen dieser Vorwölbung entsprechen in allen ihren Qualitäten den Gliazellen des Opticus, und es kann bei Verfolgung der Ausbildung dieser Vorwölbung kein $Z$ weifel daruber herrschen, daB das Pecten sich in seiner exsten Anlage aus den Gliazellen der Sehnerveninsertion differenziert.

Im Anfange läBt sich die Pectenanlage von der benachbarten, kernhaltigen Opticusinsertion nur unscharf abgrenzen (Abb. $A_{11}$, S. 267). Mit dem Einwachsen von immer zahlreicheren kernfreien Fasern wird die Abgrenzung der Pectenanlage von der Sehnerveninsertion immer schärfer (Abb. $A_{15}, S .271 . A_{16}$ und $A_{17}$. S. 272). Dabei wächst die Pectenanlage in allen Dimensionen, und aus der anfangs flachen Vorwölbung wird allmählich ein immer höher werdender Grat (Pe in Abb. $A_{11}$, S. $267, A_{15}$, S. 271, $A_{16}$, S. 272, $A_{20}$, S. 275). Entsprechend dex schiefen Richtung der Spalte, in deren Rändern das Neuropecten vorwächst, bekommt dieser Grat eine temporalwärts geneigte Lage und kommt dabei mit seiner Basis teilweise auf den temporalen Spaltrand zu liegen ( $\mathrm{Abb} . \mathrm{A}_{11}$ ).

Innerhalb der Pectenanlage kommt es zu einer Differenzierung der Zellen insofern, als die Zellen an der Oberflache sich epithelartig anzuordnen beginnen und eine dichtere Lage bilden, während die Zellen im Innern der Anlage eine mehr unregelmäßige Form haben und locker liegen (Abb. $A_{11}$, S. 267, $A_{15}$, S. 271). Zu einer zentralen Hohlraumbildung wie bei Podiceps kommt es indessen bei Anas nicht.

Im Bereiche des geteilten Neuropecten haben wir histologisch im wesentlichen die gleichen Verhältnisse vor uns wie in der ungeteilten Anlage.

Mit der weiteren Höhenzunahne des Pecten kommt es innerhalb desselben zu einer weiteren Differenzierung $\left(\mathrm{Abb}, A_{20}, S .275\right)$ : die dorsale, frei in den Glaskörperraum hineinragende Partie desselben besteht nahezu ausschließlich aus den epithelialen Wandzellen. Diese dorsale Partie sitzt einer basalen, der Opticusinsertion aufgelagerten Partie auf, die am Querschnitt eine etwa dreieckige Form hat und sich keilförmig zwischen die von nasal und von temporal her kommenden Opticusfasem einschiebt. Auch diese Partie enthält epitheliale Zellen an ihrer Oberflache, im Innern dagegen relativ locker liegende Zellen von uniegelmäßiger Form, wie sie in früheren Stadien die ganze Anlage erfüllten. Mit dem Versehwinden der Mesodermlamelle, welche in einem gewissen Stadium sich zwischen die beiden Portionen des Neuropecten einschiebt, vereinigen sich die beiden Portionen, und wir haben es zum Schlusse mit einer einheitlichen Anlage zu tun, die ihrer ganzen Ansdehnung nach den gleichen oben beschriebenen histologischen Bau aufweist.

Als Endausgang der beschriebenen Differenzierungsvorgänge 
resultiert demnach bei tnas ein Stadium, welches mit dem beschriebenen altesten Entwicklungsstadium von Podiceps vollkommen übereinstimmt. Ein einheitliches Neuropecten, welches in den Rändern der früheren proximalen Spalte bis an ihre Ende distalwärs vorgewachsen ist, wodurch sich diese offenbar so verdickt haben, daß sie zur Aneinanderlagerung und Verschmelzung kamen und die Spalte verschlossen wurde. Entsprechend der schiefen Richtung in welcher die proximale Spalte die Becherwand durchsetzt, hat auch das vorgewachsene Neuropecten cine schräge, von nasal a 3 en nach temporal innen geneigte Stellung, so daß sein innerer Teil, die Pectenanlage, ein wenig temporalwärts geneigt ist, während sein äuBerer Teil, die Sehnerveninsertion, der nasalen Wand der Furche zwischen den früheren Rändem der proximalen Spalte anliegt. Das Neuropecten nimmt also bei Anas aus den gleichen Gründen wie bei Podiceps die gleiche schiefe stellung ein.

\section{Passer domesticus.}

Stadium 1. $3,3 \mathrm{~mm}$ lang.

Augenbecher ausgebildet. Pigmentblatt aus hohen, zylindrischen. völlig unpigmentier. tein Zellen bestehend, welche gegen den Becherstiel zu an Höhe zunehmen. Sehtentrikel gröBtenteils versei: wunden, bis auf einen kleinen Rest im dorsalen Pupillarrand und einem gröBeren in der Ungebung der Recherstielinsertion. Auflockerung der Zellen an der proximalen Retinalwand (beginnende Randschleier bildung). Linse ein Blisscher mit einer dickeren hinteren und einer dünneren vorderen Wand. Becherstiel mit weit offenem Lumen.

Rekonstruktionsmodell ( $125 \times)$ : A ugenbecher mit weit offener Bechers palte, welche sich gegen die Pupillaröffnung erweitert und ohne scharfe Grenze mit divergierenden Rändern in dieselbe übergeht. Ventrale Wand ganz kurz, gestreckt zur Pupillaroffnung verlaufend. Dorsale Wand gegen die Pupillaröffnung hin umgebogen, wodurch diese ventralwärts dezentriert erscheint. Becherstiel kurz, plump und völlig hohl, an der Grenze zwischen ventraler und proximaler Wand mit etwa querovaler Ansatzfläche am Augenbecher inserierend. In der Spalte ein kurzes Gefäß, welches mit dem Gefäßplexus zusammenhängt. der sich ventral von Augenbecher und Becherstiel ausbreitet. Dem Gefäße folgen, wie die Schnittbilder zeigen, Mesodermzellen in den Augenbecher hinein.

Stadium 2. $5.1 \mathrm{~mm}$ lang.

Zellen des Pigmentblattes im allgemeinen wesentlich flacher als vorher. Sie enthalten spärliches Pigment. In der Gegend der früheren Spalte ist jedoch die Differenzierung des Pigmentblattes nicht weiter fortgeschritten. Hier sind die Zellen desselben noch hoch wie früher und frei von Pigment. Retina mit Randschleier im ventralsten Teile der proximalen Wand, sonst noch undifferenziert. Linse: Linsenfasern entwickelt. Sie bilden einen in das Linsenlumen vorspringenden Wulst, der das Lumen bedeutend einengt. Becherstiel noch völlig hohl.

Rekonstruktionsmodell (125x): Ventrale Wand gewölbt und etwas gegen die Pupillaröffnung hin eingebogen, ebenso wie die beiden Seitenwände. Die Einbiegung der dorsalen Wand ist aber immer noch am stärksten, wodurch die Pupillenöffnung auch hier noch ventralwärts dezentriert ist. Die Becherspalte ist in ihrem mittleren und in ihrem distalen Anteilo verschlossen. Als ihre Reste zurüclsgeblieben sind $z$ wei Offnungen: eine proximale, die unmittelbar vor der Insertionsstelle des Becherstiels liegt und dieForm einer ganz kurzen $S$ palte hat, und eine distale, unweit des Pupillarrandes gelegene, die ein kleines Loch darstellt. Zwischen beiden Öffnungen rerläuft an der Außen- und an der Innenseite des Augenbechers je eine Furche, welche der Aneinanderlagerungszone der ursprünglichen Becherspaltränder entsprechen. Der nasale Rand der äuBeren Furche ist breiter und stärker vorgewölbt als der 
temporale. Becherstiel läuge: und schlanker als vorher, noch völig hohl. Seine Ansatzstelle am Augenbecher ungefahr von rundlicher Form, jedoch nicht scharf rom Augenbecher abgrenzbar. Thr entspricht an der Imnenseite des Augenbechers eine Einsenkung, die ebenfalls rundliche Form bat. Bei dem Verschluß der Becherspalte wird das Gefäf zum Teile in die Augenbecherhöble aufgenommen, $s o$ daB es nummehr, von Mesodermzellen begleitet, den Augenbecher durch die proximale Uftnung betritt, innen in der der VersehluBstrecke der Becherspaltrïnder entsprechenden Furche Feriänt whl den Augenbecher durch die distale Ufinung verläßt.

\section{Stadium 3. $7 \mathrm{~mm}$ lang.}

Zellen des Pigmentblatts yon kubischer Gestalt und stärker pigmentiert als vorher. Sehventrikel großtenteils eine enge Spalte. Etwas weiter ist develbe nur in der ventralen Wand

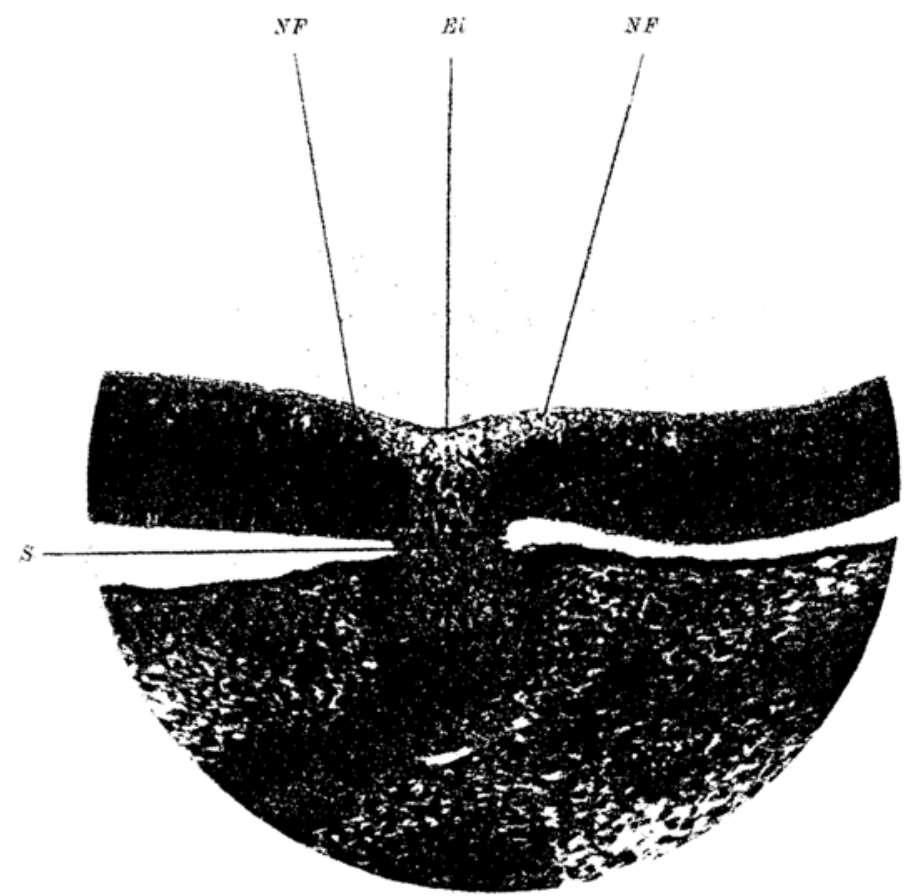

Abi. $\left.\mathrm{Pa}_{1}{ }^{1}\right)$ : Photographie eines quer auf die Längsrichtung der anmittelbar proximal von der proximalen Spaltöfnung gelegenen Einsenkung fallenden Śchnittes ron einem $8,7 \mathrm{~mm}$ langen Enbryo von Passer dom. Vergr. 168/1.

nahe den fruheren spalträndern und an der Insertionsstelle des Becherstiels, wo er sich dirckt in das Lumen des Becherstiels fortsetzt. Randschleierzone mit noch späxlichen Nervenfasern im ventralen Teile der proximalen Retinalwand und an der ventralen Wand des Becherstiels, (ler noch völig hohl ist. Die ventrale Wand des Becherstiels ist dadurch der dorsalen gegenüber relativ verdickt und sein Lumen dorsalwärts verlagert. Linse mit hohen Linsenfasern und einem Lumen in Form einer noch ziemlich weiten spalte.

Rekonstruktionsmodell (125x): Pupillaröffnung ventralwärts dezentriert wie bei den früheren Stadien. Die Insertion der Sehnervenanlage, welche dem rorigen Stadium gegenüber in proximodistaler Richtung velïngert ist, wird durch eine in der Fortsetzung der proximalen Spalte proximalwärts verlaufende Furohe distal in zwei Teile geteilt, von denen der nasale ganz bedeutend gröBer ist als der temporale. Diese beiden T eile ge ben ohnescharfe Grenzein die Rảder der proximalen Offnungüber, welche hier dem vorhergehenden Stadium gegenuber bedeutend verlängert und zu

1) Enklärung der Abkuirzungen am Schlusse der Arbeit (S. 342). 
286 C.Lindahl und A. Jokl: Cber den Terschlol der fötalen Augenhecherspalte.

einer langen, schmalenspaltegeworden ist. Wir werden sie daher im folgenden ats "proximale Spalte" bezeichnen. Der nasale Rand tritt als deutlich ausgesprochener Wulst hervor, in den sich, wie gesagt, die stärkere nasale Hälfte der Opticusinsertion ohne scharfe Grenze fortsetzt. Der temporale Rand ist mehr flach. Entsprechend der Formation ihrer Ränder erhalt die proximale Spalte eine schiefe Richtung durch die Becherwand: sie alurchsetzt dieselbe ron aasal a uBen nach temporal innen. Zwischen proximaler Spalte und rlistaler Öfanng verläuft eine Furche. Distale Offnung wie fruher ein kleines Loch, unweit des Pupillartindes gelegen, weleher hier za beiden seiten desselben etwas verdickt erseheint.

Der Ansatzfläche der Sehnervenanlage an der Außenseite entsprechend eine etwos langgestreckte Einsenkung an der Innenseite, die sich direkt in die proximale Spalte fortsetzt. Der nasale Spaltrand auch an der Innenseite etwas stärker vortretend als der temporale. Eine deutliche Furche zwischen proximaler Spalte und distaler Öffnung auch in diesem Stadium.

Das erwähnte GefüB (in die Rekonstrulition nicht mit aufgenommen) kommt zunächst in die beschriebene, das distale Ende des Sehnerven teilende Furche zu liegen und verlauft in dieser zur proximalen Spalte, durchsetzt diese, von Mesodermzellen begleitet, in schiefe: Richtung und gelangt auf diese Weise in die Becherhöhle. Hier lagert cs sich der beschriebenen Furche an der Innenseite des Angenbechers zwischen proximaler Spalte und distaler Öffnung ein, zieht in derselben zur distalen Offnung und verläBt daselbst die Becherhöhle.

Sonst zeigt das histologische Studium dieses Objekts eine sehr deutliche Auflockerung der Zellen in proximalen Teile der genannten Einsenkung ( $\mathrm{Ab} . \mathrm{Pa}_{\mathrm{i}}$, Ei). Fs finden sich hier nur spärliche Zellen. Diese lassen weite Lücken zwischen sich frei und endigen an der Membr. lim. int. mit deutlichen Radiärfaserkegeln. Im Gebiete der Becherspalte sind die Zellen des Pigmentblattes innerhalb einer der Spalte zunächst gelegenen Zone besonders hoch. Diese Zone betrifft den nasalen Rand in größerer Ausdehnung als den temporalen.

Stadium 4. $7,6 \mathrm{~mm}$ lang.

Pigmentblatt flach, stark pignentiert, mit Ausnahme der Gegend der proximalen Spalte (s. später). Differenzierung der Retina auf die Ausbildung der Opticusfaserschicht in der Umgebung der Sehnerveninsertion beschränkt. Die Xervenfasem ziehen zur ventralen Wand des Becherstiels, die dadurch verdickt wird. Dabei wird das Becherstiellumen, welches noch seiner ganzen Länge nach vorhanden ist, dorsalwiirts verlagert. Ventrale Wand relativ dicker und ihr Lumen relativ enger als im rorigen Stadium. Linse mit im Quersehnitt sehmalsichelförmigem Lumen.

Rekonstruktionsmodell (125 X).

A ußenseite: Das in die Rekonstruktion mit aufgenommene Endstiock des Opticus ist stark nasalwärts umgebogen. Die Insertionsfläche des Sehnerven dem früheren Stadium gegenüber bedeutend verlängert. Sie bildet ein langgestrecktes Oval, dessen distales, sich verschmälemdes Ende ohne scharfe Grenze in den nasalen Rand der proximalen Spalte übergeht. An ihrer temporalen Seite trägt die Sehnerveninsertion eine tiefe Furche, welche sie von der benachbarten Augenbecherwand trennt und die sich distalwärts unwittelbar in clie in gleicher Richtung verlaufende proximale Spalte fortsetzt. Auch an cler nasalen Seite der Sehnerveninsertion befindet sich eine derartige, die Sehnerveninsartion von der Becherwand abscheidende Furche, doch ist dieselbe bedeutend seichter und verflacht distalwärts. Von der dem früheren Modell gegenüber ebenfalls verlängerten proximalen Spalte springt der temporale Ranci etwas stärker vor als der nasale. Dies beruht darauf, daß die der Spalte zunäehst gelegenen Partien des nasalen Randes stärker gegen das Augenbecherinnere zu eingebogen sind als die entsprechenden Pandpartien an der temporalen Seite. Durch diese Formation der Ränder bekommt die proximale Spalte wie früher eine schiefe Richtung von nasal außen nach temporal innen. Sie setzt sich an der Außenseite distalwärts in eine Furche fort, welche in derselben Richtung weiter distalwärts bis zur distalen Öffnung verläuft und sich äber diese hinaus bis zum Pupillarrand fortsetzt. Der letztere ist ein wenig eingekerbt und zu beiden Seiten dieses Endstückes der Furche wulstig verdickt. Die erwähnte Furche entspricht offenbar dem distalsten, verschlossenen Teile der Augenbecherspalte. Die distale Öffnung liegt wie früher unweit des Pupillarrandes und stellt ein kleines Loch dar. 
Innenseite: (Abb. Pa.). Eine der langen Sehnerveninsertion an der AuBenseite entsprechende, ebenfalls in proximodistaler Richtung stark verlängerte Finsenkung (Ei), die in der gleichen Richtung verläuft wie die Sehnerveninsertion. Sie endigt eine Strecke weit proximal von der proximalen Spalte und gibt einer Arhöhung Raum, welche unmittelbar in (ten nasalen Rand der proximalen Spalte übergeht, welcher entsprechend seiner stärkeren Einbiegung gegen die Augenbecherhöhle zu stärker vorspringt als der temporale $(n W)$.

Aucb an der Innenseite eine die proximale Spalte $(p O)$ und die distale Öffnnng verbindende Furche. (An der Abbildung von dem Gefäbe [GG] eingenommen.) Dieses Gefäb zieht zunaichst an der AuBenseite des Augenbechers in der erwithnten Furche an der temporalen Seite der Sehnerveninsertion und verläuft aut diesen Wege zur proximalen Spalte. Es tritt aber nicht sofort in dieselbe ein, sondern verläuft weiterhin an der Außenseite des Augenbechers in der gleichen Richtung weiter und betritt die Recherhöhle erst durch das distale Ende der proximalen Spalte. Dann lagert es sich an der Innenseite des Augenbechers in die erwahnten Furche zwisehen proximaler Spalte und distaler (offnung ein (Abb. $\mathrm{Pa}, \mathrm{GG}$ ) und verläbt durch die letztare wieder die Becherhöhle.

Ein histologisches Schnittstudium des vorliegenden Objektes lehrt folgendes:

Die hei der Modellbeschreibung erwähnte, der Sehnerveninsertion auben entsprechende. Einsenkung an der Innenseite des Augenbechers liegt an der Vereinigungsstelle zweier Nervenfaserbüdel, welehe rou nasal und temporal her aus der Retina sich sammeln und zum Sehnerven ziehen. Bei ihrem Verlaufezum sehnerven benutzen diese Fasern wls Passage die Ründer der proximalen spalte, welche dabei offenbir verdiekt werden und zur Versehmelzung kommen. Wir finden niimlich die proximale spalte hier in ihrem proximalen Anteile ge. sehlossen. Entsprechend dem Zuwachsen neuer Nervenfasern, welche aus immer weiter distal gelegenen Teilen der Retina kommen und sich auf die schon gebildeten auflagern, ist auch der an der Aufenseite des Augenbechers wulstförmig hervortretende Teil der Sehnerveninsertion distalwärts in das Spaltgebiet vorgewachsen. Vergleicht man das Rekonstruktionsmodell des vorliegenden Stadiums mit dem des zuletzt beschriebenen, so finden wir, daß von den beiden durch eine Furche unvollständig getrennten Portionen des distalen Teiles des Sehnerven hier nur die nasale vorhanden zu sein scheint, so dals jene Furche, die früher die Sehnerveninsartion distal unvollständig in zwei Teile teilte, hier dieselbe temporalwärts zu begrenzen scheint. Wie die Schnittbilder zeigen,

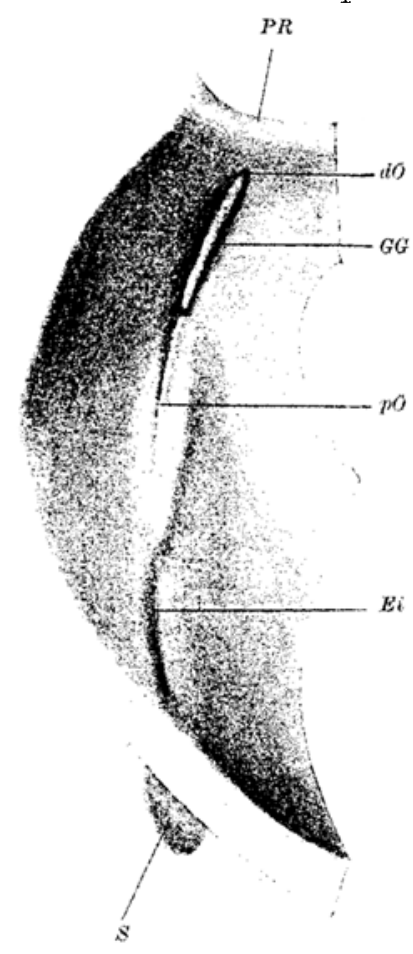

Abb. $1^{3} a_{2}^{1}$ ): Rekonstruktionsmodell $(195 x)$ eines Teiles der ventralen Wand des Augenbechers eines 7,6 mm langen Fimbryos you Passer dom., von innen her geseben. $4 / 9$ d. nat. Gr. ist jedoeh die Opticusinsertion auch hier in ihrem distalen Anteile durch jene Furche in zwei Teile geteilt; der temponale ist jedoch so schwach, daB er am Modell nicht als Wulst hervortritt.

Wir müssæn also diesberüglich unseren am Modell erhobenen Befund auf Grund des Schnittbildes dahingehend modifizieren, dab diese Furehe distal in Optieus selbst liegt und in demselben eine weitans größere nasale Partie von einer kleineren temporalen scheidet. Was uns am Modell als Wulst der Opticusinsertion entgegentritt, ist in der Tat nur ihr größerer nasaler Abschnitt. Im distalen Teile hat die Sehnerveninsertion auch einen kleineren temporalen Abschnitt, weloher aber so unbedeutend ist und der Becherwand so dicht anliegt, daB er sich am Modell nicht abhebt. Die Verwölbung, die wir am Modell an der Innenseite un-

1) Erklärung der Abkürzıngen am Schlusse der Arbeit (S. 342). 
mittelbar proximal ron der proximalen Spaltöffnung gefunden haben, entsteht dadurch, daß der nasale Rand stark nach innen zu eingebogen ist. Wachsen nun Sehnervenfasern in die Spaltränder ein und verschließt sich dabei die Spalte, so bleibt eine Vorwölbung zurück, welche sich, wie das Modell zeigt, direkt in den eingebogenen, die Spalte nasalwärts begrenzenden Rand fortsetzt.

Schnittbildor durch den offenen Teil der proximalen Spalte lassen ihre auch am Modell hervortretende sehiefe Richtung von nasal auß $\$$ n nach temporal innen dentlich erkemen. Der nasale Rand der proximalen Spalte ist bedeutend stärker nach innen zu eingebogen als der temporale. Der temporale Rand schiebt sich ein Stück weit über den eingebogenen Teil cles nasalen Randes hinüber. Diese Formation ihrer Ränder bedingt im wesentlichen die schiefe Stellung der Spalte. Das Pigmentepithel in der unmittelbaren Nähe des nasalen Spaltrandes zeigt in der nïchsten Nähe der Spalte anffallend hohe Zellen. Auf diese Erscheinung soll später zurückgekommen werden.

Ein Stadium von $8,2 \mathrm{~mm}$ L ̈̈nge, welches ebenfalls rekonstruiert and im Schnitt untersucht wurde, zeigte mit dem beschriebenen stadium volikommen ükereinstimmende Verhältnisse, und es soll daher auf dasselbe nicht näher eingegangen werden.

Stadium 5, $10,2 \mathrm{~mm}$ lang.

Zellen des Pigmentblattes flach und reich an Pigment (iber ihre besondere Beschaffenheit im Gebiet der Ründer der proximalen Spalte s. später). Sehventrikel größtenteils

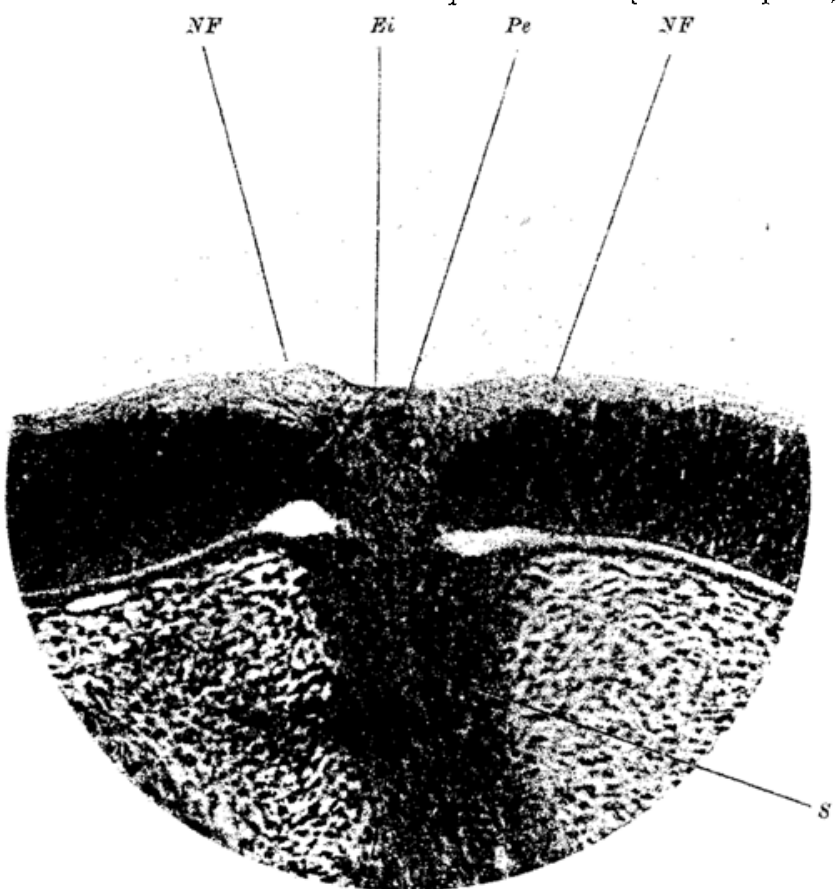

Abb. Pa ${ }_{3}^{1}$ ): Photographie eines Schnittes durch den proximalsten Teil der Anlage des Sehnerven und des Pecten von einem

$10.2 \mathrm{~mm}$ langen Embryo von Passer dom. Vergr. 168!1. verschwunden. Nur ein kleiner Rest noch in der Cmgebung der Becher. stieleintrittstelle vorhanden, der direkt in das Lumen des Becherstiels ubergeht. Dieses ist hier im distalen Teile des Becherstiels relativ weit, verengt sich dann in seinem mittleren Teile sehr be. deutend und wird proximalwärts gegen das Gehirn zu wieder weiter. Der Bocherstiel enthält die Nervenfasern zu einem mächtigen Bünctel gesammelt in seiner ventralen Wand, welohe daduroh bedeutend vardickt wird, so $\mathrm{daB}$ das Stiellumen clorsalwärts verlagert ist. Im Bereiche der Retina hat sich die Nervenfaserschicht weiter über die proximale Wand ausgebreitet. Die übrige Retina ist noch undifferenziert, die Zellen in Bereiche derselben zeigen cine radiäre Anordrung.

Uber die Beschaffenheit der Retina an den Spaltrïndern s. später.

Rekonstraktions modell (125x).

A uBenseite: Das in die Pekonstruktion mitaufgenommene Stück des Sehnerven ist nasalwärts umgebogen. Sehnerveninsertion in ihrem distalen Teile durch eine Furrhe unvoll.

1) Erklïrung der Abktirzuncen am Schlusse der Arbeit (S. 342). 
ständig in zwei Hälften geteilt, von denen die nasale bedeutend kräftiger ist als die temporale. Die besagte Furche setzt sich direkt in die proximale Spalte fort, wclche dem zuletzt beschriebenen Stadium gegenüber verlängert erscheint, während die beiden Teile des Opticus in die entsprechenden, eingebogenen Spaltränder ohne scharfe Grenze iibergehen. Zwischen proximaler Spalte und distaler Offnung eine Furche, die sich über die distale Öffnung hinas bis zum Pupillarrand fortsetzt.

In nenseite: Der Sehnerveninsertion entsprechend eine langgestreckte, seichte Einsenkung. Aus derselben erhebt sich eine gratartige Vorwölbung, welche in proximodistaler Richtung an Höhe bis zur proximalen Spalte zunimmt. Hier geht sie ohne Grenze in die wulstförmig verdickten Ründer der proximalen Spalte über. Diєser Grat stellt, wie die histologische Untersuchung des Objekts zeigt. die erste Anlage des Pecten dar. Näheres über den histologischen Ban dieser Bildung s. später.

Zwischen proximaler Spalte und distaler Öfnung eine seichte Furche. Distale Öffnung ein kleines Loch nabe dem Pupillarrand. Uber sie hinaus setzt sich die erwïhnte Furche his zum Pupillarrand fort. Die proximale Spalte ist von einer schwachen Mesodennlamelle durchzogen, welche sich jedoch nur stellenweise ein ganz kurzes Stuick weit frei in den Glaskörperraum erstreckt und im allgemeinen auf den unmittelbaren Spaltbereich beschrïnkt bleibt. Das erwähnte GefäB lagert sich zunächst in die Furche zwischen den beiden Portionen der Sehnerveninsertion ein und zieht so zur proximalen spalte. Fis betritt dieselbe jedoch

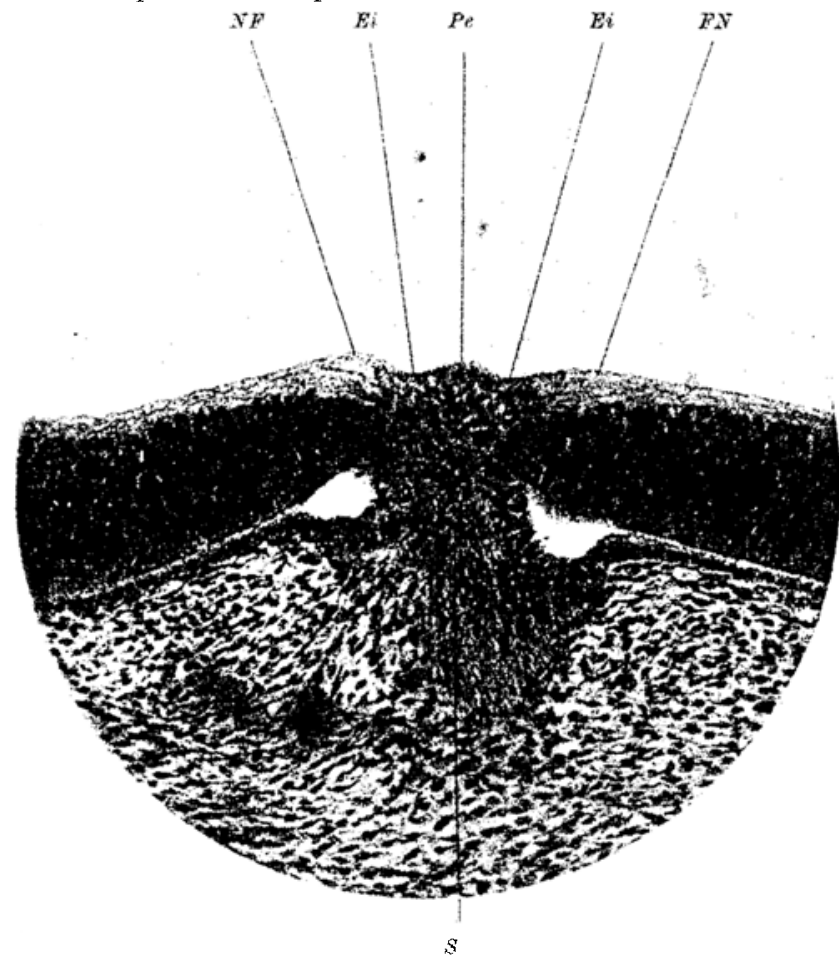

Abb. $\left.P_{a_{4}}{ }^{1}\right)$ : Photographie eines Schnittes durch die gleichen Gebilde desselben Stadiums (Passer 10,2 mm). 8 Schnitte weiter distal als $P_{3}$. Vergr. $168 / 1$. nicht sofort, sondern zieht in der Furche zwischen ihren etwas eingebogenen Ründern weiter. Erst nabe ihrem distalen Ende passiert es die proximale Spalte in schiefer Richtung, gelangt so an die Imnenseite des Augenbechers, lagert sich hier der Furche zwischen proximaler Spalte und distaler offnung ein und verläBt durch die letztere den Augenbecher wieder.

Das histologische Sehnittbild des vorliegenden Objektes ergibt folgende Verhältnisse:

Die Sehnervenfasern der Retina ziehen wie früher in Form zweier Bündel von nasal und von temporal her zum Sehnerven. Die kernlose Nervenfaserschicht dex Retina wird dadurch gegen den Opticus zu immer breiter. Wo die beiden Nervenfaserbündel bei ihrem Einstrahlen in die Opticusanlage sich vereinigen, da entsteht zwischen ihnen eine Einsenkung, die entsprechend der langen Finstrahlungszone in die langgestreekte Sehnerveninsertion ebenfalls langgestreckt ist. Auf diese Weise entsteht die früher beschriebene, an der Innen-

1) Erklärung der Abkürzungen am Schlusse der Arbeit (S. 349). 
290 C. Lindahl and A. Jokl: Cher den Versehluk der fötalen Augenbecherspalte,

saite des Modells der Sehnerveninsertion anßen entspreehende Einsenkung. Während die Nervenfaserbündel im Bereiche der Retina volkommen kernfrei sind (Abb. $\mathrm{Pa}, \mathrm{NF}$ ), befinden sich im Bereiche der Opticusanlage (S) zahlreiche Kerne zwischen den Nervenfasern, die offenbar Gliazellen angehören. Diese Gliazellen der Opticusanlage haben sich proximal ents prechend der Ansatzotelle der Sehnerven. anlage $z$ wischen den kernlosen Nervenfasern gegen die erwähnte Einsenkung (Ei) hin yorgeschoben. Weiter distal erreichen sie den Grund dieser Einsenkung und wölbenderselben vor, sodaB sichnun mehrauscher Einsenkung eineleichte Vorwölbung eriebt $\left(A b b\right.$. $\left.\mathrm{Pa}_{4}, \mathrm{Pe}\right)$. Diese Vorwölbung wird anfangs von Nervenfasern gebildet, welche durch die aus der Sehnerveninsertion sich vorsehiebenden $Z \in l l e n$ gegen das Becherlumen zu hügelförnig vorgewölbt sind. Noch weiter distal haben sich die Gliazellen selbst bis zur Oberfläche vorgeschoben und bilden einen kleinen Hügel, welcher in die Becherhöhle $z u$ hineinragt $\left(\mathrm{Abb} . \mathrm{Pa}_{\mathbf{4}}, \mathrm{Pe}\right)$. Es besteht also die Pectenanlage bei Passer wie bei den anderen Arten aus einem von der Sehnerveninsertion sich gegen die Becherhöhle vorschiebenden Wulste von Gliazellen. Dieser liegt proximal noch innerhalb der Opticusinsertion und wölbt die Innenfläche der Retina etwas vor, wäh end er weitel distal frei in den Glaskörperraum hineiniagt Entsprechend der Tatsache, daßsich auch bei Passerdie Pectenanlage aus der Sehnerveninsertion herausdifferenziert, fassen wir in Cuber-

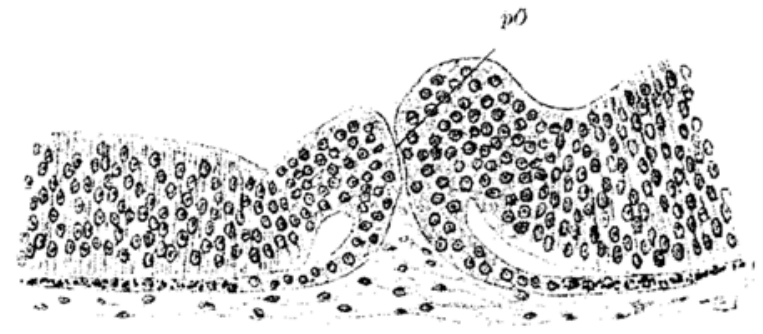

Abb. $\left.\mathrm{Pa}_{5}{ }^{1}\right)$ : Zeichnung eines Schnittes durch die proximale Spalte mit ibren undifferenzierten Randteilen von einem 10,2 mm langen Embryo von Passer dom. Vergr. $200 / 1$; auf $9 / 10$ verkleinert. einstimmung mit den vorher beschriebenen Arten auch hier Sehnerveninser. tion und Pecten $z u$ einem einheitlichen morpholo. gischen Begriffe $z$ usammen und nennen sie mit einem gemeinsamen Namen ,Nenropectent.

Unser Modell zeigt, daß die beiden Portionen der Sehnervenlanlage auBen und die Pectenanlage innen distalwärts ohne scharfe Grenze in die Pünder der proximalen Spalte ibergehen. Wie aus den Schnittbildern hervorgeht, erfolgt dieser Übergang in eine der Spalte zunächst gelegene Zone ihrer eingebogenen $R$ änder, welche sich der übrigen Retina gegenüber durch eine besondere histologische Beschaffenheit a uszeichnet ( $A b b$. $P_{a_{5}}$ ). Die Zellen des Pigmentblattes sind hier, ebenso wie wir dies schon bei den früher bese hriebenen Stadien hervorgehoben haben, im Gegensatz zu den flachen, stark pigmentierten Zellen des übrigen Pigmentblattes von hoch zylindrischer Form und völlig frei von Pigment. Die Zellen des retinalen Blattes in dieser Zone zeigen eine unregelmäßige Anordnung gegeniiber den radiür angeordneten Zellen der ïbrigen Retina und etwas hellere Kerne. Es sind also die Zellen dieser Pandzone ihrer histologischen Beschaffenheit nach a uf einem jungen Entwicklungsstadium stehen geblieben und mit zunehmendem Alter nicht in denselben DifferenzierungsprozeB wie die Zellen des Pigment-und des Retinablattes eingegangen. Diese undifferenzierte Randzone umfaBt am nasalen Rande ein größeres Gebiet als am temporalen, wie auch die Retina selbst nasit dicker ist als temporal.

Es ist diese undifferenzierte Randzone, in welche das Neuropecten distalwärts ohne scharfe Grenze übergeht. Diese Randzone dient offenbar als Bahn für die distalwäts vorwachsende Opticusanlage und das sich aus ihr differenzierende Pecten. Denn in dem Bereiche jener Zone, wo das Neuropecten in den Spaltbereich distalwärts vorgewachsen ist und die Spalte sich geschlossen hat, finden wir dasselbe direkt an die differenzierte Retina grenzen. Eine undifferenzierte Randzone ist hier nicht mehr rorhanden, sie ist offenbar in das vorwachsende Neuropecten aufgegangen.

1) Erklärung der Abkürzungen am Schlusse der Arbeit (S. 342). 
Stadium 6. $13 \mathrm{~mm}$ lang.

Pigmentblatt überall mit flachen, reichlich Pigment enthaltenden Zellen (über den Bereich der Spaltränder s. später). Zwischen Retinalblatt und Pigmentblatt ein offenbar sekundär durch Abhebung entstandener schmaler Spaltraun. In der Retina hat sich die Nervenfaserschicht weiter ausgebreitet, sonst aber ist ihre Differenzierung nicht weiter fortgeschritten. Sehnervenlumen bis auf eine kleine taschenförmige Ausstülpung, welche sich ils Fortsetzung des Spaltraumes zwischen Pigmentblatt und Retinalblatt in das distale Sebnervende hinein erstreckt, vollkommen verschwunden. Mit Ausnahme der Wand dieser Tasche, welche noch von epithelialen Zellen gebildet wird, besteht die ganze Opticusanlage nunmelr ausschließlich aus Neurofibrillen mit zwischen diesen liegenden Gliazellen. $(125 \times)$

Rekonstruktionsmodell

A ußenseite: Das distale, in rlie Rekonstruktion mitaufgenonmene Endstück des Opticus stark nasalwïrts abgt bogen. Sehnerveninsertion clem früheren Stadium gegenüber sehr bedeutend verlängert; die Inser tion flache stellt ein langgestrecktes, distal mit einer $s \in$ hr lang ausgezogenen Spitze endigendes Oval dar. Der distale Teil der Sehnerveninsertion liegt in einer Ein senkung, welche offenbar durch die stark eingebogenen Ränder der proximalen Spalte gebildet wird. Sie liegt hauptsächlich der nasalen Wand dieser Einsenkung an. Nasul und temporal begrenzt sie je eine Furche, von welchen die temporale bedentend tiefer ist und sich direkt in die proximale Spalte fortsetzt, welche in derselben Richtung verliiuft wie diese. Die Sehnerveninsertion reicht mit ihrer distalwärts ausgezogenen Spitze bis an die proximale Spalte heran. Letztere ist dem früheren Stadium gegenüber ebenfalls verlängert und liegt in cler Tiefe einer Einsenkung, welche dureh ihre eingebogenen Rinder gebildet wird. Zwischen proximaler Spalte und distaler Offnung entsprechend dem hier geschlossenen Teile

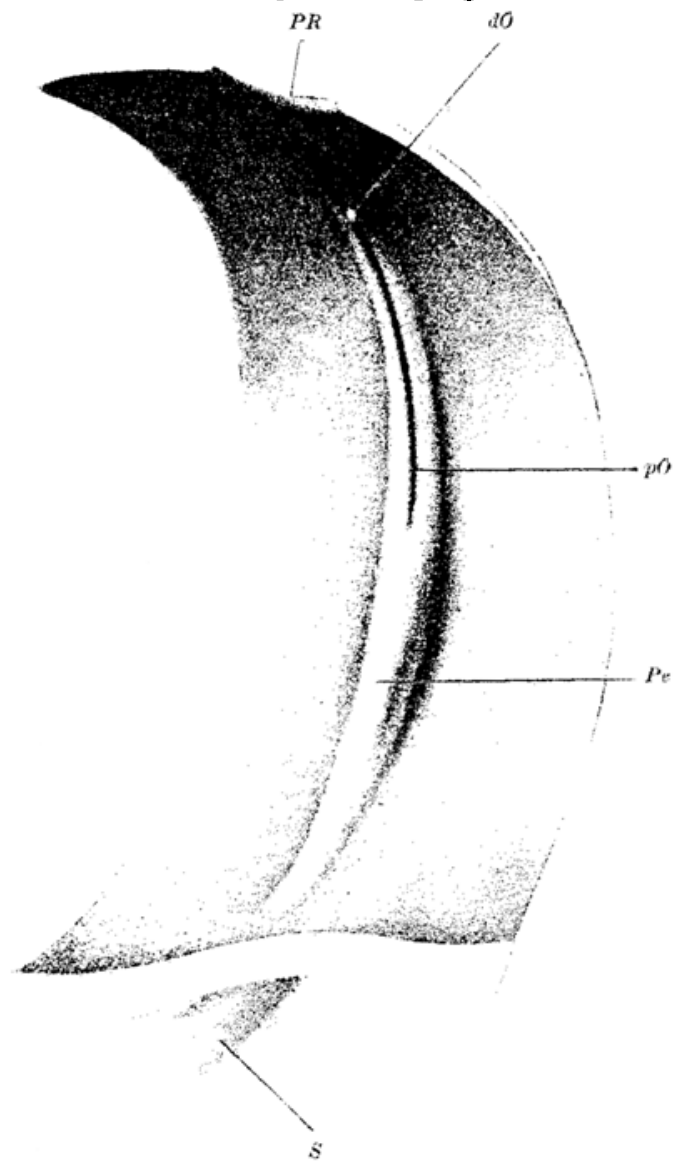

Abb. $\left.\operatorname{Pa}_{6}{ }^{1}\right)$ : Rekonstruktionsmodell (125以) eines Teiles der ventralen Ward des Augenbechers eines 13,0 mm langen Embryos von Passer dom., von innen her gesehen. ${ }^{\prime \prime} \mathrm{d}$. nat. Gr. rer früheren Becherspalte eine Furche. Distale Offnung nicht weit rom Pupillarrande gelegen. In der fortsetzung der 5 erwähnten Furche verläuft von der distalen Offnung bis in die Nähe des Pupillarrandes ein flacher Wulst.

In nenseite: (Abb. $\left.\mathrm{Pa}_{6}\right)$ : Langgestreckte Pectenanlage, sich wie trüher in ihrem proximalen Teile aus einer langgestreckten, seichten Einsenkung erhebend. Die Pectenanlage nimmt in proximodistaler Richtung kontimuierlich etwas an Höhe und anch an Breite zu und geht ohne scharfe Grenze in die eingebogenen Ränder der proximalen Spalte über. Die Einbiegung des nasalen und temporalen Randes ist hier ungefähr gleich stark. Die Spalte

1) Erklärang der Abkürzungen am Schlusse der Arbeit (S. 342). 
setzt sich distalwärts in eine Furche fort, welche zur distalen öffnung und über sie hinaus bis unweit vom Pupillarrand reicht.

Die histologischen Sohnittbilder dieses Stadiums zeigen folgende Details:

Die am Modell beschriebene Einsenkung liegt wie bei den früheren Stadien zwischen den von nasal und von temporal aus der Retina sich sammelnden und zur Sehnerveninsertion ziehenden Nervenfasern, wo diese ron beiden Seiten kommend sich vereinigen. Die aus dieser Einsenknng sich erhebende Vorwölbung der Pectenanlage ist in thren proximalen Anteile nicht mehr wie früher von Nervenfasern iberkleidet, sondern hat sich auch hier vollständig aus der Sehnerveninsertion erhoben ( $\mathrm{Abb} . \mathrm{Pa}_{7}, \mathrm{Pe}$ ). Sie besteht wie früher aus Zellen, die den Charakter von Gliazellen haben; es ist jedoch in diesem Stadien zu einer gewissen Differenzierung innerhalb der Pectenanlage gekommen: die Zellen an der Oberfläche des Pecten

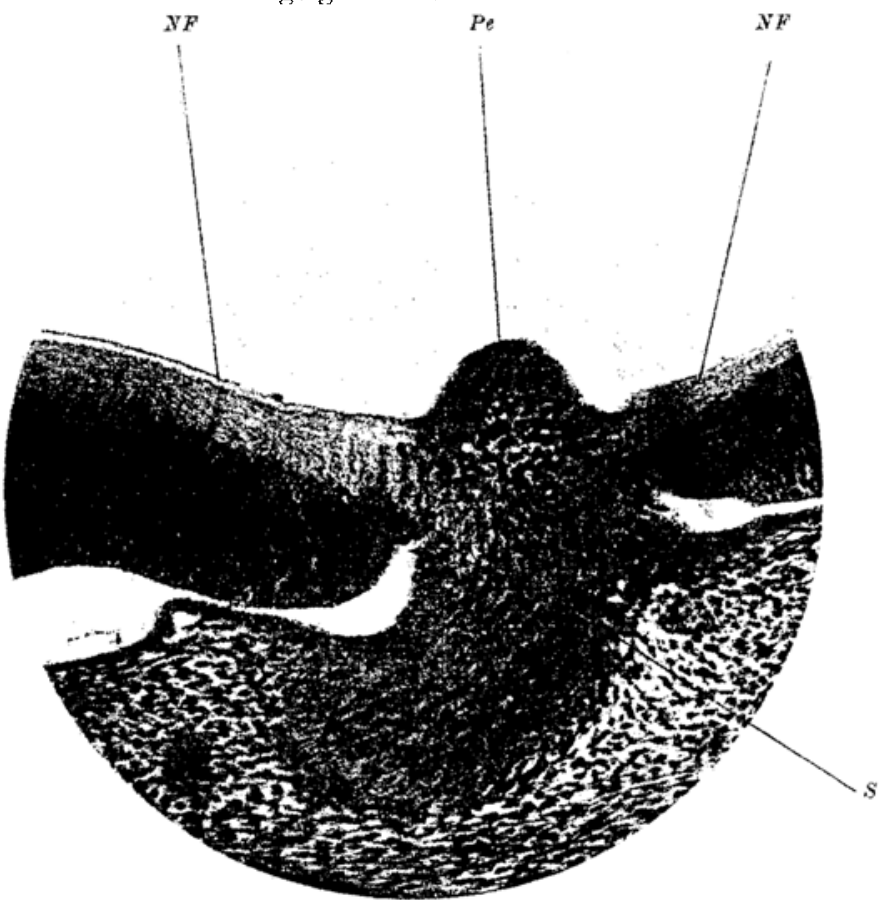

$\left.A b b, \mathrm{~Pa}_{7}{ }^{1}\right)$ : Photographie eines Schnittes durch den proximalen Teil von Sebnerveninsertion und Pectenanlage eines $13,5 \mathrm{~mm}$ langen Embryos von Passer clom. Vergr. 168/1.

zeigen eine gewisse Tendenz, sich epithelartig anzuordnen, während die Zellen in der Tiefe unregelmäßige Anordnung zeigen und kleine Lücken zwischen sich freilassen, so daß das Gewebe hier eine etwas lockere Beschaffenheit bekommt.

Entsprechend dem am Modell erhobenen Befund, daB die Pectenanlage in ihrem distalen Teile, wo sie sich nicht mehr aus einer Einsenkung erhebt, breiter und höher ist als proximal, finden wir im Schnittbilde, daß die Pectenanlage distal auf die hier eingebogenen Pänder der trüheren Spalte aufgelagert ist. Sie grenzt dabei direkt an die differenzierte Retina. Foch weiter distal geht sie in die wie früher undifferenzierten, innersten Teile der aufgebogenen Ränder der hier noch offenen proximalen Spalte über, welohe hier durch eine düne Mesodermlamelle voneinander getrennt werden.

Betreffs der Sehnervenanlage zeigt das Schnittbild, dab diese distal wie früher durch eine Furche unvollständig in eine bedeutend mächtigere nasale and eine bedeutend sch wächere temporale Portion geteilt ist. Diese Furche entspricht jener, welche am Modell den distalen Teil der Sehnerveninsertion temporalwärts zu begrenzen schien und welche sich distal direkt

1) Erklänung der Abkürzungen am Schlusse der Arbeit (S. 342). 
in die proximale Spaite fortsetzt. Dieser temporale Teil der Sehnerveninsertion ist indessen so schwach, dab er an unserem Modell nicht besonders hervortritt. Die besagte Furche begrenzt also, wie die Schnittbilder zeigen, in Wirklichkeit nicht die ganze Sehnerveninsertion an ibrer temporalen Seite, sondern nur ihren mächtigen nasalen Teil. Die am Modell hervortretende Furche an der Nasalseite des Sehnerven entspricht jedoeh in Wirklichkeit, wie die Schnittbilder zeigen, der nasalen Grenze der Sehnerveninsertion. Distal gehen die beiden Portionen der Sehnerveninsertion ebenso wie die Pectenanlage an der Innenseite ohne scharfe Grenze in die undifferenzierten Randteile der offen stehenden Spalte über.

Sehnerveninsertion an der AuBen- und Pectenanlage an der Tnnenseite, die wir, wie gesagt, als Neuropecten zusimmenfassen, grenzen überall an die differenzierte Retina an, dort wo das Pigmentblatt sich ins retinale Blatt unschlägt. Es hat sich also das Neuropecten bei seinem Vorwachen distalwärts der undifferenzierten Randzone am nasalen und temporalen Spaltrande als Bahn bedient, wobei die Spalte selbst im entsprechenden Teile zum VersehluB gekommen ist. Die undifferenzierten Randteile sind dabei im Neuropecten aufgegangen.

Die proximale Spalte zeigt eine, wern auch wenig ausgesprochene, so doch deutliche sehiefe Richtung, indem sie die Wand von nasal außen nach temporal innen durchsetzt. Dementsprechend hat auch das in die undifferenzierte Randportion vorgewachsene Neuropecten eine etwas schiefe Richtung, so daß an der Außenseite die Sehnerveninsertion hier hauptsächlich an die nasale Wand der Einsenkung angelagert ist, in der sie liegt, während das Pecten ein wenig temporalwärts geneigt ist. Die proximale Spalte wird ihrer ganzen Länge nach von einer sehr schmalen, sich nur an gewissen Stellen in den Glaskörperraum vorschiebenden Mesolermlamelle durchzogen, welche mit dem Mesoderm ventral vom Augenbecher zusammenhängt. Das Glaskörpergefä $B$ liegt zuerst in der Furche, welche die nasale und die temporale Portion des Sehnerven scheidet und gelangt so zur proximalen Spalte, betritt dieselbe jedoch nicht sofort, sondern verlüuft weiter an der Außenseite in der Furche zwischen ihren eingebogenen Rändern bis zu ihrem distalen Ende, wo es in die Becherhöhle eintritt und in der Furehe zwischen proximaler Spalte und distaler öfnung zur letzteren zieht and durch sie tlie Becherhöhle wieder verläBt.

\section{Stadium 7. $13.5 \mathrm{~mm}$ lang.}

In Bereiche der Retina beginnt sich unter der Nervenfasernschicht, welche sich noch weiter ansgebreitet hat als früher, in der proximałen Retinalwand eine Ganglienzellenschicht rom übrigen, undifferenzierten Teile der Petina zu differenzieren. Opticus rollkommen solide, seine epitheliale Anlage gänzlich verschwonden. Ciliarkörperanlage gefaltet.

Rekonstruktionsmodell $(125 \times)$.

A uBenseite: Das in die Rekonstruktion mitaufgenommene Endstück der Sehnervenanlage stark nasalwärts umgebogen. Kräftige, langestreckte Sehnerveninsertion, welche distal sich verschmälert und sich von der Augenbecherwand scharf abgrenzen läßt. An ihrer Temporalseite scheint sie in ihrem distalen Teile von einer Furche begrenzt zu sein, welche clistalwärts an Tiele immer mehr zunimmt und in die proximale Spalte übergebt. Die ganze Opticusinsertion ist etwas nasalwärts gewendet, die proximale Spalte dem fr üheren Stadiun gegenüber bedentend verkürzt. Sie öfnet sich wie früher in der Tiefe einer Einsenkung, die durch ihre eingebogenen Ränder gebildet wird.

Innenseite: Langgestreckte, kräftige etwas temporalwärts geneigte Pectenanlage, proximal in gleicher Höhe wie die Sehnerveninsertion beginnend und distalwärts an Höhe und auch an Breite zunehmend. Ihr proximaler Teil erhebt sich wie früher aus einer seichten Einsenkung. Distalwärts geht sie ohne scharfe Grenze in die Begrenzungsränder der proximalen Spalte über. Von diesen tritt der nasale kräftiger hervor als der temporale und beide sind ebenso wie die Pectenanlage ein wenig temporalwärts geneigt, wodurch die Spalte eine sehiefe Richtung bekommt, so daB sie die Augenbecherwand von nasal auBen nach temporal innen durchsetzt. Sie wird ihrer ganzen Länge nach von einer dünnen Mesodermlamelle durchzogen. Nahe ihrem distalen Ende passiert sie das früher erwähnte GefäB, welches dann, der ventralen Becherwand dicht anliegend, zur distalen, unweit des Pupillarrandes gelegenen Öffnung zieht und durch dieselbe die Besherhöhle verläßt. 
Histologische Beschreibung. Die Pestenanlage erscheint im proximalen Anteile auf Sehnitten, die quer zu ihrer Längsrichtung fallen, in Form eines Hügels, welcher sich aus der Einsenkung zwischen den von der Tasal- und der Temporalseite von der Retina zur. Sehnerveninsertion ziehenden Nervenfasern erhebt ( $\mathrm{vgl}$. Abb. Pa, S. 292). Die Zellen dieses Hügels sind wie früher an der Oberfläche epithelartig angeordnet, wïhrend sie im Innern unregelmäßig liegen und ein lockeres Gefüge zeigen.

Weiter distal, wo die genamte Einsenkung nicht mehr vorhanden ist, hat die Pectenanlage an quer zu ihrer Längsrichtung verlaufender Schnitten die Gestalt eines Dreiecks, dessen Basis der Opticusinsertion aufsitzt und von clessen Seiten die temporale steiler gegen die Becherwand abfallt als die nasale. Die Zellen zeigen hier die gleiche Anordnung wie im

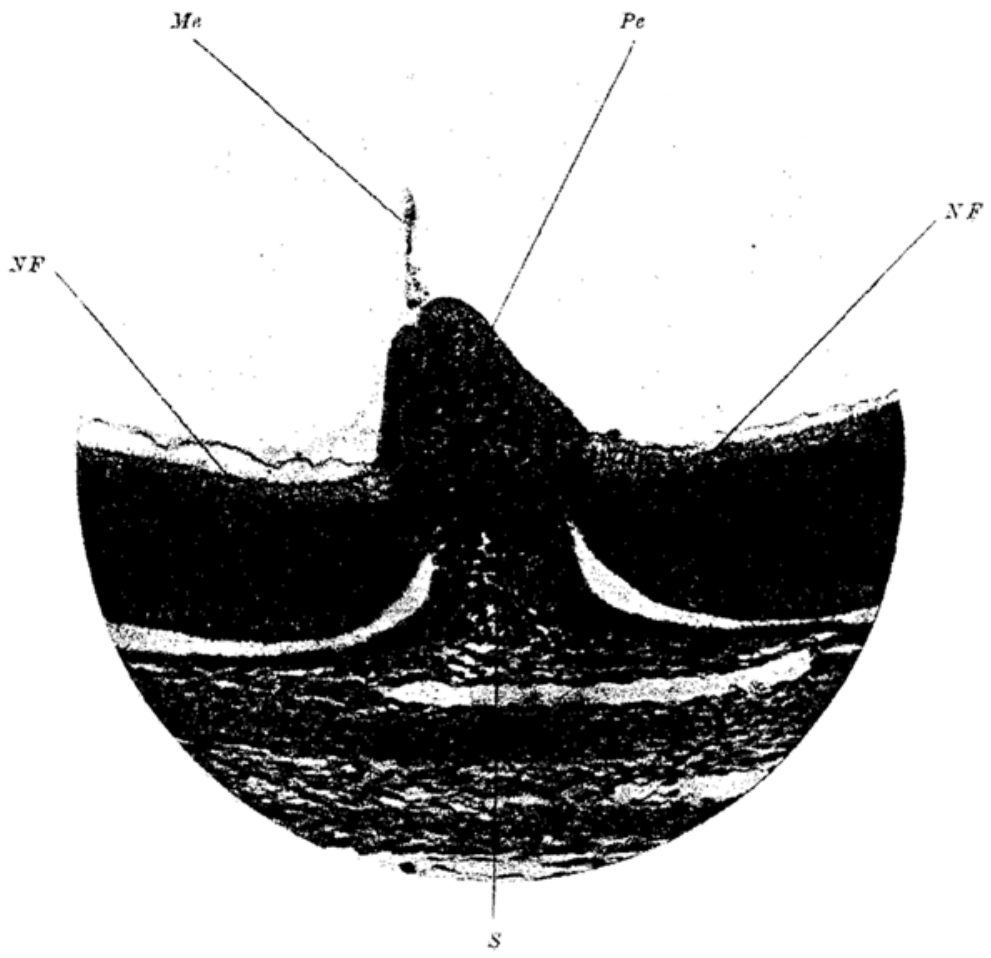

Abb. $P a_{8}{ }^{1}$ ): Photographie eines Schnittes durch den distalen Teil der gleirben Gebilde bei demselben Embryo (Passer dom., 13,5 mm lang). Vergr. 168/1.

proximalen Teile der Pectenanlage. Was die Anlage der Sehnerveninsertion betrifft, so finden wir dieselbe wie friher durch eine furche wrollstïndig in 2 Portionen getailt, ron denen die temporale ganz unbedentend ist. Weiter distal ist nur die kräftigere nasale Portion vorhanden, während der temporale Rand eine undifferenzierte Zone aufweist (Abb. $\mathrm{Pa}_{8}$ ). Noch weiter distal geht diese nasale Portion ohne scharfe Grenze in die undifferenzierte Zone des masalen Randes ïber, so daß hier beide Spaltränder eine undifferenzierte, innere Zone besitzen, von denen die nasale kräftiger ist als die temporale. - Soweit der Sehner veninsertion distalwärts gefolgt werden kann, so weit finden wir auch an ihrer Innenseite ein Pecten. Das Neuropecten ist also in der undifferenzierten Zone der Spaltränder weiter distalwärts vorgewabsen. Dieses Vorwachsen erfolgte zum weitaus überwiegenden Teile im Bereiche des nasalen Randes und distal sogar ansschließlich in diesem. Bei diesem Vorwachsen ist die undifferenzierte Randzone in das Neuropecten aufgegangen, so da $B$ dieses direkt an die differenzierte Retina grenzt.

1) Erklärung der Abkürzungen am Schlusse der Arbeit (S. 342). 
Im distalen Teile, wo das Forwachsen ausschließlich entsprechend dem nasalen Rande erfolgte, ist diesem gegenuber am temporalen noch dic undifferenzierte Randrone erhalten geblieben.

\section{Stadium 8. 22,5 mm lang.}

Die Differenderung der Retina ist so weit fortgeschritten, daß alle ibre Sohichten aus. gebildet sind. Ciliarkörperanlage stark gefaltet. Mesenchymale Irisanlage reicht bis zum Pupillarrand.

Das Neuropecten fült die proximale Spalte ihrer ganzen Länge nach aus. so dak diese bis an ihr distales Ende geschlossen ist. Die undifferen. zierte Randzone ist tabei ins Neuropecten aufgegangen, so da $B$ dieses uberall, auch in seinem distalen Teile, an die differenzierte Retina grenzt. In seinem proximalen Teile (Abb. $\mathrm{Ba}_{9}$ ) liegt das Pecten zwischen den von nasal und ron temporal zur Sehmerveninsertion ziehenden Nervenfasern, von denen die nasale Portion wesentlich mächtigex entwickelt ist als die temporale. Es grenat sich scharf gegen die Nerronfasern ab. An der Pectenun. lage selbst lassen sich 2 Anteile unter.

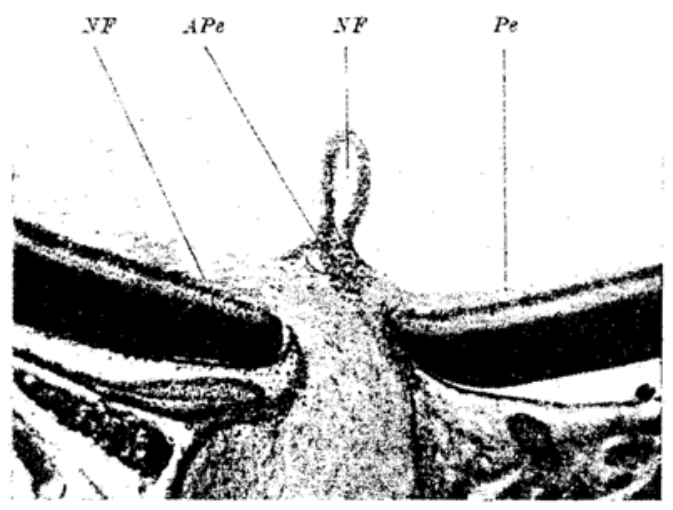

Abb. $\left.P_{9}{ }^{1}\right\}$ : Photographie eines Schnittes durch den proxirualen Teil der Anlage von Sehnerveninsertion und Pecten eines $22,5 \mathrm{~mm}$ langen Eubryos von Passer dom. Vergr. 5?/1.

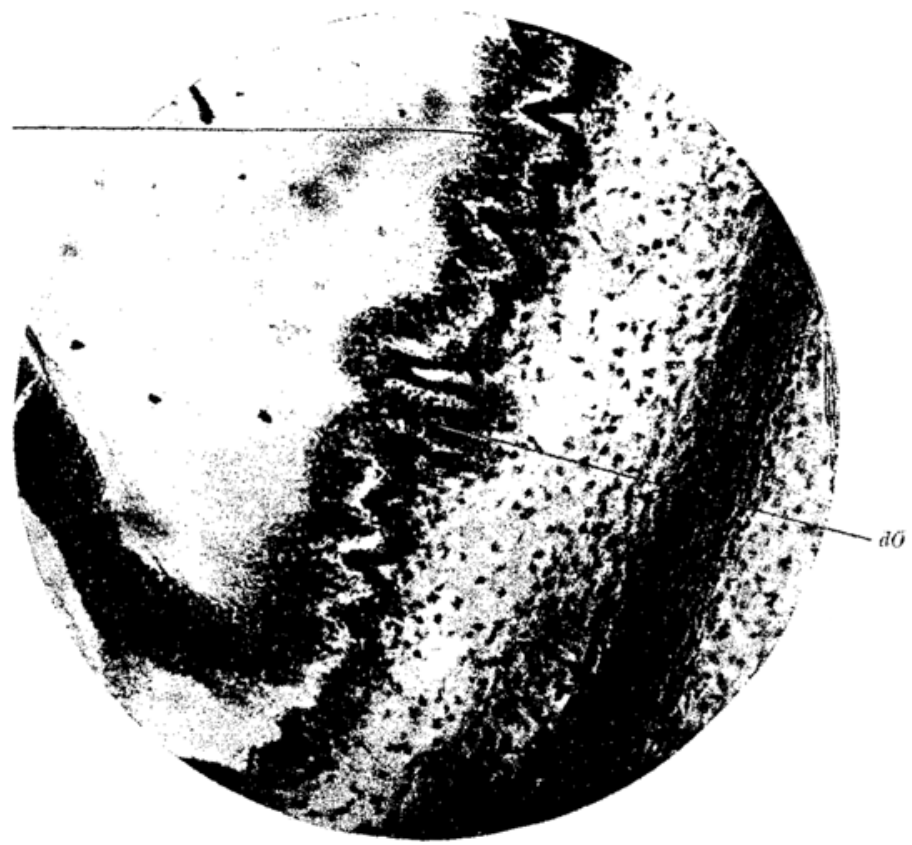

Abb. $\left.\mathrm{Pa}_{10}{ }^{1}\right)$ : Photographie eines Schnittes durch das Gebiet des Corpus ciliare mit dem Reste der distalen Offnung von einem 22,5 mm langen Embryo von Passer dow. Vergr. 168/1; aut $3 / 4$ verkleinert.

1) Erklärung der Abkürzungen am Schlasse der Arbeit ( 6.342 ). 
scheiden (Abb. $\mathrm{Pa}_{3}$ ), ein basaler, breiterer, welcher sich in die Einsenkung zwischen den Nervenfasern bin einschiebt und aus unregelmäßig angeordneten Zellen in seinem Inneren und epithelartig angeordneten an seiner Oberfläche besteht, und ein oborer, schmalerer, weit in den Glaskörperraum bineinragender Anteil, welcher wesentlich aus diesen epithelialen Wandzellen besteht, welche einen Hohlraum zwischen sich fassen (möglicherweise im Kunstprodukt). An der Grenze des erstgenannten Teiles, zwischen diesem und den Opticusfasern, verläuft ein größeres Gefäß (Arteria basalis pectinis). Das besprochene Glaskörpergefäß, wclches bei früheren Stadien die Becherhöhle passierte, ist hier verschounden. Von der distalen Öfnung ist ein in der Region des Corpus ciliare gelegener Rest zurückgeblieben. Dieser hat die Form von zwei dicht aneinander gepreßten, nach außen gewendeten Lippen, an deren Rändern das Pigmenblatt sich in das Retinablatt umschlägt ( $\mathrm{Abb} . \mathrm{Pa}_{10}$ ).

\section{Zusammenfassung.}

An unserem jüngsten Stadium $(3,3 \mathrm{~nm})$ finden wir die fötale Augenspalte ihrer ganzen Länge nach offen und distal mit divergierenden Rändern ohne scharfe Grenze in die Pupillaröffnung übergehend. In dieselbe schiebt sich ein von Mesenchymzellen begleitetes Gefäß ein, welches ebenso wie diese Zellen aus dem Mesoderm der Umgebung des Augenbechers stammt.

Im nächsten Stadium (5,1 $\mathrm{mm}$ ) ist die proximale spalte in ihre m mittleren und ihren distalsten Anteile geschlossen. Als ihre Reste zurückgeblieben sind zwei Öfrnungen: eine proximale, unmittelbar vor derStielinsertion gelegene, welchedie Form einer kurzen S palte hat, und eine distale, welche unweit vom Pupillarrand gelegen ist und ein kleines Loch darstellt. Zwischen diesen beiden Öfnungen verläuft an der Außen- und an der Innenseite der Augenbecherwand je eine Furche, welche den etwas eingebogenen Rändern der früheren Becherspalte entsprechen, die hier zur Aneinanderlagerung gekommen sind. An der Außenseite ist der nasale Begrenzungsrand der Furche stärker hervortretend als der temporale.

Das von Mesodermzellen begleitete Gefäß ist nun teilweise in die Becherhöhle aufgenommen worden, so daß es nun durch die proximale Offnang in dieselbe eintritt, der ventralen Wand entlang in der genannten Furche distalwärts verläuft und die Becherhöhle durch die distale Öfnung verläßt. Auf diesem ganzen Verlaufe ist das Gefäß von Yesodermzellen begleitet.

Im nächsten Stadium $(7 \mathrm{~mm})$ ist die proximale Ôffnung zu einer langgestreckten Spalte verlängert. Ihre Ränder, besonders der nasale, sind etwas gegen die Becherhönle zu eingebogen, wodurch die Spalte selbst in die Tiefe einer Furche an der AuBenseite des Augenbechers zu liegen kommt. Der nasale Rand dieser Furche springt als breiter, mächtiger Wulst vor, während der temporale relativ flach ist.

Der Formation ihrer Ränder entsprechend bekommt die proximaleSpalte eineschiefe Richtung: siedurchsetztdieAugenbecherwand in der Richtung $\nabla \circ n$ nasal auBen nach temporal innen.

Die erwähnte Einsenkung, in deren Tiefe die proximale Spalte sich öfnet, setzt sich in Form einer Furche über sie hinaus distalwärts bis zur distalen Offnung fort, welche unweit des hier wulstig verdickten Pupillarrandes gelegen ist.

GefäB und Mesodermzellen verhalten sich wie bei dem vorigen Stadium.

Beim nächsten Stadium $(7,6 \mathrm{~mm})$ ist die proximale Spalte noch weiter verlängert (vgl. Abb. Pa, S. 287, pö). Entsprechend der Tatsache, daß der nasale Rand 
der proximalen Spalte stärker gegen das Becherinnere zu eingebogen ist als der temporale, finden wir an der Innenseite der proximalen Spalte ihren nasalen Rand ( $\mathrm{Abb}$. Pa $\mathrm{Pa}_{2}$, rechts von der Spalte) stärker hervortretend als den temporalen, während umgekehrt außen sich der temporale Rand stärker markiert als der nasale. Zwischen proximaler Spalte und distaler Öfnung wie früher an der Außenund der Innenseite des Augenbechers je eine Furche. Die Furche an der Außenseite setzt sich über die distale Offnung hinaus bis zun Pupillarrand fort, welcher an der Stelle, wo die Furche endigt, wulstig verdickt ist. Offenbar entspricht diese Furche zwischen distaler Offnung und Pupillarrand der Verschlußstelle des distalsten Teiles der Becherspalte.

In den folgenden Stadien $(8,2,10,2,13,0$ und $13,5 \mathrm{~mm}$ lang) nim $\mathrm{mt}$ die proximale spalte distalwäts kontinuierlich an Länge $z u$. wahrend sie von proximal her gleichzeitig in proximodistaler Richtung verschlossen wird in einer Weise, die später geschildert werden wird. Da dieser Verschluß mit der Ausbildung der Sehnerveninsertion und des Pecten innig zusammenhängt, so soll zunächst auf die Entwicklung dieser Gebilde eingegangen werden.

Bei unseren jüngsten Stadien $(3,3 \mathrm{~mm})$ inseriert der sehr kurze und plumpe, ein weites Lumen enthaltende Becherstiel mit annähernd querovaler Ansatzflache an der Grenze zwischen ventraler und proximaler Wand des Augenbechers. Die Ansatzfläche ist im nächsten Stadium $(5,1 \mathrm{~mm})$, wo der Stiel selbst bedeutend schmäler und länger ist, von ungefähr rundlicher Form. Sie wird bei den folgenden Stadien in proximodistalex Pichtung immer mehr verlängert, and der am Augenbecher inserierende Teil der Sehnervsanlage erscheint an den Rekonstruktionsmodellen mit zunehmender Entwicklung als ein langgestreekter Wulst, welcher proximal am höchsten und breitesten ist und distalwärts sich verflacht und verschmälert.

Bei den Stadien von 7.0 und 10,2 mm Länge ist dieser Wulst distal durch eine sich distalwärts direkt in die proximale Spalte fortsetzende Furche in eine mächtigere nasale and eine schwächere temporale Portion geteilt. Im weiteren Verlaufe der Entwicklung nimmt dieser Wulst, mit dem die Sehnervenanlage an der Becherwand inseriert, distalwärts immer mehr an Länge zu. Dabei überwiegt die nasale Portion immer mehr über die termporale an Mächtigkeit, während die temporale so unbedeutend wird und der Becherrand so dicht anliegt, da $\beta$ sie an unseren Modellen nur undeutlich oder überhaupt nicht hervortritt. (Im Schnittbild bleibt sie jerloch nachweisbar.) Die erwähnte Furche, welche in früheren Entwicklungsstadien das distale Opticusende in zwei Hälften teilte, scheint nunmehr an den Modellen den Wulst der ganzen Anlage der Opticusinsertion temporalwärts zu begrenzen, während sie in Wirklichleit, wie die Schnittbilder zeigen, auch hier innerhalb des Opticus gelegen ist. In einem späteren Stadium $(13,5 \mathrm{~mm})$ eilt die nasale Portion der Anlage der Opticusinsertion der temporalen bei ihrem Vorwachsen distalwärts voraus, so daß hier die erwähnte Furche in diesem Teile tatsächlich, wie die Schnittbilder zeigen, die Sehnerveninsertion temporal begrenzt (vgl. $\mathrm{Abb}, \mathrm{Pa}_{\mathrm{s}} \mathrm{S} .294$ ).

Die Anlage der Sehnerveninsertion liegt mit ihrem lang ausgezogenen, distalen Anteile in eimer Einsenkung, welche von den eingebogenen Rändern der in diesem 
298 L. Lindahl und A. Jokl: Über den Ferschluß der tötalen Augrenbecherspalte.

Bereich geschlossen proximalen Spalte gebildet zu werden scheint ( $\mathrm{vgl}$. Abb. $\mathrm{Pa}_{7}$, S. 292), und reicht wenigstens in den jüngeren Stadien mit ihrer distalen Spitze bis an des proximale Ende der affenstehenden Spalte heran. Da mit fortschreitender Entwicklung der Wulst der Sehnerveninsertionsanlage sich distalwärts immer mehr verlängert, während die offene Spalte gleichzeitig immer kürzer wird, so gelangt man bei der Betrachtung der Modelle zur Auffassung, daß die Spalte von proximal her durch die einwachsende Sehnerveninsertion verschlossen wird. Für diese Auffassung scheint auch der Umstand zu sprechen, daß wir an den Modellen den langgestreckten distalen Teil der Sehnerveninsertion. an die nasale Wand der besagten Einsenkung angelehnt finden, entsprechend der Tatsache, daß die proximale Spalte die Becherwand in schiefer Richtung von nasal auBen nach temporal innen durchsetzt.

Die Betrachtung der histologischen Schnittbilder bestätigt diese Auffassung nicht nux, sondem ergänzt sie auch insofern, als sie über die Art dieses Vorwachsens der Sehnerveninsertion und den Verschluß der Spalte näheren Aufsehluß gibt. Es soll nunmehr dem früher an den Modellen beschriebenen VerschluB der proximalen Spalte, dem Schicksal der Becherstiels und der Entwicklung von Sehnerveninsertion und Pecten an der Hand der histologischen Schnittbilder gefolgt werden.

An unserem Modell des Stadiums ron $7,6 \mathrm{~mm}$ Länge finden wir der Sehnerveninsertionsanlage entsprechend an der Innenseite des Augenbechers eine etwas langgestreckte Einsenkung ( $\mathrm{Abb}, \mathrm{Pa}_{1}, \mathrm{~S} .285$ und $\mathrm{Pa}_{2}, \mathrm{~S} .287$, Ei). Die Rutinazellen zeigen im Bereiche derselben ein eigentümliches Verhalten. Die Zellen sind hier deutlich aufgelockert und lassen weite Lücken zwischen sich frei. Threr histologischen Beschaffenheit nach unterscheiden sich die hier befindlichen Zellen deutlich von den meisten Zellen der übrigen Retina durch ihre unregelmäßige Form und ibre helleren Kerne. An der Membrana lim. int. endigen sie mit Radiärfaserkegeln.

Durch die Wand dieser Einsenkung nehmen die ersten sich in der proximalen Retinalwand differenzierenden Nervenfasern ihren Weg zur ventralen Wand des Becherstiels, in einem hier vorhandenen schmalen Randschleier. Mit dem Fortschreiten der Differenzierung in der Retina nehmen die Nervenfasern ständig an Menge zu, wodurch der epitheliale Anteil der ventralen Wand und das Lumen des Becherstiels dorsalwärts verlagert werden. SchlieBlich kommt das Lumen des Becherstiels zum Verschluß. Dieser Verschluß erfolgt in der Richtung von distal nach proximal, jedoch bleibt an der Übergangsstelle des Becherstiels in den Augenbecher ein taschenförmiger Rest des Lumens ziemlich lange Zeit bestehen. um endlich ebenfalls zu verschwinden, Von dem ursprünglichen Epithelrohr des Becherstiels kann unan schlieBlich keine Spur mehr finden. Es scheint damit der frühere Becherstiel vollkommen durch Nervenfasern (und zwischen diesen liegenden Gliazellen) substituiert.

Wir können demnach in einem Stadium der Entwicklung des Sehnerven an demselben zweidnteile unterscheiden: einen epithelialen, den Becherstiel, welcher eine Verbindung des Diencephalon mit dem Augenbecher darstellt, und einen neurofibrillär-gliösen Anteil, welcher sich a ufangs als schwaches Lager der ventralen 
Wand des epithelialen Anteils einlagert, allmählieh an Cmfang zunimmt, den epithelialen Anteil immer mehr verdrängt and schlieblich vollkommen substituiert, so dab endlich keine Spur von diesem zurückbleibt.

Das in unsere Rekonstruktionsmodelle mit aufgenommene Endstück der Sehnervanlage ist stets nasal wärts umgebogen.

Die früher erwähnte, der Sehnerveninsertionsflache an der Innenseite des Augenbechers entsprechende Einsenkung nimmt distal wärts an Länge immer mehr zu; diese Verlängerung kommt dadurch zustande, dab die Sehnervenfasern in zwei Portionen, von nasal und von temporal her zur Sehnervenanlage ziehen und an ihrer Vereinigungsstelle eine Furche zwischen sich freilassen, welche dieser Einsenkung entspricht. Im Bereiche der Sehnerveninsertion kommen die neu einwachsenden Nervenfasern immer distal und ventral auf die schon ausgebildeten zu liegen, und dadurch wächst die Sehnerveninsertion, wie wir an den Modellen gesehen haben, in proximodistaler Richtung in die Lïnge.

Das Vorwachsen der Sehnerveninsertion erfolgt innerhalb einer ganzbestimmten histologischvonder übrigen Retinascharf geschiedenen Zone der Ränder der proximalen spalte, welche auf Grund des Verhaltens der Zellen hier a priori dazu bestimmt zu sein scheint, als Durchgangsbahn für die aus der Retina zurn Opticus ziehenden Nervenfasern zu dienen $\left(\mathrm{Abb} . \mathrm{Pa}_{5}, \mathrm{~S} .290\right)$. DieseZone u $\mathrm{m} \mathrm{fa}_{\mathrm{B}} \mathrm{B}$ sowohldas retinalewiedas Pigmentblatt. Wahrend die Zellen des Pigmentblattes in der übrigen Retina mit zunehmender Entwicklung immer flacher werden und sich in ihnen Pigment ansammelt, behalten sie in dieser Zone ihre ursprüngliche hohe zylindrische Form bei and verbleiben hier unpigmentiert. Die Zellen des retinalen Blattes, welche sich mit fortschreitender Entwicklung im Bereiche der übrigen Retina in radiären Peihen anordnen, behalten innerhalb dieser Randzone die unregelmäßige Anordnung bei, welche die jungen Entwicklungsstadien innerhalb der ganzen Retina aufweisen. Diese Zone umfaßt am nasalen Rande ein größeres Gebiet als am temporalen.

Es ist diese undifferenzierte Zone der Rander der proximalen Spalte, welche den von der Retina zum Sehnerven verlaufenden Nervenfasern als Durchgangsstelle und damit der Sehnervenin. sertion als Bahn bei ihrem Vorwachsen distalwärts dient. Mit dem Einwachsen der Nervenfasern verdicken sich die Ründer hier offenbar so, daß sie zur Aneinanderlagerung und Verschmelzung hommen, wodurch die Spalte sich in diesem Gebiete in proximodistaler Richtung schlieBt. Daß diese undifferenzierte Randzone tatsachlich als Bahn für die vorwachsende Sehnerveninsertion dient, ergibt sich daraus, daß dort, wo die Sehnerveninsertion in den Spaltbereich vorgewachsen ist, dieselbe direkt an differenzierte Retina grenzt: die undifferenzierte Randzone ist offenbar in die Sehnerveninsertion aufgegangen. Möglicherweise werden die Zellen dieser undifferenzierten Zone ganz oder teilweise zu Gliazellen des Opticus umgewandelt.

Die Tatsache, daß die undifferenzierte Zone auf der nasalen Seite kräftiger entwickelt ist als auf der temporalen, entspricht dem Faktum, daß ron nasal her aus der Retina dem Sehnerven wesentlich mehr Nervenfasern zugeführt werden (vgl. $\mathrm{Abb}$. Pa, S. 295) als von temporal. Dieses Verhalten kommt an den 
Rekonstruktionsmodellen in jüngeren Stadien $(7,0,10,2 \mathrm{~mm})$ dadurch zum dusdruck, daß die Sehnerveninsertion distal durch eine Furche unvollständig in eine kräftige nasale und eine schwache temporale Portion geteilt ist. An späteren Stadien $(13,0 \mathrm{~mm})$ ist dieser Unterschied in der Menge der von nasal und von temporal kommenden Nervenfasern so ausgesprochen, daß an anseren Modellen, wie schon erwähnt, nur die nasale Portion hervortritt, während die temporale nur im Schnittbild nachweisbar ist.

Die nasale Portion der Sehnerveninsertion ist nicht nur kräftiger, sondern in einem gewissen Entwicklungsstadium $(13,5 \mathrm{~mm})$ auch 1 änger als die temporale, was sich so erklärt, daß sie bei ihrem Vorwachsen distal der temporalen Portion der Sehnerveninsertion vorauseilt. Infolgedessen finden wir hier proximal im Bereich der offenen Spalte an der nasalen Seite die on die differenzierte Retina. grenzende Sehnerveninsertion, an der gegenüberliegenden temporalen Seite dagegen noch die undifferenzierte Randzone (vgl. $\mathrm{Abb}$. $\mathrm{Pa}_{8}$, S. 294). Später wächst die Sehnerveninsertion auch im Bereiche des temporalen Randes vor und vereinigt sich mit der nasalen zu einer einheitlichen Anlage.

Wir wenden uns nunmehr der Entwicklung des Peeten zu. In der mehrfach erwahnten, der Anlage der Sehnerveninsertion an der Auhenseite entsprechenden Einsenkung ( $\mathrm{Ei}$ in $\mathrm{Abb}$. $\mathrm{Pa}_{1}, \mathrm{~S} .285$ und $\mathrm{Pa}_{2}, \mathrm{~S} .287$ ) finden wir bei dem Stadium ron $10,2 \mathrm{~mm}$ Länge zum ersten Male eine Vorwölbung. Diese ist der Einsenkung, in welcher sie liegt, entsprechend von langgestreckter Form, nimmt distalwärts an Höhe und Breite zu und geht ohne scharfe Grenze in, die eingebogenen Ränder der proximalen Spalte über. Wie die Schnittbilder zeigen, besteht diese Vorwölbung aus Gliazellen, welche sich hier aus der Sehnerveninsertion in die sonst kernfreie Nervenfaserschicht hineinschieben (Abb. Pa, S. 288). Im proximalen Teil wölben diese Zellen die Nervenfasem ein wenig gegen das Becherinnere zu vor; weiter distal haben sie sich in die besagte Einsenkung hineingeschoben, dieselbe teilweise ausgefült und bilden im Querschnitte durch die Anlage einen kleinen, gegen die Becherhöhle zu vorspringenden Hügel (Abb. $\mathrm{Pa}_{4}, \mathrm{~S} .289$ ). In späteren Stadien besteht die Pectenanlage auch proximal ausschließlich aus diesen aus der Sehnerveninsertion ausgewanderten Gliazellen. Es stellt also die Pecten. anlage a uch bei Passer ein reines Differenzierungsprodukt der Sehnerveninsertion dar. Anfangs läßt sie sich auch basal vom Sehnerveneintritt nicht scharf abgrenzen (vgl. Abb. Pa $\mathrm{a}_{1}, \mathrm{~S} .289, \mathrm{~Pa}_{7}$, S. 292). Mit zunehmender Menge der belderseits von der Anlage einwachsenden kernlosen Nervenfasern wird diese Grenze mit fortschreitender Entwicklung immer schärfer (vgl. Abb. $\mathrm{Pa}_{9}$, S. 295). Dieaus der Opticusinsertion zur Entwicklung gekommene Pectenanlage entsprichtihrer Länge und Richtung nach der ersteren, und wir fassen beide Gebilde wiefriher zu einem einheitlichen morphologischen Begriffe zusammen und nennen sie mit einem gemeinsamen Namen Neuropecten. Sehnerveninsertion an der Außen- und Pecten an der Innenseite des Augenbechers gehen distal ohne scharfe Grenze in die undifferenzierten Randteile der proximalen Spalte über. Entsprechend der beschriebenen schiefen Richtung, in welcher die proximale Spalte die Becherwand durchsetzt, ist auch das in ihren Rändern vorgewachsene Neuropecten schief gestellt; die Sehnerveninsertion liegt, wie schon erwähnt, haupt- 
sächlich an die nasale Wand jener Einsenkung angelagert. welche durch die Einbiegung der Spaltründer zustande gekommen ist, während die Pectenanlage eine leichte Neigung temporalwärts aufweist.

Die Einbiegung der Ränder der proximalen Spalte nimmt mit zunehmender Entwicklung besonders distal immer mehr zu. Das hat zur Folge, daB von dem in diesen Rändern vorgewachsenen Neuropecten die Opticusinsertion an unseren Modellen in einem gewissen Stadium $(13.5 \mathrm{~mm})$ nicht bis zur proximalen Spalte zu reichen scheint. Sie liegt nämlich hier distal so tief $z$ wischen den eingebogenen Spalträndern eingebettet, daß sie am Modell nicht als Wulst hervortreten kann, während sie sich im Schnitt bis zum Beginn der Spalte und in späteren Stadien nasal über diesen hinaus distalwärts verfolgen läßt. Andererseits scheint auf den Modellen die Pectenanlage distal höher zu sein als sie in Wirklichkeit ist. Dies beruht darauf, daß das Pecten hier, wie die Schnittbilder zeigen, den eingebogenen diffe. renzierten Spalträndem aufliegt, $z$ wischen welche die Opticusinsertion tief eingeschoben ist, so daß Pectenanlage und diese Randteile am Modell als einheitlicher Wulst hervortreten.

In dieser Weise wächst das Neuropecten inden undifferenzierten Randteilen der proximalen Spalte immer weiter distalwärts vor, wobei diese selbst in proximodistaler Richtung zun VerschluB kommt. Abb. $\mathrm{Pa}_{6}$ (S. 29l) zeigt ein Stadium dieses Entwicklungsganges von einem $13 \mathrm{~mm}$ langen Embryo. Die Pectenanlage hat hier die Form eines in proximodistaler Richtung an Höne und an Breite kontinuierlich zunehmenden. Grates. Distal geht sie ohne scharfo Grenze in die Ränder der proximalen Spalte über, deren Einbiegung hier nasal und temporal etwa gleich stark ist. In dieser Weise wächst das Neuropecten bis andas distale Ende der proximalenspalte vor und im Endstadium haben wir wieder das gleiche Bild vor uns wie bei den übrigen beschriebenen Arten; ein einheit. liches Neuropecten, welches in seiner Längsausdehnung der frü. heren proximalen spalte entspricht und der schiefen Richtung derselben entsprechend ebenfalls schief gestellt ist, indem die Sehnerven. insertion sich nasalwärts, das Pecten temporalwärts wendet. Das Neuropecten grenzt seitlich überall direkt an die differenzierte Retina, dort, wo sich retinales Blatt in das Pigmentblatt unschlägt.

Die in späteren Stadien verlängerte proximale Spalte wird ihrer ganzen Länge nach, soweit sie offen steht, von einer dünnen Mesodermlamelle durchzogen, welche mit dem Mesoderm an der Ventralseite des Augenbechers zusammenhängt und sich nur stellenweise in den Glaskörperraum exhebt. Das erwähnte Gefäß lagert sich außen der Furche zwischen den beiden Opticusportionen ein und zieht in derselben zur proximalen Spalte, folgt dieser dann an der AuBenseite des Augenbechers bis zum distalen Spaltende und betritt hier die Becherhöhle. Im Innern des Augenbechers ( $G G$ in $A b b . P a_{2}, S .28 i$ ) lagert es sich wie früher an der Innenwand der Furche zwischen proximaler Spalte und distaler Offnung ein und verläßt durch die letztere die Becherhöhle.

Mit dem fortschreitenden Versehluß der Spalte verkürzt sich die Mesodermlamelle gleichzeitig in proximodistaler Richtung. Hat der VerschluB das distale Ende der proximalen Spalte errejeht, so ist auch die Mesodermlamelle vollkommen 
verschwunden. Gleichzeitig wird auch das hier befindliche GefäB atrophisch. und verschwindet schließlich vollig, worauf die Ründer der distalen Offnung sichaneinander legen. Ein Rest derselben bleibt jedochauch bei den älesten von uns untersuchten Stadien erken nbar als eine in Corpus ciliare gelegene Stelle, welche die Form zweier dicht aneinanderliegender, nach außen gewendeter Lippen hat, an deren Rändern das Pigmentblatt sich in das retinale Blatt umschlägt ( $\left.\mathrm{Abb} . \mathrm{Pa}_{10}, \mathrm{~S} .295\right)$.

Die näheren Details der Formentwicklung und der histologischen Differenzie. rung der Pectenanlage verlaufen bei $P$ asser in übereinstimmender Weise wie bei den übrigen hier beschriebenen Arten. Es soll daher hierauf nicht näher eingegangen werden und wir verweisen dieshezüglich auf die bei Podiceps gegebene genaue Darstellung dieser Verhältnisse.

\section{Gallus domestieus. Stadium 1. $79^{\mathrm{h}}$.}

Augenbecher mit Pigmentblatt aus hohen, cylindrischen, noch vollkommen pignentfreien Zellen bestehend. Sehventrikel nur stellenweise vorhanden, hauptsüehlich in der ven-

AS

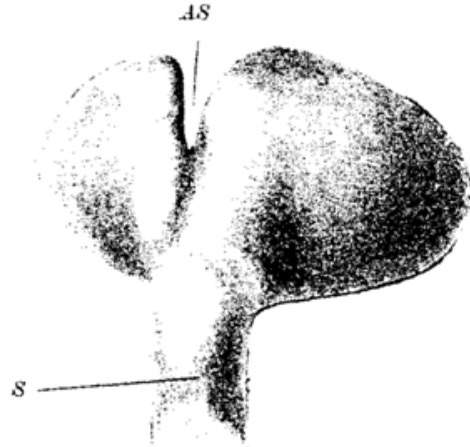

Abb. $\left.\mathrm{G}_{1}{ }^{\mathrm{I}}\right)$ : Rekonstruktionsmodell $(125 \times)$ des Augenberhers eines $79^{\text {h }}$ alten Embryos von Gallus dom., von ventral her gesehen. I/3 d. nat. Cir. tralen Wand des Augenbechers. Retinales Blatt mehrschichtig, in Bereiche der proximalen Wand am dicksten. Die Differenzierung der Retina hat im ventralsten Abschnitte der proximalen Wand mit der Ausbildung eines schmalen Randschleiers begonnen, der einige wenige Nervenfasern enthält. Die Linse ohne Lumen.

Fukonstruktions modell ( $125 \times$ ) ron rentral gesehen (Abb. $\mathrm{G}_{1}$ ): Ventrale Wand des Augenbechers gestreckt zur Pupillaroffnung verlaufend, die übrigen Wände, besonders stark die dorsale, gegen die Pupillaröffnung zu eingebogen, worlurch diese eine ventralwarts decentrierte Lage belommt. Becherstiel (S) kurz, plump, seiner ganzen Länge nach hohl, inseriert an der Grenze zwischen ventraler und proximaler Wand mit annähernd queroviler, jedoch nicht scharf ron der Becherwand abgegrenzter Ansatzfläche, welche indessen gegen die Becherspalte hin distalwärts etwas verlungert erscheint. Bechers palte (AS) ganz offenstehend, in ihrem proximalen Anteile verhältnismäBig schmal, geht distalwärts mit allmählich divergierenden Rändem ohne scharfe Grenze in den Pupillarrand über.

In der Spalte liegt außer Mesodermzellen ein Gefä ${ }^{2}$, welches aus dem dichten GefïBplexus stammt, der sich an der Ventralseite des Augenbechers ausbreitet.

An der Innenseite des Modells erkennt man, dab die annähernd gestreckt verlaufende ventrale Wand mit dem ebenfalls gestreckt verlaufenden ventralen Stiucke der proxi. malen Wand einen spitzen Mächenwinkel einsehlieBt. Der Becherstielinsertion entsprechend vertieft sich dieser Flächenwinkel zu einer recht tiefen Finsenk $\mathrm{kng}$, welche sich direkt in die Becherspalte fortsetzt. Längs der Wand dieser Einsenkung ziehen, wie das Sehnittbild zeigt, die spärlichen Nervenfasern aus den sich differenzierenden Teilen der Pvetina zum Becherstiel.

\section{Stadium 2. $116^{\mathrm{h}}$.}

Pigmentblatt uberall Pigment enthaltend, mit Ausnahme der Gegend der mumittelbaren Nachbarschaft der früheren Becherspalte an der ventralen Wand. Sehventrikel überill ver-

1) Frklärnng der 1bkürzungen am Schlusse der Arbeit ( $\$$. 342).

?) In die Rekonstruktion nicht mit aufgenommen. 
whwunden, mit Ausnahme eines schmalen Restes am dorsalen Pupillarrand und der ventralen Wand, wo er an beiden Seiten der früheren Becherspalte noch relativ weit offen ist. Retina mit deutlichem Randschleier an der proximalen Wand in der Umgebung der Becherstielinsertion. Die Xervenfasern sind zahlreicher geworden. Sie sammeln sich hier aus den differenzierten Retinaabschnitten und ziehen zur ventralen Wand des Becherstiels.

Das Rekonstruktionsmodell ( $125 \times)$, Abb. $G_{2}$, AuBenseite, und $G_{3}$, Innenseite, zeigt, da $B$ die Becherspalte in ihrem mittleren und in ihrem distalsten $A b-$ achnitte geschlossen ist. Als ihre Reste sind zurückgeblieben zwei spaltförmige Öffmngen, eine relativ lange proximale $(\mathrm{p} O)$ und eine kürzere distale $(\mathrm{d} O \mathrm{O})$. Die Vereinigungsstelle fler Spaltränder markiert sich an rler AuBen- und Innenseite durch je eine kurze Furche (AuBen-

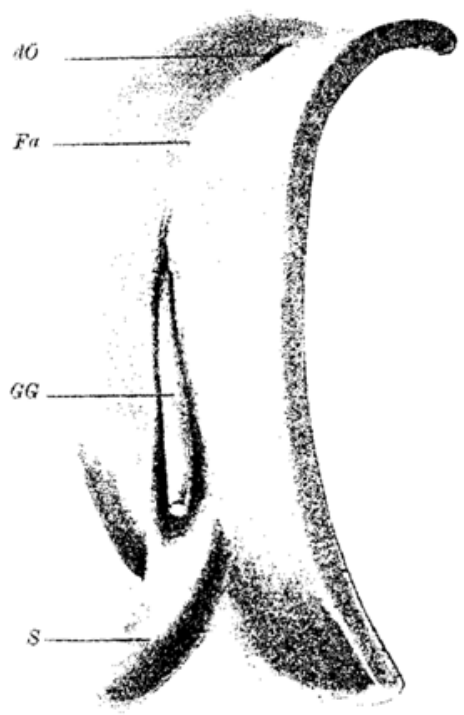

Abb. $\left.\mathrm{G}_{2}{ }^{2}\right)$ : Rekonstruktionsmodel1 $\left.{ }^{1}\right)(125 \times)$ eines Teiles der ventralen Wand des Augenbeehers eines $116^{\mathrm{h}}$ alten Fmbryos von Gallus dom., ron außen her gesehen. ${ }^{8 / 15}$ d. nat. Gr.

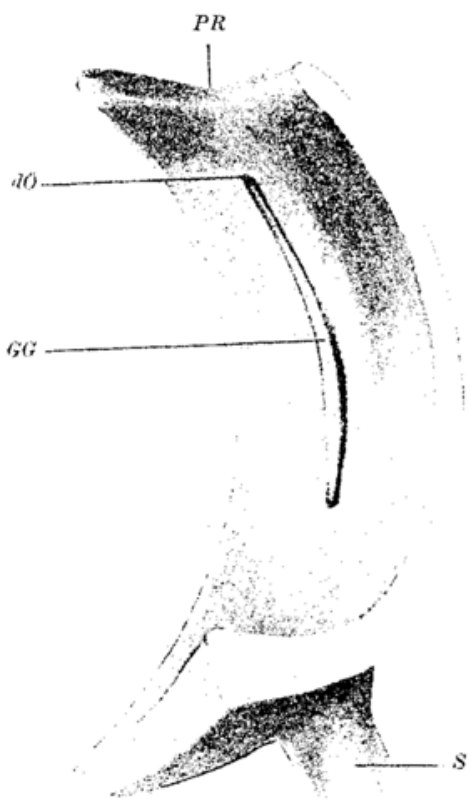

Abb. $\left(\mathrm{G}_{3}^{2}\right)$ : Das glejche Rekonstruktionsnodell (Gallus dom, $116^{\text {h }}$, won innen gesehen. ${ }_{i 15}$ d. nat. Gr.

seite Fa), welche proximale und distale Öffnung miteinander verbinden. Die Furche an der Innenseite ist durch zwei flache Wülste begrenzt, welche den etwas eingebogenen früheren Becherrändern entsprechen. Die Sehnerveninsertion (S) zeigt eine distal etwas Ferlängerte, längsovale Ansatzfläche. Thr distaler Teil wird durch eine Furche, die sich unnittelbar in die proximale Öffnung fortsetzt, in zwei ungleiche Teile, einen mächtigeren nasalen (in der Abb. rechts) and einen schwächeren temporalen, geteilt. Diese Furche dient dem früher erwähnten GefäBe (GG) zur Einlagerme, welehes auf diesem Wege zur proximalen öffnung gelangt, diese in schrüger Richtung ihrer ganzen Länge nunh durchzieht, sich dann der erwahnten Furche an der Innenseite des Augenbechers einlager und in derselben zur distalen Öffnung zieht, aurch welehe es die Becherhöhle wieder verläßt $\left(\mathrm{Abb}, \mathrm{G}_{3}\right)$. Auf seinem ganzen Wege ist das Gefä $B$ ron Mesodermzellen begleitet.

Aus der Imenseite des Rekonstruktionsmodelis (Abb. $G_{3}$ ) erkennt nan an einer der

1) Hier und bei den folgenden Stadien wurde nicht mehr der ganze Augenbecher, son. dem der mittlere Teil der ventralen Fand vom Ansatze des Stiels bis zum Pupillarrand rekonstruiert.

2) Erklärung der Abkürzungen am Schlusse der Arbeit. (S. 342). 
Insertionsfläche der Sehnervenanlage entsprechenden Stelle eine langgestreckte, ganz seichte Einsenkung. Unmittelbar von der prosinalen Öfrnung macht dieselbe jedoch einer leichten Erhühung Platz, die allmählich ohne Grenze in die eingebogenen Ränder der proximalen Offaung übergeht.

Wie die Schnittbilder zeigen, wird die besagte Einsenkung durch die Nervenfasern gebildet, welche von nasal und von temporal her dem Sehnerven zustreben. Diese laufen zur ventralen Wand des Becherstiels und bilden hier an der Ventralseite ein relativ mächtiges Lager, wodurch die ventrale Wand desselben bedeutend verdickt und das Stiellumen dorsalwärts verschoben ist. Wie sich die erwähnte Erhöhung unmittelbar proximal von der proximalen Spalte histologisch erklärt, soll beim nächsten Stadium auseinandergesetzt werden, da die parallel mit der Spaltrichtung verlaufende Schnittrichtung dieses Objekts dasselbe für diesbezügliche Sichnittstudien weniger geeignet machte.

\section{Stadium 3. $106^{\text {h. }}$.}

Dieses Stadium ist in seinem Entwicklnngszustande von dem zuletzt beschriebenen nicht sehr verschieden. Äußeres und inneres Blatt des Augenbechers durch einen offenbar künstlich entstandenen Spaltraum teilweise voneinander abgehoben. Pigmentblatt wie im Stadium vorher aus platten, pigmenthultigen Zellen bestehend, mit Ausnahme des Gebiets der früheren Becherspalte, wo sie höher und pigmentfrei sind. Die Nervenfaserschicht bat sich auf der proximalen Wand weiter ausgebreitet und erstreckt sich nun auch auf die benachbarten Gebiete der ventralen Wand.

Das Rekonstruktions modell zeigt an der $A$ ußenseite eine bedeutend verlängerte Opticusinsertionsfläche von längsovaler Form, die sich von der Becherwand nicht scharf abgrenzen läßt und bis an die proximale Offnung herantritt. Sie trägt temporal eine Furche, welche ebenfalls gegen die proximale Ötfnung hinleitet und das distale Ende der Sehnerveninsertion in zwei Hälften teilt. Diese beiden Teile gehen ohne scharfe Grenze in die Ränder der proximalen Offnung über. Dieselbe ist dem früheren Stadium gegenüber bedeutend ver. längert und soll von nun an "proximale Spalt te genannt werden. Die Ränder derselben sind nach innen zu eingebogen und bilden derart eine Einsenkung zwischen sich, in deren Tíefe die proximale Spalte zu liegen kommt. Zwischen proximaler Spalte und distaler Offnung wie früher eine Furche. Distale Öffnung nunmehr ein rundes Loch. Der distale Teil der ventralen Augenbecherwand stark gegen die Pupillaröffnung zu umgebogen.

An der Innenseite des Modells erkennt man, entsprechend dem ungefurchten Teil der Opticusinsertion an der Außenseite des Augenbechers, eine seichte, langgestreckte Einsenkung, welche nächst der proximalen Spalte einer leichten Vorwölbung Platz läBt, die sich zu beiden Seiten ohne Grenze in die eingebogenen Ränder der proximalen Spalte fortsetzt. Der nasale Spaltrand tritt stärker gegen das Becherinnere zu vor und die ganze Spalte hat eime schiefe Richtung durch die Becherwand, indem sie dieselbe von nasal anßen nach temporal innen durchsetzt.

Das erwähnte Gefä $B$ lagert sich wie früher in die Furche im distalen Teile der Opticusinsertion ein und verläuft auf diesem Wege zur proximalen Spalte, durchzieht diese schief ihrer ganzen Länge nach und gelangt auf diese Weise in die Becherhöhle, läuft hier eine Strecke weit distalwärts an der ventralen Wand, hebt sieh dann ein wenig von ilhr ab, so daß es mit seinem distalsten Anteile frei durch die Becherhöhle zur distalen Offnung zieht, durch welehe es den Augenbecher wieder verläßt.

Wie die Schnittbilder zeigen, kommt die bei der Beschreibung des Modells erwähnte, dem proximalen Teil der Sehnerveninsertion an der AuBenseite entsprechende Ein. senkung an der Imnenseite des Augenbechers dadurch zustande, daß die ron nasal and von temporal zur langgestreckten Sehnerveninsertion ziehenden Nervenfasern bei ihrer Vereinigung eine Furche zwischen sich entstehen lassen. Betrachten wir durch die Gegend der proximalen Spalte fallende Schnitte, so erkennen wir hier, daß die der S palte $z$ un $\mathrm{n}$ ächst gelegenen Teile ihrer $R$ änder sich in ihrem Bau von der übrigen Retina unterscheiden. (Vgl. Abb. G ${ }_{6}$ S. 306). Die Zellen des Pigmentblattes sind bier wesentlich höher als sonst und frei von Pigment. Die Zellen des retinalen Blattes zeigen zunächst dem Umschlagsrande dieselbe unregelmäßige Anordnung, wie sie die Zellen in der ganzen Retina 
bei jüngeren Stadien aufweisen, während die Zellen in der übrigen Retina hier in radiären Peihen angeordnet sind.

Die beschriebene Frhöhung unmittelbar proximal von der proximalen Spalte kommt, wie die Schnittbilder zeigen, dadurch zustande, daß hier die Nervenfasern in die eingebogenen Ränder der proximalen Spalte eingewachsen sind, so da $B$ diese sich offenbar verdickt haben und zur Aneinanderlagerung und Verschmelzung gekommen sind, wodureh die Spalte in diesem Gebiete zum VerschluB gelammen ist. Hier trügt die Opticusinsertion ventral eine Furche und grenzt unmittelbar, ebenso wie auch weiter proximal, seitlich direkt an die differenzierte Retina. Distal geht sie ohne scharfe Grenze in das genannte undifferenzierte Gebiet der Spaltränder über.

\section{Stadium 4. $124^{\mathrm{h}}$.}

Zellen des Pigmentblattes ganz flach. Sie enthalten überall Pigment, mit Ausnahme der Nachbarschaft der proximalen Spalte. Pigmentblatt dem retinalen Blatt dicht anliegend,

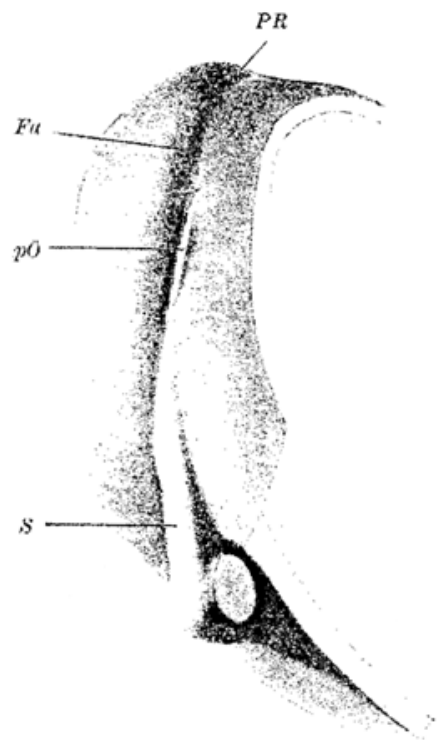

Abb. $\left(G_{4}{ }^{2}\right)$ : Rekonstmktionsmodell $(125 x)$ eines Teiles der ventralen Wand des Angenbechers eines $124^{\mathrm{h}}$ alten Embryos von Gallus dom, von auBen her gesehen. $1 / 3$ d. nat. Gr.

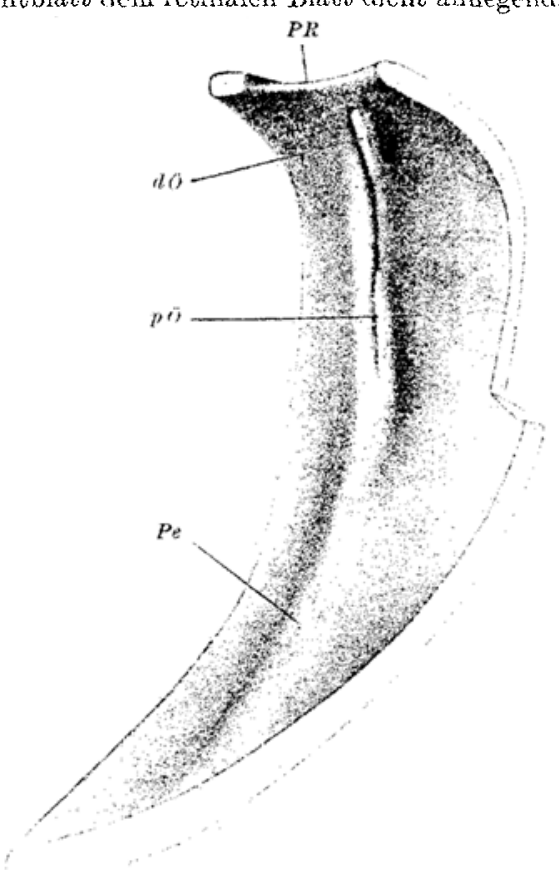

Abb. $G_{\overline{5}}$ ): Dasselbe Rekonstruktionsmodell (Gallus dom., 124 $4^{\mathrm{h}}$, ron imen gesehen. $1 / 3$ d. nat. Gr.

nur ein kleiner Rest des Sehventrikels in der Umgebung des Sehnerven in den Begrenzungsrändern der proximalen Spalte und am Pupillarrande des Augenbechers vorhanden. Differenzierung der Retina wuf ein Nervenfaserlager in der Umgebung des Sehnerveneintritts beschränkt. Die Nervenfasern ziehen zur ventralen Wand des Becherstiels, wodurch diese bedentend verdickt wird und sein überall noch offenes Lumen dorsalwärts verlagert wircl. Rekonstruktionsmodell (125X).

A u Benseite $\left(\mathrm{Abb} . \mathrm{G}_{4}\right)$ : Schmale, langgestreckte Sehnerveninsertion (S), mit einer lang ausgezogenen Spitze distalwärts bis zur proximalen Spalte reichend. Sie ist temporal (in der $\mathrm{Abb}$. links) durch eine ziemlich tief einschneidende Furche abgegrenzt. An ihrer nasalen Seite finden wir eine solche, die Sehnerveninsertion gegen die Beeherwand abgrenzende Furche nur in ihrem proximalen Teile, während sie in ihrem distalen Teile

1) Erklärung der Abkürzungen am Schlusse der Arbeit (S. 342). 
nasalwärts ohne scharfe Grenze in die benachbarte Becherwand übergeht. Die temporale Furche geht distalwärts in die proximale Spalte (p0) über, welche in der clirekten Fortsetzung derselben gelegen ist. Dieselbe ist etwas lünger als in Stadium vorher und hat eine lange, spaltförmige Gestalt. Der zwisehen proximaler Spalte und distaler Öffnung liegende geschlossene Tejl der früheren Augenbecherspalte ist relativ kurz und an der Außenseite durch eine Furche (Fa) markiert. Die distale Öffnung (Abb. $G_{\tilde{n}}$, dib) von langgestreckt ovaler Form. Man gewinnt bei der Betrachtung der Außenseite des Rekonstruktionsmodells den Eindruck, als wäre die Sebnerveninsertion distalwärts in die proximale Spalte hinein vorgewachsen und hätte diese dabei zum VersehluB gebracht. Dabei käme die Sehnerveninsertion mit ihrem distalen Teile in die Einsenkung zwischen den eingebogenen Spalträndem zu liegen, jedoch so, daß sie sich vornehmlich an die nasale Wand dieser Einsenkung anlehnt.

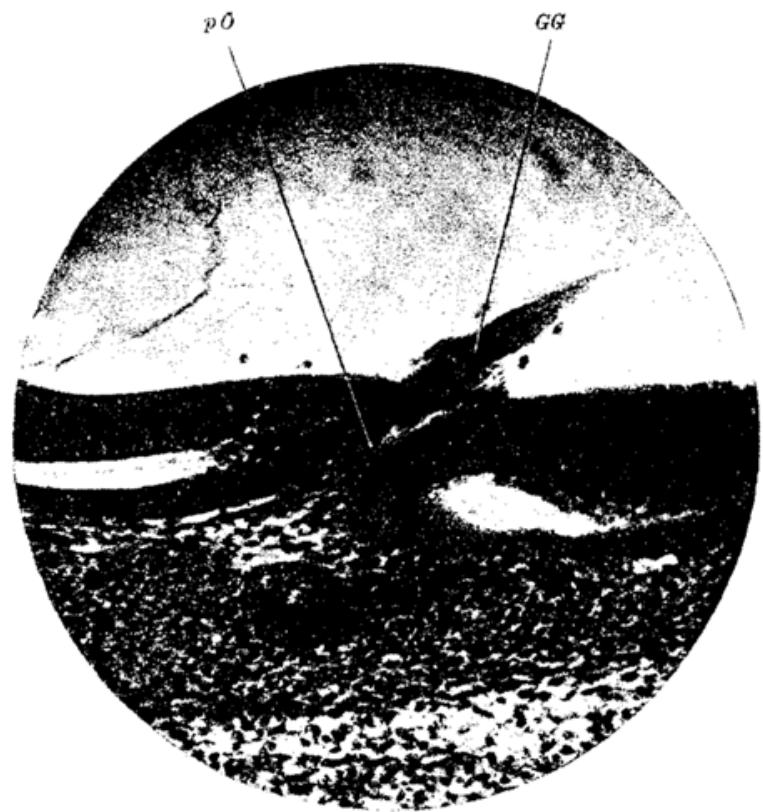

Abb. $\left.\mathrm{G}_{6}{ }^{1}\right)$ : Photographie eines Schnittes durch die Region der proximalen Spalte mit ihren undifferenzierten Randteilen und dem in die Becherhöhle eintretenden Gefäße bei einem $124^{\mathrm{b}}$ alten Embryo von Gallus dom. Vergr. 110/1.
Weiteres hierüber siehe bei der Beschreibung der histologischen Schnittbilder.

Innenseite des Modells (Abb. $G_{5}$ ): Entsprechend dem überwiegenden proximalen Teile der langgestreckten Sehnerveninsertion sieht man eine ganz niedrige, langgestreckte Erhöhung, die Pectenanlage (Pe). Diese ist an der Nasalseite von der Vmgebung etwas schärfer a bgegrenzt als ander Temporalseite und wird distalwärts allmählich flacher. Unmittelbar proximal von der proximalen Spalte finden wir wieder die auch bei den beiden fruher beschriebenen Stadien be. obachtete Erhöhung, welche sich ohne Grenze in die beiden, nach innen zu eingebogenen Ränder der proximalen spalte ( $p \ddot{0})$ fortsetzt. Von diesen ist der nasale (in der Abb. links) etwas stärker eingebogen als der temporale und setzt sich distalwärts in einen Wulst fort, welche eine die proximale und distale Öffnung an der Imnenseite verbindende Furche nasalwärts begrenzt. Ent-

sprechend der Formation ihrer Ränder hat die Spalte eine schiefe Richtung und durchsetzt die Becherwand von nasal anßen nach temporal innen.

Das von Mesodermzellen begleitete Gefäß (in die Rekonstruktion nicht mitgenommen) lagert sich der beschriebenen Furche an der temporalen Seite der Sebnerveninsertion an und zieht in dieser distalwïrts zur proximalen Spalte, durohsetzt dieso in schiefer Richtzng, überbrückt den zwischen proximaler Spalte und distaler öffnung gelegenen Teil der Wand der Augenbecherhöhle sehnenförmig und verläßt die Becherhöhle durch die distale Öffnung.

Ein histologisches Studi u m der Schnittserie dieses Stadinms lehrt uns folgendes: In Gebiete des am Rekonstruktionsmodell hervortretenden Pectenwulstes sehen wir die Sehnervenfasern in zwei Portionen, einer bedeutend größeren nasalen und einer kleineren temporalen, zum Opticus ziehen. Zwisehen diesen von beiden Seiten her in den Opticus einwachsenden, kernlosen Nervenfaserbündeln haben sich die Gliazellen des Opticus gegen die Becherhöhle hin vorgeschoben und bildendie a mo dell beschriebene flache Vorwölbung (Pe). Sie stellt eine direkte Fortsetzung des Gliazellagers des Seh.

1) Erklärung der Abkürzungen am Schlusse dex Arbeit (S. 342). 
nerven dar und ihreZellen stimmen in allen ihren Qualitaten mit den Gliazellen des Opticus uberein. Auch beim Huhn stellt also die Peetenanlage ein Differenzierungs produkt der Sehnerveninsertionsanlage dar und besteht a us den gleichenGliazellen, wie sie im Opticus vorkommen. Wir wollen daher in der Folge auch hier sehnerveninsertion and Pecten za einem einheitlichen morphologischen Begriffe (.,Neuropecten") zusammenfassen.

Wir haben bei der Beschreibung des Modells hervorgehoben, daß die Sehnerveninsertion distalwärts zwischen die Ränder der proximalen Spalte vorgewachsen zu sein scheint. Das Studium der Schnitte bestätigt diese Auffassung insofern, da\& wir konstatieren können, daB duroh das Einwachsen von Nertenfasern a us weiter distal gelegenen Retinaabschnitten in die undifferenzierten Randabschnitteder proximalen spalte (siehe vorhergehendes Stadium) diese offenbar a uch hier an Lmfang zugenommen haben und zur Verschmelzung gekommen sind. Dabei lagern sich die neugebildeten Nervenfasern im Bereiche der Sehnerveningertion immer distal a uf die schon gebildeten a und a diese Weise hat sich die Sehnerveninsertion distalwärts verlängert. Das Forwatsen der Sehuerveninsertion erfolgt hauptsächlich entsprechend dem nasalen Rande, der Tatsache gemäß, daß hier der der S̈palte zunüchst gelegene, undifferenzierte Randteil, der ja als Bahn für die eingewachsenen Opticusfasern dient. kriftiger entwickelt ist als an der temporalen Seite. was sich im Gebiete der offenen proximalen Spalte deatlich konstatieren la $3 t$ ( $A b b . G_{6}, S .306$ und Abb. $G_{10}, S .310$ ). Ein wenn auch bedeutend schwicherer Teil der Sehnerveninsertion befindet sich indessen, wie die Schnittbilder zeigen, auch an der temporalen Seite jener Einsenkung. die uns am Modell als temporale Begrenzung der Sehmerveninsertion imponierte. Diese Portion ist aber so schmal, dab sie an den Modellen nicht zum Ausdruck kommen kann. Es entspricht also diese Furche, we aus den Schnittbildem hervorgeht, in der Tht nicht dem temporalen Begrenzungsrande der Sehnerveninsertion, sondern einer Furche in Sehnerven selbst, welehe innerhalb desselben eine viel größere nasale von einer bedeutend kleineren temporalen Portion scheidet.

\section{Stadium}

Pigmentblatt dem retinalen Blatte zun größten Teile mliegend, stellenweise von diesem leicht abgeholen. Die Zellen des Pigmentblattes überall platt und reichlich Pigment enthaltend, mit Aunnahme der Ränder der proximalen Spalte. Differenzierung der Retina nicht wesentlich veiter fortgeschritten als friiher, doch haben die Nervenfasera an Zahl zugenommen. Vom Becherstiellumen ist noch ein taschenförmiger Rest clorsal zunächst dem Augenbecher und ein ebenfalls enger Rest im proximalen Ende zurickgeblieben.

Rekonstruktionsmodell $(125 \times)$,

A u $B$ enseite $\left(A b b . G_{7}\right)$ : Sehnerveninsertion mit bedentend verlängerter Ansatzflache, die ein langes und relativ schmales, distal zu einer lingen Spitze ausgezogenes Oval darstellt. Der Wulst der Sehnerveninsertion wird distalwärts imner flacher und verschwindet schließlich cine Strecke weit proximal von der proximalen Spalte. Der distale Teil der Sehnerveninsertion liegt in einer Einsenkung, welche offenbar durch die eingebogenen Ränder der hier geschlossenen proximalen Spalte gebildet wurde. Er konmt dabei größtenteils an die nasale Seitenwand dieser Einsenkung zo liegen und geht hier ohne scharfe Grenze in die benachbarte Becherwand über. An cler temporalen Seite wird er anscheinend von der Becherwand durch eine distalwäts sich immer mehr vertiefende Furche abgerrenzt, welche sich äber die distale Spitze der Sehnerveninsertion hinaus bis an die proximale Spalte fortsetzt. Das in die Rekonstruktion mitgenommene Endstiick der Opticusanlage ist nasalwärts ungebogen. Die lange proximale Spalte liegt auch hier wieder in der Tiefe einer Einsenkung, welche von ihren eingebogenen Ründern gebildet wird. Diese Einsenkung setzt sich in Form einer Furche auch weiter distalwärts über die proximale Spalte hinaus bis zur distalen Offnnug fort. Diese ist von längsovaler Form, unweit vom Papillarrande gelegen.

An der Innenseite des Modells (Abb. $G_{g}$ ) sehen wir eine der verlängerten Sehnerveninsertion entsprechende, ebenfalls bedeutend verlïngerte seichte Einsenkung, ans der sich die Yorwölbung der Pectenanlage (Pe) erhebt. Diese ist in ihrem proximalsten Anteile am flachsten, nimmt dann distalwärts an Höhe und an Breite zu und ist unmittelbar proximal 
308 C. Lindahl und t. Jokl: Cher den Verschind der föralen Augenbecherspalte;

von der proximalen Spalte am mächtigsten entwickelt. Die Anlage geht dann ohne scharfe Grenze in die Ränder der proximalen Spalte (pÖ) über, von denen der nasale (in der $A b l$ ). rechts) wesentlich stürlser nervortritt als der temporale. Die Spalte ist dem früberen Starinm gegenüber stark verlängert. Wie dort hat sie auch hier die beschriebene schiefe Richtung durch die Becherwand Fon nasal auBen nach temporal innen und ist ungefähr ebenso lang wie die Vorwölbung der Pectenanlage. Threr ganzen Länge naeh wird die Spalte von einer Mesodermlamelle durchzogen (in die Rekonstruktion nicht mit aufgenommen), welche mit dem Mesoderm in der Umgebung der ventralen Augen becherwand zusammenhängt. Diese Mesodermlamelle reicht ein Stück weit in die Becherhöhle hinein und ist hier entsprechend der schiefen Richtung der Spalte temporalwärts geneigt (vgl. Abb. $G_{10}$, S. $310 \%$.

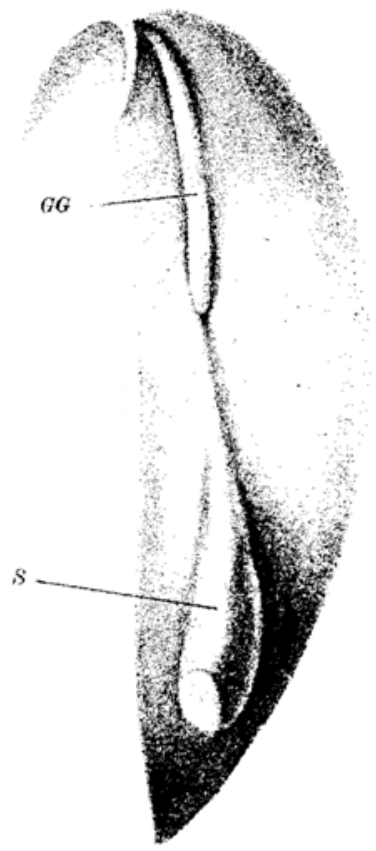

Abb. $\left(G_{7}\right)$ : Rekonstruktionsmodell (125 $\left.\times\right)$ eines Teiles der ventralen Wand des Augenbechers eines $130^{\mathrm{h}}$ alten Embryos von Gallus dom., von außen her gesehen. $1 / 3$ d. nat. Gr.

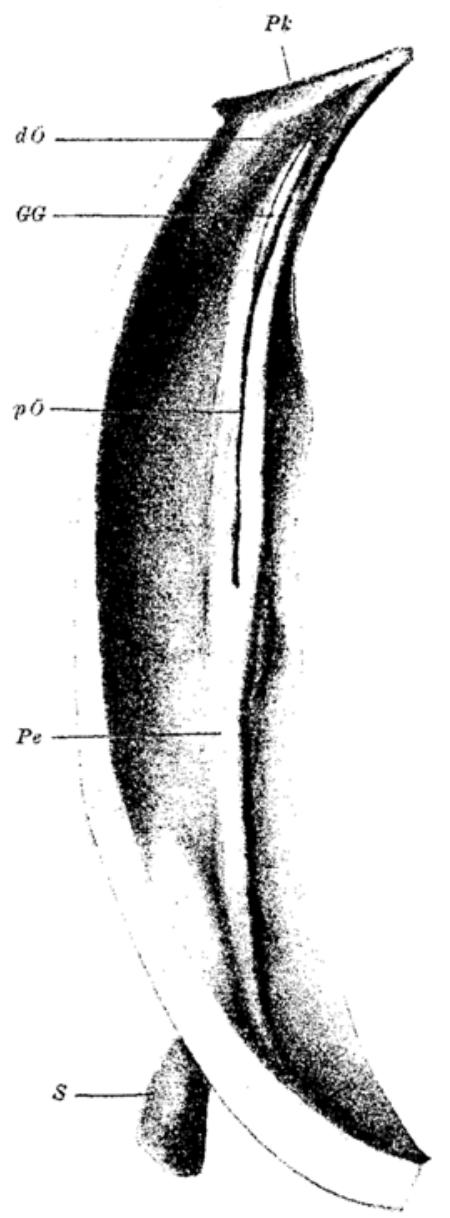

Abb. $\left(\mathrm{C}_{8}{ }^{1}\right)$ : Dasselbe Rekoustruktionsmodell (Gallus dom., 130h), von innen ber gesehen. $1 / 3$ d. nat. Gr.

Das mehrfach beschriebene Gefäß (GG) folgt der erwähnten Rinne an der temporalen Seite des Sehnerven, verläuft dann in derselben weiter distalwärts bis zur proximalen Spalte (Abb. $G_{7}$ ), dringt aber in diese nicht sofort ein, sondern verläuft weiter an der Aubenseite in jener beschriebenen Furche, in deren Tiefe die proximale Spalte jetzt liegt, bis zu ibrem distalen Ende. Erst hier betritt das GefäB die Becherhöhle durch den distalsten Teil der Spalte, verläuft sodann an der Inmenseite des Augeabechers nahe der ventralen Wand und verläßt die Augenbecherhöhle durch die distale ôffnung.

1) Erklärungen der Abktïrungen am Schlusse der Arbeit (S. 342). 
Es zeigt dieses Modell zwei Eigentünlichkeiten: erstens fällt die große Länge der proximalen Spalte auf, die sich sehr weit distalwärts erstreckt und im Verhältnis zu welcher die Wandstrecke zwisehen proximaler Spalte und distaler Offnung relativ sehr kurz ist; Zweitens muß es eigentümlich erseheinen, daß wir unmittelbar proximal von der proximalen Spalte, wo die Pectenanlage an der Innenseite des Augenbechers so mächtig entwickelt ist, an der AuBenseite keine vortretende Sehnervanlage finden. Wir haben das Pecten als Differenzierungsprodukt der Sehnerveninsertion erkannt und gesehen, wie beide Gebilde in gleicher Weise distalwärts vorwachsen. Wenn dies der Fall ist, wie kann dann an einer Stelle, wo man am Modell keinen Sehnerven findet, ein Pecten zustande kommen? Die Erklärung für diesen Sachverhalt ergibt das histologische Schnittbild (s. u.).

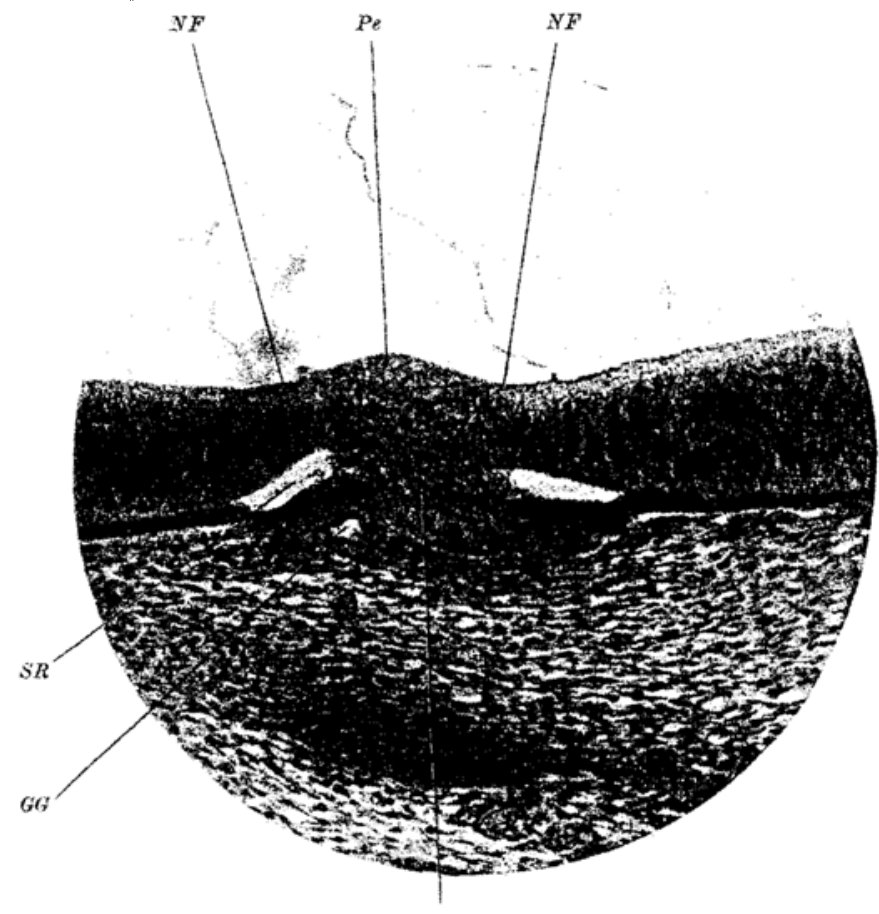

Abb. $G_{9}{ }^{1}$ ): Photographie eines Schnittes durch die Anlage von Sehnerveninsertion und Pecten bei einem $130^{\mathrm{h}}$ alten Eubryo von Gallus dom. Vergr. 168/1.

Betrachten wir die Schnitte in proximalen Teile des Neuropecten, so finden wir im wesentlichen die gleichen Verhältnisse wie früher. Aus der Einsenkung, welche durch die in gröBerer Menge von nasal, in geringerer ton temporal dem Sehnerven zustrebenden kemlosen Nervenfasern gebildet wird, erhebt sich die Pectenanlage im direkten Ansehlusse an die kernhaltige Opticusinsertion. Die Zellen der Pectenanlage stimmen auch hier wieder in allen ihren Qualitäten mit den Gliazellen des Opticus überein. Die Furche, die uns am Modell den distalen Teil der Opticusinsertion von der Augenbecherwand temporalwärts abzugrenzen schien, entspricht, wie die Schnittbilder zeigen, auch hier wieder einer temporal in der distalen Opticusanlage gelegenen Furche, wodurch dieselbe in eine bedentend gröbere nasale und eine wesentlich kleinere temporale Portion unvollständig geteilt wird (Abb. $\mathrm{G}_{3}, \mathrm{~S}$ ). Diese letztere ist so unbedeutend, daß sie am Modell nicht hervortritt. Das Neuropecten grenzte seitlich direkt an die differenzierte Retina, dort, wo Pigmentblatt und retinales Blatt sich in. einander umschlagen $\left(\mathrm{Abb}, \mathrm{G}_{3}\right)$. Es sind also offenbar die der Spalte zunächst gelegen

1) Erklārung der Abkürzungen am Schlusse der Arbeit (S. 342). 
undifferenzierten Randteile beim Vorwachsen des Neuropecten distalwärts in dasselbe aufgeyangen. Je weiter distalwärts wir kommen, desto mehr eingebogen werden die Spaltränder und das Neuropecten kommt dabei nit seinem distalen Teil tief zwischen die Spaltränder zu liegen. Dies hat zur Folge, daß hier die Sehnerveninsertion am Modell nicht als Wulst hervor. tritt. Die Schnittbilder zeigen jedoch, daß die Sehnerveninsertion in Wirklichkeit ebenso weit distal reicht, als eine Pectenanlage vorhanden ist. Distal geht das Neuropecten ohne scharfe Grenze in die Ränder der offenstehenden Spalte über, und zwar, wie früher, in die der Spalte zunächst gelegenen undifferenzierten Partien derselben, von welchen die nasale mächtiger ist als die temporale. Es fällt uns der asymmetrische Bau der Spaltränder auf (Abb. $\left.G_{10}\right)$. Der nasale Rand (in der $\mathrm{Abb}$. rechts) ist schmäler und zugespitzt und ragt ein bedeutendes Stïck weiter in die Becherhöhle vor als der temporale, welcher breit, plump und weniger gegen die Becherhöhle eingebogen ist. Der Formation und Stellung ihrer Pünder entsprechend, hat die

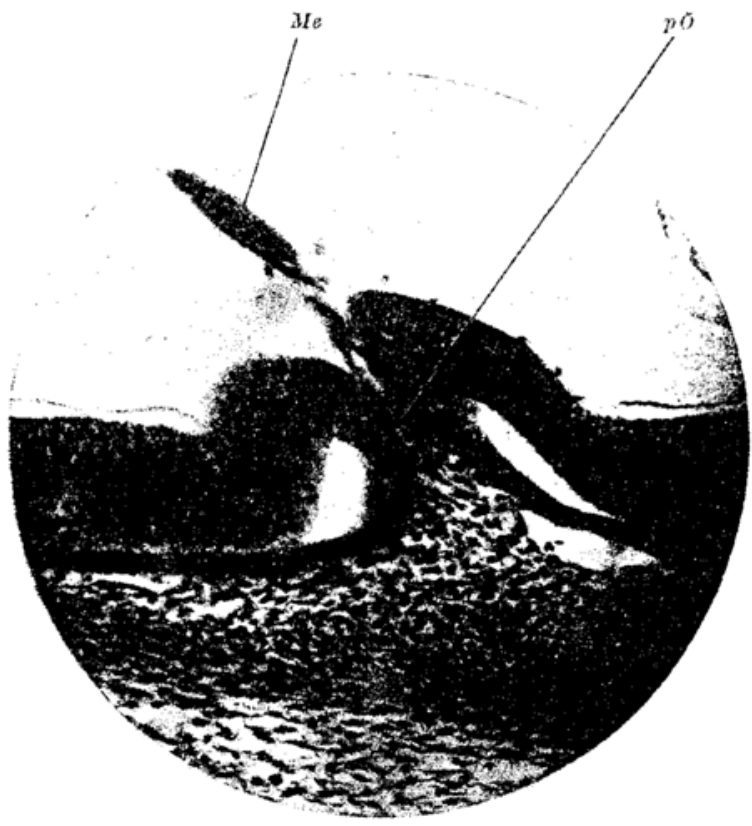

Abb. $\left.G_{10}{ }^{1}\right)$ : Photographie eines Schnittes durch das Gebiet der proximalen spalte mit ihren undifferenzierten Pandteilen von einem $130^{\mathrm{h}}$ alten Fmbryo von Gallus dom. Vergr. 162/1.
Spalte die besehriebene schiefe, von nasal außen nach temporal innen geneigte Stellung. Sie wird von der beschriebenen Mesodermlamelle ( $\mathrm{He}$ ) durchzogen. welche, wie man sieht, mit dem Mesoderm ventral von Augenbecher zusammenhaingt, die proximale Spalte durchzieht und sich dam in der gleichen Rich. tung wie die Spalte. schräg nach temporal und dorsal, frei in dem Glaskörpernam erhebt.

Wie also das Studium der histologischen Details lehrt, haben wir es auch in diesem Falle mit einem Neuropecten zu tun, welches sich ron proximal her in den undifferenzierten Randteilen der proximalen Spalte cistalwairts vorgeschoben hat, wobei diese im Bereich des rorgewachsenen Neuropectens zum Verschlub gekonmen ist. In seinem distalsten Teile liegt das Neuropecten aber so tief zwischen die aufgebogenen Spaltränder eingeschoben, daß wir, wie bereits herrorgehoben, die Sehnerveninsertion bier nicht

mehr als Wulst am Modelle sehen können. Mit dem Einwachsen des distalen Teils der Sehnerveninsertion in die undifferenzierten Teile der hier stark eingebogenen Ränder erklät sich teilweise auch eine andere Frscheinung, die wir bei diesern und anch bei den folgenden Modellen beobachten können: Die Sehnerveninsertion ist in ihrem proximalen Anteile am höchsten und nimmt distalwärts an Höhe $a b$, während die Pectenanlage sich nungekehrt verhält. Sie ist in ihrem proximalen Teile an nierhigsten und nimmt distalwärts bis zur prosimalen Spalte hin an Höhe zu. Außerdem finden wir an Modell noch eine seheínbare Inkongruenz zwischen Pecten- und Sehnervenanlage. Das Pecten wird distalwärts nicht nur höher, sondern auch breiter, während die Sehnervinsertion sich umgekehrt distalwärts versohmälert. Auch diese Verhältnisse lassen sich durch clas Stadium der Schnittserie klären. Doch soll hierauf erst in einem späteren Stadium eingegangen werden, wo sie deutlicher hervortreten, und wir verweisen diesbezïglich auf die Beschreibung des Stadiums $8\left(154^{\mathrm{h}}, \mathrm{S}, 314\right)$.

1) Erklärung der Abkürzungen am Sohlusse der Arbeit (S. 342). 
Stadium 6. $138^{\text {h. }}$.

Retinadifferenzierung so weit fortgeschritten, daß sich nummehr im ventralen Teile der proximalen Retinalwand die innere retikuläre Schicht in Form eines feinen Streifens zu differenzieren beginnt, auf diese Weise die Ganglienzellenschiebt von dem äuberen, noch undifferenzierten Teile der Retina abgrenzend. Die Nervenfaserschicht hat sich weiter ausgebreitet. Vom Becherstiellumen ist an der Dorsalseite der Opticusanlage ein proximaler: und ein distaler Rest zurückgeblieben, von denen der erstere etwas länger ist als der letztere, der nur eine seichte Tasche an der Ubergangsitelle zwischen Optieusanlage and Augenbecher clarstellt.

Das Rekonstraktionsmodell ( $55 x$ ) stimmt der Fauptsache nach mit clem unmittelbar vorher beschriebenen überein. An der AuBenseite ist die Sehnerveninsertion jedooh hier schärfer von der Limgebung abgegrenzt. Ihre Ansatzfläche bildet ein sehr schmales Oval, welches distalwäts in eine lang ausgezogene Spitze ausläuft. Die Furche, in welcher der distale Teil der Opticusanlage liegt, setzt sich über die Spitze der Sehnerveninsertion distalwärs fort bis zur proximalen Spalte, welche auch hier sehr lang ist, die Becherwand von nasal auben nach temporal innen durchsetzt und relativ weit distalwärts reicht. Ihre Ränder sind stark eingebogen und bilden eine Fortsetzung der eben genannten Furche, in deren Grunde die Spalte liegt. Die Furche zwischen proximaler Spalte und distaler Öffnung nur angedeutet.

In nenseite des Modells: Sehr lange Pectenankge, proximal in gleicher Hohe mit der Sehnerveninsertion an der AuBenseite beginnend, distalwärts bis zur proximalen Spalte reichend, wo sie ohne scharfe Grenze in die beiden eingebogenen Spaltränder übergeht. Der proximale Teil der Pectenanlage erhebt sich wie friher aus einer langgestreckten, flacben Einsenkung. Die Pectenanlage nimmt in proximaldistaler Richtung kontinuierlich an Höhe und auch an Breite zu und hat im distalen Telle die Gestalt eines Grates. Da die temporale Wand derselben steiler gegen die Augenbecherwand zu abtall als die nasale, so bekommt die ganze Bildung eine leichte Neigung temporalwärts. Die proximale Spalte durchsetzt wie früher die Augenbecherwand in schiefer, fon nasal außen nach temporal innen geneigter Richtung. Beide Ränder sind im distalen Teile der Spalte stark eingebogen, der nasale stärker als der temporale, weshalb dieser Rand auch stärker gegen die Augenbecherhöhle vorspringt. Distalwärts verflachen beide Rändex. Die Entfernung zwischen proximaler und distaler Öfnung ist ganz kurz, was darauf zurückzuführen ist, da B die proximale Öfnung so auffallend weit distalwärts reicht. Die distale Offnung ist ein kleines Louh unweit vom Pupillarmande.

Wir finden bier wieder eine die ganze Spalte durchsetzende und sich in schiefer Richtung in die Becherhöhle hineinschiebende Mesodermlamelle (in die Rekonstruktion nicht mitgenommen). Das Gefäß betritt die proximale Spalte an ihren distalem Ende, zieht das kurze Stück zwischen proximaler Spalte und distaler Öfnung nahe der Becherwand, hebt sich am weitesten distal etwas mehr von derselben ab und verläBt die Becherhöhle durch die distale öffnung.

Die histologischen Verhältnisse des Neuropecten und der Spaltregion sind der Hauptsache nach hier die gleichen wie im Falle vorher.

Stadium $7.150^{\mathrm{h}}$.

Differenzierung der Retina nicht wesentlich weiter fortgeschritten als im Stadium vorher.

Rekonstruktionsmodell ( $85 x)$.

A uBenseite $\left(\mathrm{Abb} . \mathrm{G}_{11}\right)$ : Lange, schmale, distalwärts abflachende und zugespitzt endigende Sehnerveninsertion (S). Dieselbe ist gegen die Wand des Augenbeehers schari abgegrenzt und liegt mit ihrer größeren distalen Hälfte in einer Einsenkang, welche offenbar durch die eingebogenen Ränder der hier zum Verschluß gekommenen proximalen Spalte gebildet wird. Dabei lehnt sich die Insertion ein wenig an die nasale Wand dieser Einsenkung an und das in die Rekonstruktion mitgenommene Endstück des Optious ist nasalwärts umgebogen. Diese durch die eingebogenen Rïnder gebildete Einsenkung setzt sich über das zugespitzte Ende der Sehnerveninsertion hinaus distalwärts fort bis zur proximalen Spalte ( $\mathrm{pO}$ ), welche wie früher in den Grund dieser Einsenkung zu liegen kommt. Der Abstand zwischen der distalen Spitze der Sehnerveninsertion und der proximalen Spalte ist hier länger als im vorhergehenden Stadium, die Spalte selbst dagegen kürzer. Distale Öff. 
312 C. Lindahl und A. Jokl: Üher den Verschlub der tötalen Augenbecherspaltr,

nung ein kleines Loch nahe dem Pupillarrande; die Furche zwischen proximaler und distaler Öffnung verschwunden.

Innenseite des Modells (Abb. $\mathrm{G}_{13}$ ): Die Pectenanlage (Pe) ist dem früheren Stadium gegenüber verlängert. Sie nimmit distalwärts bis zur proximalen Spalte an Höhe und Breite zu and entspricht proximal in ihrer Lage und Richtung vollkommen der Sehnerveninsertion an der Außenseite, erstreckt sich aber clistalwärts über dieselbe hinaus

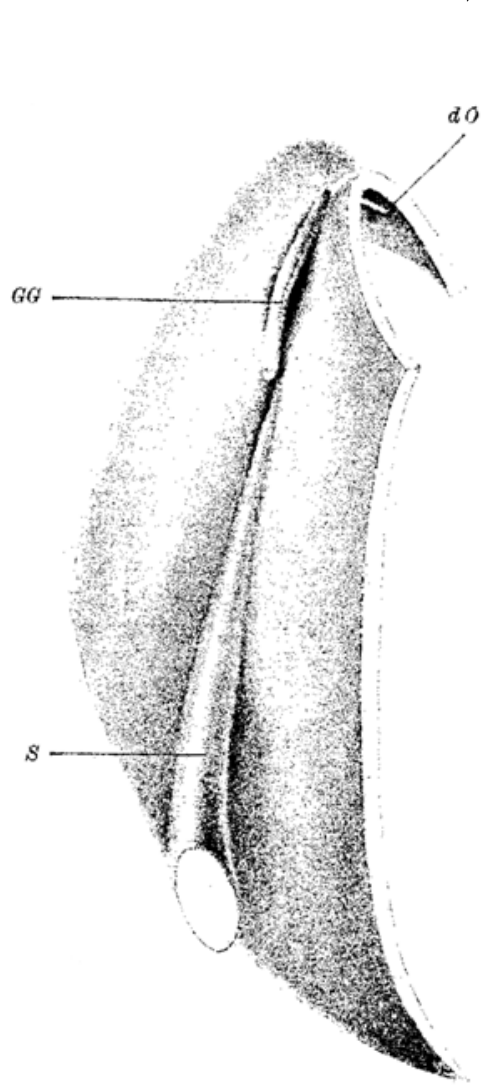

Abb. $\left.\mathrm{G}_{11}{ }^{1}\right)$ : Rekonstruktionsmodell $(85 \times)$ eines Teiles der ventralen Wand des Angenbechers von einem $150^{\mathrm{h}}$ alten Embryo von Gallus dom., von außon her gesehen. $1 / 3$ d, nat. Gr.

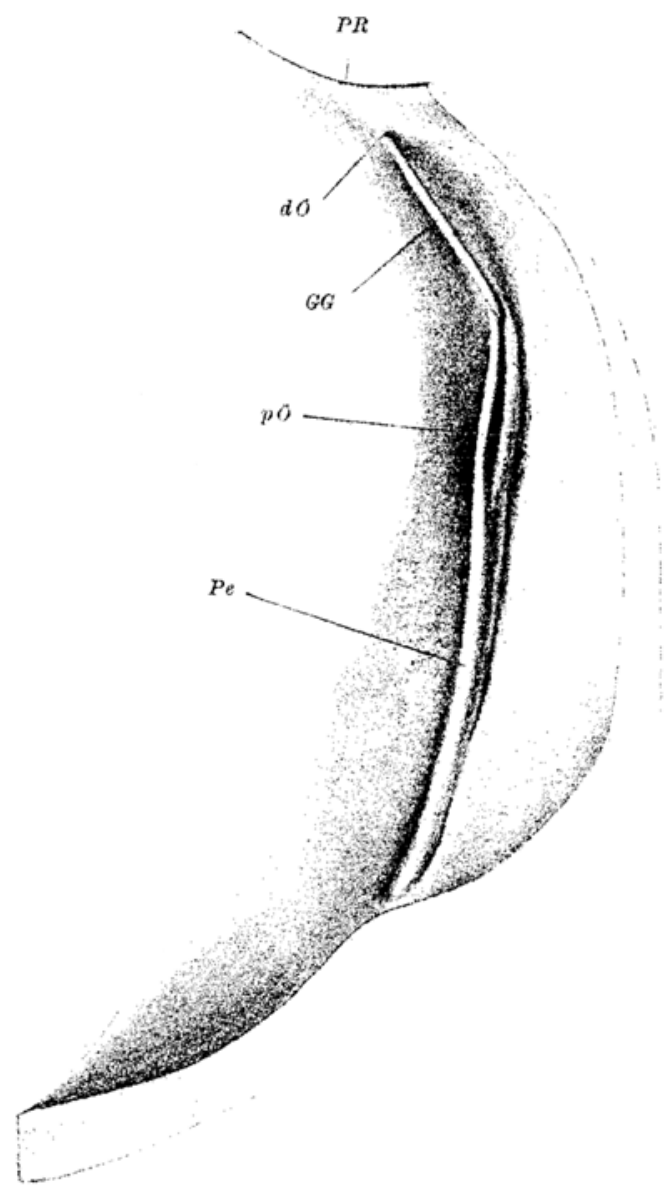

Abb. $\mathrm{G}_{12}{ }^{1}$ ): Dasselbe Rekonstruktionsmodell (Gallas dom., $150^{\mathrm{h}}$, von innen her gesehen. $1 / \mathrm{s}$ d. nat. Gr.

und reicht bis zur proximalen Spalte (pö). Während wir früher einen allmähtichen Übergang des Pecten in beide eingebogenen Spaltränder konstatieren konnten, sehen wir hier, daß sich die Vorwölbung des Pecten hauptsächlich in dem nasalen Rand (in der Abb. lisks) fort. zusetzen scheint, welcher bedeutend böher ist als der temporale. Wir werden auf diesen Ubergang der Pectenvorwölbung in den nasalen Spaltrand später zurückkommen. Die Richtung der proximalen Spalte dureh die Augenbecherwand ist dieselbe wie vorher. Sie ist hier nur etwa halb so lang wie die Pectenanlage.

Die Spalte wird wie früher von einer Mesodermlamelle durchzogen (nicht mitrekonstruiert), welche in die Augenbecherlöble frei hineinragt und wie fruher temporalwärts geneigt ist. Das beschriebene Gefä $B\left(A b b . G_{11}, G G\right)$ verläuft zuerst an der Außenseite des Augen-

1) Erklärung der Ablürzungen am Schlusse der Arbeit (S. 342). 
bechers in der erwähnten Finsenkung zwischen den eingebogenen Spalträndern bis zum distalen Ende der proximalen Spalte, wo ea dieselbe in schiefer Richtung durchzieht, um sich dann sofort von der Becherwand abzuheben (Abb. $G_{12}, G_{x} G$ ) und sehnenförmig über den gewölbten Teil der Wand der Augenbeoherhöhle zwischen proximaler und distaler Offnumg zu letzteren zu verlaufen.

Das Verbältnis zwischen der Länge der proximalen Spalte und der des Pecten hat sich hier zu ungunsten der proximalen Spalte so verschoben. dab diese etwa die Hilfie der Pectenlinge ausmacht.

Das his tologische Schnittbild lehrt im übrigen folgendes:

Die Pectenanlage lißßt sich, wenigstens in ihrem proximalen Teile, besser? als friher von der Sehnervenamlage abgrenzen (Abb. $G_{13}$, Pe). Sie besteht aus distal gelagerten Glinzellen, welche sich oberflächlich epithel. artig anzuordnen beginned. Weiter distalwärts liegen die Zellen im Inneren der Anlage etwas lockerer. Noch besser als am Rekonstruk. tionsmodell sieht man an den Schnitten die schiefe, gegen den nasilen Spaltrand angelehnte Stellung der Opticusinsertion entsprechend der schiefen Pichtung der Spalte, in Geren Pändern sie vorgewablen ist.

Die Furche, welche fruher eine kleinere temporale Portion des distalen Teiles der Opticusinsertion fon einer bsdeutend gröBeren nasalen abgrenzte (vgl. die histol. Beschrejbung bei Stadium 5 (S. 306), ist jetzt nahezu vollkommen ausgeglichen, womit die Opticusinsertion frst vollständig an den nasalen Spaltrand zu liegen kowmt.

Die beider Beschreibung des Modells erwähnte Tatsache, daß die proximale

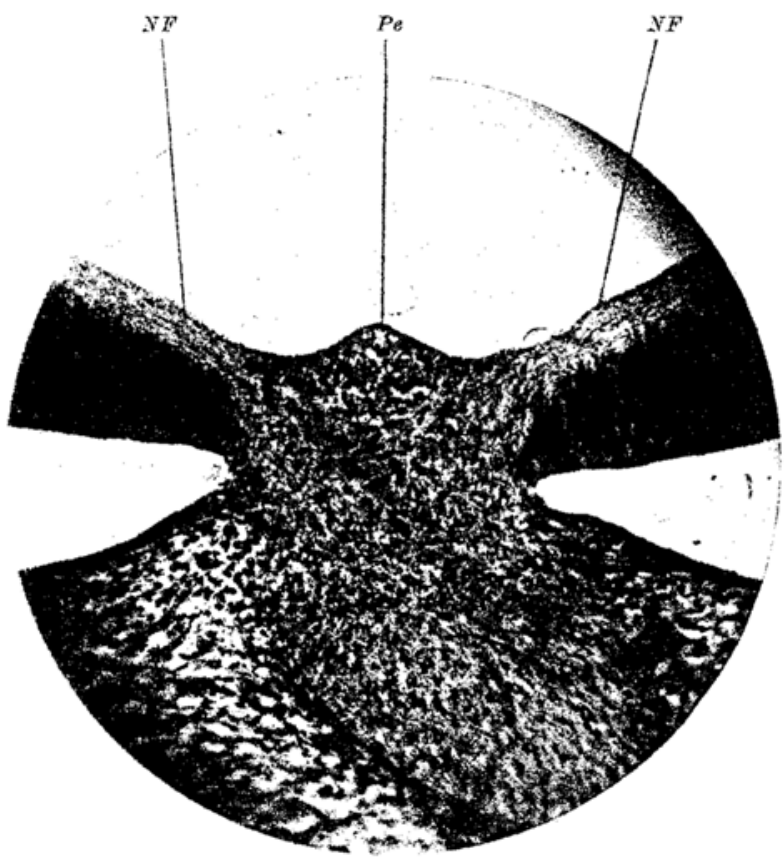

Abb. $\mathrm{G}_{13}{ }^{2}$ ): Photographie eines Schnittes durch die Anlage ron Sahnerveninsertion und Pecten bei einem $150^{\mathrm{h}}$ alten Embryo von Gallus dom. Vergr. 154/1. Spalte im Verbältnis zum Neuropecten so bedeutend kirzer geworden ist, erklät sich, wie die Schnittbilder zeigen, daraus, daß das Nenropecten noch weiter in den undifferenzierten Randteilen der proximalen Spalte distalwärts vorgewachsen ist und diese sich dabei geschlossen hat. Distal sind die Ränder der proximalen Spalte so stark nach innen zu eingebogen, das ihre undifferenzierten innersten Teile in die Augenbecherhöle verlagert sind, was offenbar zur Folge hat, daß die in ihnen vorgewachsene Sehnerveninsertion an der Außenseite des Modells hier nicht mehr als Wulst hervortreten kann. Wenn diese Innenteile der Ränder sich durch das Einwachsen von Nervenfasern wie friher verdicken und zum Verschmelzen kommen, so kann nur eine Einsenkung an der AuBenseite entstehen, welche auch arm Nodell zwischen der Spitze, in welcher die Sehnerveninsertion distal zu endigen scheint, und dem proximalen Beginn der proximalen Spalte vorhanden ist. Das Schnittbild zeigt, daß3 sich die Opticusinsertion ebenso weit distalwärts verfolgen läßt wie das Pecten.

1) Erklärung der Abkürzungen am Schlusse der Arbeit (S, 342). 
$31 \pm$ C. Lindali mol A. Jokl: Über den Terschlub der fötalen Angenbecherspalte.

\section{Stadium S. $154^{\text {h }}$.}

Diffcrenzierung cler Retina nicht weiter fortgeschritten.

Pekonstruktionsmodell ( $85 x)$.

A uBenseite: Wie in dem zuletzt beschriebenen Stadium zeigt auch dieses Hodell eine langgestreckte Sehnerveninsertion mit einem distalwärts sich ablachenden und

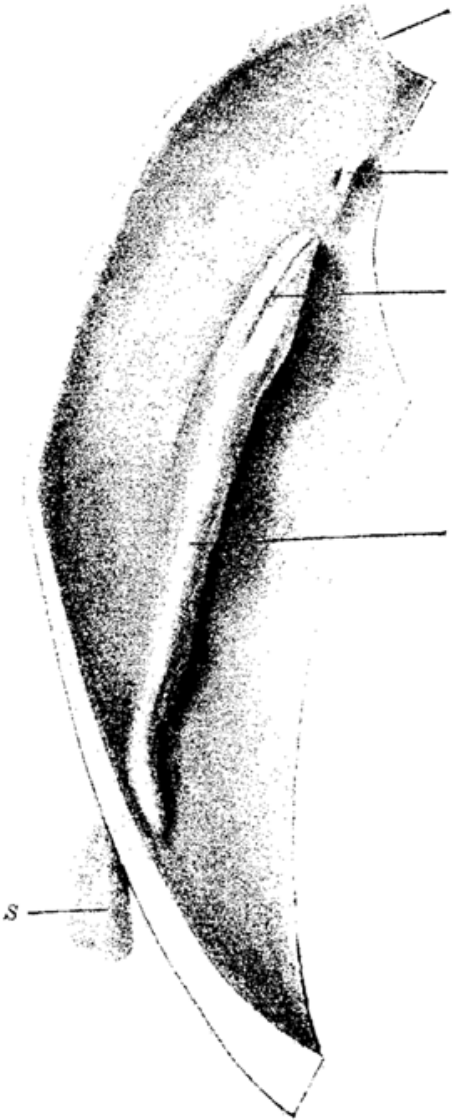

Abb. $\left.\mathrm{G}_{14}{ }^{1}\right)$ : Rekonstruktionsmodell $(85 x)$ eimes Teiles der ventralen Wand des Augenbechers von einem $154^{\text {hl }}$ alten Embryo von Gallus dom., von innen her gesehen. ${ }^{1 / 3}$ d. nat. Crr. verschmälemden und schlieBlich spitz auslaufenden Ende, welches distal nicht bis zur proximalen Spalte reicht. Distaler Teil in der Einsenkung zwisehen den fruheren eingebogenen Spaltrïndern gelegen, an die nasale Wand angelehnt. Das in die Rekonstruktion nitgenommene Endstiick des Opticus ist wie früher nasalwärts umgebogen. Die ganze Sehnerveninsertion breiter and kriiftiger als rorher. Die erwähnte Ein. senkung reicht bis zur proximalen spalte und diese öfnet sich in ihrem Grunde. Die Strecke zwischen proximaler Spalte und distaler Öffnung ganz kurz. Distale Offrnung ein kleines Loch nahe dem Pupillarrand.

Innenseite des Modells (Abb. $G_{14}$ ): Die Pectenanlage $(\mathrm{Pe})$ ist zu einem mächtigen, breiten Grate geworden, der in proximodistaler Richtung bis zur promixalen Spalte hin kontinuierlich an Breite und Höhe zunimmt. Er setzt sich ohne scharfe Grenze in den nasalen Spaltrand fort (in der Abb. rechts), weleher ganz bedeutend höher ist als der temporale. Beide Ränder verflachen sich distalwärts. Die Spalte (pÖ) ist wieder bedeutend kürzer als beim Stadium vorher (etwa ein Drittel der Pectenanlage) und ihre

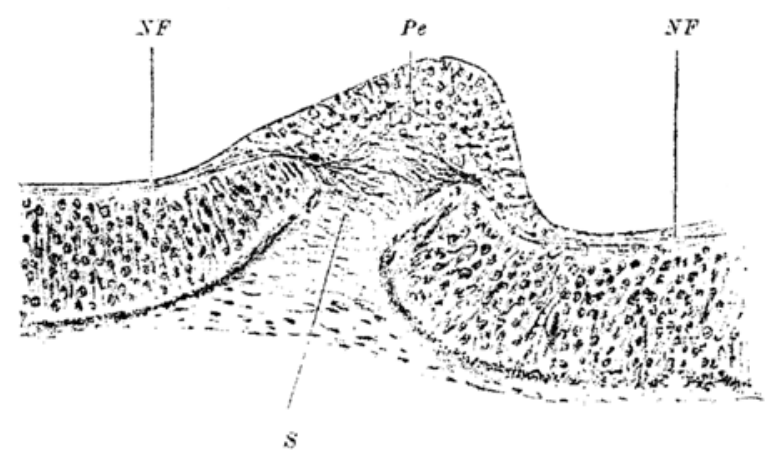

Abb. $\left(\mathrm{C}_{15}{ }^{3}\right)$ : Zeichnung eines Sohnittes durch den mittleren Teil der Anlage von Sehnerveninsertion nud Pecten bei einem 15 $4^{\prime \prime}$ alten Embryo von Gallus dom. Vergr. $195 / 1$.

Ränder liegen im proximalen Teile einander dicht an. Das erwähnte GefäB ist atrophisch geworden. Nahe der distalen Öffnung noch ein kleiner Rest desselben (GG) vorhanden.

Im Schnittbild ${ }^{2}$ ) sehen wir in mittleren Teile des Neuropectens die Pecten. anlage in Form eines Hügels gegen den Glazkörperraum hin vorspringen ( $\mathrm{Abb} . \mathrm{G}_{13}, \mathrm{Pe}$ ).

1) Erklärung der Abkürzungen am Schlusse der Arbeit (S. 342).

2) Die große Schnittdicke $(18, b)$ dieser und der folgenden Serien von Gallus ließ eine photographische Wiedergabe der Schnitte nicht zu, weshalb statt dessen Zeichnungen rorgelegt werden. 
Die temporale Wand des Pecten (in der Abb. rechts) fällt steiler gegen die Becherwand ab als die nasale. Durch die aus der Retina in den Opticus einwachsenden Nervenfasern ist das Pecten von diesen beiden Gebilden recht scharf abgegrenzt. Es besteht aus locker liegenden, mit verästelten Fortsätzen versehenen Zellen, welche mit einander anastomosieren und auf diese Weise ein Netzwerk bilden, in dessen Knotenpunkten die von spïrlichem Protoplasma umgebenen Zellkerne liegen. Die ganze Bildung erhält auf die Weise einen porös-schwammigen Charakter. Die Verdichtung der Zellen an der Obertläche ist hier nur angedentet. Die ganze Anlage (Pe) ist wesentlich breiter als die Sehnerveninsertion $\left.(S)^{\mathrm{y}}\right)$ wie dies auch an Model hervortritt. Es beruht dies darauf, daß die Pectenanlage nicht nur den ganzen Raum zwischen den von nasal und temporal in den Sehnerven verlaufenden Nervenfasern ausfült, sonderm mit ihren seitlichen Partien anch auf die benaehbarte Retina zu liegen kommt. Die undifferenzierten Teile der stark eingebogenen Ränder sind nunmehr in die Sehnerveninsertion aufgenommen worden. Dadurch haben die Ränder, wie früher erwähnt wurde, so an Umfang zugenommen, daB sie zur Aneinanderlagerung gekommen sind, so da Spalte hier geschlosson hat. Die Sehnerveninsertion kommt dabei so tief eingebettet zwischen die differenzierten Teile der eingebogenen Ränder der früheren Spalte zu liegen, daB sie an der AuBenseite des Modells in dieser Gegend kaum als Wulst hervortritt. Sie grenzt direkt an die differenzierte Retina, dort, wo äußeres und inneres Blatt derselben

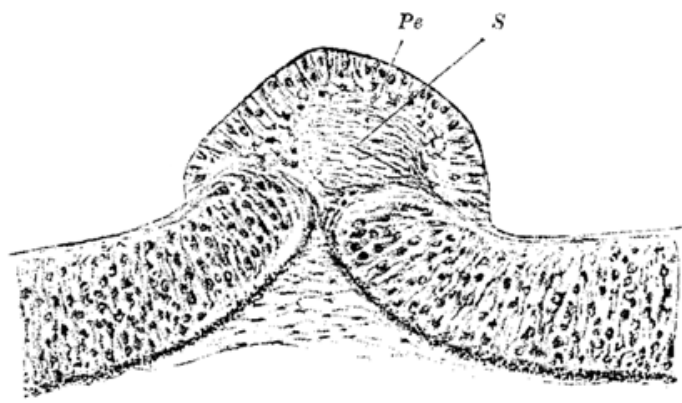

Abb. $\left(i_{16}{ }^{2}\right)$ : Zeichnung eines Schnittes duch die gleichen Gebilde desselben Embryos

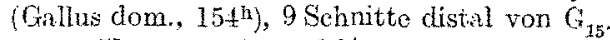
Vergr. $195 / 1$; auf $3 / 5$ verkleinert.

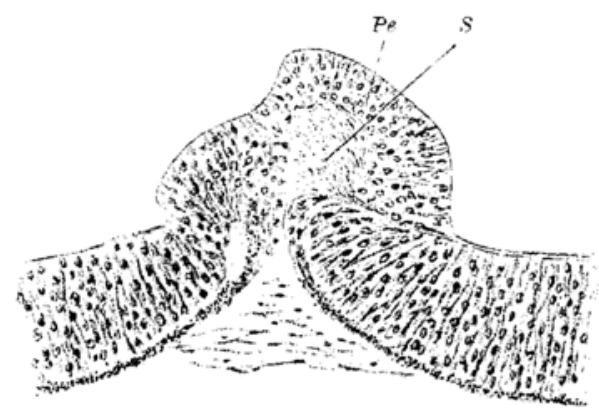

Abb. $\left(\mathrm{C}_{17^{2}}\right)$ : Zeichnung eines Schnittes durch die gleiehen Gebilde desselben Fmbryos (Gallus dom., 154 $)$; Sohnitte distal von $\mathrm{G}_{\mathrm{a} 2}$. Vergr. 195/1; auf $3 / 5$ verkleinert.

in einander übergehen, ein Beweis clafür, daB die undifferenzierten Ründer in die Sehnerveninsertion aufgenommen wurden. Gehen wir weiter distalwärts, so erhaiten wir folgendes Bild $\left(\mathrm{Abb}, \mathrm{G}_{16}\right.$ ). Die Sehnerveninsertion (S) ist zwiwchen die hier noch mehr eingebogenen Spaltründer so weit nach innen verlagert, daB die Spaltränder sich auberhalb derselben aneinander gelegt haben, so dab sie vollkommen in die Becherwand aufgenommen erscheint. Die Pectenanlage (Pe) aber liegt nusgebreitet wie eine Kappe auf der Sehnerveninsertion und den benachbaten differenzierten Spaltiandern. Sxhon an diesem Bilde sieht. man, daB der Sehnery mehr den nasalen Spaltrand interessiert. Noch deutlicher wird dieses weiter distal (Abb, $\mathrm{G}_{17}$ ). Hier liegt die Sehnerveninsertion (S) ausschlieblich dem differenzierten Teile des nasalen Spaltrandes anfgelagert, während der temporale (in der Abb. links) hier noch seine undifferenzierte Zone besitzt. Die Pecteranlage (Pe) breitet sich kappenförmig uber die Sehnerreninsertion und den differenzierten Teil des nasalen Spaltrandes aus und grenzt nur längs eines schmalen Stückes an den undifferenzierten temporalen Rand. Entsprechend der Tatsache, daß der nasale Rand friher stärker gegen die Becherhöhle eingebogen war als der temporale, finden wir auch hier, daß dieser Rand mit dem in seiner

1) Die Bündel in der Sehnerveninsertion sind zum größten Teile nicht quer, sondern sohief geschnitten, entsprechend der Tatsache, daß sie aus der Retina von beiden Seiten her in schiefem Verlaufe von distal-nasal resp. distal-temporal her in die Sehnerveninsertion eintreten.

9) Erklärung der Abküzungen am Schlasse der Arbeit (S. 342).

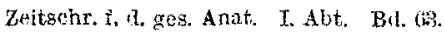


316 C. Lindabl und A. Jokl: Cber den Verschluß der fotalen dugenbecherspalte,

andifferenzierten Randportion vorgewachsenen Neuropecten stärker gegen die Becherhöhle zu vortritt als der temporale. Die Grenze beider Ründer markiert sich durch eine seichte Furche dort, wo die Peetenanlage an den undifferenzierten temporalen, saltrand grenzt. Am weitesten distal in der offenen Spalte zeigt anch der nasale Rand eine undifferenzierte Zone, welche hier kräftiger ist als die entsprechende temporale.

\section{Stadium 9. $168^{\mathrm{h}}$.}

Nervenfaserschicht, Ganglienzellenschicht und innere retikuläre Schicht in der proximalen Wand der Retina ausgebildet. Beginnende Anlage des Corpus ciliare.

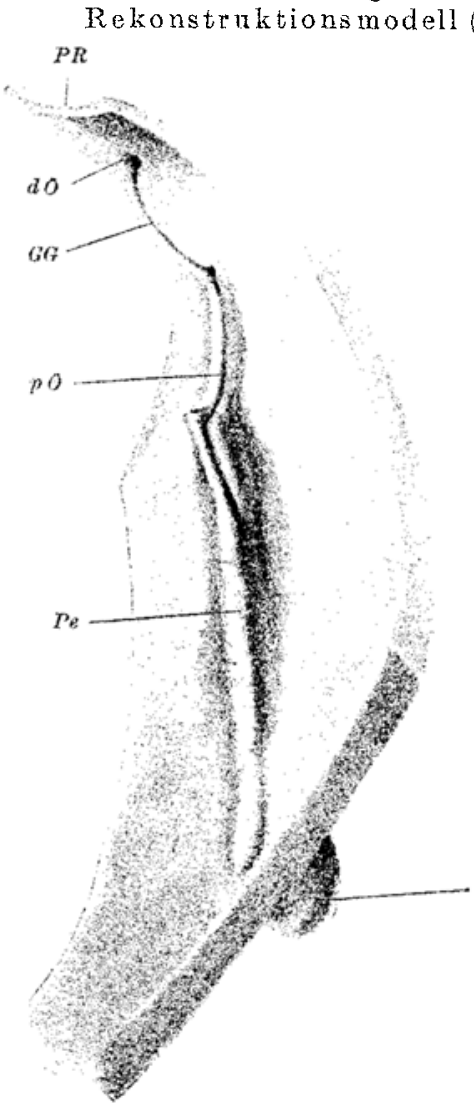

Abb. $\left.G_{18}{ }^{1}\right)$ : Rekonstruktionsmodell $(85 \times)$ eines Teiles der ventralen Wand des Augenbechers eines $168^{\mathrm{h}}$ alten Embryos von Gallus dom., von innen her gesehen.
AuBenseite: Kräftige Sehnerveninsertion von der gleichen Form und Lage wie im Stadium vorher, sich noch etwas weiter distalwirts exstreckend als dort. Ihr distalster Teil liegt wie früher in einer Einsenkung, welche sich distalwärts über die Spitze der Sehnerveninsertion hinaus fortsetzt. Im distalen Teile dieser Einsenkung liegt die proximale Spalte, welche hier abermals riel küzer geworden ist als im Falle vorher.

In nenseite (Abb. $\mathrm{G}_{18}$ ): Breite, kräftige Pectenanlage (Pe), in proximo-distaler Pichtung an Breite und allmählich auch an Höhe zunehmend, um unmittelbar vor der proximalen Spalte (pö) ganz plötzlich wieder abzufallen und in die bedeutend niedrigeren Begrenzungsränder der Spalte überzugehen; von diesen ist wie früher der nasale etwas höher als der temporale. Die Pectenanlage trägt an ihrer temporalen seite, etwa im distalen Viextel, einè seichte Furche, welche eine höhere nasale (in der $\mathrm{Abb}$. links) und eine niedrigere temporale

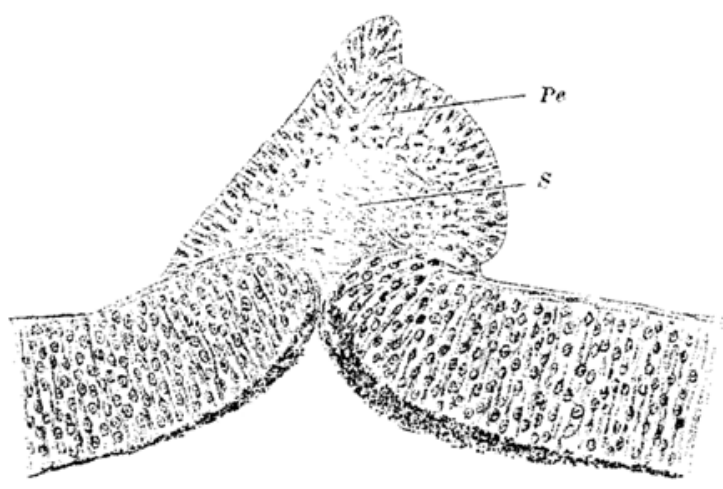

Abb, $\left.\mathrm{G}_{19}{ }^{1}\right)$ : Sehnitt durch den distalen Teil der Anlage von Sehnerveninsertion and Pecten bei einem $168^{\mathrm{h}}$ alten Embryo von Gallus dom. Vergr. 195/1; auf $3 / 5$ verkleinert.

Portion des Pecten unvollständig scheidet und distal in die proximale Spalte (p 0 ) ausläuft. Die Länge der proximalen Spalte betrügt hier ungeführ ein Viertel der Pectenlänge. Im proximalen Teil der Spalte eine schwanhe Mesenchymlamelle (in die Rukonstruktion nicht mit aufgenommen), und distal betritt dieselbe ein atrophisches GefäBrest (GG), der in schwachen Bogen zur Stelle der distalen Öfnung zieht. Die Öffnung selbst ist bereits verschlossen.

1) Erklërung der Abkiürzungen am Schlusse der Arbeit (S. 342). 
Betrachten wir die Schnittbilder dieses Objekts, so finden wir im proximalen Teile desselben im wesentlichen gleiche Verhältnisse wie beim Stadium vorher. Wir sehen die nasalwärts gerichtete Sehnerveninsertion, welche die Retina durchsetat und der innen ein hügelförmiges Pecten aufsitzt von gleicher histologischer Btruktur als vorher, welches die ganze Einsenkung zwischen den von nasal und temporal kommenden und sich hier vereinjgenden Nervenfasern ausfüllt und mit seinen seitlichen Teilen auf der benachbarten Retina liegt. Weiter distal, ungefähr in der Mitte der Pectenanlage sehen wir die Opticusinsertion tief eingeschoben zwischen den etwas eingebogenen Spalträndern liegen. Diese zeigen hier nicht mehr die früher beobachtete undifferenzierte Randzone zunächst der Spalte, sondern dieselbe scheint in den Sehnerven und das Pecten aufgegangen zu sein und diese beiden Gebilde grenzen direkt an die differenzierte Retina ( $\mathrm{gl}$. $\mathrm{Ab}$ b. $\mathrm{G}_{15}$ ). Die Seh. nerveninsertion ist etwas nasalwärts gerichtet und billet an der AuBenseite nur eine leichte Vorwolbung. Das Pecten ist höher als proximal und üher die Tnnenseite der etwas eingebo. genen Spaltränder wie eine Kappe ausgebreitet. Noch weiter distal ( $A b b . G_{19}$ ), im Berciche des gefurchten Pecten ( $v$ gl. Modellbild $G_{18}$ ) sohen wir die Sehnerveninsertion (S) noeh nrehx zwizhen die eingebogenen differenzierten Ränder eingeschoben, so daß sie an die Innenseite derselben zu liegen kommt und diesen beiden größtenteils aufliegt, dem nasalen aber stärkcr als dem temporalen. Nach auBen von ihr haben sich die seitlichen Teile der Ründer aneinander gelegt. Über die Sehnerveninsertion und uber die Spaltränder breitet sich die Peetenanlage (Pe) aus, welche demgenäß auch mit einer größeren und höheren Portion auf dem nasalen Spaltrand utd mit einer kleineren und niedrigeren auf dem temporalen Rand liegt, zwischen welchem eine seichte Furche verläuft, welche der Furche entepricht, die wir an Modell im distalsten Viertel der Pectenanlage beobachtet haben.

Im distalsten T'eile der noch offenen Spalte sehen wir die Ränder mit ihrem innersten Anteile so stark zurüekgebogen, duß sie teilweise auf die benach harte Retina zu liegen konmen. Die Wülste, welche die stark gegen die Becherhöhle eingebogenen Pänder bei früberen Stadien bildeten, sind dadurch hier (am weitesten distal) relativ niedriger. Doch ist auch hier der nasale etwas höher als der temporale. Ihre Zellen baben die gleiche undifferenzierte Beschaffenheit beibehalten wie in den früheren Stadien und das Neuropecten geht ohne scharfe Grenze in diese undifferenzierten Teile über.

Die an Modell im distalen Teile der Pectcnunlage sichtbare Furche, welche dieselbe hier in einen höheren nasalen und einen niedrigeren temporalen Abschnitt unvollotitindig teilt, kommt, wie die Sehnittbilder zeigen, dadurch zustande, da $B$ das Neuropecten hier in z wei Portionen distalwarts vorgewachsen ist, von denen die nasale kräftiger entwickelt ist, entsprechend der mächtigeren undifferenzierten Randzone, in der sie vorwuchs. Ihr stürkeres Vortreten gegen die Becherhöhle zu wird auch dadurch bedingt, daß der nasale Rand stärker eingebogen war als der temporale. Wir können diesen Sachverhalt auch in der Weise auffassen, daB wir es hier mit einem im distalen Anteil in $z$ wei ungleich starke Portionengeteilten Neuropectenzu tun haben, die jedoch sich gleichzeitig mit ihrem Vorwachsen distalwarts sogleich aneinander legen. Threr Aneinanderlagerungsstelle entspricht die am Modell sichtbare Furche im distalen Anteil der Pectenanlage.

Die Pectenanlage an dem Modell entspricht, wie das Schnittstudium lehrt, nicht nur dieser allein, sondern dem ganzen Neuropecten plus den eingebogenen differcnzierten Randteilen der früheren Spalte $\left(\mathrm{Abb} . \mathrm{G}_{19}\right)$.

\section{Stadium 10. $266^{\mathrm{h}}$.}

Die Differenzierung der Retina ist so weit fortgeschritten, daß in der proximalen Retinalwand die äufere retikulire Sehicht in Form eines schmalen Streifens siehtbar geworden ist.

Sehr hohe Pectenanlage mit epithelartig differenzierten Zellen an ihrer Oberfläche und locker angeordneten Zellen im Inneren. In ihrem distalen Teile kamn man an derselben zwei Abteilungen unterstheiden: eine frei in die Becherhöhle hineinragende plattenförmige von bedeutender Höhe, welche im wesentlichen aus den epithelartigen Zellen besteht und nur einen schmalen Streifen des lockeren Gewebes enthät, und einen basalen Teil von am Querschnitt et wa dreieckiger Form, der die epithejale Schicht an seiner Außenseite und reichliche lockere Zellen im Inneren enthält. Der basale Teil des Pecten präsentiert sich proximal auf 
Schuitten, die quer zu demselben gerichtet sind, als keilförmig zwischen die von beiden Seiten zur Sehnerveninsertion ziehenden Nervenfasern eingelagert. Im distalen Teile der Anlage sehen wir nunmehr, dass das mächtiger gewordene Neuropecten den Raum zwischen den differenzierten Randteilen der früheren Spalte völlig ausfüllt, so daß diese Randteile einander nun außen von der Sehnerveninsertion nicht mehr anliegen, sondern vielmehr durch das größer gewordene Neuropeeten auseinander gedrängt sind. Die frühere Einbiegung der Ränder gegen die Becherhöhle hin ist nun auch im distalsten Teile fast ganz ausgeglichen. Das Neuropecten ist in den undifferenzierten Randteilen der Spalte bis an ihr Ende vorgewachsen und hat diese vollkommen a usgefüllt, so daß von einer offenen Spalte keine Spur zurückgeblieben ist. Entsprechend der sehiefen Richtung der Spalte, in deren Rändern das Neuropecten vorgewachsen ist, sehen wir die Sehnerveninsertion nasalwärts, dar Pecten temporalwäts gewendet.

Das schon in vorigen Stadium atrophische Gefäß ist nun verschwunden. Dagegen ist ein deutlicher Rest der distalen Offnung zu sehen in Formeiner auf mehreren aufeinander folgenden Schnitten sichtbaren Stelle innerhalb des numehr stark gefalteten Corpus ciliare vorhanden, welche Stelle sich als zwei nach a ußen um. gebogene Lippen darstell $\mathrm{t}\left(\mathrm{Abb} . \mathrm{G}_{20}\right)$. Diese liegen mit ihren Innenseiten dicht gegeneinander, und an ihren freien Rändern schlägt sich das Retinablatt der Pars ciliaris in dus Pigmentblatt um.

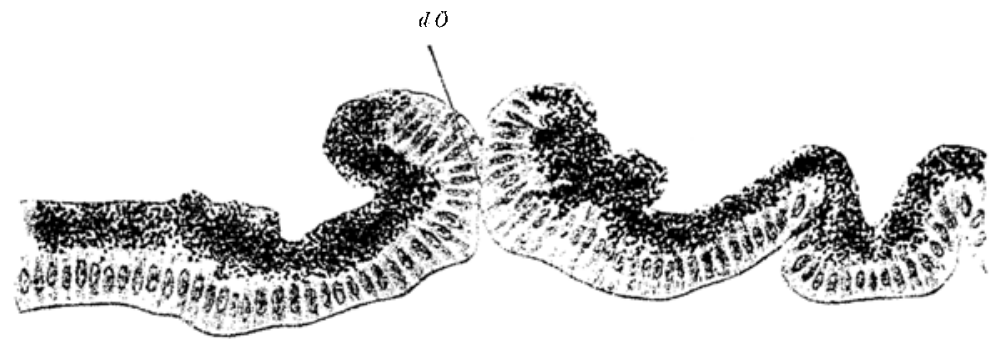

Abb. $G_{20}{ }^{1}$ ): Zeichnung eines Schnittes durch den Rest der distalen Öfnung im Ciliarkörpergebiet ron einem $266^{\mathrm{h}}$ alten Embryo von Gallus dom. Vergr. $268 / 1$; auf $9 / 10$ verkleinert.

Wir haben also in diesem Endstadium der uns vorliegenden Serie von Hühnerembryonen den gleichen Sachverhalt vor uns wieindem Endstadium von Podiceps, Anas u ud Passer: Ein ungeteiltes Neuropecten, welches in den undifferenzierten Rändern der proximalen spalte bis an ihr distales Ende vorgewachsen ist und sie dabei zum Ferschluß gebracht hat. Fntsprechend der schiefen Richtung der Spalte ist dieses Neuropecten wie bei den anderen Arten ebenfalls beim $\mathrm{Huhn}$ sohief gestellt, so daß das Pecten sich temporalwärts, der Wulst der Sehnerveninsertion nasalwärts neigt.

\section{Zusammeniassung.}

Die fötale Augenspalte (AS in Abb. $G_{1}, S .302$ ) ist bei unserem jüngsten Stadium (1) ihrer ganzen Länge nach offen und geht distal mit divergierenden Rändern in die Pupillaröfnung über. Sie wird von einem Gefäß durchzogen, welches von dem ventral von Augenbecher und Becherstiel sich ausbreitenden GefäBplexus stammt. In seiner Ungebung finden sich Mesodermallen, die ebenfalls aus dem Mesoderm der Umgebung der ventralen Argenbecherwand stammen. An unserm nächsten Stadium (2) Abb. $\mathrm{G}_{2}, \mathrm{G}_{3}$ (S. 303) ist die Spalte in ihrem mittleren und ihrem distalsten Anteile ver-

1) Erklärung der Abkürzungen an Schlusse der Arbeit (S. 342). 
schlossen; als ihre Reste sind zweispaltförmige Offinungen zurückgreblieben, eine etwas längere proximale (p $\ddot{O})$ und eine etwas kürzere distale (dO). In der Verbindungslinie dieser beiden Offnungen markiert sich die Verschlußstelle durch je eine Furche an der Außenseite ( $\mathrm{Fa}$ in $\mathrm{Abb}, \mathrm{G}_{2}$ [auch in $\mathrm{Abb} . \mathrm{G}_{1}$ sichtbar]) and Innenseite $\mathrm{Fi}$ in $\mathrm{Abb} . \mathrm{G}_{5}$ (S. 305); die Furche an der Innenseite ist ron zwei flachen Wülsten begrenzt $\left(A b b, G_{3}\right.$ und $\left.G_{5}\right)$, entsprechend der Tatsache, daß die Ränder der früheren Spalte etwas gegen die Becherhöhle zu eingebogen sind. Bei dem Versehluß der Spalte wird das erwähnte Gefäß zum Teil in die Becherhöhle aufgenommen, in der Weise, daß es nunmehr die proximale Offnung in schräger Richtung durchzieht (vgl. Abb. $\mathrm{G}_{2}$, S. 303, GG) und auf diese Weise in das Innere des Augenbechers gelangt. Darauf lagert es sich, auch hier von Mesodermzellen begleitet, der erwännten Furche ein, welche die beiden Öffnungen an der Innenseite des Augenbechers verbindet und verläßt denselben wieder durch die distale öffnung (vgl. $A b b . G_{3}, S .303 G G$ ).

Im weiteren Verlaufe der Entwicklung nimmt die proximale Offnung in distaler Richtung bedeutend an Länge zu [pÖ Abb. $G_{4}$ (S. 305), $G_{5}$ (S. 305) $G_{8}$ (S. 308)] und wird zu einer langen Spalte. Gleichzeitig wird sie von proximal her verschlossen in einer Weise, die weiter unten geschildert werden soll. Die Ränder dieser Spalte biegen sich immer mehr gegen die Becherhöhle zu ein und zwar sind sie im distalen Teile der Spalte immer stärker eingebogen als im proximalen. Der nasale Rand übertrifft dabei stets den temporalen (vgl. $A b b . G_{10}$ S. 310, nasaler Rand rechts). Betrachtet man an einem Rekonstruktionsmodell die Spaitgegend vin der Innenseite, so erscheinen die Spaltränder hier in Form zweier die Spalte jederseits begrenzender Wülste, von welchen der nasale stets stärker hervortritt als der temporale (Abb. $\mathrm{G}_{12}, \mathrm{~S} .312$ ). Diese Umbiegung der Spaltränder geht in älteren Stadien im distalsten Teile der Spalte so weit, daß die Ründer hier vollkommen nach innen zu umgelegt sind, so daß ihr äußerstes Ende auf die benachbarte Retina zu liegen kommt. Ihre Höhe wird dadurch hier geringer $\left(A b b . G_{18}, S .316\right)$. Die Einbiegung der Ränder hat zur Folge, daß an der Außenseite des Augenbechers eine im Querschnitt keilförmige Einsenkung entsteht, in deren Tiefe sich die proximale Spalte offnet (vgl. Abb. $\mathrm{G}_{10}$ ). Die beiden Spaltränder sind, wie die Schnittbilder zeigen, nicht symmetrisch gebaut. Der nasale ist schräler, spitz zulaufend und stärker eingebogen, während der temporale breit, plump und in seinem innersten Teile ein wenig aufgebogen ist. Durch die Formation der Ränder erhält die Spalte eine schräge Stellung: sie durchsetzt die Augenbecherwand von nasal außen nach temporal innen $\left(A b b . G_{10}\right)$.

Die der proximalen Spalte zunächst gelegenen Partien ihrer Ränder zeigen ein eigentümliches Verhalten. Während nämlich die Zellen der übrigen Retina sich mit zunehmendem Alter immer weiter differenzieren, bleiben sie im Bereiche dieser Randpartien auf einem primitiven Entwicklungsstadium stehen (vol. Abb. $G_{10}$ ): Die Zellen des Pigmentblattes bleiben hier boch zylindrisch und frei von Pigment ${ }^{\mathbf{1}}$ ), während sie sonst im Pigmentblatt überall platt und pigmenthaltig geworden sind. Die Zellen des inneren Blattes behalten in diesem der Spalte zunächst

1) Letzteres tritt auf der Photographie nicht hervor. 
liegenden Gebiete ihre unregelmäBige Anordnung bei, welche sie in jungen Stadien in der ganzen Retina aufweisen, während sie im äbrigen Retinalblatte sich bald radiär stellen und dann weiter in die Differenzierung der Schichten eingehen. Von diesen undifferenzierten Randteilen betrifft der nasale ein größeres Gebiet als der temporale. Diese undifferenzierten Randteile dienen, wie später näher ausgeführt werden soll, als Bahn für das distal vorwachsende Neuropecten.

Der Verschlul der proximalen Spalte steht in innigem Zusammenhang mit der Entwicklung der Sehnerveninsertion und des Pecten, auf welche Ge. bilde nun eingegangen werden soll.

Der Becherstiel setzt sich bei unserem jüngsten Stadium (Abb. $G_{1}, S$. (S. 302) an der Grenze zwischen der gestreckt zur Pupillaröffnung ziehenden ventralen und der in ihrem ventralen Teile ebenfalls gestreckt sich erhebenden proximalen Wand an den Augenbecher an. Er zeigt eine wenn auch noch nicht scharf gegen die Umgebung abgegrenzte Ansatzfläche von annähernd querovaler Form, welche ein wenig gegen die Spalte hin verlängert erscheint. Der Insertionsfläche entsprechend finden wir an der Innenseite eine Einsenkung (Stadium 2 und 3), welche sich gegen die proximale Offnung hin erstreckt und direkt in dieselbe äbergeht. In den Wänden dieser Einsenkung wachsen die ersten Nervenfasern aus den sich differenzierenden Teilen der Retina zur ventralen Wand des Becherstiels. Die Nervenfasern nehmen im weiteren Verlaufe der Entwicklung mit der fortschreitenden Differenzierung der Retina ständig an Menge zu und nehmen ihren Weg zum Becherstiel durch die früher beschriebenen unditferenzierten Randteile der proximalen Spalte. Diese nehmen durch das Einwachsen der Nervenfasern allmählich an Dicke zu und kommen in proximodistaler Richtung zur Aneinanderlagerung und Verschmelzung, wodurch die Spalte sich schließt.

Die aus der Retina sich differenzierenden Nervenfasern ziehen aus derselben zum Opticus in Form zweier Bündel, eines stärkeren nasalen und eines schwächeren temporalen (vgl. Abb. $\mathrm{G}_{9}$, S. 309, NF). Dem entspricht auch die Tatsache, daB, wie wir früher beschrieben haben, das undifferenzierte Gebiet des nasalen Spaltrandes kräftiger entwickelt ist als das des temporalen. Bei der Passage der Nervenfasern durch die undifferenzierte Randzone wird diese Zone in die Sehnerveninsertion a ufgenommen, so da $B$ die letztere $n$ un direkt an die differenzierte Retina grenzt, dort, wo sich das Pigmentblatt in das retinale Blatt umschlägt.

Die neuen zur dusbildung kowmenden Nervenfasern sind immer gegen das proximale Ende der noch offenen proximalen Spalte gerichtet und lagern sich daselbst den schon ausgebildeten Nervenfasem auf. Dieser Vorgang präsentiert sich auf unseren Modellen als ein Vorwachsen der distal immer mehr spitz auslaufenden Sehnerveninsertion zwischen den eingebogenen Spalträndern, und wir haben ihn daher bei unseren Stadienbeschreibungen immer so dargestellt, weil dadurch die Beschreibung, wie wir glaubten, an Deutlichkeit zu gewinnen schien. Es wird später noch genauer auf die nähere Form des Vorwachsens der Sehnerveninsertion in Verbindung mit der Pectenentwicklung eingegangen werden.

Entsprechend den beiden ungleich mächtigen Nervenfaserportionen, aus denen die Sehnerveninsertion sich zusammensetzt, seben wir an den Modellen 
unserer jungen Stadien die Insertion durch eine Fusche distal unvollständig in zwei ungleiche Hälften, eine mächtigere nasale und eine schwächere temporale, geteilt ( $\mathrm{Abb} . \mathrm{G}_{2}, \mathrm{~S} .303, \mathrm{~S}$ ). In späteren Stadien sehen wir; daB die Insertion in ihrem distalsten Teile nahezu ausschlieBlich den nasalen Spaltrand interessiert.

Distalwärts läßt sich die Sehnerveninsertion im Schnittbilde nicht scharf von den undifferenzierten Randteilen des noch offen stehenden Spaltgebietes abgrenıen, sondern geht allmählich in dieselben über.

Mit den fortschreitend in vermehrter Menge der ventralen Wand des Becherstiels zuwachsenden Nervenfasern wird diese immer mehr verdickt, ihr epithelialer Anteil wird dorsalwärts verschoben, das Lumen des Becherstiels wird immer enger und verschwindet schließlich ganz. Sein Verschluß erfolgt entsprechend dem Einwachsen der Nervenfasem in der Richtung von distal proximalwärts. Nur ganz proximal am Ubergang des Becherstiels in den Augenbecher bleibt noch eine Zeitlang ein taschenförmiger Rest des Becherstiellumens bestehen, der schlieBlich ebenfalls zum Verschwindea kommt. Durch die an Menge immer weiter zunehmenden Nervenfasern wird der epitheliale Anteil der ventralen Wand des Becherstiels immer mehr an die dorsale Wand angepreßt und schließlich versehwinden beide $W$ ände. Damit ist der Becherstiel vollkommen ron Nervenfasern substituiert worden und entsprechend seiner früheren Ansatzfläche ziehen nunmehr die Nervenfasern aus der Retina direkt zum Opticus.

Betrachtet man, wie wir es getan haben, die proximale Spalte mit ihrem undifferenzierten Rändern als die Durchgangsbahn für die aus der Retina zum Opticus ziehenden Nervenfasern, so kann man den beschriebenen Vorgang des Verschwindens des Becherstiels und der Einbeziehung seines Gebietes in die Sehnerveninsertion auch in der Weise auffassen, daß man sagt, die proximale Spalte habe sich in proximaler Richtung über das Gebiet des Becherstielansatzes ausgebreitet, wobei sie aber in diesem Gebiete sofort durch die ein. wachsenden Nervenfasern verschlossen wurde.

Inden die Nervenfasem, wie erwähnt, ventralwärts in zwei Partien, einer nasalen und einer temporalen, der Gegend der proximalen Offnung zuwachsen, bilden sie bei ihrer Vereinigung eine Finsenkung zwischen sich, welche sich mit fortschreitendem Wachstum der Sehnerveninsertion in proximo-distaler Richtung ebenfalls in entsprechender Weise distalwärts verlängert. Schon sehr früh sehen wir im Bereiche dieser Einsenkung eine Ansammlung ron Zellen auftreten, welche in ihrem Bau rollkommen mit den Gliazellen der Opticusanlage übereinstimmen und sich offenbar aus dieser in die beschriebene Einsenkung hineingeschoben haben. Sie füllen dieselbe aus und bilden einen kleinen Hügel gegen die Becherhöhle zu. (Im Beginn nicht an den entsprechenden Modellen, aber am Präparat bei stärkerer Vergrößerung sichtbar.) Diese (bald auch an den Modellen deutlich erkennbare) Vorwölbung stellt die erste Anlage des Pecten dar, welche demnach ein auschlieblich as Gliazellen bestehendes Produkt der Sehnerveninsertion darstellt. Im Verlaufe der ganzen weiteren Entwicklung bleibt das Pecten an die Sehnerveninsertion gebunden und wächst in vollkommen gleicher Weise wie diese in proximodistaler Richtung. Wir halten uns daher auch hier für berechtigt, Sehnerven. 
insertion und Pecten $z u$ einem morphologisch einheitlichen Ge. bilde zusammenzufassen, welches wir Neuropecten nennen.

Die Pectenanlage wächst der Tnnenseite der Sehnerveninsertion angeschlossen in proximo-distaler Richtung vor. Die am Anfang querovale Ansatzstelle der Sehnervenanlage nimmt dabei die Gestalt eines langgestreckten, in distaler Pichtung sich verlängernden Ovals an. Dabei kommt die Sehnerveninsertion mit ihrem distalen Teile in die durch die Einbiegung der früheren Spaltränder entstandene Einsenkung an der Außenseite des Augenbechers zu liegen, während die Pectenanlage an der Innenseite zu einem in proximo-distaler Richtung an Höhe zunehmenden Wulste wird. Von dem Verschlusse der proximalen Spalte dureh das distal vorwachsende Neuropecten bekommt man eine Vorstellung, wenn man an den Modellen, bei den verschiedenen Stadien, die Länge des Pecten mit der Länge der Spalte vergleicht. Man findet dann, daß sich dieses Verhältnis mit fortschreitender Entwicklung ständig zu ungunsten der Spalte rerschiebt. Bei dern Embryo von $130^{\mathrm{h}}$ (Abb. $\mathrm{G}_{\mathrm{s}}$, S. 308) ist die Pectenanlage etwa ebenso lang als die Spalte, im nächsten Stadium $\left(138^{h}\right)$ bereits ein Stück länger, bei dem Embryo von $150^{\mathrm{h}}$ (Abb. $\mathrm{G}_{12}$, S. 312), etwa doppelt, bei dem Embryo von $1.4^{\mathrm{h}}$ (Abb. $\mathrm{G}_{14}$, S. 314) dreimal und bei dem Embryo von $168^{\mathrm{h}}$ (Abb. G $\mathrm{A}_{18}$, S. 316) viermal so lang als die Spalte.

Wir haben gehört, daß die proximale Spalte eine schiefe Richtung hat, indem sie die Augenbecherwand von nasal außen nach temporal inner durchsetat. Hieraus ergibt sich, daß das in die undifferenzierten Randteile der Spalte ein. wachsende Neuropecten ebenfalls eine schiefe Richtung bekommt. Dies gibt sich in seinem äußeren Anteil, der Sehnerveninsertion, derart zu erkennen, daß diese (S) hauptsächlich an die nasale Wand der durch die eingebogenen früheren Spaltränder gebildeten Einsenkung zu liegen kommt (vgl. Abb. $G_{7}$, S. 308, Abb. $G_{9}$, S. $309, A b b . G_{11}, S .312$ ), während der gratförmige Wulst der Pectenanlage an seiner temporalen Seite steiler zur Wand der Augenbecherhöhle abfällt als nasal, wodurch die Pectenanlage eine leichte Neigung temporalwärts erhält.

Vergleichen wir auf unseren Modellen die Länge der Sehnerveninsertion und des Pecten, so finden wir, daß bei älteren Entwicklungsstadien diese beiden Gebilde einander in ihrer Längsausdehnung nicht vollkommen zu entsprechen scheinen. Während nämlich die Pectenanlage überall bis an die proximale Spalte heranreicht (Pe in $A b b . G_{8}, S .308, G_{12}, S .312, G_{14}, S .314$ ) und ohne scharfe Grenze in die Ränder derselben übergeht, scheint die distale Spitze der Seh. nerveninsertion bereits eine Strecke weit proximal von der Spalte zu endigen (S in Abb. $G_{7}$, S. $308, G_{18}$, S. 316). Dieses Verhalten muß auffallend erscheinen, wenn wir uns rergegenwärtigen, daß das Pecten ja ein Differenzierungsprodukt der Sehnerveninsertion darstellt. Diese auf den Modellen hervortretende Inkongruenz zwischen der Länge der Sehnerveninsertion und des Pecten ist jedoch, wie die Schnittbilder zeigen, nur eine scheinbare. Die Ränder der Spalte werden, wie erwähnt, mit zunehmender Entwicklung immer mehr gegen die Becherhöhle zu eingebogen, und diese Einbiegung macht sich distal immer stärker geltend als prosimal. Da nun, wie wir gehört haben, die Sehnerveninsertion in den innersten, der Spalte zunächst liegenden Teilen der eingebogenen Spaltränder vorwächst, kommt sie distal so tief in die Einsenkung zwischen den einge- 
bogenen Rändern zu liegen, daß sie wohl am Schnittbild nachweisbar ist, nicht aber an den Modellen als $W u l s t$ hervortritt ( $A b b . G_{15}, 5.314$ ). Schließhich legen sich die Ränder außen von der Sehnerveninsertion aneinander ( $\nabla$ gl. $G_{16}, S .315$, $\mathrm{G}_{19}$, S. 316), wodurch die in das Innere des Augenbechers aufgenommen er. scheint. Es ist klar, daß eine derart gelagerte Sebnerveninsertion noch weniger auf den Wodellen hervortreten kann. Im Schnittbild läßt sich die Sehnerven. insertion aber entsprechend der ganzen Länge der Pectenanlage immer feststellen.

Noch in einer anderen Beziehung scheinen Sehnerveninsertion und Pectenanlage auf unseren Modellen einander nicht vollkommen $\mathrm{zu}$ entsprechen: die Pectenanlage wird distal allmählich immer breiter, während der Wulst der Sehnerveninsertion sich distalwärts immer mehr verschmälert. Auch diese Inkongruenz ist, wie die Schnittbilder zeigen, nur scheinbar. Das Pecten breitet sich nämlich in seinem distalen Anteile seitlich über ein Gebiet der benachbarten differenzierten Retina aus (Abb. $G_{15}$, S. 314, $G_{16}, S .315, G_{19}, S$ 316) und wird so distal immer breiter, während die Sehnerveninsertion, soweit ihr am Modell distalwärts gefolgt werden kann, immer schmäler wird.

Mit dieser Ausbreitung der Pectenanlage über die differenzierten Teile der Spaltränder hängt auch teilweise eine andere Erscheinung an unseren Modellen zusammen, die auffallen muß: Während die Sehnerveninsertion in ihrem proximalen Anteil am höchsten ist und distalwärts immer niedriger wird, sehen wir bei der Pectenanlage gerade das entgegengesetzte Verhalten: sie nimmt in proximo-distaler Richtung kontinuierlich an Höhe zu. Zum Teil findet diese Intiongruenz ihre Erklärung in dem schon erwähnten Comstande, daß die Sehnerveninsertion distal in den innersten, undifferenzierten Randteilen der distal verhältnismäßig am stärksten eingebogenen Spaltränder vorwächst. Es hat diese Erscheinung aber noch einen anderen Grund. Was wir an unseren Modellen sehen und bisher hier immer als die Vorwölbung der Pectenanlage bezeichnet haben, das ist in seinem distalen Anteile nicht die Pectenanlage allein. Es liegt hier nämlich, wie erwähnt, die Pectenanlage distal ausgebreitet auf den hiev verhältnismäBig am stärksten eingebogenen (differenzierten) Spalträndern und es lassen sich diese Gebilde im Modell nicht roneinander sondern. Und da die Einbiegung der Ränder in proximo-distaler Richtung stärker wird, so ist es klar, daß die aus Rändern und Pectenanlage bestehende, an den Modellen nur als Pectenanlage imponierende Torwölbung ebenfalls distalwärts höher werden muB. Im übrigen erscheint uns tatsitchlich die Pectenanlage im distajen Anteile im Vergleich mit dem entsprechenden Anteil der Sehnerveninsertion lrärftiger entwickelt zu sein.

Wir haben früher gehört, daß die Sehnerveninsertion bei ihrem Vorwachsen distalwärts hauptsächlich den nasalen Spaltrand interessiert. Diesem Vorwachsen folgt dementsprechend auch die Pectenanlage, so daß diese zum größeren Teile im Bereiche des nasalen Spaltrandes entwickelt erscheint. Diese Verschiedenheit in der Ausbildung des Neuropecten im Bereiche des nasalen und des temporalen Spaltrandes geht in einem gewissen Stadium $\left(G_{\beta}, 154^{h}\right)$ so weit, daß wir hier distal das Neuropecten ausschließlich entsprechend dem nasalen Spaltrand ent. wickelt finden, während der innerste Teil des temporalen noch die früher besprochene undifferenzierte Beschaffenheit aufweist ( $A b b, G_{17}, S$. 315). Fs ist also 
hier die Entwicklung des Neuropecten im Bereiche des nasalen Spaltrandes der des temporalen vorausgeeilt. Später (Stadium $G_{9}, 168^{h}$ ) wächst auch im Bereiche des letzteren das Neuropecten vor. Hier ist jedoch dasselbe entsprechend der im temporalen Rande geringer ausgebildeten undifferenzierten Randzone weniger mächtig als nasal (vgl. Abb. $G_{19}$, S. 3l6). Dazu kommt, daß, wie beschrieben, der temporale Rand schwächer eingebogen ist als der nasale. Dementsprechend finden wir hier die Opticusinsertion distal in einem kleineren Teile sich anch ins Gebiet des temporalen Randes erstreckend und am Pecten distal eine Furche, welche dasselbe in einem mächtigeren nasalen und einem schwächeren temporalen Teil unvollständig scheidet $\left(A b b . G_{19}\right)$. Man könnte diesen Vorgang in der Weise aufassen, da $B$ wir hier distal ein in $z$ wei getrennten Portionen vorwachsendes Neuropecten vor uns haben, von denen dieweit mächtigerenasale Portion sich früher distalwärts entwickelt als die schwächere temporale. Die beschriebene Furche im distalen Teile der Pectenanlage in den letzgenannten Stadien entspräche dem. nach der Vereinigungsstelle dieser beiden Portionen. An der Opticusinsertion sieht man hier kein deutliches Kennzeichen dafür, daß sie sich aus zwei getrennten Portionen zu tiner einheitlichen Insertion vereinigt hat. Eine solche Teilung der clistalen Opticusinsertion haben wir indessen bei unserem jungen Stadium feststellen können, indem hier, wie erwähnt, eine deutlich markierte Furche den distalen Teil derselben in eine mächtigere nasale und eine schwächere temporale Portion unvollständig teilte (Abb. $\mathrm{G}_{2}, \mathrm{~S} .303$ ).

Wir haben erwähnt, daß an unserem jüngsten Stadium die noch völlig offen. stehende Augenbecherspalte von einem von Mesoderrozellen begleiteten Gefäß durchzogen wird, welches aus einem Gefäßplexus ventral vom Augenbecher stammt. Beim Verschinß der Augenbecherspalte wird, wie ebenfalls schon hervorgehoben wurde, dieses GefäB zum Teile in der Weise in den Augenbecher aufgenommen, daß es nunmehr die proximale Offnung in schiefer Richtung durchsetzt und auf diese Weise in die Becherhöhle gelangt. Dabei lagert es sich der erwähnten Furche zwischen proximaler und distaler öffnung ein und verläßt durch letztere die Becherhöhle (Abb. $G_{3}, S .303, G G$ ). Der auBerhalb des Angenbechers gelegene Teil des Gefäßes liegt dabei, bevor er in die Augenbecherhöhle eintritt, in jener Furche, welche die beiden ungleichen Portionen der distalen Opticusinsertion roneinander scheidet (Abb. $\left.G_{2}, S .303\right)$. Bei alteren Stadien liegt dieser äußere Teil des Gefäßes in jener Furche, die an den Modellen den distalen Teil der Sehnerveninsertion an der temporalen Seite abzugrenzen scheint und in ihrer Fortsetzung bis zur proximalen Spalte reicht ( $\nabla g l . \mathbf{A b b}, \mathbf{G}_{7}$. S. 308), welche Furche aber, wie die Schnittbilder zeigen, in Wirklichkeit noch im Bereiche der Sehnerveninsertion liegt (Abb. G, S. 309, GG). Wit zunehmender Verlängerung der proximalen Spalte ändert sich nunmehr der Verlauf des Gefäßes durch die Spalte derart, daß es dieselbe jetzt nicht mehr ihrer ganzen Länge nach schief durchsetzt, sondern es verläuft an der ventralen Seite der Spalte außerhalb von ihr bis zu ihrem distalen Ende, wo es die Augenbecherhöhle betritt ( $G G$ in Abb. $G_{7}$, S. 308, $G_{11}, S .312$ ). In derselben liegt das Gefäß jetzt nicht mehr in jener Furche der Innenwand, die proximale und distale Offnung verbindet, sondern zieht anfangs geradlinig wie eine Sehne 
die Entwicklung der Sehnerveninsertion und die Anlage des Pecten bei Vögeln. 325

(vgl. Abb. $G_{12}$, S. $312 G G$ ), später in einem Bogen zur distalen Öfnung (vgl. Abb. $G_{18}$, S. 316).

Die proximale Spalte wird, sobald sie eine gewisse Länge erreicht hat, ibrer ganzen Länge nach von einer Mesodermlamelle durchzogen, welche mit dem Mesoderm ventral vom Augenbecher zusammenhängt und ein Stück weit frei in die Becherhöle hineinragt (Abb. $G_{10}$, S. 310). Entsprechend der schiefen Richtung der Spalte von nasal außen nach temporal innen hat auch die Lamelle eine Neigung temporalwärts (vgl. Abb. $G_{10}, S .310$ ). Mit dem Vorwachsen des Neuropecten in proximo-distaler Richtung und dem in Zusammenhang damit erfolgenden Verschluß der Spalte verschwindet nach und nach die Mesodermlamelle ebenfalls in proximo-distaler Richtung. Sobald dieser Verschluß bis zum distalen Ende der Spalte fortgeschritten ist, ist auch die Mesodermlamelle vollkommen verschwunden. Auch das Gefäß wird dabei früher oder später atrophisch (vgl. Abb. $\mathrm{G}_{14}$, S. 314) und verschwindet mit seinem frei durch die Becherhöhle ziehenden Teile. Im $Z$ usammenhang damit legen sieh die Ränder der distalen öfnung aneinander. Diese Stelle bleibt jedoch auch in dem ältesten untersuchten Stadium erkennbar. Sie markiert sich als zwei, mit ihren Innenseiten dicht aneinander liegenden Lippen, an deren nach auswärts gewendeten Rändern sich das retinale Blatt in das Pigmentblatt umschlägt (Abb. $G_{20}$, S. 318).

\section{Zusammenfassung der Hauptresultate.}

Ausgangspunkt unserer Untersuchung bildet für jede Art ein Stadium, bei welchem die Becherspalte noch ihrer ganzen Länge nach offen steht (AS in Abb. $\mathrm{Po}_{1}$, S. 236, Abb. A, S. 260, Abb. $\mathrm{Q}_{1}$, S. 302).

Diese reicht hier bei allen Arten mit ihrem proximalen Ende bis an die Insertion des Becherstiels ( $S$ ) heran, die sich am Ubergange der proximalen in die ventrale Wand des Augenbechers befindet. Distal gehen die Spaltränder ohne scharfe Grenze divergierend in den Pupillarrand über. Die Becherspalte wird überall von einem von Mesodermzellen begleiteten Gefäß durchzogen, welches wir Glaskörpergefäß nennen (primitive Augenbecherarterie Froriep $\left.\mathrm{Abb} . \mathrm{Po}_{2}, \mathrm{~S} .236, \mathrm{GG}\right)$. Es stammt aus einem Gefäßplexus, der sich im Mesenchym ventral rom Augenbecher ausbreitet. Die ventrale Wand des Augenbechers verläuft gestreckt zur Pupillaröffnung, während die Seitenwände, besonders aber die dorsale Wand, gegen die Pupillaröffnung zu umgebogen sind, wodurch diese eine nach unten dezentrierte Lage bekommt.

Später finden wir bei allen untersuchten Arten dieBecherspalte in ihrem mittleren und ihrem distalsten Teile geschlossen (Abb. $\mathrm{Po}_{3}$, S. 237, Po. S. 237, A, S. 263). Als ihre Reste bleiben von ihr zwei kleine Öffnungen übrig, eine proximale (pÖ), welche dem proximalsten Teile der Becherspalte entspricht und daher unmittelbar vor derStielinsertion liegt, und eine distale, unweit des Pupillarrandes gelegene (d O). Entsprechend der Tatsache, daß sich die Ränder der Becherspalte beim Verschluß mehr oder weniger nach innen gegen die Becherhöhle za einbiegen, finden wir die VerschluBstelle durch je eine Furche an der AuBen- 
326 C. Lindahl and A. Jokl: Über den Fersehub der fotalen Aagenbesherspalte,

seite (Fa) und an der Innenseite (Fi) des Augenbechers markiert, welche die beiden Öffnungen rerbinden.

Bei den verschiedenen Arten verschieden stark ausgesprochen, finden wir im Bereiche der verschlossenen Spalte den nasalen Rand stärker nach innen zu umgebogen als den temporalen, was sich je nach der verschiedenen Formation der Ränder als ein stärkeres Hervortreten desselben an der Außen- und an der Innenseite des Augenbechers geltend macht.

Wie dieser partielle Verschluß der Becherspalte mit der Zurücklassung der genannten beiden Offnungen in seinen einzelnen Phasen erfolgt, konnte bei Anas und teilweise auch bei Podiceps genauer verfolgt werden.

Die Ränder der Becherspalte nähern sich einander in einem mittleren $\mathrm{Ab}$ schnitte (Abb. $\left.A_{1}, S .260\right)$ und lagern sich aneinander ( $\left.A b b . A_{2}, S .260\right)$, wodurch die Spalte sich hier schließt. Von derselben bleiben dabei zwei Teile zurück, die genannte proximale Öffnung ( $\mathrm{p} \ddot{\text { Ö) }}$ und eine winkelförmige Einkerbung des Pupillarrandes (EK). Die Ränder der letzteren nähern sich immer mehr einander (Abb. $A_{3}$, S. 261), wodurch der Winkel zwischen ihnen immer spitzer wird, and gelangen schlieBlich nahe dem Pupillarrand zum VerschluB. (Abb. $A_{5}, \mathrm{~S} .262, A_{6}, \mathrm{~S} .263$ ). Dadurch entsteht die früher genannte distale Öfnung. Es bleibt noch eine kleine Einkerbung im Pupillarrand zurück, die sich später ausgleicht (EK in Abb. A. S. 262, $\mathrm{Po}_{3}, \mathrm{~S} .237$ and $\mathrm{Po}_{4}, \mathrm{~S} .237$ ). Mit fortschreitender Ent. wicklung krümmt sich auch die ventrale Wand immer mehr gegen die Pupillaroffnung ein, wobei die dezentrierte Lage derselben weniger ausgesprochen wird. Diese nach abwärts dezentrierte Lage scheint jedoch lange beibehalten zu werden.

Während die Augenbecherspalte in dur geschilderten Weise unter Zurücklassung der beiden genannten Offnungen zum Verschlusse kommt, wird das von Mesodermzellen begleitete GlaskörpergefäB zum Teile in die Becherhöhle autgenommen in der Weise, daß es nummehr den Augenbecher durch die proximale Öffnung betritt, an der Innenseite in der genannten hier befindlichen Furche zwischen proximaler und distaler öffnung zur letzteren verläuft und durch dieselbe die Becherhöhle wieder verläBt (GG in $\mathrm{Po}_{6}, \mathrm{~S} .239, \mathrm{G}_{2}, \mathrm{~S} .303, \mathrm{~A}_{8}$, S. 266).

In der nächsten Periode der folgenden Entwicklung nimmt die proximale ôffnung kontinuierlich bedeutend an Länge zu und wird dabei $z$ u einer in proximo-distaler Richtung verlaufenden langen Spalte umgewandelt (pÖ in Abb. $A_{9}$, S. 265, $A_{10}$, S. 265, $G_{4}$, S. $305, G_{5}$, S. $305, G_{3}$, S. $308, P a_{2}$, S. 287), welche wir aus später zu erörternden Gründen die embryonale Papillenöffnung nennen wollen. Die Verlängerung derselben geschieht in distaler Richtung, während sie gleichzeitig von proximal her verschlossen wird, ein Vorgang, welcher in Zusammenhang mit der Entwicklung der Sehnerveninsertion und des Pecten steht und später genauer geschildert werden wird. In gewisser Beziehung kann man von einer Verlängerung der Papillenöffnung auch in proximaler Richtung sprechen. Näheres darüber siehe später.

Die Ränder der verlängerten embryonalen Papillenöffnung werden mit zunehmender Entwicklung gegen die Augenbecherhöhle eingebogen (Abb. $\mathrm{G}_{10}$ ) 
S. 310 und $\mathrm{Pa}_{5}$, S. 290 , vgl. auch $\mathrm{Abb} . \mathrm{G}_{5}, \mathrm{~S} .305$ und $\mathrm{G}_{12}$, S. 312). Durch diese Finbiegung entsteht an der AuBenseite des Augenbechers eine langgestreokte Einsenkung, in deren Tiefe die Offnung zi liegen kommt. Die Einbiegung betrifft zuerst den nasalen Rand und ist in diesem stärker ausgesprochen (Abb. $G_{6}$, S. 306, Abb. $\mathrm{C}_{10}$, S. 310 r und $A b b . \mathrm{Po}_{10}, \mathrm{~S} .243$ l, Abb. $\mathrm{G}_{12}, \mathrm{IS} .312$ ). Mit fortschreitender Entwicklung wird die Einbiegung an beiden Rändern distal stärker ausgesprochen als proximal, was sich bei den verschiedenen Arten mit verschiedener Stärke geltend macht. Durch diese Formation ihrer Ränder bekommt die Öfnung eine schiefe Richtung, so daB sie die Becherwand von nasal a uen nach temporal innen durchsetzt ( $A b b$. $A_{12}$, S. 268, Abb. $G_{6}$, S. 306, Abb. G $G_{10}$, S. 310 und Abb. Po 10 , S. 243). (Dieselbe schiefe Richtung zeigt bei Podiceps die ganze noch offenstehende fötale Augenbecherspalte.)

Eine gewisse, zunächst der Papillenöffnung gelegene Zone ihrer beiden eingebogenen Ränder weist bei allen untersuchten Arten eine besondere histologische Beschaffenheit auf (Abb. $A_{12}$, S. 268, Abb. Pa, S. 290 und $\mathrm{Po}_{11}, \mathrm{~S} .243$ ). Der Unterschied dieser Zone der übrigen Retina gegenüber tritt in einem Stadium hervor, wo die beiden Retinablätter sonst einen gewissen Differenzierungsgrad erreicht haben, nämlich dann, wenn die Zellen des auberen Blattes flach und pigmenthaltig geworden sind und die Zellen des inneren Blattes sich in radiären Reihen angeordnet haben. Wir finden nämlich, daß die Zellen in einer der Papillenöfnung zunächst gelegenen Zone ihrer beiden Ränder den DifferenzierungsprozeB der übrigen Retina nicht mitmachen, sondern a af einem Entwicklungsstadium verharren, welches in frühen Stadien die Zellen in dem ganzen äuBeren und inneren Retinablatt a ufwiesen. Es endigt der Sehventrikel beiderseits in einer gewissen Entfernung von der Offnung und das differenzierte äußere und innere Blatt gehen in eine Zone über, deren Zellen außen hochzylindrisch und pigmentfrei sind, während sie innen eine unregelmäBige Anordnung zeigen, Verhältnisse, wie sie in jungen Stadien innerhalb aller Zellen des Pigment- bzw. des Retinablattes der Retina vorhanden sind. Diese undifferenzierte Zone niromt am nasalen Rande stets ein größeres Gebiet ein als am temporalen. Wie später näher gezeigt werden wird, dienen die undifferenzierten Randzonen der Papillenöffnung als Bahn für die von der Nasal-und der Temporalseite aus der Retina zur Sehnerveninsertion ziehenden Nervenfasern sowie für die sich aus der letzteren entwiokelnde Pectenanlage.

Die langgestreckte embryonale Papillenöffnung wird bei allen untersuchten Arten mit Ausnahme von Podiceps von einer mehr oder weniger mächtigen Mesodermlamelle (Me in Abb. $A_{12}, S .268, A b b . G_{10}, S .310, A_{13}, S .269$, und $A_{14}$, S. 270, durchsetzt, welche mit dem Mesoderm ventral vom Augenbecher zusammenhängt und sich mehr oder weniger weit frei in den Glaskörperraum hinein erstreckt. Entsprechend der schiefen Richtung, in der die embryonale Papillenöfnung die Wand durchsetzt, ist auch die sie durchziehende Mesoderm. lamelle mit ihrem frei in den Glaskörperraum hineinragenden Teil temporalwärts geneigt. Mit Ausnahme von Podiceps, wo das GlaskörpergefäB die 
Papillenöffnung ihrer ganzen Länge nach in schiefer Richtung durchsetzt (GG in Abb. $\mathrm{Po}_{7}$, S. 241 und $\mathrm{PO}_{12}$, S. 245), betritt es bei allen untersuchten Arten den Augenbecher durch das distale Spaltende $\left(G G\right.$ in $A b b . A_{13}, S .269$ und $A_{14}, S .270$, $\mathrm{G}_{7}$, S. 308, $\mathrm{G}_{\mathrm{S}}$, S. 308, $\mathrm{G}_{11}$, S. 312, $\mathrm{G}_{12}, \mathrm{~S} .312$ and $\mathrm{Pa}_{2}$, S. 287).

Es soll nunmehr auf die Entwicklung des Becherstiels und der Sehnerveninsertion eingegangen werden, so wie sich diese Gebilde an unseren Modellen präsentieren. Der an unseren jüngsten Stadien kurze, plumpe und vollkommen hohle Becherstiel ( $S$ in $A b b . P_{1}, S .236, A_{1}, S .260, A_{2}, S .260$ und $G_{1}, S .302$ ) in. seriert, wie schon erwähnt wurde, an der Grenze zwischen proximaler und ventraler Wand mit annähernd querovaler Ansatzfläche. Wit fortschreitender Ent. wicklung streckt sich der Becherstiel in die Länge und wird dabei relativ schmal ( $\mathrm{S}$ in $\mathrm{Abb} . \mathrm{A}_{3}, \mathrm{~S} .261, \mathrm{~A}_{5}, \mathrm{~S} .262$, seine Ansatzfläche wird rundlich und bekommt später allmählich eine längsorale Form ( $\mathrm{S}$ in $\mathrm{Abb} . \mathrm{A}_{6}, \mathrm{~S} .263$ ). Diese Formveränderung der Ansatzfläche steht, wie später ausgeführt werden wird, im Zusammenhang mit dem Zuwachsen von Nervenfasern aus der Retina und mit einer allmählichen Substitution des Becherstiels durch die letzteren.

Die Anlage der Sehnerveninsertion wächst in den folgenden Stadien kontinuierlich distalwärts in die Länge. Siebildetander AuBenseite des Augenbechers einen. Wulst, der proximal am höchsten und breitesten ist und sich distalwärts immer mehr verschmälert und abflacht (S in $\mathrm{Abb} . \mathrm{Po}_{7}$ S. $241, P_{12}$, S. $245, A_{9}$, S. 265 , A 18 , S. $274, G_{4}$, S. $305, G_{7}$, S. 308, G G $_{11}$. S. 312). Bei den untersuchten Arten mit Ausnahme von Podiceps finden wir in einem frühen Stadium dieser Verlüngerung den Wulst der Sehnerveninsertionsanlage distal durch eine Furche unvollständig in zwei Teile geteilt (vgl. Abb. $\mathrm{G}_{2}$, S. 303), von denen der nasale immer bedeutend mächtiger ist als der temporale. Später scheint der Wulst der Sehnerveninsertionsanlage an den Modellen einheitlich zu sein (ist es aber nicht in Wirklichkeit, wie die Schnittbilder zeigen; siehe später) und endet mit einer lang ausgezogenen Spitze am proximalen Ende der Papillenöffnung.

Mit dieser Umgestaltung der Sehnerveninsertionsanlage wird ihre Ansatzfläche am Augenbecher zu einem distalwärts sich immer mehr verlängernden Oval, welches distal mit einer lang ausgezogenen Spitze endigt.

Der Wulst der Sehnerveninsertionsanlage liegt mit seinem größeren distalen Teile in einer Einsenkung, welche sich distaiwärts direkt in die schon erwähnte Einsenkung fortsetzt, die durch die Einbiegung der Pünder der Papillenöffnung zustande gekommen ist und in deren Tiefe sich die letztere öfnet. Der Wulst der Sehnerveninsertionsanlage wird an seiner temporalen und an seiner nasalen Seite von je einer Furche begrenzt, von denen die temporale eine direkte Fortsetzung der genannten Einsenkung in proximaler Richtung darstellt. Diese temporale Begrenzungsfurche der Sehnerveninsertion entspricht bei den untersuchten Arten mit Ausnahme von Podiceps jener erwähnten Furche, welche bei diesen Arten (ausgen. Podiceps) in jüngeren Stadien don Wulst der Sebnerveninsertion distal in eine größere nasale und eine kleinere temporale Portion unvollständig teilt. Wie die Schnittbilder zeigen, entspricht der an den Modellen hervortretende Wulst hier in den älteren Stadien in der Tat nur seinem nasalen Abschnitte, während der temporale mit fortschreitender Entwicklung relativ so schwach. 
wird, daß er an den Nodellen nicht hervortritt, sich jedoch im Schnittbilde nachweisen läbt (Abb. $A_{11}$, S. 267, Abb. $G_{9}, S .309$ ). (Bei Podiceps entspricht die Furche an der temporalen Seite tatsächlich der temporalen Grenze der Sehnerveninsertionsanlage, vgl. Abb. $\mathrm{Po}_{9}, \mathrm{~S} .242$ und $\mathrm{Po}_{11}, \mathrm{~S}, 244$, so wie dies mit der nasalen Furche auch bei den anderen Arten der Fall ist.) Da sich die Papillenöffnung mit fortschreitendem Längenwachstum der Selnerveninsertionsanlage allmählich immer mehr verkiurzt, so gewinnt man bei der Betrachtung der Modelle die Auffassung, daß die Sehnerveninsertion distal in dieser Einsenkung, in deren Grund die Papillenöfnung sich befindet, und in der Papillenöffnang selbst vorwächst, wobei gleichzeitig diese letztere sich schließt. Für die Auffassung, dal die Sehnerweninsertion tatwächlich in der Spalte rorgewachsen ist, spricht der Tmstand, daß der Wulst der sehnerreninsertionsanlage der nasalen Wand der besagten Einsenkung angelagert ist, entsprechend der Tatsache, das die Papillenöffnung die Wand des Augenbechers in schiefer Richtung von nasal auben nach temporal innen durchsetat.

In spiteren Stadien scheint an unseren Modellen die Sehnerveninsertionsanlage nicht bis zur proximalen Spalte zu reichen (Abb. $G_{7}$, S. 308). In Wirklichkcit reicht sie aber, wie die Schnittbilder zeigen (Abb. $A_{16}$, S. 272, Abb. $G_{15}$, S. 314), auch hice bis an diese heran, nur liegt sie distal so tief zwischen den, wie erwhint, hier besonders stark eingebogenen Rändern der Papillenöffnung eingebettet, dals sie an den Wodellen nicht als Wulst hervortreten kann.

Das in unsere Modelle mitaufgenowamene Endstück der Sehnervenanlage ist bei den älteren Stadien überall mehr oder weniger nasalwärts umgebogen (Abb. $\mathrm{Po}_{7}$, S. 241, $\mathrm{Po}_{12}$, S. 245, Abb. G $\mathrm{G}_{7}$, S. 308, G $\mathrm{G}_{11}$, S. 312).

Es soll nun darauf eingegangen werden, wie sich die Substitution des Becherstiels durch die Sehnervfasern und die Entwicklung der Sehnerveninsertion auf den histologischen Schnittbildern rerfolgen laßt.

Der Insertion des Becherstiels entspricht in frühen Stadien an der Innenseite des Augenbechers eine auch an einem Teil der Modelle hervortretende Einsenkung (Ei in Abb. $A_{4}$, S. $261, A_{7}$, S. 263, $\mathrm{Pa}_{1}, \mathrm{~S} .285$ ), welche sich distalwärts direkt in die Papillenöffnung fortsetzt. Die Retinazellen im Bereiche dieser Einsenkung zeigen einen eigentümlichen, von den Zellen der übrigen Retina abweichenden Charakter. Sie liegen locker und lassen Lücken und Spalten zwischen sich frei, welche durch Fortsätze überbrückt sind, mittels derer diese Zellen miteinander anastomosiercn. An der Limitans interna endigen sie mitunter mit Radiärfaserkegeln.

Die ersten Nervenfasern, welche sich in der proximalen Retinawand differenzieren, nehmen ihren Weg zum Becherstiel durch die Wand dieser Einsenkung ( $\mathrm{NF}$ in $\mathrm{Abb} . A_{1}, \mathrm{~S} .261$, und in $\mathrm{Abb} . \mathrm{Po}_{5}, \mathrm{~S} .238$ ). Im Bereiche des Bccherstiels gelangen sie an die ventrale Seite der ventralen Wand in einen daselbst befindlichen schmalen Randschleier. Mit fortschreitender Zunahme dieser Fasern bilden dieselben entlang der epithelialen Anlage der ventralen Stielwand ein immer dickeres Lager. Dadurch wird die ventrale Wand in ihrer Gänze verdickt und das immer enger werdende Stiellumen dorsalwärts verschoben. Fnt. sprechend dem Einwachsen der Nervenfasern in den Becherstiel von distal her schlieBt sich sein Lumen in disto-proximaler Richtung unter Zurücklassung eines 
taschenförmigen Restes dorsal am Übergang des Stiels in den Augenbecher; dieser Rest bleibt lange Zeit bestehen, verschwindet aber schlieblich völlig. Nachdem sich das Stiellumen durch Anlagerung der ventralen Wand an die dorsale geschlossen hat, kommen auch die epithelialen Wände desselben allmählich vollkommen zum Verschwinden.

Wirkönnen also in einer Periodeder Entwicklung des Sehnerven an demselben eine epitheliale Anlage unterscheiden, welche nichts anderes darstellt als eine epitheliale Verbindung zwischen Augenbecher und Diencephalon, also den ursprïnglichen Becherstiel präsentiert, und eine neurofibrillär-gliöse. Die exstere istanfangs allein vorhanden. Suäter ersetzt die letztere in der eben beschriebenen Weise die erstere und nimmt dabei allmählich vollkommen lhren Platz ein, so daß also die primäre, epitheliale Anlage des Sehnerven durch eine neurofibrilür-gliöse substituiert wird.

Mit fortschreitender Ausbildung der Nervenfaserschicht der Retina über einen größeren Teil derselben verlaufen die Nerven. fasern in zwei Portionen, einer nasalen und einer temporalen, zur Sehnerveninsertion (NF in Abb. $\mathrm{Pa}_{3}, \mathrm{~S} .288$ ). An der Vereinigungsstelle dieser beiclen Portionen lassen sie eine Einsenkung zwischen sich trei ( $\mathrm{Ei}$ in $\mathrm{Abb} . \mathrm{Pa}_{3}$ ), welche eine direkte Fortsetzung der früher erwähnten, der Becherstielinsertion entsprechenden Einsenkung an der Innenseite des Augenbechers in distaler Richtung darstellt. Indem sich die neugebildeten Nerven fasern bei ihrem Verlaufe zur Sehnerveninsertion immer distal an die schon ausgebildeten Fasern anschließen, wächst einerseits die genannten Einsenkung an der Innenseite, andererseits die Sehnerveninsertionsanlage an der Außenseite kontinuierlich distalwärts in die Länge (Ei in Abb. Pa, S. 287). Offenbar entspricht diese Einsenkung der Excavatio physiologica papillas n. optici bei Säugetierembryonen, welche bei Vögeln, dem langgestreckten Sehnerveneintritt bei diesen entsprechend, ebenfalls eine langgestreckte Form hat. Bei ihrem Verla ufe a us der Retina zum Opticus benützen die Nervenfasern die früher beschriebenen, undifferenzierten Partien der Rïnder der embryonalen Papillenöffnung als Bahn, wobei die nasale Nervenfaserportion durch die nasale, die temporale darch die temporale Zone des betreffenden Randes ihren Weg nimmt. Bei dieser Passage der Nervenfasern werden die beiden Randzonen offenbar so verdickt, daß sie zur Aneinanderlagerung und Verschmelzung kommen, wodurch die Papillenöffnung selbst von proximal her fortschreitend längs einer immer größeren Strecke zum Verschluß kommt. Entsprechend der Tatsache, daß diese undifferenzierten Teile der Spaltränder als Bahn für die Nervenfasem dienen, finden wir im Bereiche der geschlossenen Spalte dieselben verschwunden und die Sehnerveninsertion direkt an die differenzierte Petina grenzen (vgl. Abb. $\mathrm{A}_{15}$, S. 271, $\mathrm{G}_{9}$, S. $309, \mathrm{G}_{13}$, S. 313, Pa, S. 288, Pa, S. 289 und $\mathrm{Pa}_{7}$, S. 292). Es liegt die Annahme nahe, daß die Zellen dieser undifferenzierten Randpartien nach ihrer Aufnahme in die Sehnerveninsertionsanlage daselbst in Gliazellen umgewandelt werden. 
Von den beiden aus der Retina zum Sehnerven ziehenden Nervenfaserportionen ist, bei verschiedenen Arten verschieden stark, aber überall merkbar, die nasale Portion liäftiger als die temporale (vgl. Abb. Po $\mathrm{P}_{11}, \mathrm{~S} .214, \mathrm{~Pa}_{7}$, S. 292, $\mathrm{Pa}_{9}, \mathrm{~S} .295, \mathrm{G}_{3}, \mathrm{~S} .309$ ). Dem enspricht die schon hervorgehobene Tatsache, daß die undifferenzierte Randzone an der Nasalseite der Papillenöffnung überall kröftiger ausgebildet ist als an der Temporalseite (vgl. Abb. $A_{12}$, S. 268, $\mathrm{G}_{1 n}$, S. $310, \mathrm{Po}_{10}, \mathrm{~S} .243, \mathrm{~Pa}_{5}, \mathrm{~S} .290$ ).

Wir haben bisher immer von einer Verlängerung dev Papillenöfnung in distaler Richtung gesprochen. Denkt man jedoch an die beschriebene Substitution des unmittelbar proximal von dieser Öffnung gelegenen Becherstiels durch die Sehnervenfascrn, so läbt sich dieser Vorgang auch in der Weise auffassen, daB sich die Papillenöffnung auch proximalwärts über das Gebiet des Becherstiels ausgedehnt hat, daß jedoch dieser ihr proximalster Teil sogleich von einwachsenden Nervenfasen ausgefüllt wird, so daß dieser Teil der Öffnung in der Tat nur virtuell ist. Schlieft man sich dieser Auffassung an, dann ben ützen tatsichlich sämtliche Nervenfasern diese Offnung als Durchgangspforte bei ihrem Verlauf aus der Retina zum Sehnerven. Aus diesem Grunde haken wir diese Otfnung "embryonale Papillenöffnung" genannt, obgleich eine „Papilla nervi optici" in des Wortes eigentlicher Bedeutung bei Vögeln nicht vorkommt, da der Sehnerveneintritt mit dem Niveau der Retina in seiner Umgebung in gleicher Hohe liegt.

Die Entwicklung des Pecten geht in der mehrfach erwähnten Einsenkung (Ei in Abb. $A_{3}$, S. 261, $\mathrm{Pa}_{1}, \mathrm{~S} .285$ and $\mathrm{Pa}_{3}, \mathrm{~S} .288$ vor sich, die wir als ein Homologon der embryonalen Papillenexcavation bei Säugetieren erkannt haben.

Wenn diese Einsenkung eine gewisse Länge erreicht hat - bei verschiedenen Arten früher oder später - können wir beobachten, daß sich aus der Sehnerveninsertionsanlage Gliazellen zwischen den hier einstrahlenden zellfreien Nervenfasern gegen die besagte Einsenkung hin vorschieben ( $\mathrm{Abh} . \mathrm{Pa}, \mathrm{S} .288$ ), Sie erreichen den Grund dcrselben, füllen sie teilweise aus und bilden alsbald einen an den Modellen langgestrecktcn, im Querschnitt hügelförmigen Wulst, der: sich, anfangs nur unbedeutend in die Becherhöble erhebi ( $\mathrm{Pe}$ in $\mathrm{Abb}$. $\mathrm{Po}_{8}$ : S. $241, A_{10}$, S. 265 , Abb. $G_{5}$, S. 305, Po, S. 242, Po, S. 244, Pa, S. 289). Dieser Wulst stellt die erste Anlage des Pecten dar. Er besteht ausschlieblich aus Gliazellen, welche aus der Sehnervenanlage in die besagte Einsenkung sich hineingeschoben haben. Das Pecten ist also in seiner ersten Anlage ein Differenzierungsprodukt der Sehnerveninsertion und läbt sich auch anfangs basal niebt schart von derselben abgrenzen. Die Pectenanlage kommt entsprechend der ganzen Länge der Sehnerveninsertion zur Ausbildung und entspricht ihr daher in Lange und Richtung an der Innenseite des Augenbechers vollkommen (über gewisse, nur scheinbare Abweichungen ron diesem Verhältnisse s. später). Wir können demnach Sehnerveninsertion und Pecten zu einem einheitlichen morphologischen Begriff $z$ usammenfassen, und wir nennensie mit cinem gemeinsamen Namen Neuropecten.

Das Neuropecten - also Pectenanlage und Sehnerveninsertion - wächst mit fortschreitender Entwicklung distalwärts

Zeitschr. f. A. ges. Anat. I. Abt. Bu. os. 
vor, wobei auch das Pecten ebenso wie die Sehnerveninsertion die undifferenzierten Ränder der Papillenöfinung als Leitbahn bei seinem Vorwachsen distalwärts benützt. Da die Einbiegung der Spaltränder, in deren undifferenzierten Randportionen das Vorwachsen des Neuropecten erfolgt, distal - wohl bei den verschiedenen Arten verschieden stark, aber überall merklich - stärker ausgesprochen ist als proximal, so koinmt das Neuropecten mit seinem distalen Teile immer tiefer zwischen die differenzierten Ränder zu liegen. Dies hat zur Folge, daB an unseren Modellen die Sehnerveninsertion, wie erwähnt, distal nicht mehr sichtbar ist (vgl. Abb. G $\mathrm{G}_{\tilde{\tau}}, \mathrm{S} .308$ ), während die Pectenanlage distalwärts bis zu ihrem Ende an Höhe zuzunehmen scheint (vgl. Pe Abb. $G_{8}, S .308, G_{12}, 5.312, G_{11}, S .314, G_{18}$, S. 316 und $P_{6}$, S. 291, was sich so erklärt, daß der auf den Modellen hervortretende Wulst, wie die Schnittbilder zeigen, distal aus den eingebogenen differenzierten Rändern mit dem auf ihnen aufgelagerten Neuropecten besteht (vgl. Abb. $A_{15}$, S. 27l, $A_{16}$, S. $272, A_{17}$, S. $272, G_{14}$, S. 314, G $G_{15}$, S. $314, G_{16}$, S. $315 G_{17}$, S. 315). Entsprechend der schiefen Richtung von nasal außen nach temporal innen, in welcher die Papillenöffnung die Wand durchsetzt, bekommt auch das in ihren Rundern vorwachsende Neuropecten eine dementsprechende Schiefstellung, die dadurch zum Ausdruck kommt, daß sein äußerer Anteil, die Sehnerveninsertion, wie schon erwähnt, der nasalen Wand der durch die eingebogenen Ränder der Papillenöffnung entstandenen Einsenkung zu liegen kommt, während sein innerer Anteil, die Pectenanlage, mehr oder weniger stark temporalwärts geneigt ist. In dieser Weise wächst das Neuropecten in den Ründern der langgestreckten Papillenöfnung immer weiter distalwïrts vor, wobei diese gleichzeitig in diesem Gebiete zum Verschluß kommt. Die undifferenzierten Randteile sind in dem Gebiete, wo das Neuropecten vorgewachsen ist versch wunden, and dieses grenzt beiderseits überall an die differenzierte Retina. Mit diesem Einwachsen des Neuropecten in die undifferenzierten Randteile wird die Einbiegung der Pänder der Papillenöffnung immer geringer und gleicht sich in späteren Entwicklungsstadien vollständig aus. Distalwärts konnten wir an unserem Material das Neuropecten nicht scharf abgrenzen, sondern es ging dieses stets ohne scharfe Grenze in die undifferenzierten Randpartien des noch offenstehenden Teils der Papillenöffnung über ${ }^{1}$ ).

Dieses Vorwachsen des Neuropecten in den Rändern der Papillenoffnung findet bis an ihr distales Ende statt, wo es seine Grenzehat.

Während dieses Vorwachsens distalwärts macht die Pectenanlage gewisse Formveränderungen durch. Aus der anfangs flachen Vorwölbung wird mit fortschreitender Entwicklung ein an Hohe immer mehr zunehmender Grat, dessen Wände steil zur ventralen Becherwand abfallen ( $\mathrm{Pe}$ in Abb. $\mathrm{Po}_{13}, \mathrm{~S} .246$, $\mathrm{Po}_{15}$, S. 249, Pa, S. $291, \mathrm{~A}_{19}$, S. 274, $\mathrm{G}_{14}, \mathrm{~S} .314, \mathrm{G}_{18}, \mathrm{~S} .316$ ). Später - soweit wir der Entwicklung dieses Gebildes hier gefolgt sind - wird, wie die Modelle zeigen, der innere, frei in die Becherhöhle hineinragende Teil der Pecten-

1) Vielleicht wäre eine solehe schärfere Abgrenzung an einem dünner geschnittenen und mit spezifischen Nervenfärbungs- resp. Gliafärbungsmitteln behendelten Material möglich gewesen, welches uns jedoch nicht zur Verfügung staud. 
anlage in einer schmalen, temporalwärts geneigten. Platte ungewandelt, welche einem basalen, breiteren, gratförmigen Teile aufsitzt (Abb. $\mathrm{A}_{21}, \mathrm{~S} .277$ ).

Während dieser Formentwicklung der Pectenanlage macht dieselbe, was ihre Histogenese anbelangt, folgende Veränderungen durch.

Mit fortschreitender Entwicklung grenzt sich die Pectenanlage durch das Einwachsen kernfreier Nervenfasern aus der Retina in die Sehnerveninsertion immer schärfer basal gegen diese ab (Abb. $A_{15}, S .271, G_{13}, S .313$ ). Die zu Beginn der Entwicklung in der ganzen Anlage ungefähr gleich dicht liegenden Gliazellen (Abb. $G_{y}$, S. 309, $G_{13}$, S. 313), ordnen sich später an der der Becherhöhle zugewendeten Pectenoberfläche epithelartig an (Abb. $A_{11}, \mathrm{~S} .267, A_{15}, \mathrm{~S} .271$ ), während sie im Innern der Anlage ein mehr lockeres Gefüge bekommen. Es entstehen hier Lücken und Spalten zwischen den Zellen ( $\mathrm{Ab}$ b. Po $\mathrm{O}_{1 ;}, \mathrm{S} .249$ ), welche durch Ausläufer derselben überbrückt sind, mittels welcher sie miteinander anastomisieren. Bei der Umgestaltung des oberen Teils der Pectenanlage in eine schmale Platte wird dieselbe fast ausschlieBlich von den epithelialen Zellen gebildet, welche einen mehr oder weniger breiten Spaltraum zwischen sich fassen, in welchem mitunter spärliche, unregelmäßig geformte Zellen liegen $\left[\mathrm{Abb} . \mathrm{Pa}_{3}\right.$, S. $\left.295^{1}\right)$ ]. Dieser plattenförmige Anteil sitzt, wie wir gehört haben, einem breiteren basalen auf ( $\mathrm{Abb}$. $\mathrm{A}_{\mathrm{i} 0}, \mathrm{~S} .275$ ), welcher an seiner freien Oberfläche die gleichen, epithelialen Zellen trägt wie der plattenförmige Anteil, während sein Inneres von den unregelmäßig geformten ästigen Zellen erfiillt ist, aus denen früher die ganze Pectenanlage in ihrem Innern bestand.

Die Entwicklung des basalen PectengefäBes (APe) komnte wegen der Dünne seiner Wand und der Blutarmut der Embryonen nur bei ein paar Arten und auch hier nur unvollständig gefolgt werden. Es gelangt hier (Podiceps [Abb. Po 17 , S. 251], Anas [Abb, A 20 , S. 275], im Ansehluß an eine die Sehnerveninsertion durchsetzende Mesodermlamelle (Me) an seinen späteren Bestimmungsort an der Pectenbasis, wo es verbleibt, während die Mesodermlamelle sich zurückbildet und verschwindet. Soweit wir beurteilen konnten, hat dieses GefäB zu dem früher erwähnten Glaskörpergefäß keine Beziehung.

Dem weiteren Verlaufe der Pectenentwicklung wurde, da derselbe außerhalb des Rähmens dieser Arbeit fällt, nicht gefolgt.

Bei allen untersuchten Arten gelangen wir also zu einem Endstadium von vollkommen homologer Beschaffenheit. Die Papillenoffnung ist durch das distalwarts vorwachsende Neuropecten bis an ihr distales Ende verschlossen, und das Neuropecten reicht distalwärts ebenso weit wie die proximalespalte vorher. Sein distales Vorwachsen hat damit sein Ende erreicht. Entsprechend der schiefen Richtung von nasal außen nach temporal innen, in welcher die Papillenöffnung die Becherwand durchsetzte, bekoinmt auch das in ihren Pündern vorgewachsene Neuropecten die gleiche Schiefstellung: sein äuBerer Teil, die Sehnerveninsertion, kommt an die nasale Wand der Einsenkung zu liegen, welche durch die Eimbiegung der Ränder der früheren Papillenöffnung gegen die Augenbecherhöhle entstanden

1) Inwieweit die erwähnten Lücken und dieser Spaltram artefizieller Natur sind, kann nicht mit Sicherheit beurteilt werden: sie finden sich jedoch bei allen untersuchten Arten in einem gewissen Entwicklungsstadium und verschwinden später, 
ist, während sein innerer Anteil, die Sehnerveninsertion, mehr oder weniger stark temporalwärts geneigt ist. Das Neuropecten grenzt überall an die differenzierte Retina, und die undifferenzierte Randzone, in der sein Vorwachsen erfolgt ist, ist völlig in dasselbe aufgegangen. Der restliche differenzierte Teil der Ränder, zwischen welchen das Neuropecten gelegen ist, ist bei unseren Endstadien noch mehr oder weniger stark gegen die Becherhöhle za eingebogen. Diese Einbiegung gleicht sich, wie wir festgestellt haben, unter der späteren Entwicklung immer mehr aus.

Wie wir gehört haben, wird die Papillenöfinung bei allen untersuchten Arten mit Ausnahme von Podiceps von einer Mesodermlamelle durchsetzt (Me in $A b b . A_{12}$, S. 268, $A_{13}, S .269, G_{10}$, S. 310), welche von verschiedener Stärke ist und sich verschieden weit frei in die Becherhöhle erhebt. Bei Podiceps findet sich eine solche Mesodermlamelle nicht vor. Außerdem wird sie von dem GlaskörpergefäB GG durchzogen. Bei Podiceps passiert dieses, von Mesodermzellen begleitet, die Öffnung schief ihrer ganzen Länge nach (GG in Abb. $\mathrm{Po}_{7}$, S. 241, $\mathrm{Po}_{3}$, S. 241, $\mathrm{Po}_{12}$, S. 245 und $\mathrm{Po}_{13}$, S. 246), bei den übrigen erst an ihrem distalen Ende (GG in $\mathrm{Abb} . \mathrm{A}_{13}$, S. 269, G $\mathrm{G}_{8}, \mathrm{~S} .308, \mathrm{G}_{12}, \mathrm{~S} .312, \mathrm{G}_{18}$, S. 316). Bevor dieses Gefäß die Becherhöhle betritt, verläuft es an der AuBenseite des Augenbechers in der erwähnten Furche an der temporalen Śeite der Sehnerveninsertionsanlage distalwärts bis zur Papillenöffnung ( $G G$ in $A b b$. $\mathrm{Po}_{7}$, S. 241, $\mathrm{PO}_{12}$, S. $245, \mathrm{G}_{7}, \mathrm{~S} .308$ und $\mathrm{G}_{11}$, S. 312 und bei allen Arten außer bei Podiceps an der Außenseite des Augenbechers in der Einsenkung zwischen den eingebogenen Pändern der Papillenöffnung bis an ihr distales Ende weiter. Im Innern des Augenbechers" nimmt das GlaskörpergefäB bei den einzelnen Arten einen etwas verschiedenen Verlauf, was dort näher beschrieben ist, zieht aber überall zur distalen öfnung und verläßt durch dieselbe den Augenbecher.

Mit dem Vorwachsen des Neuropecten and dem gleichzeitigen Verschlus der Papillenöffnung verkürzt sich bei Passer und Gallus die Mesodermamelle in proximodistaler Richtung immer mehr. Etwas anders gestalten sich die Verhältnisse bei Anas, während bei Podicéps der die Papillenöffnung passierende Teil des Gefäßes immer weiter distalwärts verschoben wird. Hat das Vorwachsen das distale Ende der Papillenöfnung erreicht, so ist die Mesodermlamelle überall vollkommen verschwunden. Gleichzeitig wird auch das hier hindurch ziehende Gefäß atrophisch and verschwindet ebenfalls mit seinem das Becherinnere passierenden Teile. Ein Rest der distalen Öf. nung ließ sich jedoch bei sämtlichen Arten mit Ausnahme von Podiceps nachweisen als eine im Corpus ciliare gelegene stelle in Form zwoier dicht aneinander gepreBter, nach auswärts gewen. deter Lippen, an deren Rändern sich das äuBere in das innere Blatt des A ugenbechers umschlagt (Abb, $A_{22}, S .277, G_{20}, S .318$ und $\mathrm{Pa}_{10}$, S. 295 .

Bezüglich näherer Details verweisen wir auf die bei den einzelnen Spezies gegebenen Zusammenfassungen und in letzter Hand auf die Beschreibung der Stadien. 


\section{Kritik friherer Untersuchungen.}

Vergleicht man unsere hier vorgelegten Untersuchungsresnitate mit den eingangs referierten Resultaten früberer Untersucher, and fragt man sich, wieso diese zu so unrollständigen and größtenteils unrichtigen Auffassungen über die hier in Frage Lommenden Entwicklungsverhältnisse gelangten, so hat dies unserer Auffassung nach folgende Gründe.

Erstens wurden nahezu alle bisherigen Untersuchungen ausschießlich am Huhn vorgenoumen, obgleich es bekannt ist, daP das Huhn ein verhältnismäßig ungünstiges Objekt für das Studium entwicklungsgeschichtlicher Vorgänge innerhalb der Vogelreihe ist - es nimmt hier eine ähnliche Stellung ein wie der Nenseh unter ten Säugetieren - indem sich hier oft komplizierende tbweichungen von dem allgemeinen Typus dér Entwicklung bemerkbar machen, die das Verstandnis erschweren. Dies gilt, wie wohl aus unserer Darstellung hervorgegangen sein dürfte, in hohem Maße auch für die uns hier interessierenden Entwicklungsvorgänge und wir glauben kaum, daß man za einer klaren Vorstellung gelangen kann, wenn man seine Untersuchungen auf das Huhn beschränkt.

Zweitens hat sich kein einziger der Untersucher der Bornschen Plattenrekonstruktionsmethode bedient, sondern alle beschränkten sich auf das Studium fon Schnittserien, meistens von solchen, die normal zur Längsrichtung der Becherspalte und des Pecten geführt waren. Ohne Rekonstruktionsmodelle ist es vollkommen unmöglich, ein klares Bild über den Verschluß der Becherspalte, über die Verlängerung der proximalen Offnung und uher die Art der Ausbildung der Sehnerveninsertion und des Pecten zu erhalten. Den Wert der Rekonstruktionsmethode Borns haben so zahlreiche Untersuchungen erwiesen, daß es überflüssig scheint, ihn hier nochmals zu betonen. Fast jede Untersuchung morphogenetischer Verhältnisse bleibt unvollständig, wenn sie sich nicht auf Rekonstruktionen stützt.

Außerdem geschah auch die Untersuchung der Schnitte vielfach nicht mit der nötigen Genauigkeit. Insbesonders wurde auf die histologische Zelstruktur des Schnittbildes zu wenig Gewicht gelegt, was daraus hervorgeht, daB Bernd nahezu ausschlieBlich and auch $v$. Husen teilweise nur. UmriBzeichnungen ihrer Schnitte abbilden.

Im speziellen wäre zu den referierten Arbeiten folgendes zu bemerken:

Das Material Bernds ist für eine eingehende Untersuchung viel zu klein. Von seinen zwölf Embryonen hat er überdies einige, welche ,ungünstig:" d. h. nicht normal zur Längstichtung der Becherspalte, bzw. des Pecten geschnitten waren, nur flüchtig in seine Untersuchungen mit einbezogen.

Dieses kleine, ausschließlich aus Hühnerembryonen bestehende und daher schon deswegen ungünstige Naterial hat Bernd anßerdem unzureichend bearbeitet, sowohl rom morphogenetischen wie rom histogenetischen Standpunkte aus. Vom morphogenetischen deswegen, wcil er, wio gesagt, nicht rekonstruiert hat. Sein ,Schema der Pectenentwicklung: (Stadium VII, S. 29) ist eine Gedankenrekonstruktion und trägt den Fehjer der meisten derartigen Rekonstruktionen, daß es nämlich mit den tatsächlichen Verhältnissen nur in sehr geringem Grade übereinstimmt. Zwar vertröstet Bernd anf eine spätere, ansführlichere Darstellung, die auch Plattenrekonstruktionen hätte enthalten sollen -- doch ist 


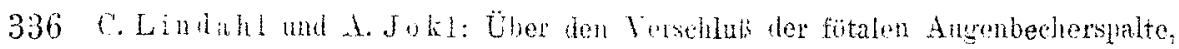

er uns dieses Versprechen schuldig geblieben. Wenigstens konnten wir in der Literatur eine spätere Arbeit Bernds zu diesem Gegenstande nicht auffinden.

Auch vom histogenetischen Standpunkt aus ist Bernds Untersuchung sehr mangelhaft. Fast überall beschreibt er nur die äuBeren Konturformen und bildet auch nur diese ab. Bei einem einzigen Stadium (VIT) geht er auf den histologischen Bau etwas näher ein und bildet von diesem Stadium ein Schnittbild ab (Abb. 6). Auch rom Pecten des Stadiums VIII ist ein Schnittbild beigefügt ( $\mathrm{Abb} .7)$. Es muB jedoch die Richtigkeit dieser beiden Bilder stark in Zweifel gezogen werden.

Auf die genannten Ursachen sind wohl die zahlreichen Irrtïmer Bernds zurückzuführen. Der Mangel an Rekonstruktionen bewirkte es, daß Bernd den Vorgängen bei dem Verschluß der Augenbecherspalte nicht folgen konute und nicht erkannte, daß es nicht die noch offene Augenbecherspalte ist, durch welche sich das Mesoderm einschiebt, sondern die zu einer Spalte verlängerte proximale Öffnung. Obgleich Bernd bei seinen Stadienbeschreibungen tatsächlich auf den Versehluß dex Augenbecherspalte za sprechen kommt, erwähnt er von der distalen Offnung kein Wort -- was umso mehr verwundem muB, als Bernds Lehrer Nußba um die Bildung derselben genau beschrieben und sie als einen Rest der Becherspalte richtig gedeutet hat.

Auf der unzureichenden histologischen Untersuchung seiner Objekte beruht die ganze unrichtige Auffassung Bernds von der Pectenbildung aus den ,am Mesodermkeil emporgewachsenen und über demselben zusammengeschlossenen Augenspalträndern": Bei genauerem Studium hätte es Bernd auffallen müssen, daß es sich im Bereiche der Pänder der noch offenen Spalte um ein anderes Gewebe handelt als in Bereiche der weiter proximal zur Entwicklung gekommenen Pectenanlage. Was Bernd (S. 32) über den histologischen Bau des neugebildeten Pecten sagt (Verlust des Pigments im äuBeren, unregelmäBige Anordnung der Zellen in inneren Retinablatte) das bezieht sich in der Tat auf die innerste Zone der Ränder der proximalen Spalte, in die das Neuropecten später einwächst, wobei es sich jedoch nicht, wie Bernd glaubt, um eine sekundäre Veränderung der Retina. und Pigmentblattzellen, sondern um ein Erhaltenbleiben ursprünglicher Zustände handelt. Ferner hat Bernd die unregeloäBig angeordneten Zellen im Inneren der Pectenanlage bei äiteren Stadien fälschlicherweise als Mesodermzellen gedeutet, während sie in Wirklichkeit nur besonders differenzierte Gliazellen sind. Das Mesoderm beteiligt sich, wie aus unserer Darstellung hervorgeht, am Aufban des Pecten überhaupt nicht, und nur seine Gefäße sind mesodermaler Herkunft.

Die Abb. 6 und 7, die Bernd ron seinen Schnittbildern bringt, können den tatsächlichen Verhältnissen wohl kaum entsprechen. In Abb. 6 befinden wir uns entweder noch im Gebiete der offenen Spalte - dann könnten aber die \$paltränder nicht so, wie Bernd sie zeichnet, verwachsen sein; oder das Neuropecten. ist an dieser Stelle bereits in den Speltbereich vorgewachsen; dann müBte aber dieser Schnitt ganz andere Strukturverhältmisse haben, als Bernd sie abbildet. Das letztere gilt bestimmt für Bernds Abb.7, wo wir uns sicher schon im Bereiche der Pectenregion befinden, und wo Bernd die Zellen des Pecten ebenso zeichnet wie in den Rändern der offenen Spalte. Eine Opticusinsertionsanlage läßt dieser Schnit völlig vermissen. Uberhaupt läBt Bernd das Verhältnis zwischen Opticus- 
stiel und Pecten völlig im unklaren. Es ist schwer begreiflich, wie wir uns eine Verlängerung des Opticussticles distalwärts durch ein Verschmelzen des äuBeren Blattes zu beiden Seiten der Spalte denken sollen; so, wie Bernd die Sache darstellt. Auf das Einwachsen der Opticusfasem geht er überhaupt nicht ein.

Wir glaubten die Arbeit Beruds so eingehend kritisieren zu sollen, da sie überail als Grundlage für die Darstellung der Pectenentwicklung angeführt wird und auch für die einzige ausführlichere Bearbeitung der Pectenentwicklung aus spätercr Zeit, jene r. Husens, richtungsgebend war.

Die Arbeit $\nabla$.Husens leidet teilweise unter den gleichen Mangein wie Bernds Arbeit: auch sic untersuchte ausschließlich Hünerembryonen und bediente sich nicht der Rekonstruktionsmethode. Doch ist ihr Material wesentlich größer (34 gegenüber Bernds 12 Stadien) und auch genauer histologisch untersucht. Trotzdem war es r. Husen nicht möglich, den Vorgingen beim Verschlusso der Augenbecherspalto richtig zu folgen. Auffallend ist es, daB v. Husen, wenn sie von den ,zwei Verschlubgebieten der Augtnbecherspalte" spricht, auf den Verschlup derselben in dem Gebiete zwischen Ciliarspalte und Pupillaroffmung überhaupt nicht Rückicht nimmt.

Was die Pectenentwicklung anbelangt, so stand $v$. Husen offenbar viel zu sehr unter dem Einflub yon Bernds Arbeit, als da 3 sie diesbezüglich anf Grund eigener Beobachtungen zu einer richtigen Auffassung hätte kommen können. Auch sie faßte daher das Pecten als cin Produkt der Verwachsung der Augenbecherränder auf und übersah vollkommen seine Beziehung zur Sehnerveninsertion. Über die Entwicklung der letzteren dagegen machte v. Husen eine Anzahl richtiger Beobachtungen. Sic erkannte, dab ihr Forwachsen distalwärts in einem gewissen Stadium in zwei getrennten Portionen zu beiden Seiten der Spalte ( $v$. H usen glaubt, es handle sich am die noch offene Augenbecherspalte, und weiß ebensowenig wie Bernd etwas von der verlängerten proximalen Offnung) erfolgt, von welchen Portionen die rostrale (nasale) mächtiger ist als dic candale (temporale), and daß bei diesem Forvachen ein bestimuter Anteil jedes Randes, den sie „Ektoderm"- oder „Opticuslappen" nennt, als Bahn dient. Indessen schienen uns ihre diesbezüglichen Angaben so schwer verstänlich dargestelit zu sein, daß man es auch bei rollkommener Vertrautheit wit dem Stoffe schwer hat, sich zurechtzufinden.

Ma n n (1921) sagt über sein Material und seine Arbeitsmethole gar nicht: Er scheint nur Hühnerembryonen untersucht zu haben; Rekonstruktionsmodello dürfte er kaum angefertigt haben. Jedenfalls erwähnt er nichts davon und legt nur in sehr gedrängter Form seine Untersuchungsresultate vor. Mann beschreibt richtig, wie sich die Becherspalte zuerst in ihrem mittleren Teile schliebt. Daß sich ihr proximaler Rest später sekundär verlängert, dürfte er angenommen haben - es scheint uns dies aus seiner Darstellung herrorzugehen, wenn ef' es auch nicht ausdrücklich erwähnt. Wine eigentiimliche Beschaffenheit der Spaltränder hat Mann ebenfalls gesehen und als Ektropionierung des Retinablattes nach außen gedeutet. Wir glauben jedoch nicht, daß diese seine Auffassung hinreichend gestützt ist. Der Umstand, daß die Zellen des Pigmentblattes hier nahe der Spalte hoch zylindrisch sind und kein Pigment enthalten, gibt doch keineswegs ohne weiteres das Recht, sie als Retinazellen anzuspreehen. 
Und weiter geht, wie wir Mann gegenüber hervorheben müssen, ihre Jhnlichkeit mit Retinazellen nicht. Stets ist hier nur eine einzige Zellreihe forhanden, während das Retinablatt doch mehrschichtig ist. Aus allen diesen Gründen glauben wir nicht, daB eine solche von $\mathrm{Ma}$ an angenommene Ektropionierung des Retinablattes vorliege, sondem halten unsere Auffassung für näherliegend, daß es sich hier um ein Erhaltenbleiben ursprünglicher Zustände handelt, aus einer Zeit, wo die Zellen des inneren und des äuBeren Blattes des Augenbechers in ihrem histologischen Bau noch nicht stark roneinander verschieden sind.

Von einer Kritik der Darstellung, welche Mann über den Verschluß des proximalen Spaltanteils und der Bildung des äuBeren Wulstes (Sebnerveninsertion) und des imneren Wuistes (Pecten) gibt. glataken wir absehen zu könnon und verweisen diesbezüglich auf unsere eigene Darstellung.

Die Aluflockerung der Zellen in Innem der Pectenanlage, zu der es in gewissen Entwieklungsstadien kommt, beschreibt Wann deutlich. Von den epithelialen Zellen an der Oberfläche erwähnt ex dagegen nichts.

Auf zwei offenbare Irrtümer Manns soll hier noch hingewiesen werden: Erstens bezeichnet Mann den malaren (temporalen) Spaltrand als den stärker eingebogenen, whihrend wir in Ubereinstimroung mit $v$. Husen beim Huhn stets den nasalen Rand stärkor eingebogen getunder haben. Auch bei den anderen untersuchten Vogelarten war der nasale Spaltrand immer stäker eingebogen als der temporale, und wir können daher nichts anders annehmen, als daß Mann den nasalen und den temporalen Spaltrand witeinander verwechselt hat.

Ferner ist es unrichtig; wenn Wan n erklärt, die Einbiegung der Spaltränder sei proximal am stärksten. Das Tingekehrte int der Fall : Die Einbiegung der Spaltränder wird distalwärts bis zum Ende der proximalen Spalte immer stärker.

Da es aus Cntersuchungen am Aage erwachsener Vögel längst bekannt war, (Laß das Pecten an der Innenseite des Auges den gleichen Raum einnimmt wie die Sehnerveninsertion an der AuBenseite und sich aus der Mulde erhebt, welche zwischen den ron masal und von temporal her zur Sohnerveninsertion ziehender Ner venfasem bei ihror V'ereinigung entsteht, dab mit einer einzigen Ausnahme keiner der Untersucher auf die embryogenetische Beziehung dieser beiden Gebilde größeres Ge wicht gelegt hat. Diese Ausnahme betrifft die Arbeit Parreidts. Er hat richtig erkannt, daß das Pecten in seiner ersten Anlage als im Quersehnitt dreieckige Leiste über dem Opticus entsteht. Auf die näheren Vorgänge, wie diese Leistenbildung erfolgt, geht er nicht näher ein und entwertet seine Beobachtung durch die Bemerkung, die Zellen dieser Leiste glichen denen der Retina. Auf seinen Abbildungen sehen sie aber anders aus als die Retinazellen und gleichen in ihrer Anordnung viel unehr den Gliazellen des Opticus (Abb. 18 und 19). Es ist unverständlich, wieso Parreidt dies entgangen war. Eudyptes chrysocome scheint, nach den Abbildungen za schließen, sehr klare, übersichtliche Bilder zu lieferm ${ }^{1}$. Leider stand dieses Material nicht zu unserer Verfügung.

Über die noch auf dem alten Standpunkt der mesodermalen Pectenbildung stebende Darstellung Frorieps (1906) in Hertwigs Handbuch der Entwicklungslehre ist nicht mehr zu sagen, als daß in einem so verbreiteten, überall

1) Abb. 19 zeigt sehr schön die epitheliale Anordunng der Pectenzellen an der Oberfliiche. 


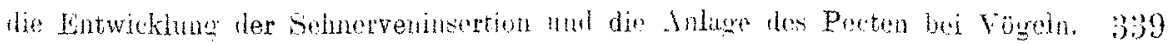

als Nachschlagewerk verwendeten Handbuch eine modemere Darstellung der Entwieklungsverhältnisse des Pecten dringend exforderlich wäre.

Von einer näheren Kritik der Darstellung Slonakers (1921), welcher die neueren Arbeiten über die ektodermale Entstehung des Pecten nicht kannte und dasselbe, hauptsächlich im Anschlusse an die von Froriep gegebene Darstellung in Hertwigs Handbuch, als ein Organ von mesodermaler Herkunft ansah, glauben wir absehen zu können. Betrachtet man Slonakers Abbildungen der jüngsten Stadien der Pectenentwicklung, so findet man überall, daB aich der Wulst der Pectenanlage uber der Anlage des Optieus crinebt, und man fragt sich unwillkürlich, wie Vesodermzellen dorthin ihren Wog gefunden haben mögen. Dem so deutlichen Zusammenhang zwisehen Opticusanlage und Pectenanlage schenkt Slonaker heine Beachtung. Seine Mikrophotographien aind übrigens in viel za kleinem Maßstab gehalten. als raB sie histologische De. tails hervortreten lieben.

Was Froricps Auffassung über die Beduting der Augenbecherspalte als Bahn für die von der Retina zum Sehneven ziehendon Nervenfasern betrifft, so wäre dieselbe dahingehend zu modifizieren, daß nicht die proximale Spalte als solche, sondern die bei ihrem VerschluB entstehende und später selwundär verlaingerte proximale Offnung es ist, die den Sehnervenfasem zum Durchtritt dient, and daß diese durch eine histologiseh in bestimmter Weise gcbaute Randpartie ihren Weg nehmen.

Hinsichtlich der: GefäBverhälnisse im embryonalen Pecten hat auch unsere Tntersuchung keine endgültige Klarheit gebracht. Wohrscheinlich kann diese Frage nur an einem für diese Zweche besonders präparierten Materiale bofriedigend gelöst werden. Wit aller Sicherheit können wir sagen, daß das GlaskörpergefäB (die Angenbecherarterie, Art. cupulae opticae ect., der verschiedenen Autoren) nicht in das Pecten eintritt, sondern der Atrophie verfallt. Sie kann daher unmöglich zur Arterie II des bleibenden Pecten werden, wio r. Huson annimmt. Ob dagegen sine Ferbindung des Claskigryergetübes mit dex Art. bas. pectin is vorhanden ist oder eine Verbindung anderer trt besteht, wie sie v. H usen annimmt - darüber können wir uns nicht entscheidend äußern. Wir haben trotz sorgfältigen Suchens eine Verbindung zwischen diesen beiden GefäBen nirgends feststellen können; doch kann dies darauf beruhen, dab das sehr diinnwandige GefäB blutleer war und sich deshalb der Beobachtung entzog. Damit ergibt sich die Frage, wie die Art. basalis pectinis an ilren Bestimmungsort, die Basis des Peoten gelangt. Wir haben bei Podiceps und Anas Andeutungen gefunden, die uns eine Vorstellung darüber geben könnten, wie dies möglicherweise geschieht. Doch sind unsere diesbezüglichen Befunde zu spärlich, urm sichere Schlüsse zu ermöglichen.

Den Ausführungen NuBbaums (1901) über das Offenbleiben der Becherspalte im Ciliargebiet können wir uns vollimhaltlich anschließen und hinzufügen, daß eine solche Offnung wenigstens bei den von uns untersuchten Embryonalstadien vorkommt, nieht nur bei Huhn und Fasan, sondern auch bei der Ente und dem Sperling. Diese Öffnung entspricht der Austrittstelle des Glaskörpergefäßes. Während letzteres atrophiert und verschwindet, bleibt sie bestehen und hat sogar, wie Hess (1912) glaubt, physiologische Bedeutung. Hierzu können 
340 C. Lindahl und A. Jokl; Uber den Verschlub ter fötalen Augenbecherspaite,

wir uns nicht äuBern. Wohl scheinen die Lippen der Spalte bei unsern Em. bryonen dicht aneinander zu liegen, doch ist es möglich, daß in vivo ein feiner Spaltraum zwischen ihnen bestand, durch welchen Flüssigkeit durchtreten kann. $\mathrm{Zu}$ der Hessschen Beobachtung, daß diese Öfnung bei (erwachsenen) Nacht. vögeln fehlt, kann es in Parallele gesetzt werden, dab auch bei Podiceps die distale Öfnung sich nach Atrophie des GlaskörpergefäBes schlieBt, anscheinend ohne eine Spur zu hinterlassen. Wir konnten im Ciliargebiet dieser Tierart bei älteren Stadien nichts derartiges finden.

Zum Schlusse sollen hier nochmals die Hauptergebnisse unseror Untersuchung in gedrängtester Form zusammengefaßt werden:

Die fötale Augenbecherspalte sehlieBt sich zuerst in ihrem mittleren, dann in ihrem distalen Teile unter Zurücklassung zweier kleiner Offnungen, einer proximalen und einer distalen. Die proximale wächst sodann beclentend in die Länge und wird zu einer langen Spalte. Die Randteile derselben behalten ibre undifferenzierte Beschaffenheit, während die Differenzierung in der übrigen Retina fortschreitet, bei und dienen als Bahn fürdie ausder Retina zum Opticus ziehenden Nervenfasern. Der Verla uf der Sehnervon. fasern, welche in zwei Portionen, einer (kräftigeren) nasalen und einer (schwächeren) temporalen schief von distal und dorsal kom. mend die Spaltenränder im proximalsten Teile der (noch offenen) Spalte passieren, bewirkt es, daB die Sehnerveninsertion mit fortschreitender Entwicklung die Form eines der ventralen Augenbecherwand aufsitzenden Wulstes bekommt, welcher proximal am höchsten und breitesten ist, distalwärts immer schmaler und flacher wird und mit einer lang ausgezogenen Spitze an der proximalen Spalte endigt. Durch die aus immer weiter distal gelegenen Abschnitten der Retina kommenden Nervenfasern, welche sich den schon ausgebildeten auflagern, wächst dieser Wulst der Sehnerveninsertion kontinuierlich distalwärts in die Länge.

Bei der Vereinigung der nasalen und der temporalen Nervenfaserportion entsteht eine der Excavation physiologica papillae nervi optici bei Säugetieren homologe, langgestreckte Einsenkung, welche die gleiche Länge wie der Sehnerveninsertionswulst hat. In sie schieben sich, sobald sie eine gewisse Länge erreicht hat, Gliazellen aus der Sehnerveninsertion hinein, füllen sie a us und bilden eine flache, langgestreckte, in die Becherhöhle hineinragende Vorwölbung. Diese ist die erste Anlage des Pecten. welches also ein aus Gliazellen bestehendes Differenzierungsprodukt der Opticusinsertion darstellt. Es kommt entsprechend ihrer ganzen Länge zur Entwicklung und wächst mit ihr gemeinsam distalwärts vor, wobei es sich ebenfalls der undif. ferenzierten Randteile als Bahn bedient. Die Spalte selbst gelangt dabei entsprechend dem Gebiete, in welches Pecten- und Sehnervenanlage vorgewachsen sind, zum VerschluB. Haben sie bei ihrem Wachstum das distale Spaltende erreicht, so ist die 
die Entwicklung der Sebnerveninsertion und die Anlage des Pecten bei Fögeln. 341

Spalte völlig geschlossen und das distale Wachstum beider Ge. bilde zu Ende.

Die vorliegenden Resultate wurden erreicht durch ausgedehnte Anwendung der Bor nschen Rekonstruktionsmethode und durch ständigen Vergleich zwischen Rekonstruktionsmodell and Schnittbild einerseits und zwischen gleichaltrigen Stadien versehiedener Spezies andererseits.

Herm Professor J. A. Hammar, der uns Arbeitsplätze und das reichhaltige Material seines Institutes zur Verfügung stellte und mit nie weichendem Interesse unserer Arbeit folgte, statten wir hiermit unseren wärmsten Dank ab.

\section{Literaturverzeichnis.}

Bauregard, H. (1876) Recherches sur les réseaux vasculaires de la chambre postérieure de l'œil des Vertébrés. Ann. Soc. nat. (6) Zool. Vol. 4. - Bernd, A. N. (1905) Die Entwicklung des Pecten im Auge des Hühnchens aus den Blättern der Augenblase. Diss. med. Bonn. - Bloohmann, F. und v. Husen, (1911) Ist der Pecten des Vogelauges ein Sinuesorgan? Biol. Zentralbl. 31. Denissenko, G. (1881), ther den Ban und die Funktion des Kammes (Pecten) im Auge der Fögel. Arch. f. mikr. Anat., 19. - Franz, V. (1013), Sehorgan. Lehrb. d. vergl. mikr. Anat. d. Wirbelt., 7. Teil. - Froriep, A. (1906), Die Entwicklung des Auges der Wirbeltiere. Handb. d. Entwicklungslehre d. Wirbeltiere, z, Teil 1, Kap. 7. - Hess, C. (1912), Cntersuchungen zur vergleichenden Histologie und Morphologie des Ciliarrings. Festschr. f. Spengel. Zool. Jahrb. Suppl. 15. 3. - v. H use n, E. (1913), Zut Kenntnis des Pectens im Vogelauge. Zool. Jahrb. Abt. 1. Anat. 36. - H uschlse, (1827), Commentatio de pectinis in oculo avium potestate anatomica et physiologica. Jena. Kessler, L. (1877), Zur Entwichlung des Auges der Wirbeltiere, Leipzig. - Lieberküh n, N. (1879), Beiträge zur Anatomie des embryonalen Auges. Arch. f. Anat. u. Entwicklungsgesch. - Mann, J. C. (1921), On the development of the fissural and associated regions in the eye of the chick, with some observations on the mammal. Journ. of Anat., :33. - Michalkovies, V. (1873), Untersuehungen über den Kamm des Vogelauges. Arch. mikr. Anat., 9. Nuss baum, M. (1899), Entwicklung des Auges. Graefe-Saemischs Handb. d. ges. Augenheilk., II. Aufl., 2. - Nuss ba u m, M. (1901), Die Pars ciliaris retinae des Vogelauges. Arch. f. mikr. Anat, 57. - Parreidt, R. (1901), Beiträge zur Anatomie des Auges bei Eudyptes chrysocome und zur Entwicklung des Pectens im Vogelauge. Diss. Leipzig. - Remak, P. (1851), Untersuchungen über die Entwicklung der Wirbeltiere. Berlin. - Slon aker, J. R. (1921), The development of the eye and its accessory parts in the English sparrow (Posser dom.). Journ. of. Morph, 35. - Vi rehow, H. (1900), Fäeher, Zapfen, Leiste, Polster, GefäBe im Ghaskörperraum von Wirbeltieren usw. Ergebn. d. Anat. u. Entw., 10.

\section{Bemerkung zu den Abbildungen.}

Die Rekonstruktionsmodelle wurden mit Hilfe eines photogr. Apparates in ihren Konturen umrissen und dann ausgeführt. Es bestand ursprünglich die Absicht, von den Schnittbildern nur Mikrophotogramme abzubilden; doch wurde später eine kleine Anzahl derselben durch Zeichnungen ersetzt, entweder weil die betr. Schnitte ihrer Dicke wegen fïr die Photographierung rungeeignet waren, oder weil sich gewisse Strukturdetails nicht deutlich genug abhoben. Rekonstruktionsmodelle und Schnitte wurden von Fräulein Gerda Jungberg in mustergültiger Weise gezeichnet, wofür wir ihr hiermit unseren Dank abstatten. 
342 O. Limath 1 und A. Jokl: Über den rershub der Etalen Angenhecherspalte, usw.

\section{Frklärang der Ahkïrangen.}

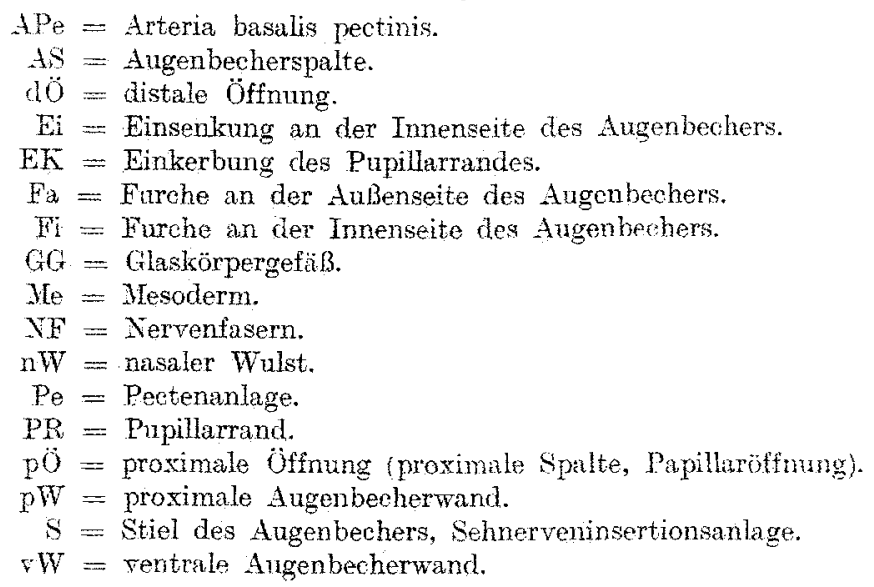

